UNIVERSIDADE DE SÃO PAULO

FACULDADE DE ECONOMIA, ADMINISTRAÇÃO E CONTABILIDADE DEPARTAMENTO DE ADMINISTRAÇÃO PROGRAMA DE PÓS-GRADUAÇÃO EM ADMINISTRAÇÃO

GESTÃO DO CONHECIMENTO EM EMPRESAS ATUANTES

NA INDÚSTRIA DE SOFTWARE NO BRASIL:

UM ESTUDO DAS PRÁTICAS E SUAS

INFLUÊNCIAS NA EFICÁCIA EMPRESARIAL

Marcos Antonio Gaspar

Orientador: Prof. Dr. Silvio Aparecido dos Santos

SÃO PAULO

2010 
Prof. Dr. João Grandino Rodas Reitor da Universidade de São Paulo

Prof. Dr. Reinaldo Guerreiro

Diretor da Faculdade de Economia, Administração e Contabilidade

Prof. Dr. Adalberto Américo Fischmann

Chefe do Departamento de Administração

Prof. Dr. Lindolfo Galvão de Albuquerque Coordenador do Programa de Pós-Graduação em Administração 


\title{
GESTÃO DO CONHECIMENTO EM EMPRESAS ATUANTES NA INDÚSTRIA DE SOFTWARE NO BRASIL: \\ UM ESTUDO DAS PRÁTICAS E SUAS INFLUÊNCIAS NA EFICÁCIA EMPRESARIAL
}

\author{
Tese apresentada ao Departamento de \\ Administração da Faculdade de Economia, \\ Administração e Contabilidade da Universidade de \\ São Paulo, como um dos requisitos para a obtenção \\ do título de Doutor em Administração.
}

Orientador: Prof. Dr. Silvio Aparecido dos Santos

\section{SÃO PAULO}


Tese defendida no Departamento de Administração da Faculdade de Economia,

Administração e Contabilidade da Universidade de São Paulo - Programa de Pós-

Graduação em Administração, pela seguinte banca examinadora:

Prof. Dr. Silvio Aparecido dos Santos

Prof. Dr. Moacir Miranda Oliveira Júnior

Prof. Dr. Denis Donaire

Prof. Dr. Marcio Shoiti Kuniyoshi

Prof. Dr. José Osvaldo De Sordi

Data da defesa: $16 / 12 / 2010$.

Resultado:

\section{Gaspar, Marcos Antonio}

Gestão do conhecimento em empresas atuantes na indústria de software no Brasil : um estudo das práticas e suas influências na eficácia empresarial / Marcos Antonio Gaspar. - São Paulo, 2010. $219 \mathrm{p}$.

Tese (Doutorado) - Universidade de São Paulo, 2010.

Orientador : Silvio Aparecido dos Santos.

1. Gestão do conhecimento 2. Eficácia organizacional 3. Teletrabalho I. Universidade de São Paulo. Faculdade de Economia, Administração e Contabilidade. II. Título.

CDD - 658.4038 
À Deus, pela incomparável dádiva da vida;

À minha amada Adriana, fonte inesgotável de ternura com quem tanto aprendo todos os dias;

Às minhas filhas Vitória e Bruna, que provam que a vida pode $e$ deve ser simples de ser vivida;

À minha mãe Maria, pela sabedoria do sempre presente estímulo ao estudo e ao crescimento contínuos;

À minha irmã Elizabete, pela bondade ao ensinar-me as primeiras letras, sem nunca esperar nada em retribuição. 


\section{AGRADECIMENTOS}

O hoje somente existe graças ao ontem... E o que somos, devemos aos que nos construíram. Por isso gostaria imensamente de agradecer aos professores da FEA/USP, funcionários e colegas do Programa de Pós-graduação em Administração pela solicitude e disposição constantes durante toda esta caminhada do curso de doutorado.

De forma mais direta, desejo também agradecer algumas pessoas e instituições, a saber:

Ao Prof. Dr. Silvio Aparecido dos Santos, pela sempre presente disposição em orientar, além do mais sincero interesse e comprometimento na formação deste pesquisador. Nestes pouco mais de três anos de convivência, muito pude aprender com este mestre e amigo.

Ao Prof. Dr. Denis Donaire que, embora talvez não o saiba, foi o responsável direto pelo meu ingresso definitivo na vida acadêmica.

Ao Prof. Dr. Marcio Shoiti Kunyioshi, amigo mais recente, mas sempre presente em minhas andanças pelas veredas da ciência, quer seja em eventos, quer seja em debates, quer seja em pesquisas.

Ao Prof. Dr. José Osvaldo De Sordi, a quem muito admiro por sua excelência no desenvolvimento de nossa área de conhecimento.

Ao Prof. Dr. Eduardo de Camargo Oliva que, com muita determinação, impeliu-me à realizar o processo seletivo deste programa há anos atrás. Embora julgasse que ainda não estivesse preparado naquele momento, sua insistência foi determinante naquele momento e durante todo o curso.

Ao Prof. Silvio Augusto Minciotti e à Universidade Municipal de São Caetano do Sul - uma instituição lastreada por grandes indivíduos, pela disposição em buscar investir em seus recursos humanos.

Ao Prof. Leandro Campi Prearo, um novo grande amigo que descobri em função do desenvolvimento deste trabalho, pela gentileza e humildade em compartilhar sua sapiência nos domínios da estatística sem nada esperar em troca.

Aos amigos e amigas que, de forma direta ou indireta, me suportaram de todas as formas possíveis nos bons e maus momentos deste percurso (seja na prestação de apoio ou na demonstração de paciência): Marlene Forestieri de Melo, Nathalia Peixoto de Lima, Ivanir Brancaglione Cristofi e Ademir Lamenza. 
"O homem é mortal por seus temores e imortal por seus desejos" Pitágoras 


\section{RESUMO}

As empresas utilizam vários tipos de recursos tais como matérias primas, insumos, recursos humanos e recursos financeiros para gerar seu portfólio de produtos e/ou serviços. No último século os gestores das empresas desenvolveram práticas e ferramentas de gerenciamento para maximizar os resultados decorrentes da aplicação destes recursos. Nas últimas duas décadas o conhecimento passou a ser considerado mais um dos recursos a serem geridos e aplicados pelas empresas para alcançar diferenciais competitivos frente aos seus concorrentes. Por ser um recurso intangível com características diferentes dos demais recursos, várias práticas e ferramentas específicas foram desenvolvidas com o objetivo de explorar ao máximo os resultados do uso do conhecimento nas empresas. Esta tese teve como objetivo identificar e especificar as práticas de gestão do conhecimento e as ferramentas de tecnologia da informação e comunicação empregadas em empresas instaladas na indústria de software no Brasil, incluindo aquelas que são utilizadas por teletrabalhadores. Buscou ainda identificar e especificar se há diferença na utilização dessas práticas e ferramentas em ambientes de teletrabalho, além de verificar as influências da gestão do conhecimento na eficácia empresarial dessas mesmas empresas. Para tanto, como método de pesquisa foi realizado um estudo descritivo-quantitativo junto a 319 funcionários de 15 diferentes empresas de médio e grande portes integrantes da indústria de software do país. Os dados coletados foram tratados por meio de análises estatísticas descritivas e da modelagem de equações estruturais, mediante o emprego dos aplicativos SPSS (Statistical Package for the Social Sciences) e PLS-PM (Partial Least Squares Path Modeling). Os resultados encontrados permitem concluir que: a) as práticas de gestão do conhecimento mais utilizadas nas empresas pesquisadas são: reuniões e conferências virtuais, treinamentos virtuais, treinamentos presenciais, e-learning, call center/help desk/suporte online, portal corporativo, biblioteca corporativa, sistema de avaliação, centros de inovação, mapeamento de processos e gestão da inovação; b) as ferramentas de tecnologia da informação e comunicação voltadas à gestão do conhecimento mais empregadas nas empresas analisadas são: e-mail, telefone via internet, telefone celular/rádio, intranet; servidores web e navegadores, telefone fixo, mensagens instantâneas, portal corporativo e treinamento baseado em computador; c) as práticas e ferramentas de tecnologia da informação e comunicação empregadas na gestão do conhecimento são mais usadas em ambientes de teletrabalho do que em ambientes de trabalho presencial e, por fim; d) as práticas e ferramentas de tecnologia da informação e comunicação voltadas à gestão do conhecimento influenciam a eficácia empresarial das empresas examinadas, com prevalência das práticas sobre as ferramentas. A conclusão é que as práticas e ferramentas empregadas na gestão do conhecimento são mais utilizadas em ambientes de teletrabalho e que a gestão do conhecimento em si influencia a eficácia empresarial das empresas.

Palavras-chave: Gestão do conhecimento. Eficácia organizacional. Teletrabalho. Indústria de software. 


\begin{abstract}
The companies use some types of resources such as raw material, human resources and financial resources to generate its set of products and/or services. In the last century the managers of the companies had developed management practices and tools to maximize the decurrent results of the application of these resources. In last the two decades the knowledge became to be considered another one of the resources to be managed and applied by companies in order to reach competitive differentials comparing to its competitors. As the knowledge is an intangible resource with different characteristics comparing to other resources, several specific practices and tools had been developed in order to better explore the results of the use of the knowledge in the companies. This thesis proposed to identify and specify the knowledge management's practices and information and communication technology tools used in companies of Brazil's software industry. It also attempted to identify and specify if there's a difference in the use of these practices and tools in teleworking or face to face working environments, besides verifying the influences of knowledge management in these companies organizational effectiveness. Because of this, a quantitative-descriptive research was conducted with the application of a questionnaire with 319 employees of 15 different midsize and large companies that operate in the country's software industry. The collected data were dealt by descriptive statistics analysis and structural equations shaping, by the use of SPSS application (Statistical Package for the Social Sciences) and PLS-PM (Partial Least Squares Path Modeling). The results show that it is possible to identify: a) the most used practices of knowledge management in the researched companies are: meetings and virtual conferences, virtual training, face to face training, e-learning, call center/help desk/online support, corporative gateway, corporative library, evaluation system, innovation centers, process mapping and innovation management; b) the most used information and communication technology tools turned to knowledge management in the analyzed companies are: email, web phone calling, cell phone/radio, intranet, browsers and web servers, landline phone, instant messaging, corporative gateway and computer based training; c) the practices and information and communication technology tools used in knowledge management are more used in teleworking environment than in face to face working environment, and finally; d) the practices and information and communication technology tools turned to knowledge management influence the organizational effectiveness of the surveyed companies, with more influence of the practices than the tools. The conclusion is that the practices and tools used in knowledge management are more used in telework environment and that knowledge management influences the companies' organizational effectiveness.
\end{abstract}

Key words: Knowledge management. Organizational effectiveness. Telework. Software industry. 


\section{SUMÁRIO}

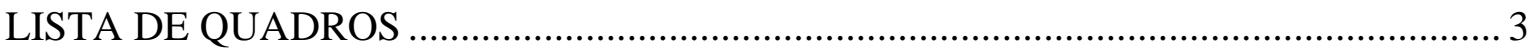

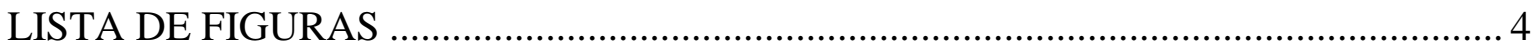

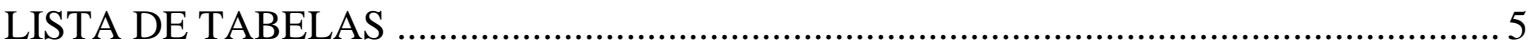

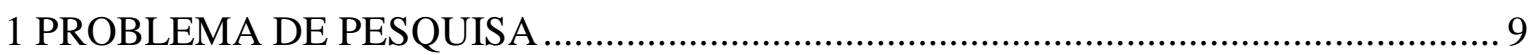

1.1 Introdução

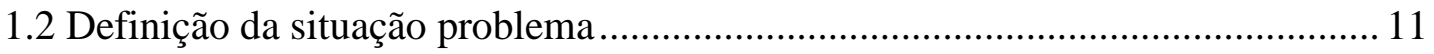

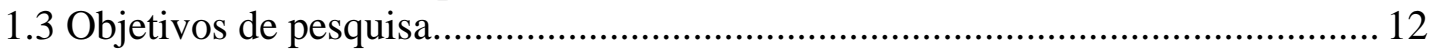

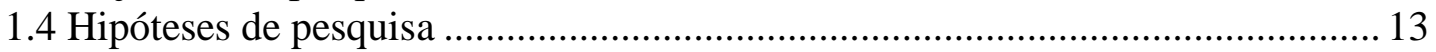

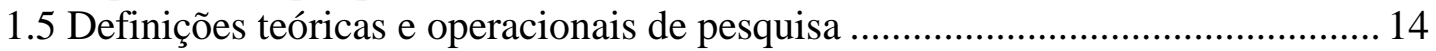

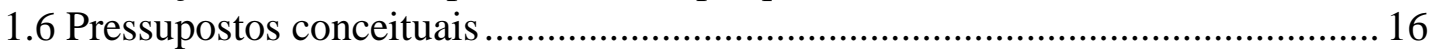

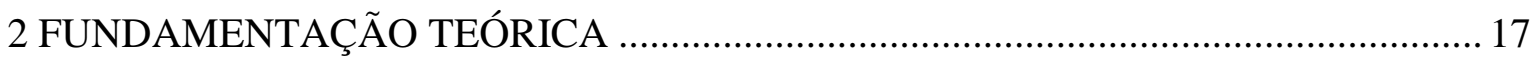

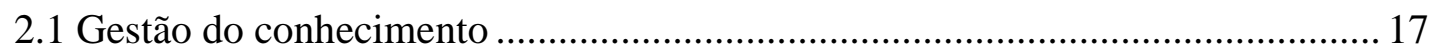

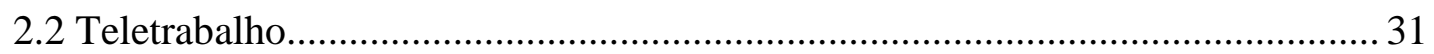

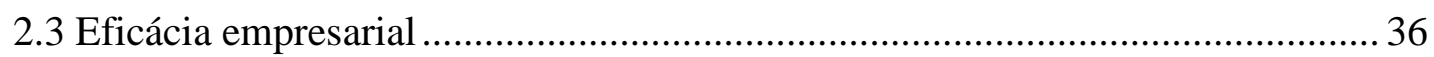

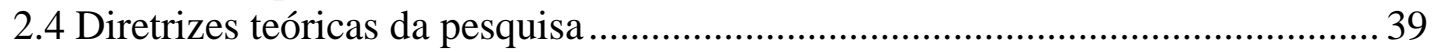

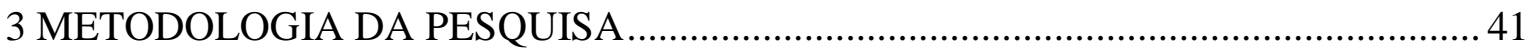

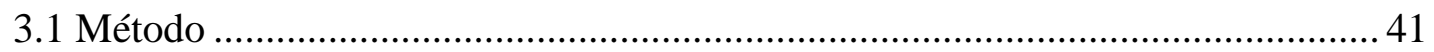

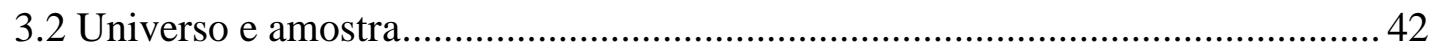

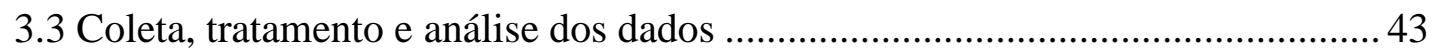

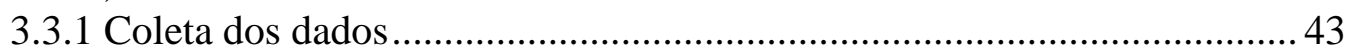

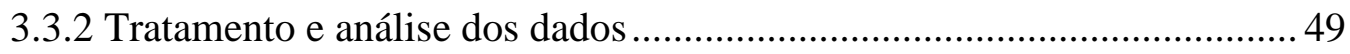

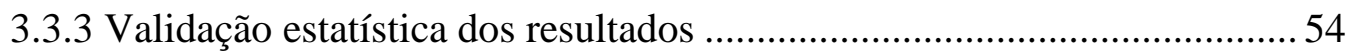

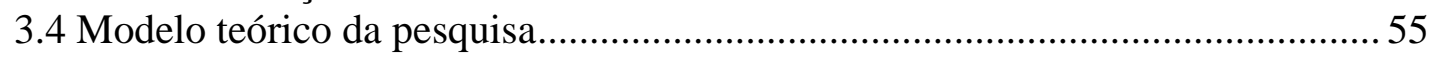

4 APRESENTAÇÃO E ANÁLISE DOS RESULTADOS …........................................... 57

4.1 Caracterização da indústria de software no Brasil ...............................................58

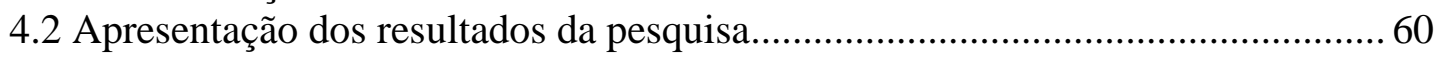

4.2.1 Caracterização dos respondentes e do ambiente de trabalho.................... 60

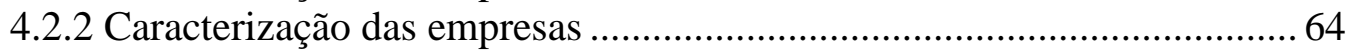

4.2.3 Gestão do conhecimento na empresa .....................................................6 66

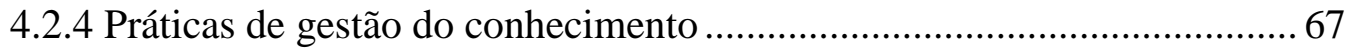

4.2.5 Ferramentas de tecnologia da informação e comunicação adotadas para a gestão do conhecimento.............................................. 100

4.2.6 Indicadores da eficácia empresarial................................................... 129

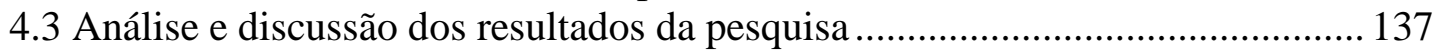

4.3.1 Principais práticas de gestão do conhecimento .................................... 138

4.3.2 Principais ferramentas de tecnologia da informação 
e comunicação adotadas na gestão do conhecimento............................ 141

4.3.3 Principais indicadores de eficácia empresarial .................................... 144

4.3.4 Influência do ambiente de teletrabalho............................................... 145

4.3.5 Influência do nível hierárquico.......................................................... 149

4.3.6 Estatísticas para validação das variáveis latentes do modelo

empírico de tratamento e análise dos dados ........................................... 153

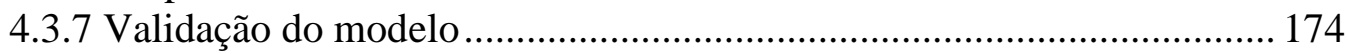

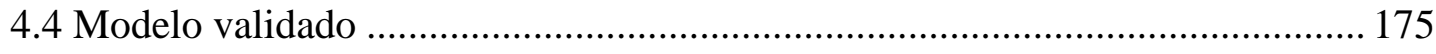

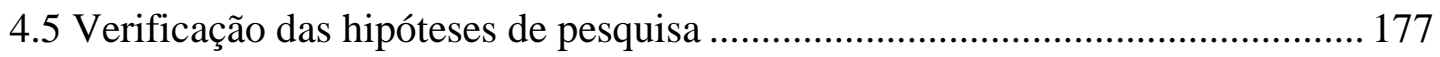

5 CONCLUSÕES E RECOMENDAÇÕES PARA FUTURAS PESQUISAS................. 181

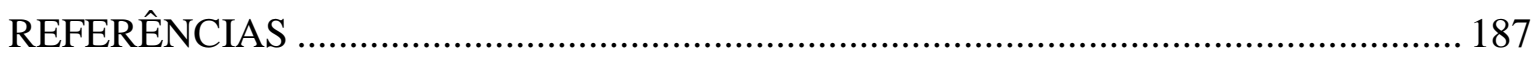

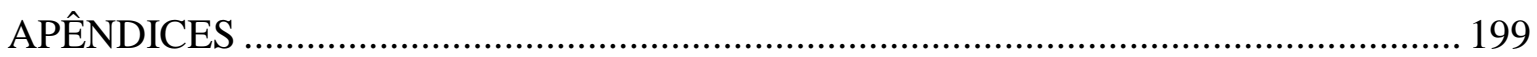

Apêndice A - Questionário aplicado aos colaboradores das empresas .................... 201 


\section{LISTA DE QUADROS}

Quadro 1 - Diferentes perspectivas sobre as atividades envolvidas no processo de

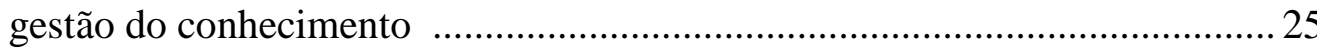

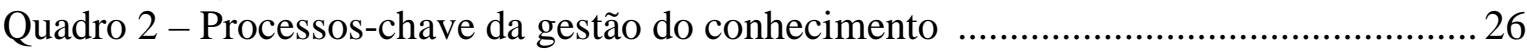

Quadro 3 - Principais ferramentas, tecnologias e técnicas de gestão do conhecimento

Quadro 4 - Dimensões organizacionais e as práticas e iniciativas de gestão

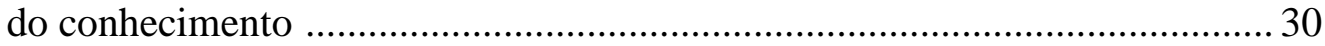

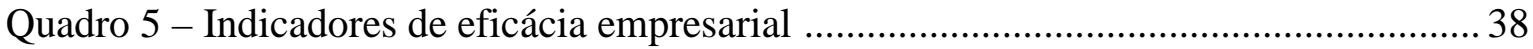

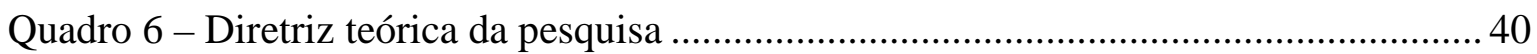

Quadro 7 - Premissas de utilização da técnica da modelagem de equações estruturais 


\section{LISTA DE FIGURAS}

Figura 1 - Conceitos centrais estudados e problema de pesquisa …................................ 11

Figura 2 - Quatro modos de conversão de conhecimento ................................................. 20

Figura 3 - Criação e transferência do conhecimento ....................................................... 21

Figura 4 - Capacitadores da gestão do conhecimento e eficácia empresarial ..................... 25

Figura 5 - Atividades realizadas no processo de gestão do conhecimento ..........................26

Figura 6 - Atividades realizadas no processo de gestão do conhecimento .........................28

Figura 7 - Modelo empírico de tratamento e análise dos dados .....................................52

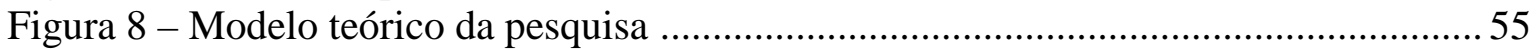

Figura 9 - Resultados das dimensões das práticas de gestão do conhecimento................. 140

Figura 10 - Resultados das dimensões das ferramentas de tecnologia da Informação e comunicação

Figura 11 - Lógica de funcionamento do aplicativo PLS-PM para tratamento e validação das variáveis do modelo

Figura 12 - Resultados dos pesos fatoriais das dimensões das práticas de gestão do conhecimento

Figura 13 - Resultados dos pesos fatoriais das dimensões das ferramentas de Informação e comunicação

Figura 14 - Resultados do teste t de student das dimensões das práticas de gestão do conhecimento

Figura 15 - Resultados do teste t de student das dimensões das ferramentas de tecnologia da informação e comunicação

Figura 16 - Resultados dos pesos fatoriais das dimensões de eficácia empresarial........... 168

Figura 17 - Resultados do teste $t$ de student das dimensões de eficácia empresarial ....... 169

Figura 18 - Fórmula de cálculo da confiabilidade composta ............................................ 169

Figura 19 - Pesos fatoriais das variáveis da dimensão econômica de eficácia empresarial

Figura 20 - Pesos fatoriais das variáveis da dimensão social de eficácia empresarial

Figura 21 - Pesos fatoriais das variáveis da dimensão sistêmica de eficácia empresarial

Figura 22 - Pesos fatoriais das variáveis da dimensão política de eficácia empresarial

Figura 23 - Fórmula de cálculo da variância extraída.

Figura 24 - Pesos fatoriais das variáveis da dimensão econômica de eficácia empresarial

Figura 25- Pesos fatoriais das variáveis da dimensão social de eficácia empresarial

Figura 26 - Pesos fatoriais das variáveis da dimensão sistêmica de eficácia empresarial

Figura 27 - Pesos fatoriais das variáveis da dimensão política de eficácia empresarial

Figura 28 - Resultados dos pesos fatoriais das ferramentas de tecnologia de informação e comunicação e práticas aplicadas na gestão do conhecimento em relação à eficácia empresarial

Figura 29 - Resultados do teste $t$ de student das ferramentas de tecnologia de informação e comunicação e práticas aplicadas na gestão do conhecimento em relação à eficácia empresarial

Figura 30 - Modelo empírico validado 


\section{LISTA DE TABELAS}

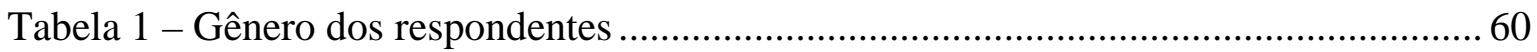

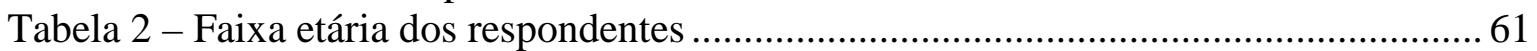

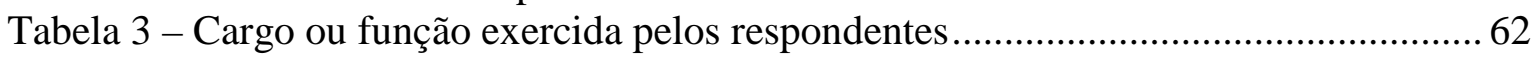

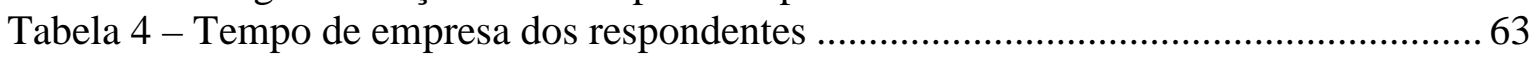

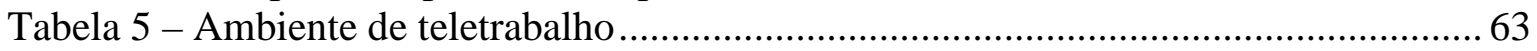

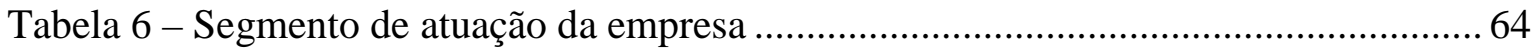

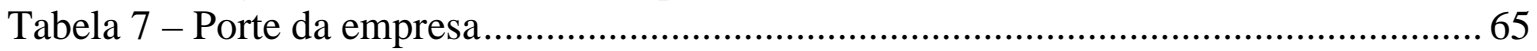

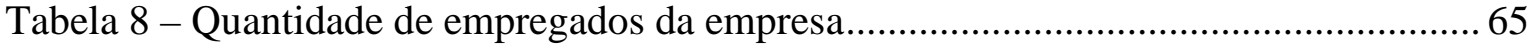

Tabela 9 - Indicação prévia acerca da gestão do conhecimento praticada

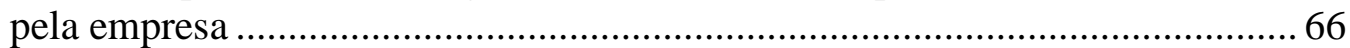

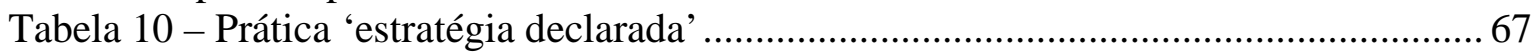

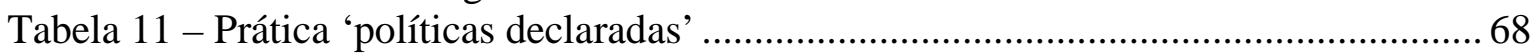

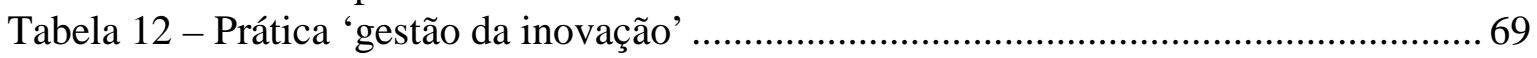

Tabela 13 - Prática 'gestão por competências' ..........................................................................69

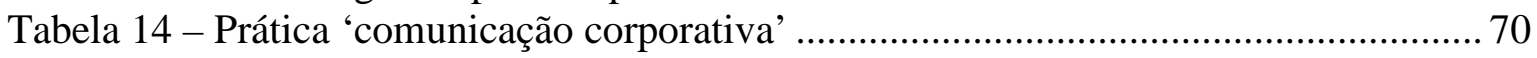

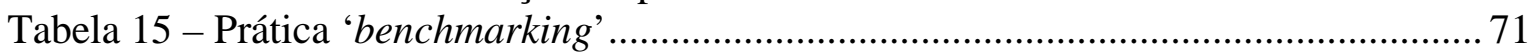

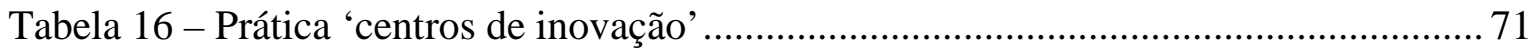

Tabela 17 - Prática 'call center/help desk/suporte online' .................................................. 72

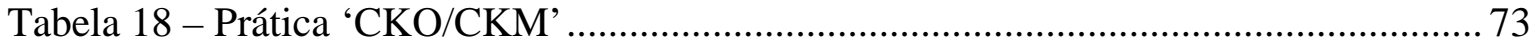

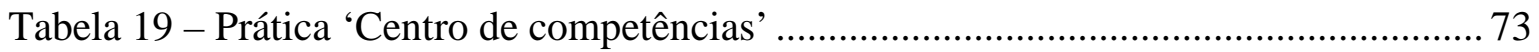

Tabela 20 - Prática 'área interna/departamento específico' ................................................. 74

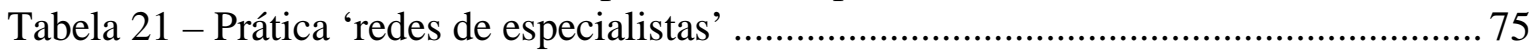

Tabela 22 - Prática 'espaços e situações para socialização' ............................................ 75

Tabela 23 - Prática 'mapeamento de competências'............................................................. 76

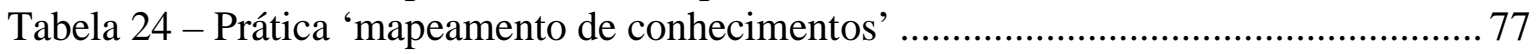

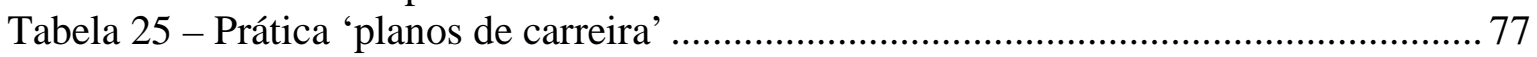

Tabela 26 - Prática 'sistema de reconhecimento e recompensa' ........................................... 78

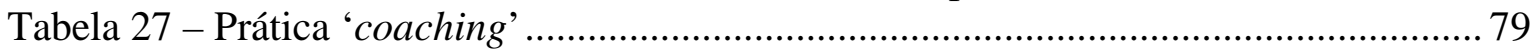

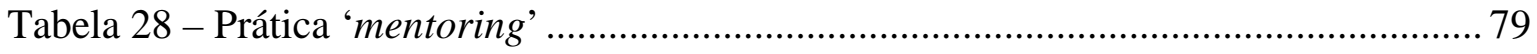

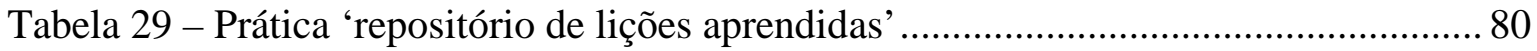

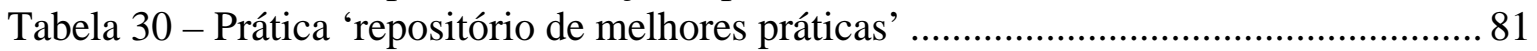

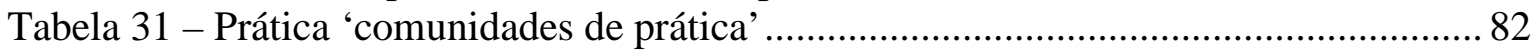

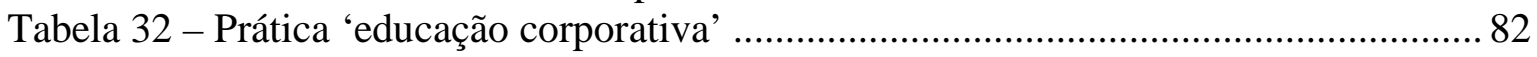

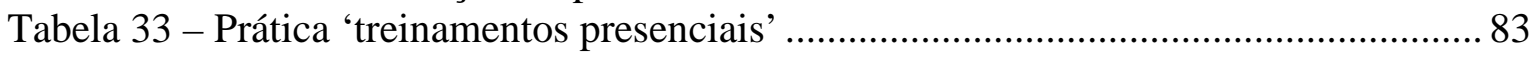

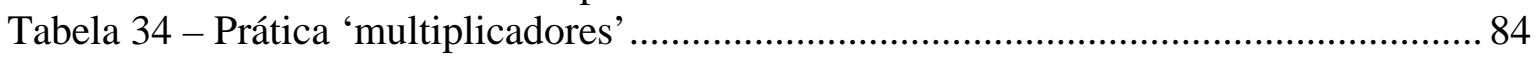

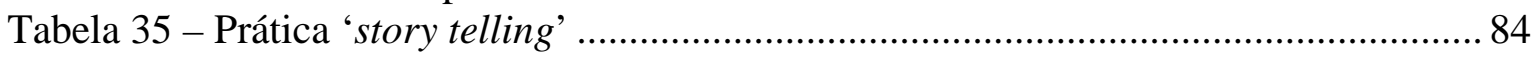

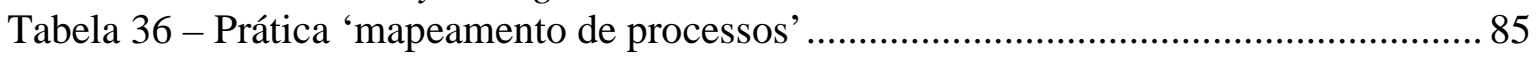

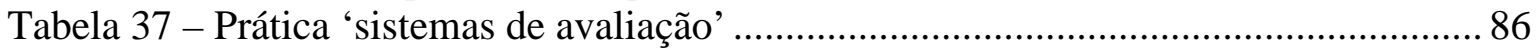

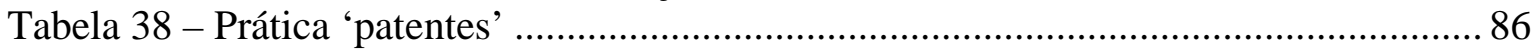

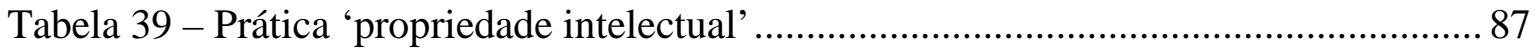

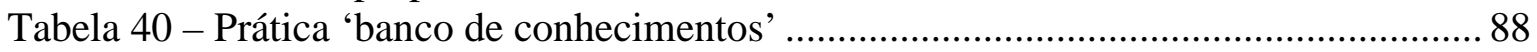

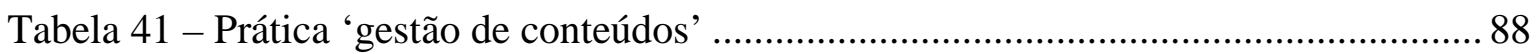

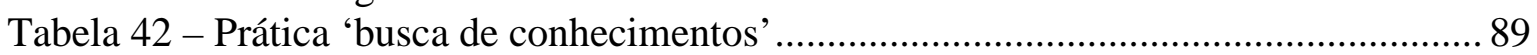

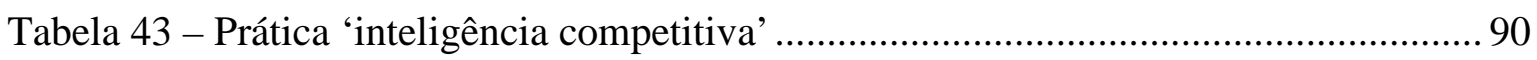

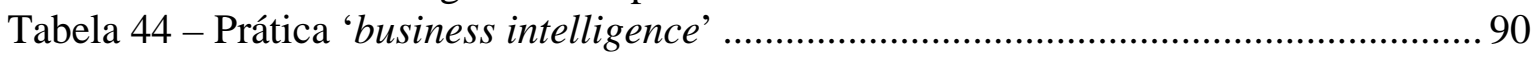

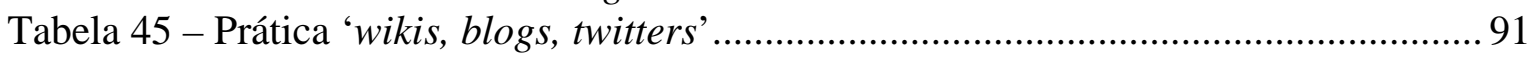

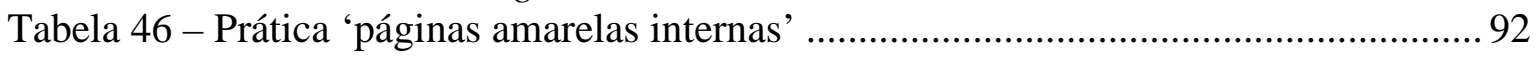

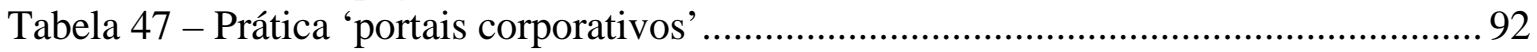


Tabela 48 - Prática 'biblioteca corporativa/diretório de documentos' ................................ 93

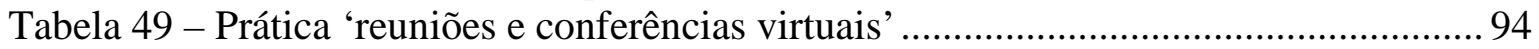

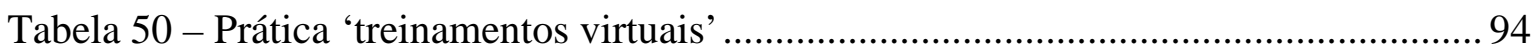

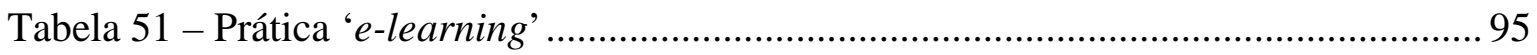

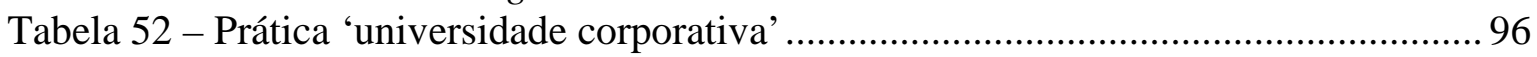

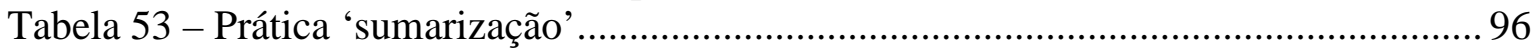

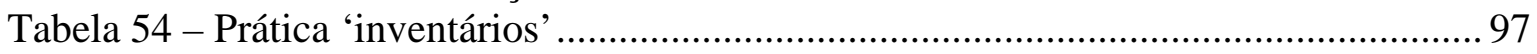

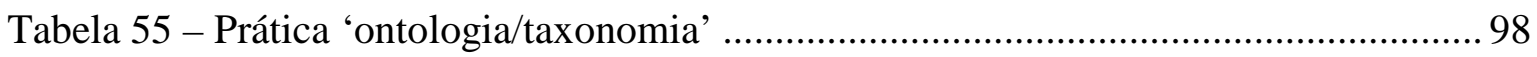

Tabela 56 - Resumo dos principais resultados verificados acerca das práticas

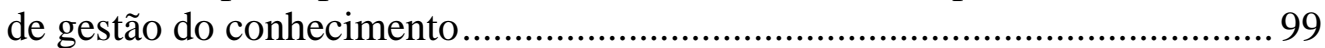

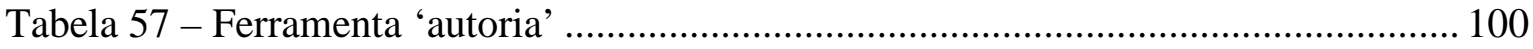

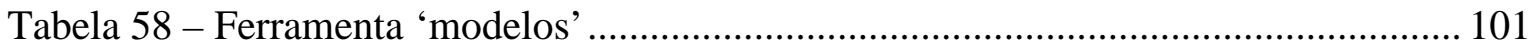

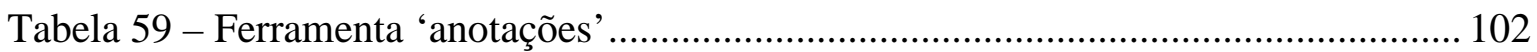

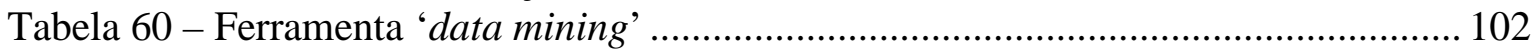

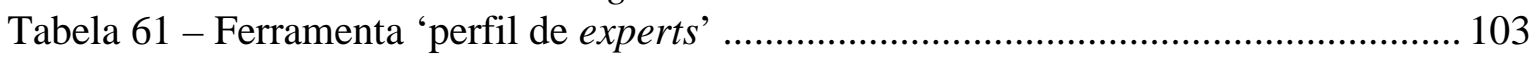

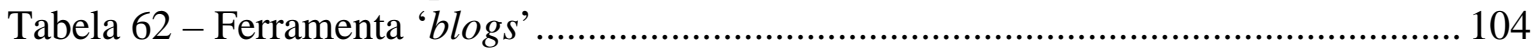

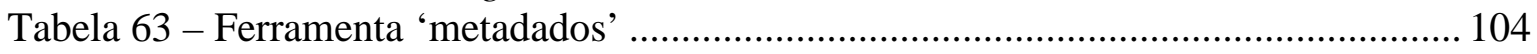

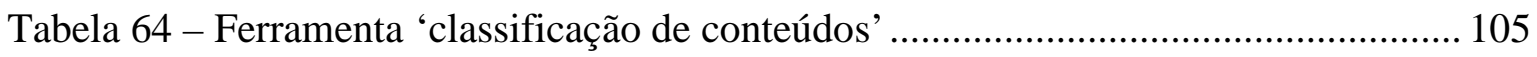

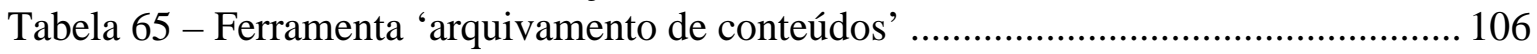

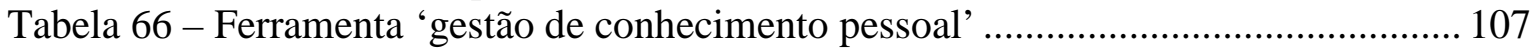

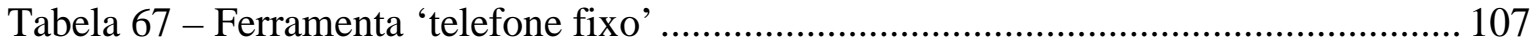

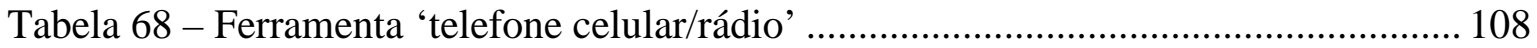

Tabela 69 - Ferramenta 'telefone vai internet' ................................................................ 109

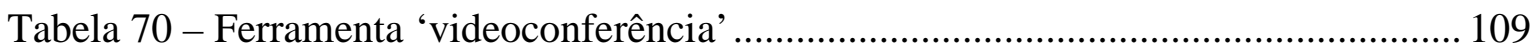

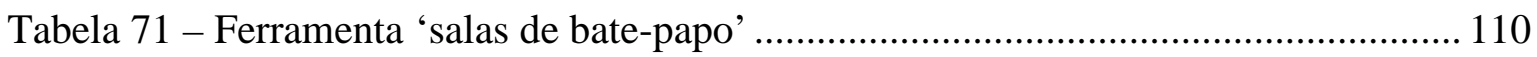

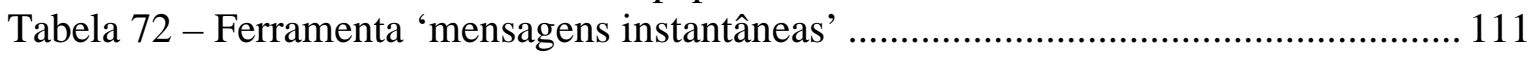

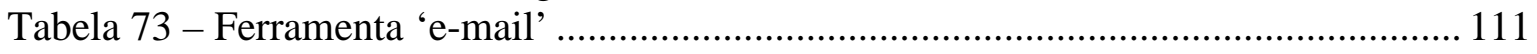

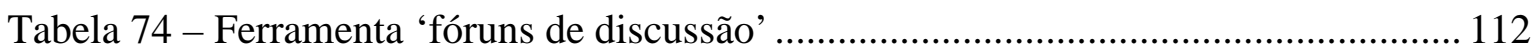

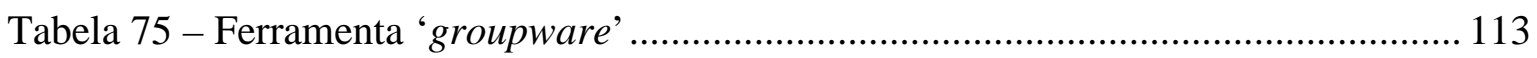

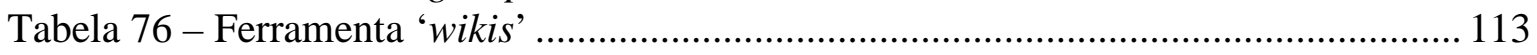

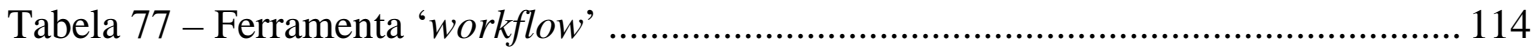

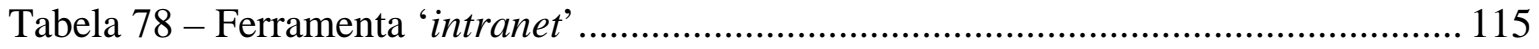

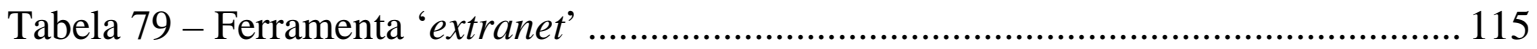

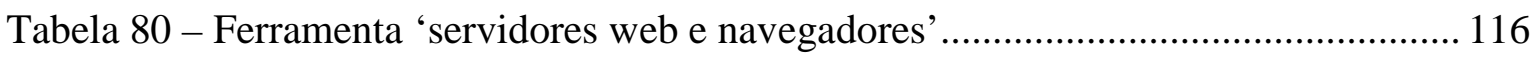

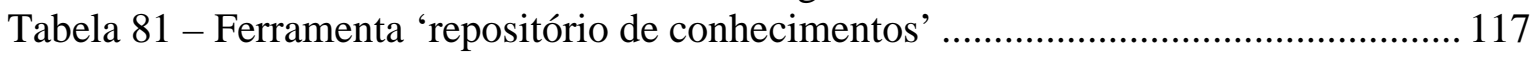

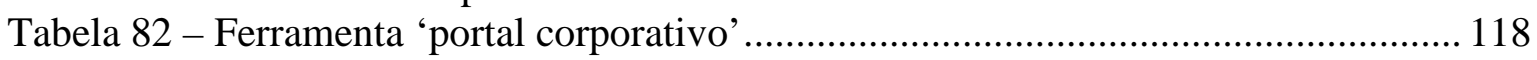

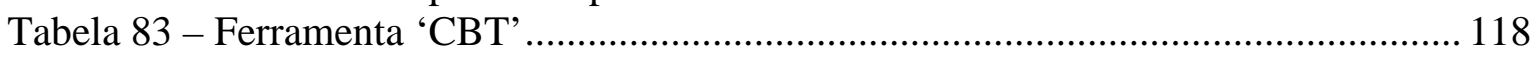

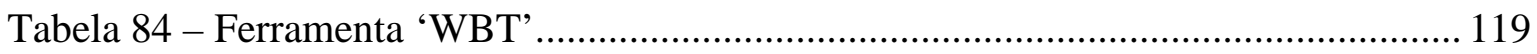

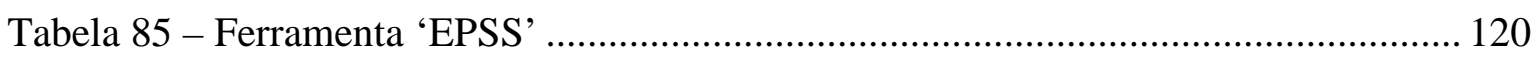

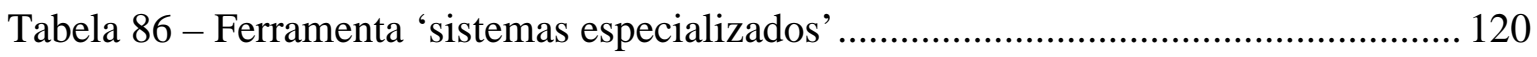

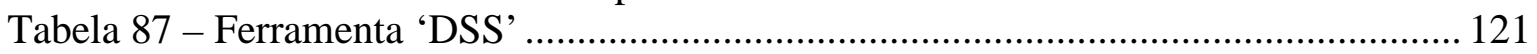

Tabela 88 - Ferramenta ‘customização/personalização' ..................................................... 122

Tabela 89 - Ferramenta 'sistema recomendador' ........................................................ 123

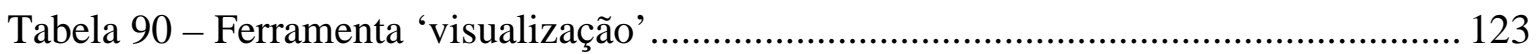

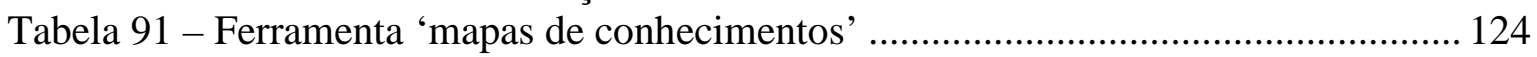

Tabela 92 - Ferramenta 'agentes de inteligência' ........................................................... 125

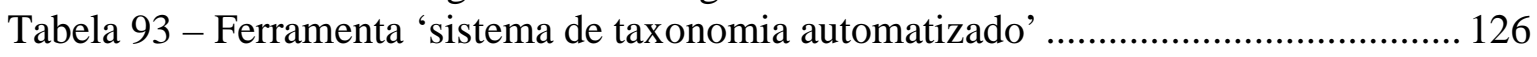

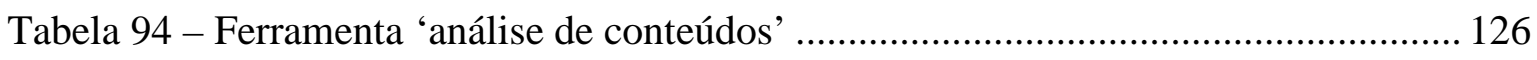

Tabela 95 - Resumo dos principais resultados acerca das ferramentas de TIC

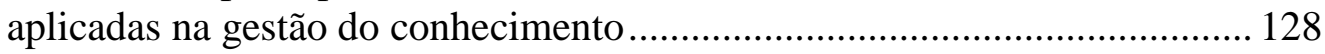


Tabela 96 - Fator de eficácia empresarial ‘objetivos corporativos' ................................. 129

Tabela 97 - Fator de eficácia empresarial 'produtividade' ............................................ 129

Tabela 98 - Fator de eficácia empresarial 'lucro e rentabilidade' .................................. 130

Tabela 99 - Fator de eficácia empresarial 'eficiência' ...................................................... 130

Tabela 100 - Fator de eficácia empresarial ‘desenvolvimento e crescimento' .................. 131

Tabela 101 - Fator de eficácia empresarial 'coesão e harmonia' ....................................... 131

Tabela 102 - Fator de eficácia empresarial 'ambiente organizacional' ............................ 132

Tabela 103 - Fator de eficácia empresarial 'moral' .......................................................... 132

Tabela 104 - Fator de eficácia empresarial 'absenteísmo' ............................................. 133

Tabela 105 - Fator de eficácia empresarial 'rotatividade' ................................................ 133

Tabela 106 - Fator de eficácia empresarial 'motivação e satisfação' ................................. 134

Tabela 107 - Fator de eficácia empresarial 'desenvolvimento das pessoas' ..................... 134

Tabela 108 - Fator de eficácia empresarial 'adaptabilidade' .............................................. 135

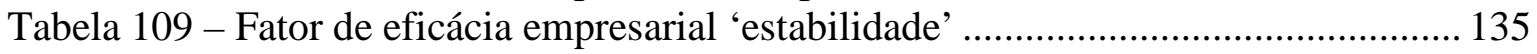

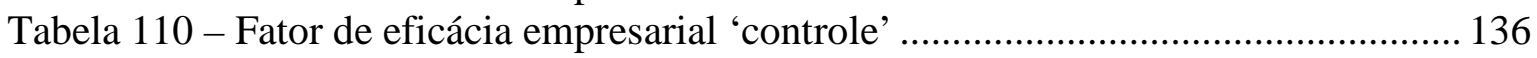

Tabela 111 - Resumo dos principais resultados acerca dos fatores

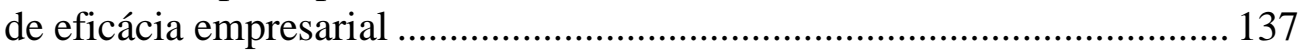

Tabela 112 - Ranking das práticas de gestão do conhecimento........................................ 138

Tabela 113 - Ranking das ferramentas de TIC aplicadas na gestão

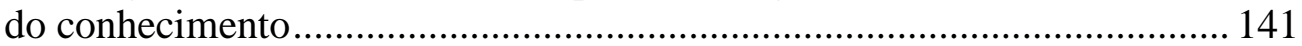

Tabela 114 - Ranking dos indicadores de eficácia empresarial ...................................... 144

Tabela 115 - Resumo comparativo dos principais resultados acerca das práticas de gestão do conhecimento entre teletrabalhadores e não-teletrabalhadores

Tabela 116 - Resumo comparativo dos principais resultados acerca das ferramentas de tecnologia da informação e comunicação aplicadas na gestão do conhecimento entre teletrabalhadores e não-teletrabalhadores

Tabela 117 - Resumo comparativo dos principais resultados acerca das práticas de gestão do conhecimento entre gestores e técnicos

Tabela 118 - Resumo comparativo dos principais resultados acerca das ferramentas TIC aplicadas na gestão do conhecimento entre gestores e técnicos ........... 152

Tabela 119 - Teste VIF das práticas de gestão do conhecimento ..................................... 155

Tabela 120 - Teste VIF das ferramentas TIC..................................................................... 157

Tabela 121 - Teste de análise fatorial (KMO e variância total) das práticas de gestão do conhecimento.

Tabela 122 - Teste de análise fatorial (KMO e variância total) das ferramentas

TIC empregadas na gestão do conhecimento

Tabela 123 - Validade discriminante das dimensões de eficácia empresarial 


\section{$1 \quad$ PROBLEMA DE PESQUISA}

\subsection{Introdução}

A intensidade das mudanças que vêm ocorrendo no mundo já é fato percebido pelas pessoas. O que talvez nem todas elas tenham percebido é que as mudanças estão cada vez mais aceleradas, criando descontinuidades que afetam a todos. Essa visão sobre a envergadura desses processos de mudança é muito bem explorada por Castells (1999), ao discorrer sobre a nova realidade introduzida pelo que o autor chamou de Sociedade da Informação. Ou seja, a sociedade industrial, na qual e por meio da qual nossos antepassados se basearam para orientar nossa formação profissional e social, foi alterada em decorrência das mudanças ocorridas nos usos, costumes e tecnologias presentes no cotidiano da sociedade atual.

As empresas são atores componentes deste contexto contemporâneo. Assim, a capacidade da empresa gerar conhecimento por meio das atividades de pesquisa e desenvolvimento e mesmo no dia a dia dos negócios, quando associada à criatividade de seus colaboradores, pode permitir que ela tenha maior capacidade de inovação e com isto consiga diferenciais competitivos. A indústria de software, por meio de seus gestores, procura tornar-se cada vez mais eficaz para satisfazer seus clientes com produtos e serviços diferenciados.

O porte e a importância da indústria de software no Brasil podem ser constatados por meio de alguns indicadores tais como o faturamento verificado em 2007 - US\$ 11,12 bilhões, ou 1,6\% do mercado mundial (BRASIL, 2006; ABES, 2009) e pelo fato de ter se consolidado em 2008 na $12^{\circ}$ posição no cenário mundial, com faturamento aproximado de US\$ 5 bilhões em software, o equivalente a 1,68\% do mercado mundial daquele ano (ABES, 2009). A indústria de software no Brasil é composta "por cerca de 8.500 empresas, dedicadas ao desenvolvimento, produção e distribuição de software e de prestação de serviços." (ABES, 2009, s.p.).

O conhecimento é um dos recursos fundamentais para que as empresas dessa indústria possam continuar a oferecer produtos e serviços diferenciados e capazes de agregar valor aos clientes e aos seus negócios. O conhecimento como recurso valioso começou a receber maior atenção 
da comunidade de pesquisadores e profissionais da ciência da Administração a partir das duas últimas décadas do século passado, notadamente com o advento da visão baseada no conhecimento (KBV - knowledge based view), conforme Eisenhardt e Santos (2002).

Assim, a gestão de empresas desenvolveu um conjunto de processos para lidar com o gerenciamento do conhecimento enquanto insumo e recurso que pode possibilitar maior competitividade à empresa. Para tanto, a gestão do conhecimento é feita por meio de práticas gerenciais aplicadas aos processos de aquisição, criação, armazenamento, compartilhamento, disseminação, utilização e descarte de conhecimentos na empresa. Não obstante, observa-se também a incorporação de novas tecnologias de apoio à gestão, desenvolvimento de produtos e de produção oriundas da tecnologia de informação e comunicação. As práticas de gestão do conhecimento e as novas tecnologias da informação e comunicação buscam capacitar a empresa a ser eficaz na consecução de seus objetivos, agregando valor aos produtos e serviços ofertados aos clientes e capacitando-a assim a enfrentar a concorrência.

Considerando-se que o conhecimento é um dos recursos mais valiosos utilizados pelos colaboradores das empresas integrantes da indústria de software no Brasil, e que estes colaboradores são, na sua maioria, trabalhadores do conhecimento altamente qualificados que desenvolvem suas atividades mesmo em ambientes de teletrabalho, ou seja, mesmo quando estão distantes das instalações da empresa; gerir este recurso por meio da utilização de práticas de gestão do conhecimento, bem como de ferramentas da tecnologia de informação e comunicação a elas associados, é uma das possibilidades de melhoria da eficácia empresarial destas empresas.

Tendo em vista a importância desses processos e suas possíveis contribuições para que a empresa alcance seus objetivos, esta tese busca identificar o uso de práticas de gestão do conhecimento e de ferramentas de tecnologia da informação e comunicação a elas associadas nas empresas atuantes na indústria de software no Brasil. Não obstante, busca ainda analisar e caracterizar suas possíveis influências na eficácia empresarial dessas empresas, sejam elas empregadas em ambientes de trabalho presencial ou em ambientes de teletrabalho. 


\subsection{Definição da situação problema}

A presente pesquisa é baseada em três vertentes conceituais fundamentais, quais sejam: gestão do conhecimento, teletrabalho e eficácia empresarial. Esses três conceitos multidisciplinares, que foram estudados no contexto da indústria de software no Brasil, constituem-se em importantes temas para o aprofundamento de estudos e pesquisas. Pode-se considerar ainda que sejam temas relativamente recentes, fato que por si só já evidenciaria suas respectivas relevâncias. Não obstante, ao refletir sobre a intersecção dos temas propostos neste estudo (gestão do conhecimento em ambientes de teletrabalho e sua possível influência na eficácia empresarial de empresas atuantes na indústria de software no Brasil), verifica-se de forma acentuada a carência de estudos empíricos que busquem analisar este campo específico. A Figura 1 evidencia a centralidade do problema de pesquisa desta tese:

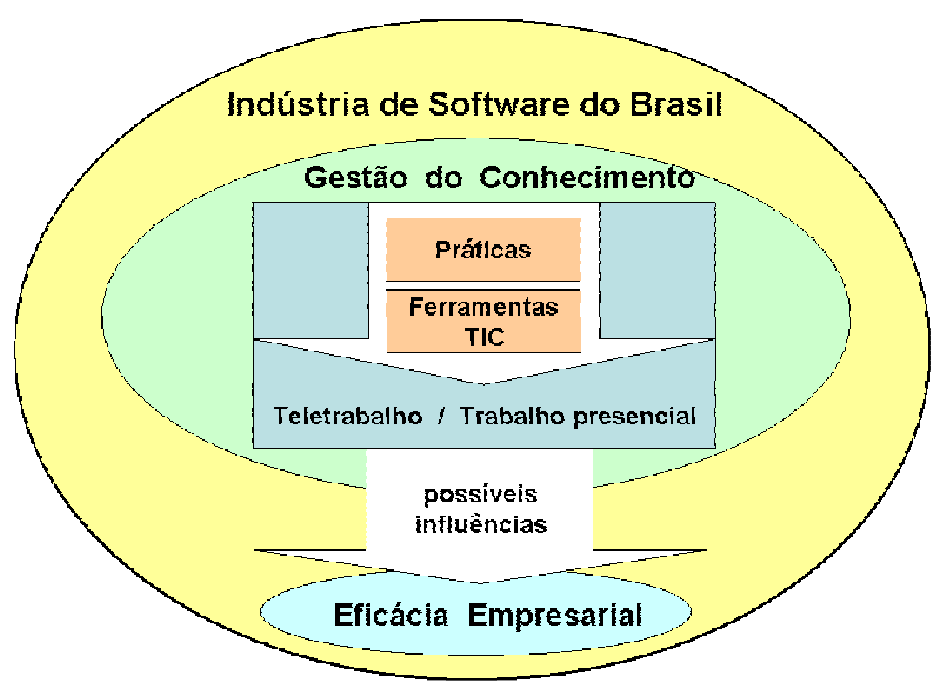

Figura 1 - Conceitos centrais estudados e problema de pesquisa.

Fonte: elaborado pelo autor.

Para uma melhor compreensão da importância de estudar tais temas, autores como Ferraresi e Santos (2006, p. 173) argumentam que a "gestão do conhecimento é objeto de busca de definições por vários autores [...] e sua base teórica ainda se encontra em construção." Também em relação à eficácia empresarial há lacunas a serem mais bem exploradas, conforme colocação de Vandenbosch e Huff (1997) acerca da dificuldade de formalização de conceitos da eficácia empresarial por meio de um conjunto de indicadores válidos. Uma intersecção entre a gestão do conhecimento e seu papel na eficácia empresarial pode ser 
encontrada nos trabalhos de Eisenhardt e Santos (2002), ao sustentarem o Knowledge Based View (visão baseada no conhecimento). Por fim, um estudo mais aprofundado da indústria de software no Brasil também se faz necessário dada sua expansão verificada a partir da década de 1990.

Além disso, o conhecimento já constituído sobre cada uma das vertentes fundamentais desse estudo baseia-se em pesquisas efetuadas no contexto dos países desenvolvidos do hemisfério norte, especialmente Estados Unidos, Europa e Ásia, conforme comprovado por meio de pesquisa do referencial teórico no corpo deste projeto de pesquisa. Ou seja, há uma lacuna teórica a ser preenchida nestas áreas de estudo, notadamente na intersecção dos temas propostos nesta pesquisa, sobretudo em relação à realidade vivenciada pelas empresas atuantes no Brasil.

A partir dessa linha de raciocínio, a pesquisa de campo buscou identificar tal situação especificamente em empresas atuantes na indústria de software no Brasil. Aliado a isso, buscou-se identificar as práticas de gestão do conhecimento utilizadas na indústria de software no Brasil, bem como as respectivas ferramentas de tecnologia da informação e comunicação que suportam a execução destas práticas, bem como as influências da gestão do conhecimento na eficácia empresarial.

Dessa forma, o problema de pesquisa é explicitado a partir da seguinte indagação: Quais são as práticas e ferramentas de tecnologia da informação e comunicação utilizadas na gestão do conhecimento em ambientes de trabalho presencial ou de teletrabalho; e sua possível influência na eficácia empresarial das empresas atuantes na indústria de software no Brasil?

\subsection{Objetivos de pesquisa}

Os objetivos a seguir buscam responder a questão formulada na seção anterior:

- Identificar e especificar as práticas de gestão do conhecimento utilizadas pelas empresas atuantes na indústria de software no Brasil; 
- Identificar e especificar as ferramentas de tecnologia da informação e comunicação utilizadas na gestão do conhecimento das empresas atuantes na indústria de software no Brasil;

- Identificar e especificar se há diferenças na utilização das práticas e ferramentas de gestão do conhecimento utilizadas em ambientes de teletrabalho e em ambientes de trabalho presencial nas empresas atuantes na indústria de software no Brasil;

- Identificar e especificar as influências da gestão do conhecimento na eficácia empresarial das empresas atuantes na indústria de software no Brasil.

\subsection{Hipóteses de pesquisa}

O presente estudo estabelece as seguintes hipóteses que foram posteriormente testadas para validação ou refutação a partir dos resultados obtidos na pesquisa de campo:

H01 - Não é possível afirmar que a utilização de práticas de gestão do conhecimento adotadas pelas empresas atuantes na indústria de software no Brasil influencie a eficácia empresarial;

H02 - Não é possível afirmar que a utilização de ferramentas de tecnologia da informação e comunicação empregadas na gestão do conhecimento nas empresas atuantes na indústria de software no Brasil influencie a eficácia empresarial;

H03 - Não é possível afirmar que a utilização de práticas de gestão do conhecimento pelas empresas atuantes na indústria de software no Brasil seja mais intensa nas atividades de teletrabalho do que em atividades semelhantes realizadas por colaboradores dentro do ambiente físico interno das empresas;

H04 - Não é possível afirmar que a utilização de ferramentas de tecnologia de informação e comunicação empregadas na gestão do conhecimento das empresas atuantes na indústria de software no Brasil seja mais intensa nas atividades de teletrabalho do que em atividades semelhantes realizadas por colaboradores dentro do ambiente físico interno das empresas. 


\subsection{Definições teóricas e operacionais de pesquisa}

A seguir são expostas as definições teóricas e operacionais dos principais tópicos desenvolvidos na tese:

- Gestão do conhecimento: “coordenação deliberada e sistemática de pessoas, tecnologias, processos e estrutura da empresa na busca da criação de valor através do recurso do conhecimento. [...] Essa coordenação tanto é realizada através da criação, compartilhamento e aplicação do conhecimento como por meio de alimentação de valiosas lições aprendidas e das melhores práticas dentro da memória corporativa, fomentando continuamente a aprendizagem organizacional." (DALKIR, 2005, p. 3). Operacionalmente, para efeito desta pesquisa, a gestão do conhecimento pôde ser constatada na empresa pelos indivíduos respondentes do questionário enviado pelo pesquisador às empresas. Estas pessoas são aquelas que participam da gestão deste recurso na empresa. Os profissionais gestores questionados na pesquisa são instigados a descrever a gestão do conhecimento praticada na empresa, bem como quais as influências e efeitos (benefícios/resultados/mudanças) decorrentes dessa gestão do conhecimento realizada.

- Práticas de gestão do conhecimento: técnicas, iniciativas, métodos, tecnologias, políticas e estratégias que viabilizam que os indivíduos na empresa possam administrar a identificação, aquisição, distribuição, aplicação, criação e descarte de conhecimentos e experiências na empresa. Operacionalmente, as práticas de gestão do conhecimento puderam ser constatadas na empresa pelos indivíduos respondentes do questionário enviado pelo pesquisador às empresas. Estas pessoas são aquelas que participam das práticas de gestão deste recurso na empresa. O questionário apresentou aos respondentes as 46 práticas identificadas no referencial teórico. 
- Ferramentas de tecnologia da informação e comunicação: "ferramentas e processos para distribuir, armazenar e recuperar informações úteis às várias áreas da empresa, tais como hardware (conjunto de dispositivos), software (conjunto de programas ou aplicativos), banco de dados (conjunto organizado de registros que armazenam dados e associações entre eles), redes (sistema de conectividade) e comunicações (sistema de envio e recebimento de mensagens)." (TURBAN, 2003, p. 34). Operacionalmente, para efeito desta pesquisa, as ferramentas de tecnologia da informação e comunicação voltadas à gestão do conhecimento puderam ser constatadas na empresa pelos indivíduos respondentes do questionário enviado pelo pesquisador às empresas. Estas pessoas são aquelas que utilizam as ferramentas de tecnologia da informação e comunicação na gestão deste recurso na empresa. O questionário apresentou aos respondentes as 38 ferramentas identificadas no referencial teórico.

- Eficácia empresarial: refere-se ao "alcance dos objetivos estabelecidos pela organização, considerando-se a manutenção de seu sistema interno face à consequente adaptação ao ambiente externo." (ROBBINS e COULTER, 2002, p. 14). A eficácia empresarial se dá em função do "grau de funcionamento ótimo da empresa, podendo ser mensurada por sua capacidade de manter seus elementos internos como um sistema social coeso, além da capacidade de interagir adequadamente com o ambiente externo." (RAMOS, 1996, p. 18). Operacionalmente, para efeito desta pesquisa, a eficácia empresarial alcançada por meio da gestão do conhecimento pôde ser constatada na empresa pelos indivíduos respondentes do questionário enviado pelo pesquisador às empresas. Estas pessoas são aquelas que participam da gestão do conhecimento na empresa. O questionário apresentou aos respondentes 15 indicadores de eficácia empresarial identificados no referencial teórico, solicitando que os respondentes asseverem a influência da gestão do conhecimento desenvolvida na empresa em cada um dos indicadores apresentados.

- Teletrabalho: toda composição de trabalho na qual os empregados executam parte ou todas as suas atividades distantes dos locais de trabalho disponibilizados pela empresa, ou seja, fora do ambiente físico das instalações da empresa. Insere-se aí a utilização de tecnologia da informação e comunicação como suporte à 
flexibilidade do local de trabalho (US OPM, 2003; OLSZEWSKI e LAM, 1993; PEREZ, SANCHES e CARNICER, 2003). Operacionalmente, para efeito desta pesquisa, o teletrabalho praticado no desenvolvimento da gestão do conhecimento pôde ser constatado na empresa pelos indivíduos respondentes do questionário enviado pelo pesquisador às empresas. Estas pessoas são aquelas que participam da gestão do conhecimento na empresa. O questionário solicitava aos respondentes que indicassem se atuam em regime de teletrabalho e, em caso positivo, que especificassem ainda o período de tempo em uma semana no qual atuam nessa condição.

\subsection{Pressupostos conceituais}

Para um correto entendimento e desenvolvimento da pesquisa almejada, é imprescindível delinear alguns pressupostos conceituais como sustentáveis e isentos de contestação, quais sejam:

- O conhecimento é um recurso passível de gestão por parte da empresa;

- O conhecimento tratado como recurso pode ser gerido e aplicado nas empresas e, por consequência, ser fator de geração de diferenciais competitivos;

- A gestão do conhecimento pressupõe a utilização de conceitos e técnicas gerenciais especificamente voltadas a essa finalidade, além do emprego de ferramentas da tecnologia da informação e comunicação que sustentem tal prática gerencial;

- A gestão do conhecimento pode gerar influências positivas na eficácia empresarial da empresa;

- A gestão do conhecimento pode gerar resultados tangíveis à empresa. 
A fundamentação teórica suporta os principais conceitos e características das grandes vertentes conceituais da pesquisa em pauta: a gestão do conhecimento, o teletrabalho e a eficácia empresarial. Constituem-se assim as bases conceituais da pesquisa, abrangendo os principais autores e pesquisadores, modelos de referência e diretrizes teóricas adotadas na pesquisa.

\subsection{Gestão do conhecimento}

Na visão grega clássica, o conhecimento era considerado algo de certa forma inabalável, conforme apregoava o filósofo Platão (427-347 A.C.) ao descrever o conhecimento como crença verdadeira e justificada. Já na idade média verificou-se um período de concentração do conhecimento existente no clero e em alguns poucos pensadores e filósofos. Após o renascimento, observou-se uma retomada do estudo do conhecimento, notadamente a partir das contribuições Locke (1632-1704) e Descartes (1596-1650), dentre outros iluministas. O método cartesiano proposto por Descartes, que argumentava não aceitar qualquer verdade até que esta pudesse ser provada, abre novas perspectivas para a criação e repercussão de conhecimentos, principalmente por meio das etapas propostas em método científico (verificação, análise, síntese e conclusão). Com o advento da Revolução Industrial percebe-se que o conhecimento científico passa a ser ampliado, tanto em termos de criação quanto em termos de disseminação.

Para Giles (1993, p. 23) o conhecimento é "o ato mental fundamentado na experiência sensível, pela qual se formulam juízos verdadeiros e seguros a respeito de algum objeto ou realidade." Japiassú e Marcondes (1996, p. 51) apregoam que o conhecimento seja "uma função ou ato psíquico do indivíduo que tem por efeito tornar uma realidade ou objeto presente aos sentidos ou à inteligência." A partir desses conceitos, pode-se depreender que o conhecimento é intrínseco ao ser humano, ocorrendo como resultado de suas experiências ou por meio de seu pensamento ou raciocínio sendo, portanto, uma atividade tipicamente humana (BRAUNER e BECKER, 2006). 
Mas a percepção do conhecimento como algo dinâmico foi profundamente transformada a partir das ideias apresentadas por Polanyi (1964), que argumentava sobre o conhecimento tácito existente nas pessoas. Ou seja, as pessoas podem ter mais conhecimentos do que supõem ou aparentam ter. Assim sendo, Nonaka e Takeuchi (1997) sugerem que o conhecimento seja encarado como um fenômeno humano pragmático, sempre em contínuo desenvolvimento. Também May e Taylor (2003) asseveram que o conhecimento se origine de experiência individual e internalizada do mundo, emergindo como uma combinação de habilidades, experiências, percepções e memórias individuais.

Grant (1996) expõe um conceito ampliado de conhecimento ao discorrer que conhecimento seja aquilo que é conhecido. Lacombe e Heilborn (2003) entendem que conhecimento seja o conteúdo de valor agregado do pensamento humano, derivado da percepção e manipulação inteligente de conteúdos. Para Dalkir (2005), o conhecimento é uma maneira mais subjetiva do saber, baseado tipicamente em valores, percepções e experiências dos indivíduos. Segundo Sveiby (2001), o conhecimento é uma faculdade humana, definido pelo acúmulo de experiências e da capacidade de agir. $\mathrm{O}$ autor defende ainda que o conhecimento possa ser distinguido em duas vertentes: o conhecimento enquanto objeto como algo que pode ser armazenado, sendo suportado por tecnologias e convertido; e o conhecimento enquanto um processo que reside nas pessoas e é refletido em ações.

Firestone e McElroy (2001) distinguem três instâncias de conhecimento: a primeira é representada em objetos ou estruturas físicas (mundo material do conhecimento); a segunda é relativa às crenças sobre o mundo (mundo mental do conhecimento); e a terceira refere-se ao mundo autônomo dos objetos mentais que engloba as formulações linguísticas que possam ser compartilhadas, as teorias, modelos e postulados sobre o mundo.

Para De Sordi (2008, p. 12), “conhecimento é o novo saber, resultante de análises e reflexões de informações segundo valores e modelo mental daquele que o desenvolve, proporcionando a este melhor capacidade adaptativa às circunstâncias do mundo real.” Segundo Davenport e Prusak (1998), o conhecimento é composto pelo que é conhecido e avaliado na mente humana, incluindo-se aí as suas respectivas reflexão, síntese e contextualização. Fleck (1997) assegura ainda que deva-se associar mais uma importante característica ao conhecimento: o significado que este dá às coisas e aos fatos. 
Assim sendo, depreende-se que o conhecimento seja inerente ao desenvolvimento do homem. Tendo-se ainda como premissa que o homem é um ser essencialmente sociável em sua busca por vida coletiva, pode-se compreender que as empresas, que são feitas de e por seres humanos, podem ser consideradas como locais propícios para a aquisição, criação, aplicação, compartilhamento e disseminação do conhecimento.

Tapscott (1997), Stewart (1998) e Castells (1999) evidenciaram termos tais como 'sociedade da informação' ou 'era do conhecimento', que expressam a exata medida da importância desses ativos para as organizações contemporâneas. Davenport e Prusak (1999) discorrem que a aplicação do conhecimento possa gerar retornos crescentes e novas perspectivas para as organizações, principalmente na medida em que os ativos do conhecimento aumentam com o seu uso, uma vez que ideias geram novas ideias e o conhecimento compartilhado enriquece todos aqueles que dele participam. Nonaka (2001) enfatiza que a compreensão das ideias, intuições e conhecimentos tácitos existentes na organização seja imprescindível para aumentar o poder competitivo das empresas modernas.

Para Cavalcanti, Gomes e Pereira (2001), o conhecimento, e não tão somente o acesso às informações, é que tem propiciado o verdadeiro distanciamento das organizações, regiões e países líderes em relação aos demais. Drucker (2001, p. 10) corrobora tal perspectiva ao afirmar que "a empresa típica será baseada no conhecimento e que principalmente as grandes empresas não têm muita escolha quanto a se converterem em organizações baseadas em conhecimento."

Ao discorrer sobre o conceito e a importância do conhecimento, Pillania (2009) o insere num contexto ainda mais prático, ligado à utilização desse recurso por parte da empresa. $\mathrm{O}$ autor argumenta que o conhecimento seja toda a forma de intuições, raciocínios, discernimentos, experiências, produtos, serviços, processos, clientes, mercados, competição e o que mais capacite ações eficazes da empresa. Ou seja, o conhecimento é que capacita as pessoas nas empresas a agirem e lidarem de forma inteligente com as situações existentes, notadamente por meio da aplicação prática dos conhecimentos.

Para tanto, faz-se necessário uma melhor compreensão do tratamento dado pelas empresas quanto à manipulação do conhecimento. Nonaka (1990) entende que o processo de criação e disseminação do conhecimento seja antes de tudo, um processo de conversão social, no qual o 
conhecimento tácito e o conhecimento explícito se expandem dentro da organização em termos qualitativos e quantitativos. Para Nonaka e Takeuchi (1997), o conhecimento tácito está associado à capacidade de agir das pessoas, às suas habilidades, expertises, experiências, competências, raciocínio, modelos mentais, conclusões, geração de ideias, opiniões, emoções, valores, intuição, criatividade e crenças. Já o conhecimento explícito resulta do conhecimento tácito, podendo ser entendido como a materialização ou a representação do conhecimento de alguém a partir de algum tipo de registro, escrita ou mídia, e que possa ser transferido, transmitido, comunicado, visualizado, armazenado, preservado, compreendido e assimilado por outros. Assim, o conhecimento explícito age como um guia que leva as pessoas à produção de conhecimentos novos sejam eles tácitos ou explícitos.

A conversão dos conhecimentos na organização é exposta por Nonaka e Takeuchi (1997) por meio de um modelo que representa quatro modos de conversão de conhecimento: socialização, externalização, combinação e internalização, conforme exposto na Figura 2 a seguir.

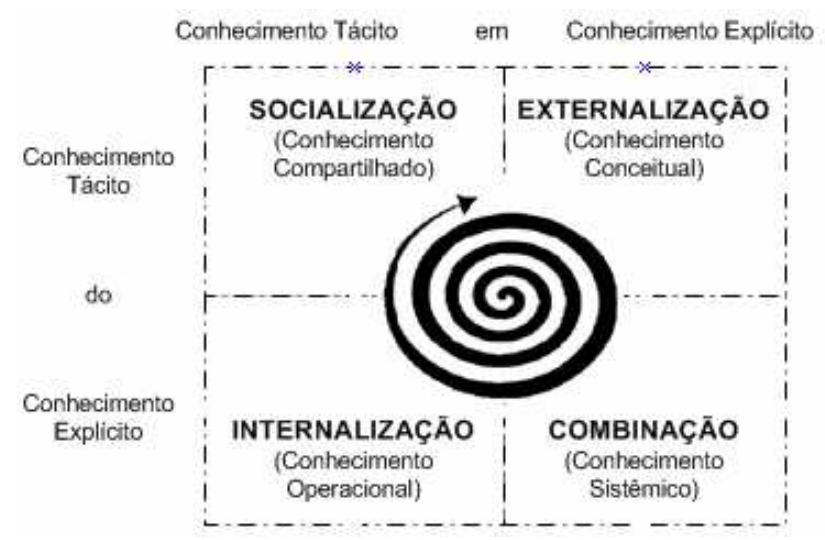

Figura 2 - Quatro modos de conversão de conhecimento.

Fonte: Nonaka e Takeuchi (1997, p. 81).

A socialização consiste no compartilhamento das experiências entre os indivíduos, que aprenderiam por meio da observação e interação uns com os outros, sem necessariamente utilizar a linguagem. Esse modo de criação de conhecimento seria um importante ativo na aquisição do conhecimento tácito. Já externalização é um processo de articulação do conhecimento tácito em conceitos explícitos, notadamente por meio do compartilhamento de metáforas, analogias, modelos ou histórias, ocorrendo geralmente com o diálogo e a reflexão coletiva. É muito importante para a criação do conhecimento, uma vez que gera conceitos novos e explícitos a partir do conhecimento tácito. A combinação é um processo de 
organização de conceitos em um sistema de conhecimento. Ou seja, é o modo pelo qual partes até então incompatíveis de conhecimento explícito já existentes se combinam, criando assim um novo conhecimento explícito. Finalmente, na internalização verifica-se o processo de incorporação do conhecimento explícito em conhecimento tácito. Está intimamente relacionada ao 'aprender fazendo', principalmente por meio de modelos mentais ou expertise técnica compartilhados. Nela há a aprendizagem e socialização mediante a repetição de uma tarefa, a fim de que os conhecimentos explícitos transformem-se em conhecimento tácito (NONAKA e TAKEUCHI, 1997).

Dixon (2000) também preocupou-se em compreender o processo de conversão de conhecimentos na empresa, principalmente em função deste processo contribuir para que a empresa alcance o retorno desejado em sua missão. Assim, o autor considera que a empresa precise continuamente reinventar e atualizar seu conhecimento, o que requer a execução repetida de duas atividades, quais sejam: desenvolvimento de meios efetivos para transformar suas experiências em conhecimento e a transferência desse conhecimento no tempo e no espaço de forma a coletivizá-lo. A operacionalização do processo de conversão de conhecimento é descrita na Figura 3 a seguir:

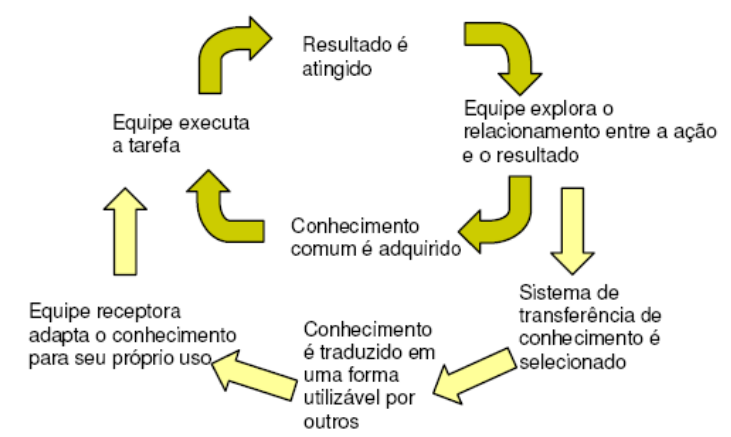

Figura 3 - Criação e transferência do conhecimento.

Fonte: Dixon (2000).

Segundo Eisenhardt e Santos (2002), a observância da conversão de conhecimentos e da gestão de conhecimentos na empresa ganha importância na medida em que a codificação do conhecimento se torne real, ou seja, quando o conhecimento tácito se torna mais explícito de maneira tal que possa ser mais facilmente comunicado e entendido pelas pessoas. Os autores exploram a importância da knowledge based view (visão baseada no conhecimento), ao considerarem o conhecimento como um recurso estratégico à empresa. 
A gestão desse recurso, ou seja, a gestão do conhecimento é uma especialidade da Administração que consiste em aplicar um conjunto de técnicas desta área de conhecimentos para gerir o conhecimento como um dos recursos utilizados pelos colaboradores da empresa no seu cotidiano, conforme Santos et al (2001). Para Pillania (2009), a gestão do conhecimento é um processo sistemático, organizado, explícito, deliberado e contínuo de criar, disseminar, aplicar, renovar e atualizar o conhecimento para alcançar os objetivos organizacionais.

Grotto (2001) complementa essa noção de conjunto de processos entendendo que a gestão do conhecimento deva administrar a geração, compartilhamento, armazenamento, aprendizado, utilização e mensuração de conhecimentos nas organizações. Para Dalkir (2005), gestão do conhecimento é a:

Coordenação deliberada e sistemática de pessoas, tecnologias, processos e estrutura da empresa na busca da criação de valor através do recurso do conhecimento e inovação. Essa coordenação é realizada através da criação, compartilhamento e aplicação do conhecimento como por meio de alimentação de valiosas lições aprendidas e das melhores práticas dentro da memória corporativa, fomentando continuamente a aprendizagem organizacional. (DALKIR, 2005, p. 3).

Segundo Teece (2000), a gestão do conhecimento é a base para a construção de vantagens competitivas. Para Leitch e Rosen (2001), entender e aperfeiçoar os processos ligados à gestão do conhecimento pode possibilitar à empresa vantagens competitivas, independentemente do segmento de mercado em que atue. De forma complementar, Andone (2009) argumenta que a compreensão do sistema de gestão do conhecimento nas empresas seja o fator-chave do sucesso da empresa.

Zack (1999) sustenta que a gestão do conhecimento deva ser ponto central da gestão estratégica da empresa, uma vez que trata de recursos baseados no conhecimento e em habilidades valiosas, inimitáveis e únicas. Soo (2002) discorre haver uma necessidade estratégica da empresa em relação à gestão do conhecimento, uma vez que os mercados atuais apresentam rápidas mudanças. Para Greiner, Bohmann e Krcmar (2007), o sucesso de ações de gestão do conhecimento deve-se ao alinhamento entre a própria gestão do conhecimento e a estratégia da empresa em si. Ou seja, a estratégia de gestão do conhecimento deve refletir a estratégia competitiva da empresa (WAJIDI e ASIM, 2009.). 
Green (2006) apresenta uma postura mais pragmática em relação à gestão do conhecimento ao indicar que esta deva estar voltada ao contexto dos negócios da empresa devendo ser, portanto desenvolvida em função deles. Nesse sentido, Buzokowitz e Williams (2002) discorrem que a gestão do conhecimento consista no esforço de se utilizar este recurso como forma de conseguir melhores resultados para a empresa e seus stakeholders, principalmente por meio da prospecção dos conhecimentos existentes interna ou externamente. Segundo Robinson, Carrilo e Anumba (2005), a gestão do conhecimento pode transformar os conhecimentos de uma empresa em ativos voltados à viabilização de um crescimento continuado e sustentável.

Em estudo conduzido por Cardoso (2007) junto a 50 empresas portuguesas, pôde-se comprovar empiricamente que a gestão do conhecimento constitui-se numa fonte de vantagem competitiva sustentável para a empresa, promovendo assim sua competitividade. Em outro estudo levado a cabo por Lee e Sukoco (2007) em grandes empresas taiwanesas, verificou-se que a gestão do conhecimento tem um impacto significativo na eficácia empresarial.

Ho (2008, p. 1247) também analisou tal questão em estudo feito com 21 empresas asiáticas de tecnologia e corrobora tal pensamento ao indicar que "a gestão do conhecimento tem uma influência direta e significativa na eficácia empresarial." Outra pesquisa conduzida por Kipley, Lewis e Helm (2009) junto a pequenas e médias empresas concluiu que a gestão do conhecimento contribui para o alcance de vantagens competitivas estratégicas dessas empresas frente aos seus competidores.

Aaron (2009) analisou casos práticos de empresas que efetuavam a gestão do conhecimento, concluindo ter havido um impacto significativamente positivo na produtividade, oriundo basicamente de economia com o tempo dos processos de trabalho. Batra (2010) conclui em pesquisa junto a 50 executivos de empresas de tecnologia da informação que a gestão do conhecimento ajuda na geração de novas ideias e práticas que auxiliam na resolução de problemas, contribuindo assim para um melhor desempenho da empresa como um todo. Estudo realizado por Sharma, Hui e Tan (2007) junto à empresa de uso intensivo de tecnologia com destacado crescimento no mercado indicou inclusive que práticas e iniciativas de gestão do conhecimento tenham contribuído decisivamente para resultados financeiros.

Hitt, Ireland e Hoskinsson (2001) afirmam que o conhecimento e a gestão sobre esse recurso da empresa, têm sido cada vez mais utilizados na criação de vantagem competitiva 
sustentável. Assim, O’Dell, Elliot e Hubert (2003) sustentam que, no atual contexto do ambiente competitivo no qual as empresas estão inseridas, a transformação do conhecimento em capital por meio da gestão desse recurso ganha importância como forma de a empresa atingir sua missão.

Vasconcelos (2001, p. 98) entende a gestão do conhecimento como "a determinação do que a empresa sabe ou deveria saber para alcançar seus objetivos estratégicos [...] As empresas competirão entre si e se diferenciarão como base naquilo que sabem." Scarbrough, Swan e Preston (1999) vão além ao apontarem que a gestão do conhecimento possa ser indutora de outro importante ganho: o conhecimento ainda a ser gerado pelos indivíduos existentes numa empresa. Tal conhecimento ainda a ser gerado é enfatizado por Allamesh e Abbas (2010) ao apontarem a forte relação existente entre a gestão do conhecimento e a inovação nas empresas, conforme observado em estudo de campo realizado em empresas do oriente médio.

Dessa forma, o conhecimento torna-se um elemento importante para o estabelecimento de diferenciais de uma organização em relação às demais congêneres. Ou seja, a gestão do conhecimento numa organização torna-se uma questão importante à medida que pode capacitá-la a ter diferenciações significativas em seu meio de atuação. Tobin (2004), bem como Graham e Pizzo (1998) entendem que uma gestão do conhecimento eficaz seja um passo indispensável na estratégia corporativa para viabilizar a transformação de boas ideias em bens com valor tangível para os negócios da organização. Para Corsoa et. al (2006), a gestão do conhecimento tem sido reconhecida como um fator-chave de sucesso na obtenção e manutenção de vantagens competitivas. A importância da gestão do conhecimento também é explicitada por Murray (2004) ao lembrar que o conhecimento resulta em ações, e que estas ações acabam por produzir resultados de negócio para a empresa.

Gold, Malhotra e Segars (2001) efetuaram pesquisa na qual analisaram a infra-estrutura e os processos de gestão de conhecimento enquanto agentes capacitadores da eficácia empresarial. Assim, a Figura 4 expõe a relação direta existente entre a infra-estrutura e os processos e práticas de gestão do conhecimento como fatores indutores da eficácia empresarial de uma empresa. 


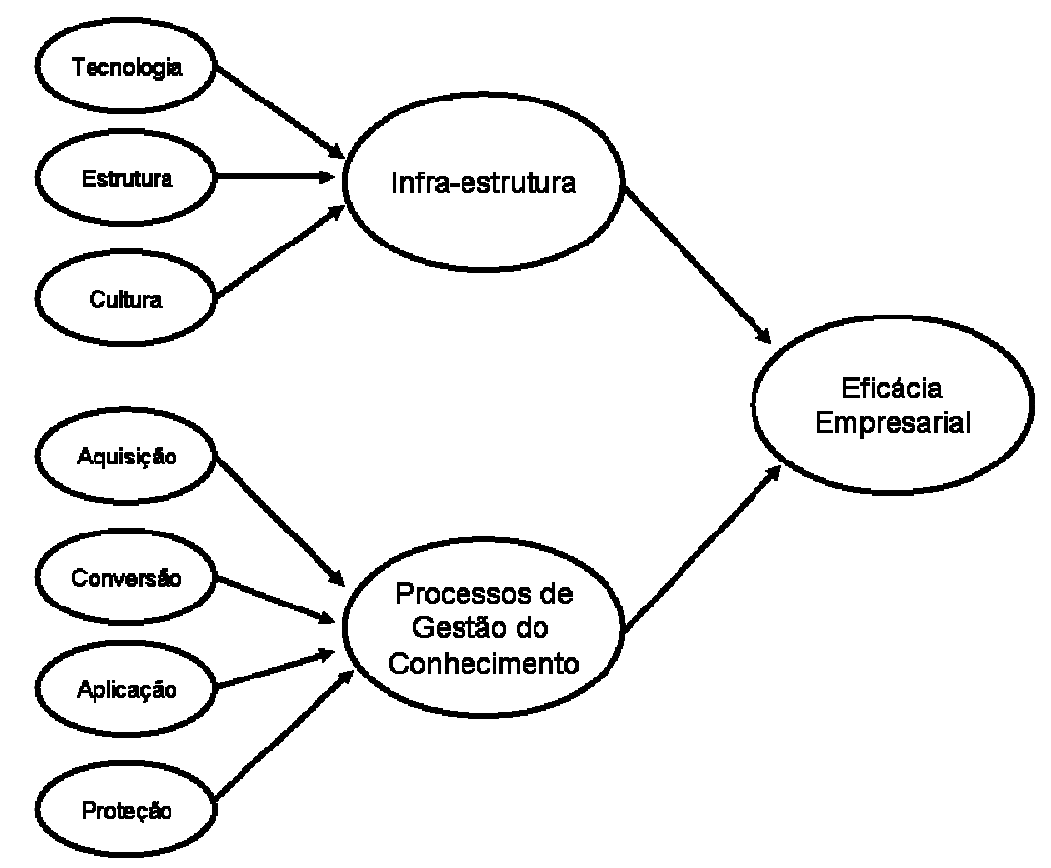

Figura 4 - Capacitadores da gestão do conhecimento e eficácia empresarial.

Fonte: Gold, Malhotra e Segars (2001, p. 193).

A partir da constatação de que a gestão do conhecimento possa gerar resultados positivos à empresa, faz-se importante compreender as principais atividades associadas ao processo de gestão do conhecimento. De Sordi (2008, p. 89) explora diversas pesquisas de diferentes autores acerca da "essência do processo de gestão do conhecimento perante as mais recentes teorias e práticas.", conforme o Quadro 1 a seguir:

\begin{tabular}{|c|c|c|c|c|}
\hline $\begin{array}{c}\text { Davenport } \\
(1997)\end{array}$ & $\begin{array}{c}\text { Bukowitz e } \\
\text { Williams (1999) }\end{array}$ & $\begin{array}{c}\text { Probst, Raub e } \\
\text { Romhardt }(2000)\end{array}$ & $\begin{array}{c}\text { Davenport e } \\
\text { Marchand (2000) }\end{array}$ & $\begin{array}{l}\text { Gupta, Bhatt e } \\
\text { Kitchens (2005) }\end{array}$ \\
\hline $\begin{array}{l}\text { - Determinar } \\
\text { exigências } \\
\text { - Obter } \\
\text { - Distribuir } \\
\text { - Utilizar }\end{array}$ & $\begin{array}{l}\text { - Obter } \\
\text { - Utilizar } \\
\text { - Aprender } \\
\text { - Contribuir } \\
\text { - Avaliar } \\
\text { - Construir e } \\
\text { sustentar } \\
\text { - Abster-se }\end{array}$ & $\begin{array}{l}\text { - Identificar } \\
\text { - Adquirir } \\
\text { - Desenvolver } \\
\text { - Partilhar/ } \\
\text { distribuir } \\
\text { - Utilizar } \\
\text { - Rever }\end{array}$ & $\begin{array}{l}\text { - Mapear } \\
\text { - Adquirir/criar/ } \\
\text { capturar } \\
\text { - Empacotar } \\
\text { - Armazenar } \\
\text { - Compartilhar/ } \\
\text { transferir/aplicar } \\
\text { - Inovar/evoluir } \\
\text { transformar }\end{array}$ & $\begin{array}{l}\text { - Criar } \\
\text { - Manter } \\
\text { - Distribuir } \\
\text { - Rever e } \\
\text { revisionar }\end{array}$ \\
\hline
\end{tabular}

Quadro 1 - Diferentes perspectivas sobre as atividades envolvidas no processo de gestão do conhecimento Fonte: De Sordi (2008, p. 89).

Dalkir (2005, p. 27) também prospectou diferentes pesquisas de autores variados acerca do processo de gestão do conhecimento. O Quadro 2 apresenta os autores analisados por Dalkir (2005): 


\begin{tabular}{|c|c|c|c|c|c|}
\hline $\begin{array}{l}\text { Nickos } \\
(1989)\end{array}$ & $\begin{array}{l}\text { Wiig } \\
\text { (1993) }\end{array}$ & $\begin{array}{c}\text { Zack } \\
(1996)\end{array}$ & $\begin{array}{c}\text { McElrooy } \\
\text { (1999) }\end{array}$ & $\begin{array}{l}\text { Rollet } \\
(\mathbf{2 0 0 3})\end{array}$ & $\begin{array}{c}\text { Bukowitz e } \\
\text { Willians (2004) }\end{array}$ \\
\hline $\begin{array}{l}\text { - Aquisição } \\
\text { - Organização } \\
\text { - Especiali- } \\
\text { zação } \\
\text { - Armazena- } \\
\text { mento/acesso } \\
\text { - Recuperação } \\
\text { - Conservação } \\
\text { - Eliminação }\end{array}$ & $\begin{array}{l}\text { - Criação } \\
\text { - Identificação } \\
\text { - Compilação } \\
\text { - Transfor- } \\
\text { mação } \\
\text { - Disseminação } \\
\text { - Aplicação } \\
\text { - Realização } \\
\text { de valor }\end{array}$ & $\begin{array}{l}\text { - Adquir } \\
\text { - Refinar } \\
\text { - Armazenar } \\
\text { e acessar } \\
\text { - Distribuir } \\
\text { - Apresentar }\end{array}$ & $\begin{array}{l}\text { - Aprendizagem } \\
\text { individual e } \\
\text { em grupo } \\
\text { - Solicitação } \\
\text { de validação de } \\
\text { conhecimento } \\
\text { - Aquisição da } \\
\text { informação } \\
\text { - Integração do } \\
\text { conhecimento }\end{array}$ & $\begin{array}{l}\text { - Planejamento } \\
\text { - Criação } \\
\text { - Integração } \\
\text { - Organização } \\
\text { - Transferência } \\
\text { - Manutenção } \\
\text { - Avaliação }\end{array}$ & $\begin{array}{l}\text { - Obter } \\
\text { - Usar } \\
\text { - Aprender } \\
\text { - Contribuir } \\
\text { - Avaliar } \\
\text { - Construir/ } \\
\text { sustentar } \\
\text { - Desinvestir }\end{array}$ \\
\hline
\end{tabular}

Quadro 2 - Processos-chave da gestão do conhecimento

Fonte: Dalkir (2005, p. 27).

De forma a condensar as pesquisas anteriores acerca das diferentes perspectivas sobre as atividades envolvidas no processo de gestão do conhecimento das empresas, De Sordi (2008) propõe o modelo exposto na Figura 5:

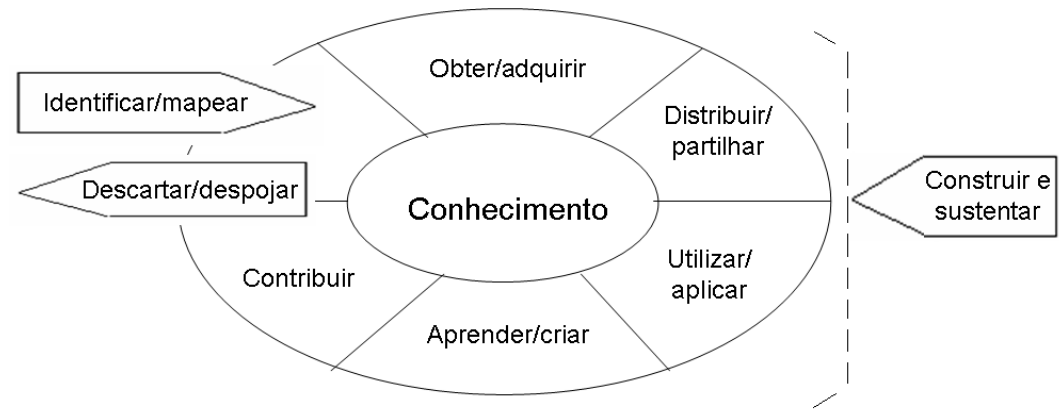

Figura 5 - Atividades realizadas no processo de gestão do conhecimento.

Fonte: De Sordi (2008, p. 90).

Uma breve descrição de cada uma das oito atividades do processo de gestão do conhecimento organizacional é feita a seguir (DE SORDI, 2008):

- Identificar/mapear conhecimento: estabelecimento do foco das informações relevantes ao negócio a serem trabalhadas pelas demais atividades do processo;

- Obter/adquirir conhecimento: conjunto de ações ininterruptas de exploração do ambiente de conhecimento da empresa, envolvendo atividades humanas e automatizadas; 
- Distribuir/partilhar conhecimento: definição da forma de disponibilização do conhecimento aos usuários, se ela será entregue ou comunicada;

- Utilizar/aplicar conhecimento: estímulo à experimentação e à receptividade em relação aos novos conhecimentos, trabalhando intensamente o comportamento organizacional no que tange ao uso das informações e conhecimentos disponíveis;

- Aprender/criar novos conhecimentos: estímulo á criatividade para geração de novos conhecimentos;

- Contribuir com novos conhecimentos: criar consciência da importância em transferir ao restante da empresa os conhecimentos aprendidos por indivíduos e equipes;

- Construir/sustentar relacionamentos: desenvolvimento e apoio da infraestrutura e das pessoas necessárias ao aumento e renovação dos conhecimentos indispensáveis à estratégia da empresa;

- Descartar/abster-se de conhecimento: o descarte pode ser feito por meio da conversão dos investimentos em conhecimentos de pouco retorno, para outras fontes de maior valor. Já a abstenção busca não abranger conhecimentos não essenciais ao negócio da empresa.

Liebowitz (2000) também expõe sua visão das atividades envolvidas no processo de gestão do conhecimento nas empresas, conforme ilustra a Figura 6. 


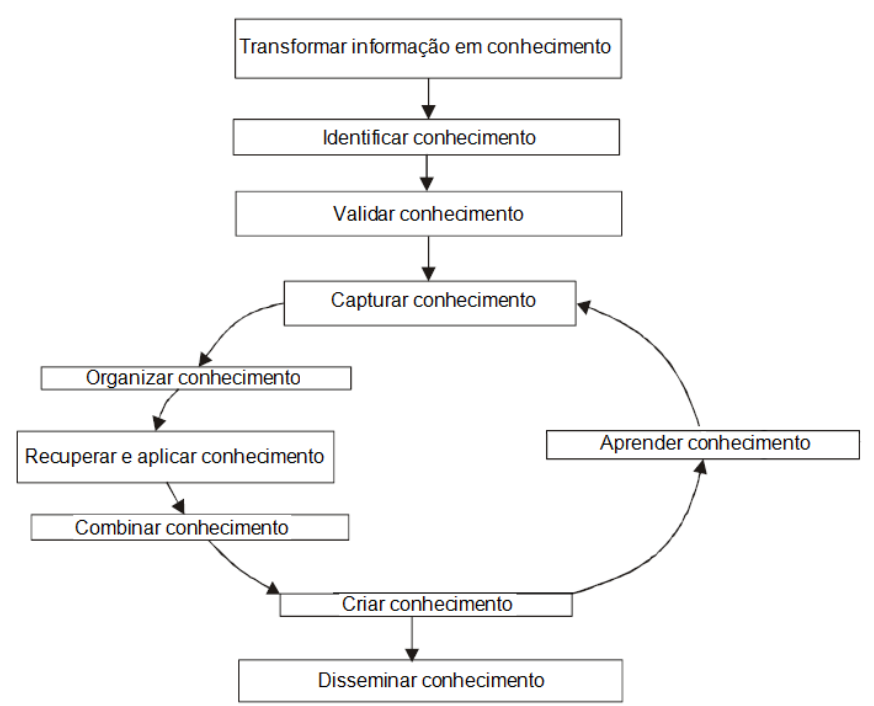

Figura 6 - Atividades realizadas no processo de gestão do conhecimento.

Fonte: Liebowitz (2000).

No caso específico de empresas pertencentes à indústria de software, cuja uma das premissas básicas de existência é a própria geração e disseminação de conhecimento, a importância das atividades de gestão do conhecimento parece ser ainda mais evidenciada. Segundo Zaim, Tatoglu e Zaim (2007), muito do sucesso de uma gestão do conhecimento eficaz provém da correta estruturação de práticas e de ferramentas de tecnologia que suportem sua evolução. Song (2001) argumenta que, por meio da utilização de práticas e iniciativas de gestão do conhecimento amparadas por ferramentas de tecnologia da informação e comunicação, as empresas de tecnologia da informação analisadas em pesquisa de campo efetuada em seu estudo, aumentaram sua eficácia empresarial.

De forma mais estruturada, Kuniyoshi e Santos (2007) expõem ferramentas, técnicas e tecnologias que podem oferecer importantes benefícios às empresas em sua busca por eficácia empresarial, conforme evidenciado no Quadro 3 a seguir: 


\begin{tabular}{|c|c|c|}
\hline $\begin{array}{c}\text { Fase de criação e captura do } \\
\text { conhecimento }\end{array}$ & $\begin{array}{c}\text { Fase de compartilhamento e } \\
\text { disseminação do conhecimento }\end{array}$ & $\begin{array}{c}\text { Fases de aquisição e aplicação do } \\
\text { conhecimento }\end{array}$ \\
\hline $\begin{array}{l}\text { Criação de conteúdo } \\
\text { - Ferramentas de autoria } \\
\text { - Modelos } \\
\text { - Anotações } \\
\text { - Data mining (mineração de } \\
\text { dados) } \\
\text { - Perfil de experts (especialistas) } \\
\text { - Blogs (diário eletrônico } \\
\text { baseado em tecnologia web) } \\
\text { Gestão de conteúdo } \\
\text { - Definir metadados } \\
\text { - Classificação } \\
\text { - Arquivamento } \\
\text { - Gestão do conhecimento pessoal }\end{array}$ & $\begin{array}{l}\text { Comunicação e tecnologias } \\
\text { colaborativas } \\
\text { - Telefone } \\
\text { - Fax } \\
\text { - Videoconferência } \\
\text { - Salas de bate-papo } \\
\text { - Mensagem instantânea } \\
\text { - Telefonia por internet } \\
\text { - E-mail } \\
\text { - Fóruns de discussão } \\
\text { - Groupware (também conhecido } \\
\text { como software colaborativo) } \\
\text { - Wikis (enciclopédia aberta } \\
\text { baseada em tecnologia web) } \\
\text { - Workflow (gerenciamento de } \\
\text { fluxo de trabalho) } \\
\text { Tecnologias de redes } \\
\text { - Intranets } \\
\text { - Extranets } \\
\text { - Servidores web, navegadores } \\
\text { - Repositórios de conhecimento } \\
\text { (lições aprendidas e melhores } \\
\text { práticas) } \\
\text { - Portal corporativo }\end{array}$ & $\begin{array}{l}\text { E-learning tecnologias } \\
\text { - CBT (treinamento baseado em } \\
\text { computadores) } \\
\text { - WBT (treinamento baseado em } \\
\text { tecnologia web) } \\
\text { - EPSS (sistema eletrônico de } \\
\text { apoio ao desempenho) } \\
\text { Inteligência artificial } \\
\text { - Sistemas especializados } \\
\text { - DSS (sistema de suporte à } \\
\text { tomada de decisão) } \\
\text { - Customização - personalização } \\
\text { - Tecnologias push/pull } \\
\text { - Sistema recomendador que } \\
\text { compara coleções de dados } \\
\text { entre si e sugere uma lista de } \\
\text { recomendações) } \\
\text { - Visualização } \\
\text { - Mapas do conhecimento } \\
\text { - Agentes de inteligência } \\
\text { - Sistema de taxonomia } \\
\text { automatizado } \\
\text { - Análises de textos-sumarização }\end{array}$ \\
\hline
\end{tabular}

Quadro 3 - Principais ferramentas, tecnologias e técnicas de gestão do conhecimento Fonte: adaptado de Dalkir (2005, apud Kuniyoshi e Santos, 2007).

Para Stankosky e Baldanza (2000), as ferramentas de tecnologia da informação e comunicação constituem um dos pilares básicos de sustentação da gestão do conhecimento desenvolvida nas empresas. Kalvan (2008) corrobora tal pensamento ao indicar que a utilização de tais ferramentas é atualmente um dos principais desafios enfrentados pelas empresas globais na gestão do conhecimento desenvolvida em suas organizações. Segundo Wild e Griggs (2008), essas ferramentas têm ainda o potencial de aumentar o desempenho das atividades voltadas à gestão do conhecimento. A relevância dessas ferramentas nesse contexto de gestão do conhecimento é enfatizada também por Grimaldi, Rippa e Ruffolo (2008), bem como Agnihotri e Troutt (2009), ao argumentarem que elas devam ser utilizadas com o intento final de melhorar a eficácia empresarial da empresa. Já para Mohamed (2008), tais ferramentas constituem na verdade um fator crítico de sucesso para qualquer iniciativa de gestão do conhecimento.

Chadha e Kapoor (2010) apontam as principais tecnologias, ferramentas e técnicas utilizadas em gestão do conhecimento, quais sejam: vídeo-conferência, banco de dados, groupware, 
sistemas de apoio à decisão, extranet, páginas amarelas corporativas, internet, e-mail e data warehousing. Em pesquisa conduzida junto a empresas indianas acerca das práticas de gestão do conhecimento empregadas em processos de desenvolvimento de novos produtos, Shankar, Acharia e Baveja (2009) apontaram a existência das seguintes iniciativas: workshops de experiências, entrevistas com expertos, relatórios de experiência, banco de dados, eventos informais, comunidades de prática, briefings de projetos, melhores práticas, corretagem de conhecimentos e serviços de pesquisa.

Em relação às práticas voltadas à gestão do conhecimento, Bishop et al (2008) asseveram que tais iniciativas têm um impacto positivo no nível de eficácia das empresas. Kunyioshi e Santos (2007) apresentam práticas e iniciativas de gestão de conhecimento segregadas de acordo com diferentes dimensões organizacionais (estratégia, estrutura, pessoas e cultura organizacional, tecnologia e processos), conforme Quadro 4:

\begin{tabular}{|c|c|c|c|c|c|c|}
\hline & $\begin{array}{c}\text { Identificação } \\
\text { e criação }\end{array}$ & $\begin{array}{l}\text { Codificação } \\
\text { e validação }\end{array}$ & Organização & $\begin{array}{l}\text { Comparti- } \\
\text { lhamento }\end{array}$ & Disseminação & $\begin{array}{c}\text { Uso e } \\
\text { proteção }\end{array}$ \\
\hline \multirow{3}{*}{ 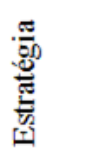 } & \multicolumn{2}{|c|}{ Aquisição de conhecimento } & Plano de sucessão & \multicolumn{2}{|c|}{ Comunicação corporativa } & \\
\hline & \multicolumn{3}{|c|}{ Gestão da inovação } & \multicolumn{2}{|c|}{ Benchmarking } & \\
\hline & \multicolumn{3}{|c|}{ Gestão por competências } & & & \\
\hline \multirow{3}{*}{ 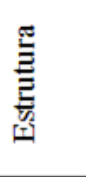 } & Centros de inovação & & CKO ou CKM & \multicolumn{2}{|c|}{ Criação de espaços para socialização } & \\
\hline & Call center / help desk & & $\begin{array}{c}\text { Centro de } \\
\text { Competências }\end{array}$ & & & \\
\hline & & & $\begin{array}{c}\text { Redes de } \\
\text { Especialistas } \\
\end{array}$ & & & \\
\hline \multirow{4}{*}{ 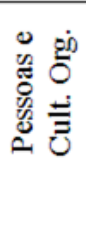 } & & $\begin{array}{l}\text { Mapeamento de } \\
\text { Competências }\end{array}$ & Planos de Carreira & Coaching & Lições aprendidas & \\
\hline & & $\begin{array}{l}\text { Mapeamento de } \\
\text { Conhecimento }\end{array}$ & $\begin{array}{c}\text { Sistema de } \\
\text { Reconhecimento e }\end{array}$ & Mentoring & Melhores práticas & \\
\hline & & & Recompensa & \multicolumn{2}{|c|}{ Comunidades de prática } & \\
\hline & & & & ucação Corporativa & Story Telling & \\
\hline \multirow{6}{*}{$\begin{array}{l}\frac{\pi}{00} \\
\frac{0}{0} \\
\stackrel{0}{0} \\
\stackrel{0}{-~}\end{array}$} & \multicolumn{5}{|c|}{ Banco de conhecimento } & Sumarização \\
\hline & & \multicolumn{2}{|c|}{ Gestão de conteúdo } & \multicolumn{2}{|c|}{ Repositórios de documentos } & Inventários \\
\hline & & \multicolumn{2}{|c|}{ Ferramentas de busca } & \multicolumn{2}{|c|}{ Reuniōes / conferências eletrônicas } & $\begin{array}{l}\text { Mapas de } \\
\text { conhecimento }\end{array}$ \\
\hline & \multicolumn{2}{|c|}{ Inteligência Competitiva } & Wikis, Blogs & \multicolumn{3}{|c|}{ Ferramentas de e-learning } \\
\hline & \multicolumn{2}{|c|}{ Business Inteligence } & Páginas amarelas & \multicolumn{2}{|r|}{ Universidade corporativa } & \\
\hline & \multicolumn{5}{|c|}{ Portal Corporativo e outras tecnologias da internet } & $\begin{array}{l}\text { Ontologia e } \\
\text { Taxonomia }\end{array}$ \\
\hline \multirow{3}{*}{$\begin{array}{l}0 \\
0 \\
0 \\
0 \\
0 \\
0 \\
0 \\
\end{array}$} & & \multicolumn{2}{|c|}{ Mapeamento de processos } & \multicolumn{2}{|c|}{ Regras e polticas da empresa } & Patentes \\
\hline & \multirow{2}{*}{\multicolumn{5}{|c|}{ Mensuração do conhecimento: sistema de avaliação para os processos de conhecimento }} & $\begin{array}{l}\text { Propriedade } \\
\text { Intelectual }\end{array}$ \\
\hline & & & & & & \\
\hline
\end{tabular}

Quadro 4 - Dimensões organizacionais e as práticas e iniciativas de gestão do conhecimento Fonte: Kuniyoshi e Santos (2007). 


\subsection{Teletrabalho}

A partir da invenção do computador, pôde-se constatar uma progressiva alteração do contexto organizacional em relação às formas pelas quais o trabalho é executado. No início, houve uma grande automatização das tarefas internas consideradas repetitivas nas empresas. Com o advento do computador pessoal em 1980, as organizações assistiram a grandes alterações no contexto do trabalho corporativo. Inicialmente, observou-se um maior acesso às Tecnologias da Informação, realidade antes existente apenas nas grandes corporações. Tal acesso permitiu a inserção de um gigantesco contingente de trabalhadores no mundo computacional. Já nos anos 1990, pôde-se testemunhar o surgimento da possibilidade de uma maior simbiose entre as organizações e as pessoas, viabilizada principalmente pela conectividade proporcionada pelas ferramentas de Tecnologia de Informação e Comunicação. Dentre essas ferramentas, pode-se evidenciar: correio eletrônico, redes internas de comunicação, intranets baseadas na tecnologia da Internet, aplicativos de trabalhos em grupo (groupware), teleconferências, banco de dados centralizado e ainda o acesso remoto aos conteúdos corporativos.

Há alguns anos e principalmente neste início de milênio, observou-se o surgimento, ascensão e fortalecimento do 'trabalhador do conhecimento'. Este profissional com características diferenciadas tem conquistado cada vez mais o seu espaço no mercado de trabalho, principalmente em função das possibilidades oferecidas pelas ferramentas anteriormente citadas.

A importância desse profissional no atual contexto da sociedade do conhecimento já era expressa por Drucker (1994) em meados dos anos 1990, ao discorrer que os trabalhadores do conhecimento assumem papel relevante no acúmulo e geração de conhecimentos nas empresas. Para Nonaka e Takeuchi (2008), os meios de produção mais importantes não são mais instalações ou máquinas, mas sim os trabalhadores do conhecimento, que detêm o insumo imprescindível às empresas atuais: o conhecimento. Alavi, Jun e Kyehyun Cho (2005) foram um dos primeiros a reconhecer a importância da empresa integrar a gestão do conhecimento desses trabalhadores atuantes em teletrabalho.

Em função disto, várias organizações de vanguarda têm provocado mudanças em suas estruturas organizacionais visando conceber novas formas de trabalho para um melhor 
aproveitamento do potencial desse trabalhador do conhecimento. Griffith e Sawyer (2006) afirmam que atualmente a gestão do conhecimento em equipes de trabalhadores do conhecimento em ambientes de teletrabalho é um importante fator a ser fomentado pelas empresas na busca de eficácia empresarial. Corroborando tal ideia, estudo conduzido por Karayaz (2009) indica a existência de relação significativa entre a gestão do conhecimento e o trabalho desenvolvido por equipes atuantes em ambientes de teletrabalho.

As novas estruturas organizacionais buscam alinhavar um denominador comum que seja satisfatório a várias questões, tais como: otimização de recursos, melhorias no ambiente de trabalho, diminuição de despesas e custos de infra-estrutura, maximização de um ambiente colaborativo, dentre outras. Nessa nova configuração da estrutura organizacional, surge a possibilidade do teletrabalho, que se encaixa perfeitamente para os trabalhadores do conhecimento, principalmente em organizações de desenvolvimento de programas para computador (software). Isso porque nessas organizações, questões como criatividade, proatividade e inovação são imprescindíveis à evolução intrínseca das mesmas. Ou seja, para ser possível aos trabalhadores do conhecimento dar vazão à criatividade, transformando-a em inovação por meio de ações pró-ativas, faz-se imperativo um ambiente de trabalho que viabilize tais condições.

Ao considerar seu aspecto multidisciplinar e até em função de seu recente surgimento, o termo teletrabalho parece ainda não ter um consenso geral já aceito por autores de diferentes áreas de estudo, como por exemplo, os pesquisadores ligados à tecnologia da informação e comunicação, gestão organizacional e relações de trabalho, entre outras. O fato é que existe uma pluralidade de terminologias para designar o teletrabalho: trabalho à distância, trabalho em casa, trabalho virtual, escritório virtual, dentre outras. Porém, cabe ressaltar que esses termos não se constituem em sinônimos.

Para iniciar o entendimento do teletrabalho deve-se antes efetuar alguns breves comentários sobre o termo 'telecomutação'. A telecomutação provém do termo telecommunting, que está relacionado originalmente à ideia de substituição dos meios de transporte que levam um indivíduo ao trabalho, por meios de comunicação de dados que levem o trabalho ao indivíduo. Ou seja, a telecomutação é a ideia inicial que viabilizou o teletrabalho. 
Segundo a Secretaria Federal de Gestão de Pessoas, órgão americano responsável pelas relações de trabalho nos Estados Unidos, o teletrabalho é toda composição de trabalho na qual os empregados executam uma parte ou todas as suas atividades distantes dos locais de trabalho disponibilizados pela empresa (US OPM, 2003). Mas essa é uma definição bastante genérica, pois não contempla uma série de especificidades inerentes ao teletrabalho.

Ao inserir o aspecto tecnológico, elemento imprescindível à viabilização do teletrabalho, Olszewski e Lam (1993) discorrem que o teletrabalho combina a utilização de tecnologia computacional e telecomunicações com a flexibilidade do local de trabalho, removendo assim as fronteiras organizacionais e geográficas. Ou seja, o teletrabalho é viabilizado por meio de ferramentas que possibilitam ao teletrabalhador estar em contato direto com a organização sem, entretanto, estar fisicamente dentro dela. Tal visão é corroborada por Perez, Sanches e Carnicer (2003), ao entenderem que a ideia central que sustenta o teletrabalho baseia-se em duas vertentes básicas: a questão da realocação do local de trabalho e a utilização das ferramentas de tecnologia da informação e comunicação disponíveis.

Para Dugal e Roy (2002), Igbaria e Guimarães (1999) e Pratt (1999), há várias razões para explicar a quantidade cada vez maior de empresas e trabalhadores que estão aderindo ao teletrabalho: a acelerada evolução da portabilidade dos equipamentos eletrônicos, o barateamento dos computadores, o aumento dos custos de aluguel de áreas corporativas, a substituição do trabalhador administrativo pelo trabalhador do conhecimento, mudanças na estrutura familiar, a necessidade de ser flexível para permanecer competitivo, redução do absenteísmo, atração e retenção de empregados, atração de candidatos mais capacitados e, principalmente, a crença de que as organizações, os funcionários e a sociedade como um todo podem se beneficiar com o teletrabalho.

Entretanto, e apesar dos muitos pontos positivos vistos, Lupton e Haynes (2000), Davenport e Pearlson (1998) e Nilles (1998) indicam que há também algumas desvantagens a serem consideradas num processo de adoção do teletrabalho, quais sejam: falta de um projeto adequado à empresa e aos trabalhadores; confusão entre os papéis 'indivíduo ser humano' e 'profissional trabalhador'; incapacidade de uma boa gestão do teletrabalhador; isolamento profissional com consequente inação social com o surgimento do sentimento de nãopertencimento à equipe; falta de saúde e segurança no trabalho e também a falta de legislação trabalhista específica no caso de eventuais litígios. 
Embora o teletrabalho tenha sido empregado inicialmente em tarefas repetitivas, atualmente as organizações já experimentam sua aplicação em outras atividades. Shin, Sheng e Higa (2000) explicam que a visão original do teletrabalho propunha que tarefas rotineiras fossem as primeiras candidatas ao seu emprego. Entretanto, os autores entendem que atualmente o teletrabalho tem sido muito praticado em atividades mais nobres, ou seja, atividades mais estimulantes e relacionadas à produção de conhecimento.

A importância do teletrabalho fica ainda mais destacada em virtude de sua associação com a produção e gestão do conhecimento. A geração de conhecimento é a mola mestra da atual configuração existente no ambiente de negócios, uma vez que é o agente indutor da mobilização de pessoas, processos, produtos e serviços.

Além disso, o conhecimento gerado em uma empresa pode fazê-la alcançar vantagens competitivas frente aos seus concorrentes. Dessa forma, a gestão do conhecimento gerado passa necessariamente pelas mãos dos trabalhadores do conhecimento e do uso que eles fazem das ferramentas de teletrabalho em seu poder. Conforme Hitt, Ireland e Hoskisson (2005), os trabalhadores do conhecimento são indivíduos criativos, inovadores e flexíveis, capazes de gerar um desempenho diferenciado, estando ainda aptos a assumir novos e conflitantes desafios a cada dia. Nesse aspecto em particular, o teletrabalho abre possibilidades para as contribuições que o trabalhador do conhecimento pode dar às empresas, agregando assim valor ao negócio.

Especificamente em relação a um ambiente de desenvolvimento de sistemas de informação, questões como criatividade, pró-atividade e inovação são cruciais. Os profissionais que atuam nessas áreas têm papel importantíssimo a desenvolver, principalmente quando a organização ou o departamento é um fornecedor de software, ou seja, tem como produto o resultado final das atividades desempenhadas por vários trabalhadores do conhecimento. Em pesquisas feitas por Lupton e Haynes (2000), Igbaria e Guimarães (1999), Hill et al (1998), foram delineadas algumas vantagens atribuídas aos ambientes de teletrabalho: nível de satisfação mais elevado, efeito positivo na flexibilidade de ações, incremento no moral e motivação, aumento do comprometimento junto à organização e ainda redução de conflitos. 
As possibilidades abertas à viabilização do teletrabalho a partir da utilização das ferramentas de tecnologia da informação e comunicação para o desenvolvimento de atividades relativas ao desenvolvimento de software são bastante promissoras. Estudos conduzidos por Huws, Jagger e Bates (2001) sinalizam que há algumas atividades que têm se adaptado mais facilmente a esse novo ambiente de teletrabalho, como é o caso do desenvolvimento e manutenção de sistemas, serviços de design de multimídia, processamento de dados e elaboração de planos e relatórios de negócio. Ou seja, parece haver um processo auto-promotor do teletrabalho em atividades e organizações ligadas às tecnologias de informação e comunicação, uma vez que as ferramentas proporcionadas por essas tecnologias acabam por fazê-las dispor de instrumentos que viabilizam e aumentam, cada vez mais, as possibilidades de realização do teletrabalho.

Em empresas ou áreas de desenvolvimento de software há uma grande concentração de trabalhadores do conhecimento. Tais profissionais têm uma natural maior facilidade de absorver novas ferramentas de tecnologia da informação e comunicação, além de também estarem mais predispostos a outras alterações em seu ambiente de trabalho, principalmente em função da rápida atualização dos contextos organizacionais e de negócios nos quais estão inseridos. Como membros de um negócio em constante evolução, no qual a obsolescência tecnológica e profissional é relativamente rápida e demanda constante atualização, esses trabalhadores do conhecimento em processos de desenvolvimento de software parecem ter grande facilidade de incorporar o teletrabalho em suas rotinas profissionais. Também em função da rede de relacionamentos existente entre esses profissionais e seus colegas de trabalho, parceiros de desenvolvimento, fornecedores de recursos, clientes e consumidores de suas atividades; a inserção do teletrabalho parece até atender a muitas das suas demandas por recursos (tempo, equipamentos, configurações e plataformas computacionais).

Pesquisas conduzidas por McDonough e Kahn (1996) concluíram haver um efeito positivo nas equipes de desenvolvimento de software que utilizam mais intensamente as ferramentas de tecnologia de informação e comunicação, diretamente voltadas à viabilização do teletrabalho. Em outro estudo, McDonough, Kahn e Barczak (2001) indicam que o desempenho dos times de trabalho analisados em regime de teletrabalho foi maior do que o desempenho de times de trabalho tradicionais com trabalhadores de diferentes nacionalidades fisicamente atuando em conjunto. Ozer (2003) atesta que dada a velocidade, conveniência, interatividade e cobertura mundial disponibilizada pela Internet, é possível coletar, classificar 
e utilizar de forma satisfatória as informações necessárias ao processo de desenvolvimento de software. Ou seja, os profissionais do conhecimento envolvidos nessas atividades são capazes de efetuá-las à distância, por meio de um ambiente de teletrabalho bem estruturado.

Uma equipe de desenvolvimento de software tem, em geral, uma grande quantidade de profissionais envolvidos. Ao observar projetos de sistemas de informação, tal afirmativa fica ainda mais evidente. E dentre esses profissionais, também é comum haver diferentes personagens atuando em prol dos objetivos dos projetos de desenvolvimento de sistemas. A título de facilitar o entendimento dessa diversidade, optou-se por classificá-los em dois grupos: gestores e analistas. No primeiro grupo, destacam-se profissionais que ocupam cargos tais como diretores, gerentes, supervisores, coordenadores e líderes de equipe/projeto. Quanto ao segundo grupo, pode-se entender que esses profissionais comumente são denominados analistas de desenvolvimento, analistas de ambiente/plataforma, analistas de banco de dados, consultores, programadores, testadores e documentadores.

Mesmo que uma empresa tenha êxito na implantação e gestão de teletrabalho, nem todos os colaboradores estão preparados para (ou mesmo desejam) atuar nesse regime. Dessa forma, é comum que haja, na prática, uma simbiose entre o ambiente de trabalho físico tradicional e o ambiente de teletrabalho, tendo-se então pessoas ou equipes segregadas entre esses dois modelos. Tais configurações são relativamente comuns em empresas ou departamentos de desenvolvimento de sistemas de informação que já adotaram, em alguma medida, o teletrabalho na rotina de alguns de seus colaboradores. Essa realidade invoca a pressuposição da existência de uma grande multiplicidade de diferentes estágios de evolução e contexto quanto aos exemplos reais de teletrabalho em áreas ou empresas de desenvolvimento de software.

\subsection{Eficácia empresarial}

A eficácia empresarial (ou organizacional) é um importante aspecto a ser considerado ao se analisar a capacidade de obtenção de sucesso por parte das empresas. Na visão de Luthans, Welsh e Taylor III (1988), bem como Altschuld e Zheng (1995), a eficácia empresarial é tida como um dos maiores objetivos da gestão corporativa, apresentando-se como um tema central no estudo da teoria e da prática das organizações contemporâneas. Isso porque no atual 
contexto de competitividade acirrada e turbulência de mercados as empresas são pressionadas a identificar fatores que contribuam para um desempenho elevado, conforme Gomes (2001). Segundo Quijano (2000), a empresa baseia-se então em indicadores que possam ser capazes de orientá-las rumo ao sucesso. Assim, a partir da análise de indicadores de eficácia empresarial é possível compreender o grau de atendimento dos objetivos da empresa.

Não obstante a sua importância, não há ainda uma teoria universalmente aceita a respeito dessa temática, conforme colocam Lewin e Minton, (1986). Isso porque é difícil formalizar e uniformizar a quantificação da eficácia empresarial num conjunto de indicadores válidos para todas as empresas (VANDENBOSCH e HUFF, 1997). Segundo Altschuld e Zheng (1995) e Savoie e Morin (2001), é exatamente esse contexto que sinaliza a falta de formalização sobre o que exatamente avaliar, além de como avaliar. Para Robbins (1990), outro fator a ser considerado ainda é a variedade de dimensões com as quais o conceito de eficácia empresarial se reveste.

De forma mais objetiva, Daft (1999) conceitua eficácia empresarial como a quantidade de recursos utilizados para a execução dos objetivos organizacionais. Robbins e Coulter (2002) e Yuchtman e Seashore (1967) expõem uma visão mais ampliada, na qual a eficácia empresarial refere-se ao atendimento dos objetivos estabelecidos pela organização, considerando-se a manutenção de seu sistema interno face à consequente adaptação ao ambiente externo. De forma similar, Ramos (1996) observa que a eficácia empresarial se dá em função do grau de funcionamento ótimo da empresa, podendo ser mensurada por sua capacidade de manter seus elementos internos como um sistema social coeso, além da capacidade de interagir adequadamente com o ambiente externo.

Argyris (1975) e Scott (1983) segregam três diferentes conjuntos de critérios para analisar a eficácia empresarial, a saber: racionalidade, uma vez que as organizações são direcionadas a atingir certos objetivos; natureza, voltado à própria sobrevivência e manutenção da organização; e sistema aberto, que considera a influência do ambiente externo na organização.

Não há consenso entre os autores que estudam o tema eficácia empresarial acerca de um modelo ou instrumento definitivo que possa efetivamente mensurar a eficácia da empresa. Basicamente, os modelos e instrumentos já vistos poderiam ser divididos em dois grandes 
conjuntos: econômicos e não-econômicos (BENNIS, 1976). O Quadro 5 a seguir expõe os principais indicadores de eficácia empresarial de acordo com a visão de diferentes autores.

\begin{tabular}{|c|c|}
\hline Autores & Indicadores de eficácia empresarial \\
\hline Yuchtman e Seashore (1967) & $\begin{array}{l}\text { Alcance dos objetivos, produtividade, coesão. Moral, adaptabilidade, lucro, } \\
\text { sucesso na aquisição de recursos escassos e de valor, controle sobre o meio } \\
\text { ambiente informação e comunicação, crescimento. }\end{array}$ \\
\hline Likert (1971) & $\begin{array}{l}\text { Qualidade da mão-de-obra, satisfação, absenteísmo, rotatividade, crescimento, } \\
\text { lucro, produtividade, confiança/interesse, motivação. Lealdade, desempenho, } \\
\text { comunicação interna e objetivos alcançados. }\end{array}$ \\
\hline Argyris (1975) & $\begin{array}{l}\text { Objetivos, manutenção da estrutura, adaptação ao ambiente, produção, } \\
\text { satisfação, absenteísmo, rotatividade. }\end{array}$ \\
\hline Steers (1975) & $\begin{array}{l}\text { Adaptabilidade, produtividade, satisfação, rentabilidade, aquisição de recursos, } \\
\text { ausência de conflitos, controle, desenvolvimento, eficiência, retenção de } \\
\text { empregados, crescimento, integração, comunicação aberta, supervisão. }\end{array}$ \\
\hline Bennis (1976) & $\begin{array}{l}\text { Adaptabilidade, objetivos, percepção da identidade, capacidade de realização, } \\
\text { crescimento, lucro. }\end{array}$ \\
\hline Scott (1983) & $\begin{array}{l}\text { Produtividade, eficiência, objetivos, satisfação, absenteísmo, rotatividade, } \\
\text { crescimento, lucro, moral, coesão, flexibilidade, adaptabilidade } e \text { aquisição de } \\
\text { recursos. }\end{array}$ \\
\hline Katz \& Kahn (1987) & $\begin{array}{l}\text { Eficiência potencial e real, lucro, sobrevivência, crescimento, objetivos } \\
\text { alcançados, satisfação, rotatividade e absenteísmo. }\end{array}$ \\
\hline Nadler (1994) & $\begin{array}{l}\text { Necessidades dos clientes, exigências e oportunidades do ambiente, } \\
\text { informação, trabalho, pessoas e tecnologia, produtividade. }\end{array}$ \\
\hline Porter (1996) & $\begin{array}{l}\text { Produtividade, redução de defeitos, redução de prazos, motivação, redução de } \\
\text { desperdícios, utilização eficiente de equipamentos, técnicas gerenciais. }\end{array}$ \\
\hline Elorduy (1998) & $\begin{array}{l}\text { Produtividade, melhoria dos relacionamentos, desenvolvimento dos indivíduos, } \\
\text { motivação. }\end{array}$ \\
\hline Daft (1999) & $\begin{array}{l}\text { Quantidade de insumos, capital e pessoal utilizado, objetivos, produção, } \\
\text { satisfação, rotatividade, absenteísmo. }\end{array}$ \\
\hline Pounder (2002) & $\begin{array}{l}\text { Estabilidade, gestão da informação e comunicação, desenvolvimento de } \\
\text { recursos humanos, coesão e moral, crescimento e aquisição de recursos, } \\
\text { adaptabilidade e flexibilidade, produtividade e eficiência, planejamento e } \\
\text { definição de objetivos, qualidade, satisfação dos interesses dos stakeholders }\end{array}$ \\
\hline
\end{tabular}

Quadro 5 - Indicadores de eficácia empresarial

Fonte: elaborado pelo autor.

Morin, Savoie e Beaudin (1994) propõem um modelo no qual os indicadores de eficácia empresarial estão segregados em quatro dimensões, a saber:

- Dimensão econômica: contribuição que os indivíduos fornecem para os resultados da empresa. Trata-se de avaliar a eficácia em termos econômicos, ou seja, a qualidade e a quantidade de recursos adquiridos e utilizados necessários ao funcionamento regular da empresa;

- Dimensão social: equilíbrio, coerência e coesão da estrutura dos relacionamentos entre indivíduos e grupos da empresa, formando assim uma unidade de continuidade e solidez dos relacionamentos que formam a estrutura; 
- Dimensão sistêmica: centrada nos fatores que são considerados relevantes para a continuidade da empresa, sua competitividade e sua adaptação ao ambiente;

- Dimensão política: reputação da empresa e as relações que mantém com os stakeholders externos de modo a avaliar sua reputação no ambiente no qual está situada, permitindo assim colocar em prática as estratégias definidas.

Para Carvalho e Gomes (2000), o modelo anterior tem como vantagem auxiliar a análise e compreensão das principais preocupações e prioridades dos gestores no âmbito da eficácia das empresas.

\subsection{Diretrizes teóricas da pesquisa}

De modo a delinear as diretrizes teóricas da presente pesquisa, o Quadro 6 evidencia as principais referências e fontes de cada vertente teórica tratada neste trabalho. 


\begin{tabular}{|c|c|}
\hline Vertente teórica & Referências e fontes \\
\hline Gestão do conhecimento & $\begin{array}{l}\text { - Visão baseada no conhecimento (KBV - knowledge based view) - Eisenhardt e } \\
\text { Santos (2002); } \\
\text { - Conceito de gestão do conhecimento - Dalkir (2005, p. 3); } \\
\text { - Gestão do conhecimento como ponto central da gestão estratégica da empresa - } \\
\text { Zack (1999); } \\
\text { - Gestão do conhecimento como transformadora de conhecimentos em ativos } \\
\text { voltados à viabilização de um crescimento continuado e sustentável - Carrilo e } \\
\text { Anumba (2005); } \\
\text { - Práticas e ferramentas de gestão do conhecimento - Kuniyoshi e Santos (2007). }\end{array}$ \\
\hline Teletrabalho & $\begin{array}{l}\text { - Gestão do conhecimento praticada por trabalhadores que atuam em ambiente de } \\
\text { teletrabalho - Alavi, Jun e Kyehyun Cho (2005); } \\
\text { - Relação significativa entre a gestão do conhecimento e o trabalho em ambientes } \\
\text { de teletrabalho - Karayaz (2009); } \\
\text { - Desenvolvimento de sistemas de informação é uma atividade que tem se } \\
\text { adaptado facilmente ao ambiente de teletrabalho - Huws, Jagger e Bates (2001). }\end{array}$ \\
\hline Eficácia empresarial & $\begin{array}{l}\text { - Eficácia empresarial como um dos maiores objetivos da gestão corporativa - } \\
\text { Luthans, Welsh e Taylor III (1998); } \\
\text { - Eficácia empresarial viabilizando o atendimento dos objetivos estabelecidos pela } \\
\text { empresa - Yuchtman e Seashore (1967); } \\
\text { - Eficácia empresarial como o grau de funcionamento ótimo da empresa - Ramos } \\
\text { (1996); } \\
\text { - Práticas de gestão do conhecimento como fatores indutores da eficácia } \\
\text { empresarial - Gold, Malhotra e Segars (2001); } \\
\text { - Indicadores de eficácia empresarial - Yuchtman e Seashore (1967), Likert } \\
\text { (1971), Steers (1975), Pounder (2002) e Morin, Savoie e Beaudin (1994). }\end{array}$ \\
\hline
\end{tabular}

Quadro 6 - Diretrizes teóricas da pesquisa

Fonte: desenvolvido pelo autor.

Face ao exposto acima, obtém-se as principais características de cada vertente teórica explorada neste trabalho. Não obstante, observam-se ainda nas características citadas a existência de correlações entre os principais temas de pesquisa ora abordados. 


\section{METODOLOGIA DA PESQUISA}

O correto delineamento da metodologia da pesquisa é um importante passo na aplicação do método científico. Para Martins e Theóphilo (2009, p. 37), “o objetivo da metodologia é o aperfeiçoamento dos procedimentos e critérios utilizados na pesquisa."

Neste capítulo são apresentados os procedimentos metodológicos empregados no desenvolvimento da pesquisa, utilizando-se para tanto marcos referenciais do estudo para o delineamento do instrumento de pesquisa utilizado. Além disso, também são feitas considerações acerca dos aplicativos empregados para a análise e interpretação dos dados coletados, bem como a descrição dos métodos estatísticos utilizados para a validação dos resultados encontrados.

\subsection{Método}

O método da pesquisa, ou seja, o conjunto das regras empregado na pesquisa para observar fenômenos e inferir conclusões a partir de observações, é descrito a seguir. Este é um estudo descritivo de natureza quantitativa que considera como método de pesquisa o levantamento de informações junto às empresas atuantes na indústria de software no Brasil, conforme classificação indicada por Hair Jr. et al (2005), Yin (2005) e Sampieri, Collado e Lucio (2006). Para tanto, faz uso de levantamento de dados primários por meio da aplicação de questionários estruturados junto aos profissionais de empresas atuantes nessa indústria específica.

Michel (2009) afirma que o método da pesquisa descritiva procura descrever situações de mercado a partir de dados primários, obtidos originalmente por meio de observações, questionários, entrevistas ou discussões em grupo. Tal método de pesquisa busca relacionar e responder as questões levantadas na definição do problema de pesquisa. Ou seja, segundo Sampieri, Collado e Lucio (2006, p. 100), os estudos descritivos buscam “descrever situações, acontecimentos e feitos, isto é, dizer como se manifesta determinado fenômeno.” 
Quanto ao enfoque quantitativo, observa-se que este emprega a coleta de dados para testar hipóteses com base de medição numérica e na análise estatística para estabelecer padrões de comportamento (SAMPIERI, COLLADO e LUCIO, 2006). Para Martins e Theóphilo (2009), os estudos descritivos de natureza quantitativa caracterizam-se por empregar uma abordagem empírico-analítica, ou seja, utilizarem técnica de coleta, tratamento e análise de dados com cunho notadamente quantitativo. Ou seja, esses estudos buscam investigar as relações causais entre as variáveis envolvidas por meio de testes de instrumentos específicos e sistematização das definições operacionais.

Já no tocante ao método de pesquisa, Martins e Theóphilo (2007) discorrem que uma característica marcante dos levantamentos é que neles são estudados os fenômenos tal qual eles ocorrem naturalmente. O levantamento também é caracterizado pela grande amplitude e pouca profundidade dos conteúdos sob análise. Assim, nesse tipo de estudo é comum haver uma quantidade relativamente alta de elementos a serem prospectados sem, contudo, haver a necessidade de profundas inserções em cada um deles. Tal contexto se faz útil quando se está mais interessado em conhecer as inter-relações entre as variáveis que ocasionam um fenômeno e, principalmente, quando for difícil entender o fenômeno sem entender suas interrelações.

Em função das características descritas anteriormente a respeito dos estudos descritivos feitos por meio de levantamento de informações, esta pesquisa aplica este método uma vez que pretende melhor compreender e descrever as práticas e ferramentas empregadas na gestão do conhecimento e sua influência na eficácia empresarial de empresas atuantes na indústria de software no Brasil analisadas na pesquisa de campo.

\subsection{Universo e amostra}

O universo de abrangência desta pesquisa é formado pelas empresas atuantes na indústria de software no Brasil. Um panorama atual dessa importante indústria brasileira é exposto no início do tópico 'IV - Apresentação e Análise dos Resultados'.

A amostra da pesquisa de campo foi selecionada a partir de critérios de conveniência e acessibilidade para a coleta de dados. Foram pesquisadas 15 empresas atuantes na indústria de 
software do Brasil de médio ou grande porte, com destacada relevância em seus segmentos de atuação.

A unidade de análise desta pesquisa de campo é o profissional que atua diretamente com as atividades de desenvolvimento, manutenção e prestação de serviços do produto software em empresas atuantes na indústria de software no Brasil. Consideradas as características da pesquisa, a amostra selecionada não tem caráter probabilístico uma vez que a técnica de amostragem a ser empregada é por acessibilidade e conveniência, conforme Sampieri, Collado e Lucio (2006). A distribuição dos instrumentos de pesquisa junto aos elementos analisados deu-se por meio do acesso ao questionário eletrônico ou de forma impressa.

A partir da técnica de tratamento e análise dos dados escolhida (Modelagem de Equações Estruturais), a quantidade de elementos para uma amostra válida ficou definida entre o mínimo de 200 e o máximo de 400 elementos pesquisados (HAIR et al, 2006), conforme exposto mais detalhadamente no item a seguir.

\subsection{Coleta, tratamento e análise dos dados}

Visando uma compreensão mais clara, este tópico está subdividido em coleta dos dados, métodos de tratamento e análise dos dados e, por fim, validação estatística dos resultados.

\subsubsection{Coleta dos dados}

Para atingir os objetivos do estudo, a coleta de dados foi feita por meio de dados primários obtidos junto aos trabalhadores das empresas selecionadas. Um recorte transversal no tempo foi estabelecido, de modo a delimitar o período de coleta de dados, que se estendeu de julho a setembro de 2010.

O instrumento de pesquisa (questionário estruturado - Apêndice A) foi aplicado via internet ou distribuído de forma impressa aos trabalhadores das empresas em foco, buscando-se informações acerca das práticas e ferramentas de tecnologia da informação e comunicação empregadas na gestão do conhecimento na empresa, bem como a influência destas na eficácia 
empresarial. O instrumento de pesquisa prospectava ainda sobre as características do teletrabalho aplicado aos trabalhadores envolvidos, quando existentes.

O questionário eletrônico, bem como a sua versão impressa, foram desenvolvidos na ferramenta Survey Monkey, que também conta com a disponibilização do endereço URL para acesso ao formato eletrônico. Ao final da fase de coleta, os registros existentes na base de dados da ferramenta Survey Monkey foram transformados em planilha eletrônica Microsoft Excel para posterior exportação aos aplicativos SPSS (Statistical Package for The Social Sciences) e PLS-PM (Partial Least Squares Path Modeling), visando o tratamento mais refinado dos dados coletados na pesquisa de campo.

Os respondentes do questionário foram segregados em dois perfis: a) gestores com poder de decisão (diretores, gerentes, coordenadores, supervisores e/ou líderes de equipes/projetos das empresas pesquisadas) e b) trabalhadores do conhecimento com funções técnicas (analistas de sistemas, analistas de ambiente/plataforma, analistas de banco de dados, analistas de redes, analistas de testes, analistas de documentação, analista de processos, consultores de negócio e programadores).

Para ambos os perfis buscou-se confrontar e validar as respostas dadas pelos dois grupos. Dessa forma, buscava-se compreender melhor a visão de profissionais gestores e de profissionais técnicos quanto às principais características envolvidas na gestão do conhecimento executada na empresa, suas práticas e suas ferramentas de tecnologia da informação e comunicação, bem como sua influência na eficácia empresarial.

Cabe ressaltar que o instrumento de pesquisa mencionado anteriormente (questionário) foi submetido à apreciação prévia de dois especialistas nos temas centrais da pesquisa em pauta. De forma complementar, o instrumento de pesquisa foi submetido ainda a um pré-teste junto a cinco profissionais de empresas atuantes na indústria de software no Brasil. Também foram acatadas as considerações feitas pelos professores doutores durante a apresentação feita à banca de qualificação. Como resultado, a partir das críticas e sugestões feitas pelos especialistas, pelos profissionais consultados e pelos professores doutores; melhorias foram incorporadas ao instrumento de pesquisa, culminando na versão aplicada na pesquisa de campo e apresentada no Apêndice A. 
A coleta de dados primários buscou evidenciar a existência de práticas de gestão do conhecimento e de ferramentas de tecnologia da informação e comunicação voltadas à gestão do conhecimento, bem como a influência destas na eficácia empresarial das empresas a serem pesquisadas. Para tanto, a definição operacional de cada um desses conjuntos é exposta a seguir:

a) As 46 práticas de GC, ora designadas genericamente por 'Pn', estão distribuídas em cinco dimensões:

- Dimensão estratégia (PAn)

PA01 - Estratégia declarada de gestão do conhecimento

PA02 - Políticas declaradas de gestão do conhecimento

PA03 - Gestão da inovação

PA04 - Gestão por competências

PA05 - Comunicação corporativa da gestão do conhecimento

PA06 - Benchmarking de conhecimentos

- Dimensão estrutura (PBn)

PB07 - Centros de inovação

PB08 - Call center/help desk/suporte online

PB09 - CKO/CKM - (Chief of Knowledge Management ou Certified Knowledge Manager) - gestor de gestão do conhecimento

PB10 - Centro de competências

PB11 - Área interna ou departamento específico para a gestão do conhecimento

PB12 - Redes de especialistas

PB13 - Espaços e situações dedicadas à socialização de conhecimentos

- Dimensão pessoas/cultura organizacional (PCn)

PC14 - Mapeamento de competências

PC15 - Mapeamento de conhecimentos

PC16 - Planos de carreira 
PC17 - Sistema de reconhecimento e recompensa por gestão do conhecimento

PC18 - Coaching (tutoria no desenvolvimento de competências) para formação de líderes voltados à gestão do conhecimento

PC19 - Mentoring (tutoria no desenvolvimento da carreira) para a formação de líderes voltados à gestão do conhecimento

PC20 - Repositório de lições aprendidas

PC21 - Repositório de melhores práticas

PC22 - Comunidades de prática

PC23 - Educação corporativa

PC24 - Treinamentos presenciais com instrutores

PC25 - Multiplicadores de conhecimentos

PC26 - Story telling (reprodução de histórias)

- Dimensão processos (PDn)

PD27 - Mapeamento de processos

PD28 - Sistema de avaliação de processos de conhecimento

PD29 - Patentes

PD30 - Propriedade intelectual

- Dimensão tecnologia (PEn)

PE31 - Banco de conhecimentos

PE32 - Gestão de conteúdos

PE33 - Aplicações específicas para busca de conhecimentos

PE34 - Inteligência competitiva

PE35 - Business inteligence - BI (inteligência de negócios)

PE36 - Wikis internas (enciclopédias virtuais), blogs internos (diários virtuais) ou twitters internos (página de publicação de notícias)

PE37 - Páginas amarelas internas

PE38 - Portal corporativo (ou de departamentos específicos)

PE39 - Biblioteca corporativa/repositório de documentos (física ou eletrônica)

PE40 - Reuniões e conferências virtuais 
PE41 - Treinamentos virtuais com a presença de instrutores online

PE42 - E-learning (auto-aprendizagem sem a presença de instrutores)

PE43 - Universidade corporativa

PE44 - Sumarização de conhecimentos

PE45 - Inventários de conhecimentos

PE46 - Ontologia (essência e natureza de cada conhecimento) ou taxonomia (sistemática de classificação dos conhecimentos)

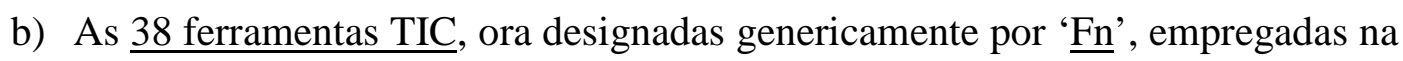
GC estão distribuídas em seis dimensões:

- Dimensão criação de conteúdo (FAn)

FA01 - Autoria

FA02 - Modelos

FA03 - Anotações

FA04 - Data mining (mineração de dados)

FA05 - Perfil de experts (especialistas)

FA06 - Blogs (diário eletrônico baseado em tecnologia web)

- Dimensão gestão de conteúdo (FBn)

FB07 - Definição de metadados

FB08 - Classificação de conteúdos

FB09 - Arquivamento de conteúdos

FB10 - Gestão de conhecimento pessoal

- Dimensão comunicação e tecnologias colaborativas (FCn)

FC11 - Telefone fixo

FC12 - Telefone móvel

FC13 - Telefone via internet (Skype, outros)

FC14 -Videoconferência

FC15 - Salas de bate-papo

FC16 - Mensagens instantâneas

FC17 - E-mail

FC18 - Fóruns de discussão 
FC19 - Groupware (software colaborativo)

FC20 - Wikis (enciclopédia aberta baseada na tecnologia web)

FC21 - Workflow (gerenciamento de fluxo de trabalho)

- Dimensão tecnologias de rede (FDn)

FD22 - Intranets

FD23 - Extranets

FD24 - Servidores web e navegadores

FD25 - Repositório de conhecimentos

FD26 - Portal corporativo da empresa ou de área específica

- $\quad$ Dimensão e-learning (FEn)

FE27 - CBT (treinamento baseado em computadores)

FE28 - WBT (treinamento baseado em tecnologia web)

FE29 - EPSS (sistema eletrônico de apoio ao desempenho)

- $\quad$ Dimensão inteligência artificial (FFn)

FF30 - Sistemas especializados

FF31 - DSS (sistema de suporte à tomada de decisão)

FF32 - Customização/personalização

FF33 - Sistema recomendador (compara coleções de dados e sugere uma lista de recomendações

FF34 - Visualização

FF35 - Mapas de conhecimento

FF36 - Agentes de inteligência

F37 - Sistema de taxonomia automatizado

F38 - Análise de conteúdos (sumarização)

c) Os 15 indicadores de eficácia empresarial, ora designados genericamente por 'En', estão segregados em quatro dimensões:

- Dimensão econômica (EAn)

EA01 - Alcance dos objetivos 
EA02 - Produtividade

EA03 - Lucro/rentabilidade

EA04 - Eficiência operacional

EA05 - Desenvolvimento/crescimento da empresa

- Dimensão social (EBn)

EB06 - Coesão

EB07 - Ambiente organizacional

EB08 - Aumento do moral

EB09 - Absenteísmo

EB10 - Rotatividade

EB11 - Motivação/satisfação

EB12- Desenvolvimento de recursos humanos

- Dimensão sistêmica (ECn)

EC13 - Adaptabilidade

EC14 - Estabilidade

- Dimensão política (EDn)

ED15 - Controle

\subsubsection{Métodos de tratamento e análise dos dados}

Embora o instrumento de pesquisa (questionário) contemplasse, em sua versão eletrônica disponibilizada pela ferramenta Survey Monkey, artifícios para uma coleta eficaz de dados (campos com preenchimento obrigatório, verificação automática de preenchimento, campos com alternativas de resposta previamente disponíveis, entre outros); após a coleta de dados foram realizados procedimentos visando detectar possíveis erros e omissões, notadamente quanto aos questionários impressos também distribuídos a parte dos respondentes. Assim, por meio dessa ação prévia à análise dos dados, pôde-se assegurar a qualidade mínima dos dados que seriam analisados posteriormente. 
Como resultado dessa verificação, as respostas oriundas de duas empresas foram descartadas. A primeira empresa foi desconsiderada em função da baixa amplitude verificada nas respostas coletadas. Já a segunda empresa foi desconsiderada pela existência de apenas uma resposta de profissional em cargo de gestão. Tais características inviabilizaram o aproveitamento das respostas dessas empresas, razão pela qual optou-se por não inseri-las na massa de dados a ser analisada mais profundamente.

As repostas que atingiram os padrões mínimos especificados foram inseridas no programa de análise estatística SPSS visando assim o tratamento mais refinado dos dados validados na pesquisa de campo. Assim sendo, foram executadas técnicas de análise univariada, bivariada e multivariada, incluindo-se a Modelagem de Equações Estruturais. Esta técnica também é conhecida por meio de outras nomenclaturas, tais como Modelagem Causal, Análise Causal ou Modelagem por Equações Simultâneas. Chin (1998) sustenta que a Modelagem de Equações Estruturais possui a habilidade de representar conceitos não-observáveis em modelos complexos, o que acaba por torná-la uma ferramenta de análise multivariada de segunda geração muito útil.

Para Baumgartner e Homburg (1996), a crescente aplicabilidade da técnica de Modelagem de Equações Estruturais deve-se a dois fatores: o bom potencial da técnica no caso de investigações empíricas abrangentes acerca de aspectos teóricos e de mensuração, além da popularização de programas de computador que suportam sua utilização (PLS-PM, LISREL, EQS, AMOS, COSAN, EZPATH, LINCS, PROC CALIS e RAMONA).

Hair Jr. et al (2006) considera que a Modelagem de Equações Estruturais seja uma evolução de outra técnica anterior, a modelagem de multiequações, que foi desenvolvida e aplicada notadamente nas áreas de Econometria, Psicologia e Sociologia. Latif (2000) especifica as condições para o uso da Modelagem de Equações Estruturais:

É utilizada quando se deseja analisar várias relações de dependência as quais são relacionadas entre si, podendo uma variável dependente numa equação ser a variável independente numa outra equação (modelo estrutural). Também pode incorporar variáveis que não são mensuradas diretamente (modelo mensuração) [...] O modelo estrutural especifica as relações causais entre as variáveis latentes, além de descrever os efeitos causais e o total da variância não explicada. Já o modelo de mensuração especifica como as variáveis latentes são mensuradas em termos das variáveis observadas, além de descrever suas propriedades de mensuração (validade e confiabilidade). (LATIF, 2000, p. 9). 
Para Pereira, Camino e Costa (2004, p. 508) as "equações estruturais são um conjunto de técnicas estatísticas que avalia relações simultâneas entre uma ou mais variáveis independentes e uma ou mais variáveis dependentes, permitindo o teste empírico de modelos teóricos." Exatamente por essas características, Hair et al (2006) argumentam que essa técnica combine aspectos de regressões múltiplas para examinar as relações de dependência e de análise fatorial, visando representar conceitos com variáveis múltiplas, permitindo assim que as equações sejam estimadas simultaneamente.

A Modelagem de Equações Estruturais é um método multivariado que compreende dois aspectos básicos: a avaliação de um modelo de medidas, ou seja, como suas variáveis se compõem em um modelo de Análise Fatorial Confirmatória; e a avaliação de um modelo de caminhos (path analysis), ou seja, avaliação das relações causais entre os constructos existentes (BYRNE, 1998).

Jöreskog e Sörbom (1999) e Hair Jr. et al (2006) alertam que a aplicação desta técnica deve considerar a existência de hipóteses, efetivação de testes e investigação das relações de dependência entre variáveis. Em complemento, Latif (2000) discorre que essa técnica deva ser aplicada quando há um modelo teórico a ser analisado que tenha sido especificado a partir de fundamentos teóricos da área de conhecimento em questão.

Em alinhamento aos critérios dispostos pelos autores retratados, o presente estudo conta com hipóteses a serem testadas por meio da verificação das relações de dependência entre as variáveis ligadas às práticas e às ferramentas de tecnologia da informação e comunicação empregadas na gestão do conhecimento em ambientes de teletrabalho, bem como sua influência na eficácia empresarial. Não obstante, o presente estudo busca ainda analisar o modelo conceitual teórico (conforme figura 7 mais adiante) formulado a partir do referencial teórico pesquisado acerca da gestão do conhecimento', do teletrabalho e da eficácia empresarial.

A aplicação da técnica de Modelagem de Equações Estruturais pressupõe como premissa que a quantidade e a qualidade das suposições dependem do método de estimação a ser escolhido. O método de estimação que tem sido mais largamente utilizado é o da máxima verossimilhança (Maximum Likelihhod Estimation). Para Jöreskog e Sörbom (1996), este 
método caracteriza-se por sua precisão quando aplicado em amostras grandes. Deve-se ainda respeitar algumas outras premissas, conforme disposto no Quadro 7 a seguir.

\begin{tabular}{l|l}
\hline \multicolumn{1}{c|}{ Premissas de aplicação } & \multicolumn{1}{c}{ Considerações / Autores } \\
\hline Normalidade Multivariada & O método de estimação deve ser considerado; Hoyle (1995); Hair et al (2006) \\
\hline Multicolinearidade & Tabachnick e Fidell (1996) \\
\hline $\begin{array}{l}\text { Ausência de observações } \\
\text { atípicas }\end{array}$ & Hoyle (1995); Schumacker e Lomax (1996); Hair et al (2006) \\
\hline Linearidade & Hoyle (1995) \\
\hline Tamanho da amostra & $\begin{array}{l}-100 \text { a 200 casos - Hoyle (1995) } \\
-200 \text { a 400 casos - Hair } \text { et al (2006); Hojo e Mingoti (2004) }\end{array}$ \\
\hline Método de estimação & $\begin{array}{l}\text { Máxima verossimilhança (Maximum Likelihhod Estimation) - Jöreskog e Sörbom } \\
\text { (1996) }\end{array}$ \\
\hline
\end{tabular}

Quadro 7 - Premissas de utilização da técnica da Modelagem de Equações Estruturais

Fonte: adaptado pelo autor a partir de Hoyle (1995); Tabachnick e Fidell (1996); Hair et al (2005); Hojo e Mingoti (2004); Jöreskog e Sörbom (1996).

De forma a facilitar o entendimento acerca do tratamento e análise dos dados coletados, a Figura 7 mostra o modelo empírico empregado a partir da utilização da técnica de Modelagem de Equações Estruturais e do método de estimação de Máxima Verossimilhança.

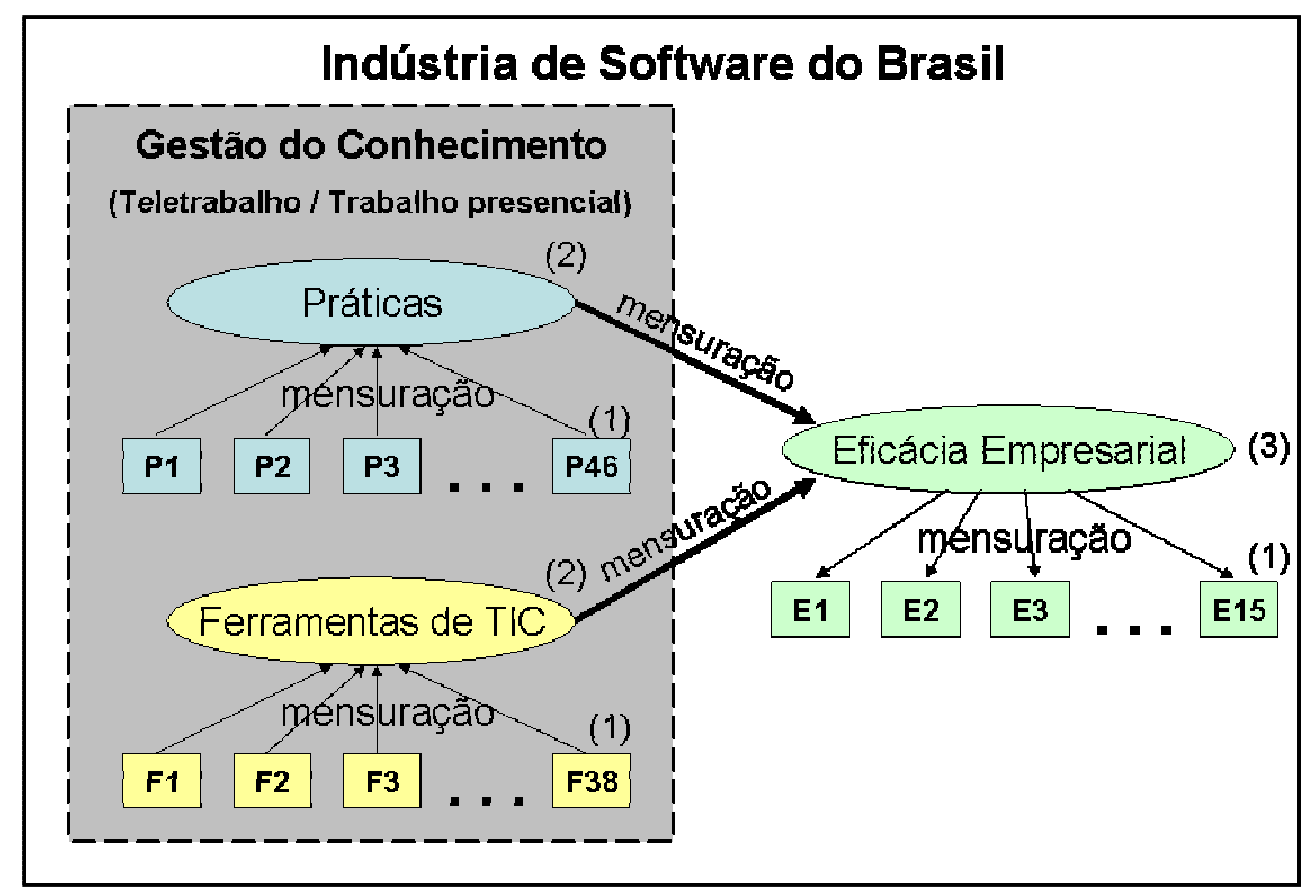

Figura 7 - Modelo empírico de tratamento e análise dos dados.

Legenda: (1) Variáveis observadas; (2) Variáveis latentes formativas; (3) Variável latente reflexiva. Fonte: elaborado pelo autor.

$\mathrm{Na}$ figura anterior, as variáveis observadas são pertencentes aos três conjuntos já anteriormente explicitados: 46 práticas de gestão do conhecimento, 38 ferramentas de 
tecnologia da informação e comunicação empregadas na gestão do conhecimento e 15 fatores de eficácia empresarial. Os dois primeiros conjuntos são formatos por variáveis latentes formativas enquanto o último conjunto é formado por variáveis latentes reflexivas. Os indicadores formativos buscam explicar um construto, não necessariamente apresentando correlação entre si. Já os indicadores reflexivos são explicados pelo construto, ou seja, são os indicadores que assinalam seus efeitos (DEVELLIS, 2003; JARVIS, MACKENZIE e PODSAKOFF, 2003).

Em seguida ao tratamento feito no SPSS, o banco de dados da pesquisa de campo foi exportado ao aplicativo PLS-PM, no qual foram efetuadas a validação, tabulação e análise do modelo acima proposto. O PLS-PM é o aplicativo mais indicado para o tratamento de dados por meio do método de mínimos quadrados parciais (PLS - partial lead squares) em modelos de equações estruturais que apresentem variáveis latentes com indicadores formativos, conforme é o caso do presente estudo (BIDO et al, 2010). Indicadores formativos buscam explicar um construto, não necessariamente apresentando correlação entre si. Já os indicadores reflexivos são explicados pelo construto, ou seja, são os indicadores que assinalam seus efeitos (CHIN, 1998).

Zwicker, Souza e Bido (2008) indicam alguns critérios importantes para a utilização do aplicativo PLS-PM, sendo todos eles respeitados neste estudo:

- Objetivo do estudo voltado à predição de um modelo;

- Abordagem baseada na variância;

- Modelo de mensuração apresenta indicadores formativos e reflexivos;

- Tamanho de amostra com no mínimo 100 casos.

Outro indicativo a favor da utilização do aplicativo PLS-PM é exposto por Bido et al (2009) ao apontar para a crescente utilização do PLS-PM em estudos nacionais que empregam a técnica da modelagem de equações estruturais. Os levantamentos efetuados pelos autores indicam a utilização do PLS-PM em diversos artigos publicados nos últimos anos em eventos da ANPAD, dentre os quais o mais significativo deles, o Encontro Nacional da ANPAD. 


\subsubsection{Validação estatística dos resultados}

Visando a validação dos resultados obtidos a partir da utilização do aplicativo PLS-PM, algumas estatísticas complementares foram aplicadas, a saber:

a) Tratamento de resultados dos indicadores formativos (práticas de gestão do conhecimento e ferramentas de tecnologia da informação e comunicação):

- $\quad$ VIF (fator de inflação da variância): valores superiores a 1,0 indicam a existência de multicolinearidade entre as variáveis do modelo o que, caso atestado, deve ser adequadamente tratado (HENSELER, RINGLE e SINKOVICS, 2009);

- Análise fatorial: subdividida em KMO Kaiser-Meyer-Olkin (valores acima de 0,5 são considerados aceitáveis para validação da variável em estudo) e Variância Total (valores acima de 0,6 são considerados aceitáveis para validação da variável em estudo) (PESTANA E GAGEIRO, 2005).

b) Tratamento de resultados dos indicadores formativos (práticas de gestão do conhecimento e ferramentas de tecnologia da informação e comunicação) e do indicador reflexivo (eficácia empresarial):

- Peso fatorial: valores acima de 0,2 são considerados aceitáveis para validação da variável em estudo (HAIR JR. et al, 2006);

- $\underline{t}$ de student: valores acima de 1,96; para um nível de confiança de 5,0\%, são considerados aceitáveis para a validação da variável em estudo (HAIR JR. et al, 2006).

Especificamente para o tratamento do indicador reflexivo (eficácia empresarial), foram adicionalmente empregadas as seguintes estatísticas: 
- Confiabilidade composta: valores acima de 0,7 são considerados aceitáveis para validação da variável em estudo (FORNELL e LARCKER, 1981);

- Variância extraída: valores acima de 0,5 são considerados aceitáveis para validação da variável em estudo (FORNELL e LARCKER, 1981);

- Validade discriminante: se a raiz quadrada da variância extraída é maior que as correlações entre as demais variáveis latentes, há validade discriminante (FORNELL e LARCKER, 1981).

O conjunto de estatísticas acima descrito foi necessário a fim de validar estatisticamente os resultados indicados a partir do tratamento e análise dos dados efetuado pelo aplicativo PLSPM. Dessa forma, buscou-se conferir maior qualidade estatística aos resultados indicados.

\subsection{Modelo teórico da pesquisa}

O modelo teórico da pesquisa é apresentado a seguir para uma melhor compreensão do estudo:

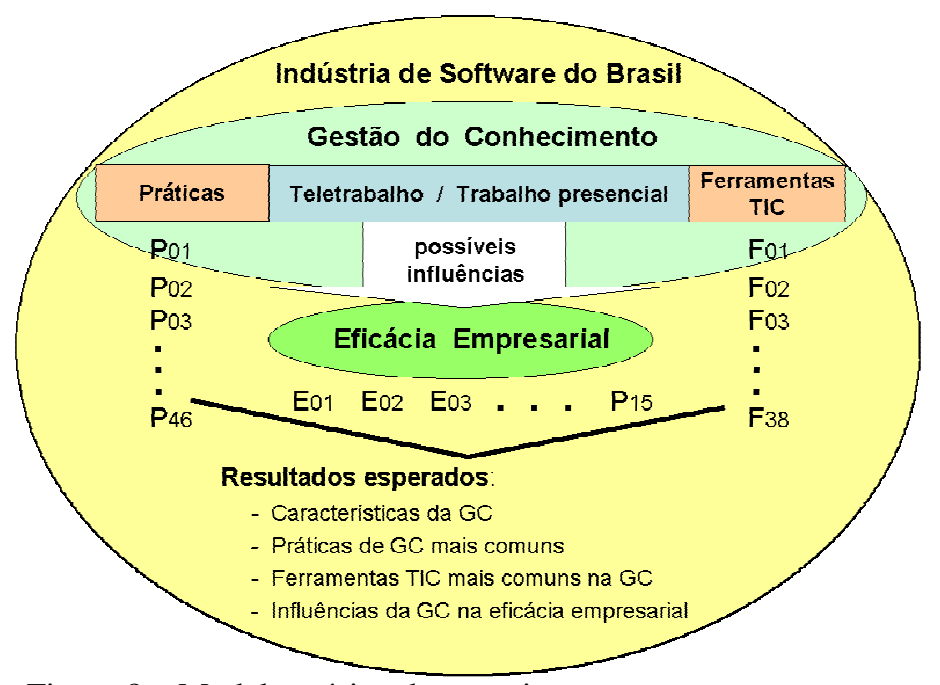

Figura 8 - Modelo teórico da pesquisa.

Fonte: elaborado pelo autor. 
O modelo teórico da pesquisa associa as três vertentes do estudo em questão no contexto das empresas atuantes na indústria de software no Brasil: gestão do conhecimento, teletrabalho e eficácia empresarial. Ou seja, busca-se compreender as relações entre esses três elementos por meio da prospecção das práticas e ferramentas de tecnologia da informação e comunicação existentes nas empresas dessa indústria específica, notadamente na efetivação da gestão do conhecimento em ambientes de teletrabalho e sua influência na eficácia empresarial das empresas analisadas. 
Este capítulo apresenta, analisa e discute os resultados da pesquisa de campo efetuada. Em primeiro plano, porém, é apresentado um breve panorama da indústria de software no Brasil, oriundo de dados secundários pesquisados acerca do tema.

Na sequência são expostos os resultados da pesquisa de campo. Para tanto, optou-se por preservar a ordem estabelecida no questionário aplicado aos respondentes na pesquisa de campo. Em seguida procurou-se analisar e explicar os resultados auferidos na pesquisa, inclusive apresentando os principais resultados de forma condensada, além de expor também estatísticas para a validação destes. Por fim, a última parte expõe o modelo validado e o teste das hipóteses do estudo. Assim este capítulo apresenta a seguinte estrutura:

- Caracterização da indústria de software no Brasil

- Apresentação dos resultados da pesquisa

- Caracterização dos respondentes e do ambiente de teletrabalho;

- Caracterização das empresas;

- Gestão do conhecimento na empresa;

- Práticas de gestão do conhecimento;

- Ferramentas de tecnologia da informação e comunicação adotadas para a gestão do conhecimento;

- Indicadores de eficácia empresarial;

- Análise e discussão dos resultados da pesquisa

- Principais práticas de gestão do conhecimento;

- Principais ferramentas de tecnologia da informação e comunicação adotadas na gestão do conhecimento;

- Principais indicadores de eficácia empresarial;

- Influência do ambiente de teletrabalho;

- Influência do nível hierárquico;

- Estatísticas para validação das variáveis latentes do modelo empírico de tratamento e análise dos dados; 
- Validação do modelo completo;

- Modelo validado e teste das hipóteses do estudo

- Modelo validado;

- Testes das hipóteses do estudo.

\subsection{Caracterização da indústria de software no Brasil}

A importância das indústrias focadas em tecnologia para o crescimento dos países em geral é indicada por Bruton, Dess e Janney (2007), relevando ainda serem as empresas dessas indústrias vitais ao crescimento de países em desenvolvimento. Assim, as empresas pertencentes à indústria de software, em específico, apresentam-se como uma importante indústria na evolução de países em desenvolvimento, como é o caso do Brasil.

A indústria de computadores nasceu de forma integrada seguindo-se, progressivamente, a desmembramentos em diferentes componentes, dentre os quais o software que deixou de ser um acessório do hardware quando a IBM passou a oferecê-los separadamente. Dessa forma, a IBM passou a comercializar seus computadores apenas com o sistema operacional, incluindo assim software aplicativos no rol dos componentes que poderiam ser ofertados por outras empresas. Tal condição é considerada como ato de fundação do mercado de software e, por consequência, da indústria de software (CAMPOS, NICOLAU e CARIO 2000; OCDE, 2005).

Existem diversos tipos de software, que vão desde sistemas comerciais aos acadêmicos, de sistemas operacionais até os jogos de computador, que são sistemas interativos que representam um subconjunto da realidade, de acordo com Crawford (2002). Devido à diversidade de tipos de software existente, dados da $\operatorname{OCDE}(2005$, p. 17) revelam que "as empresas de todos os setores da economia investem cada vez mais em software, e a participação nominal do software na formação de capital fixo bruto do setor empresarial cresce de maneira constante desde 1990.” Isto porque as aplicações de software atingem uma gama cada vez mais vasta de atividades, fazendo com que as ações de pesquisa e desenvolvimento sejam cada vez mais intensificadas para atender a demanda das diversas atividades. 
Nesta direção, a indústria de software (programas e soluções lógicas), possui um diferencial devido aos aspectos de uso, utilidade e velocidade com os quais os aplicativos são desenvolvidos, conforme Tapscott e Caston (1995). Além disso, a indústria de software valoriza mais o capital humano do que os bens de produção, assim como o trabalho colaborativo.

Roselino (2006) indica que o Brasil tem uma preocupação com a indústria de software, destacando-se assim duas metas norteadoras: que o Brasil seja referência na exportação de software e serviços correlatos; e que ocorra uma ampliação das empresas nacionais no mercado interno. Nesse sentido, o mercado doméstico de software é significativo, com pólos de desenvolvimento em todas as regiões do país, notadamente com maior concentração de empresas no Sudeste e no Sul do país, sendo a maioria formada por empresas de pequeno porte, segundo considerações de Kubota (2006). Externamente, aproveitando as capacidades locais em muitos segmentos e nichos específicos, busca-se a internacionalização de sua indústria de software. Com isso, Barros (2007) enfatiza que o Brasil entende que as políticas para essas indústrias sejam nacionais na origem, mas globais em sua perspectiva e que assim como ocorre na Índia e o Chile, o Brasil já estabeleceu seu nicho global na indústria de software.

A evolução da indústria de software no Brasil tem se intensificado de forma bastante acelerada. Em 2004 essa indústria obteve um faturamento de US\$ 1,74 bilhões, em 2005 de US\$ 2,72 bilhões, em 2006 de US\$ 3,26 bilhões e em 2007 alcançou a cifra de US\$ 11,12 bilhões, o que equivale a 1,6\% do mercado mundial (BRASIL, 2006; ABES, 2009). Em 2008, a indústria brasileira de software consolidou-se na $12^{\circ}$ posição no cenário mundial, com movimentação de US\$ 5 bilhões em software, equivalente a 1,68\% do mercado mundial daquele ano (ABES, 2009). A indústria brasileira de software é composta "por quase 8.500 empresas, dedicadas ao desenvolvimento, produção e distribuição de software e de prestação de serviços. Daquelas que atuam no desenvolvimento e produção de software, $94 \%$ são classificadas como micro e pequenas empresas.” (ABES, 2009, s.p.).

Não obstante, a expansão do mercado conquistado nos últimos anos faz com que empresas estrangeiras se interessem em realizar grandes investimentos no país, sendo cada vez mais importantes ações governamentais que promovam as empresas nacionais, estimulando-as não 
só a competir pelo mercado interno como, também, a buscar novos mercados no exterior (FREIRE e BRISOLA, 2004).

A incerteza e dinamicidade são características do ambiente da indústria de software, que intrinsecamente é calcada no binômio criatividade e inovação, para atender a demanda de informação dos aplicativos a serem criados. Desta forma, no caso específico da indústria brasileira de software, a criação e disseminação de conhecimento assumem o papel de insumos imprescindíveis ao sucesso desse tipo de organização.

\subsection{Apresentação dos resultados da pesquisa}

Nos tópicos a seguir são apresentados detalhadamente os resultados auferidas na pesquisa de campo. Para tanto, optou-se por estruturá-los na mesma ordem em que foram apresentados no questionário entregue aos respondentes.

\subsubsection{Caracterização dos respondentes e do ambiente de teletrabalho}

A caracterização dos respondentes ao questionário buscou identificar as seguintes informações: gênero, faixa etária, cargo ou função exercida, tempo de empresa e período de atuação em regime de teletrabalho.

\subsubsection{Gênero}

A distribuição de gêneros entre os 319 respondentes é exposta na Tabela 1 a seguir.

$\begin{array}{lrr} & \text { Tabela 1 - Gênero dos respondentes } & \\ & \text { Frequência } & \text { Percentual } \\ \text { Masculino } & 186 & 58,3 \% \\ \text { Feminino } & 133 & 41,7 \% \\ \text { Total } & 319 & 100,0 \%\end{array}$

A maioria dos trabalhadores que responderam ao questionário é do sexo masculino $(58,3 \%)$. 


\subsubsection{Faixa etária}

Quanto à idade dos respondentes, os trabalhadores estão assim distribuídos pelas faixas etárias, conforme Tabela 2.

\begin{tabular}{lrr}
\multicolumn{3}{c}{ Tabela 2 - Faixa etária dos respondentes } \\
Frequência & Percentual \\
Menor de 18 anos & 2 & $0,6 \%$ \\
18 a 24 anos & 57 & $17,9 \%$ \\
25 a 34 anos & 102 & $32,0 \%$ \\
35 a 44 anos & 107 & $33,5 \%$ \\
45 a 54 anos & 46 & $14,4 \%$ \\
Acima de 55 anos & 5 & $1,6 \%$ \\
Total & 319 & $100,0 \%$
\end{tabular}

A maior parte dos trabalhadores pesquisados $(33,5 \%)$ tem entre 35 e 44 anos. A segunda faixa etária mais incidente é a de 25 a 34 anos, com 32,0\%. Essas duas faixas etárias mais representativas alcançam juntas $65,5 \%$ da amostra pesquisada. Ou seja, quase $2 / 3$ da amostra tem idade entre 25 e 44 anos.

\subsubsection{Cargo ou função exercida}

Os cargos ou funções exercidas pelos respondentes estão subdivididos em dois conjuntos: gestão e técnico. A incidência de cada cargo/função está disposta na Tabela 3. 
Tabela 3 - Cargo ou função exercida pelos respondentes

\begin{tabular}{l} 
Cargo/função de gestão \\
Diretor \\
Gerente \\
Coordenador \\
Supervisor \\
Líder de equipe/projeto \\
\multicolumn{1}{c}{ Subtotal - Gestão } \\
Cargo/função técnica \\
Analista de sistemas \\
Analista de processos \\
Analista de negócios \\
Analista de ambiente/plataforma \\
Analista de banco de dados \\
Analista de testes \\
Analista de documentação \\
Consultor de negócios \\
Programador \\
Outros
\end{tabular}

Total Frequência Percentual

$\begin{array}{rr}1 & 0,3 \% \\ 14 & 4,4 \% \\ 25 & 7,9 \% \\ 8 & 2,5 \% \\ 19 & 6,0 \% \\ \mathbf{6 7} & \mathbf{2 1 , 1 \%}\end{array}$

$126 \quad 39,5 \%$

$10 \quad 3,1 \%$

$33 \quad 10,2 \%$

$17 \quad 5,3 \%$

$15 \quad 4,7 \%$

$13 \quad 4,1 \%$

$4 \quad 1,3 \%$

$7 \quad 2,2 \%$

$14 \quad 4,4 \%$

$13 \quad 4,1 \%$

$252 \quad \mathbf{7 8 , 9} \%$

$319 \quad 100,0 \%$

A maioria dos respondentes com cargo/função de gestão atua como coordenador (7,9\%), seguida de líder de equipe/projeto (6,0\%). Esses dois cargos específicos respondem por mais da metade dos respondentes com cargo/função de gestão $(13,9 \%)$.

Já em relação aos respondentes com cargo/função técnica, a grande maioria enquadra-se como analista de sistemas $(39,5 \%)$. O segundo cargo/função mais verificado foi o de analista de negócios, com 10,2\% das respostas.

Ao comparar-se a equivalência existente entre os cargos/funções de gestão e os cargos/funções técnicas, obtém-se a relação de 1 para 5, ou seja, de cada cinco trabalhadores pesquisados, um exerce cargo ou função de gestão.

\subsubsection{Tempo de empresa}

O tempo de empresa dos trabalhadores pesquisados é detalhado na Tabela 4. 
Tabela 4 - Tempo de empresa dos respondentes

Até 1 ano

Entre 1 e 3 anos

Entre 4 e 6 anos

Acima de 7 anos

Total
Frequência

28

102

124

65

319
Percentual

$8,8 \%$

$32,0 \%$

$38,9 \%$

$20,3 \%$

$100,0 \%$

A maioria dos respondentes trabalha na empresa entre 4 e 6 anos (38,9\%). É interessante observar que $91,2 \%$ dos trabalhadores pesquisados têm mais de um ano na empresa atual.

\subsubsection{Teletrabalho}

O tempo de atuação dos trabalhadores da pesquisa em regime de teletrabalho no período semanal é detalhado na Tabela 5 a seguir.

\begin{tabular}{lrr}
\multicolumn{3}{c}{ Tabela 5 - Ambiente de teletrabalho } \\
Frequência & Percentual \\
Não atua em teletrabalho & 180 & $56,4 \%$ \\
Meio período & 2 & $0,6 \%$ \\
1 dia & 60 & $18,8 \%$ \\
2 dias & 32 & $10,0 \%$ \\
3 dias & 14 & $4,4 \%$ \\
4 dias & 0 & $0,0 \%$ \\
A semana inteira & 31 & $9,8 \%$ \\
Total & 319 & $100,0 \%$
\end{tabular}

Mais da metade dos respondentes não atua em regime de teletrabalho (56,4\%). Dos teletrabalhadores $(43,6 \%)$, a maior parte $(18,8 \%)$ o faz em um único dia da semana.

\subsubsection{Principais considerações acerca da caracterização dos respondentes e do ambiente de teletrabalho}

Os principais atributos verificados na pesquisa de campo que caracterizam o perfil dos respondentes são: em sua maioria masculino (58,3\%), com idade entre 35 e 44 anos (33,5\%), ocupando cargo de gestão como coordenador $(7,8 \%)$ e cargo técnico como analista de sistemas $(39,5 \%)$ e apresentando entre 4 e 6 anos na mesma empresa (38,9\%). 
Em relação à atuação em regime de teletrabalho, a maioria dos respondentes $(56,4 \%)$ afirma não atuar em teletrabalho. Do restante dos respondentes $(43,6 \%)$, a maioria atua um único dia da semana fora do ambiente da empresa $(18,8 \%)$.

Os principais atributos verificados na pesquisa de campo que caracterizam o perfil dos respondentes são: em sua maioria masculino (58,3\%), com idade entre 35 e 44 anos $(33,5 \%)$, ocupando cargo de gestão como coordenador $(7,8 \%)$ e cargo técnico como analista de sistemas $(39,5 \%)$ e apresentando entre 4 e 6 anos na mesma empresa $(38,9 \%)$.

Em relação à atuação em regime de teletrabalho, a maioria dos respondentes $(56,4 \%)$ afirma não atuar em teletrabalho. Do restante dos respondentes $(43,6 \%)$, a maioria atua um único dia da semana fora do ambiente da empresa $(18,8 \%)$.

\subsubsection{Caracterização das empresas}

A caracterização das empresas expõe as seguintes informações: segmento de atuação, porte da empresa e quantidade de empregados.

\subsubsection{Segmento de atuação da empresa}

O segmento de atuação da empresa dentro da indústria de software está disposto dentre as seguintes alternativas: desenvolvimento, manutenção e prestação de serviços. Cabe ressaltar que os respondentes podiam assinalar mais de uma alternativa no questionário respondido. Os resultados coletados estão expostos na Tabela 6.

\begin{tabular}{lrr}
\multicolumn{3}{c}{ Tabela 6 - Segmento de atuação da empresa } \\
& Frequência & Percentual \\
Software - desenvolvimento & 314 & $98,4 \%$ \\
Software - manutenção & 235 & $73,7 \%$ \\
Software - prestação de serviços & 161 & $50,5 \%$ \\
Total & 319 & $100,0 \%$
\end{tabular}

Quase a totalidade dos respondentes $(98,4 \%)$ classifica sua empresa como essencialmente desenvolvedoras do produto software. Logo depois, $73,7 \%$ dos sujeitos pesquisados 
classificam sua empresa como voltada à manutenção do software. Por fim, praticamente metade dos respondentes $(50,5 \%)$ observa a empresa em que trabalham como uma organização prestadora de serviços relacionados ao produto software.

\subsubsection{Porte da empresa}

O porte da empresa verificado pelos respondentes está descrito na Tabela 7.

$\begin{array}{lrr} & \text { Tabela } 7 \text { - Porte da empresa } & \\ & \text { Frequência } & \text { Percentual } \\ \text { Médio } & 121 & 37,9 \% \\ \text { Grande } & 198 & 62,1 \% \\ \text { Total } & 319 & 100,0 \%\end{array}$

$37,9 \%$ dos pesquisados atestaram trabalhar em empresas de médio porte. Já os $62,1 \%$ restantes atestaram trabalhar em empresa de grande porte.

\subsubsection{Quantidade de empregados da empresa}

A quantidade de empregados das empresas pesquisadas, de acordo com os respondentes, está exposta na Tabela 8.

Tabela 8 - Quantidade de empregados da empresa

$\begin{array}{lrr} & \text { Frequência } & \text { Percentual } \\ \text { Entre } 50 \text { e } 99 \text { empregados } & 107 & 33,5 \% \\ \text { Acima de } 100 \text { empregados } & 212 & 66,5 \% \\ \text { Total } & 319 & 100,0 \%\end{array}$

Observa-se que 33,5\% dos respondentes tenham assinalado que a empresa em que trabalham possui menos de 100 empregados. A maioria (66,5\%) indicou que a empresa na qual trabalham tem mais de 100 empregados. 


\subsubsection{Principais considerações acerca da caracterização das empresas}

A maioria dos respondentes diz atuar em empresa atuante no desenvolvimento de software $(98,4 \%)$. Já 62,1\% dos trabalhadores pesquisados classificam a empresa como de grande porte e $66,5 \%$ deles atestam que a empresa na qual trabalham tem mais de 100 empregados.

\subsubsection{Gestão do conhecimento na empresa}

Este item tratava da percepção da existência da gestão do conhecimento na empresa. Propositadamente, antes de tratar de práticas e tecnologias voltadas à gestão do conhecimento, o questionário indagava o respondente quanto à sua percepção prévia da existência da gestão do conhecimento na empresa. A Tabela 9 caracteriza as percepções coletadas na pesquisa de campo.

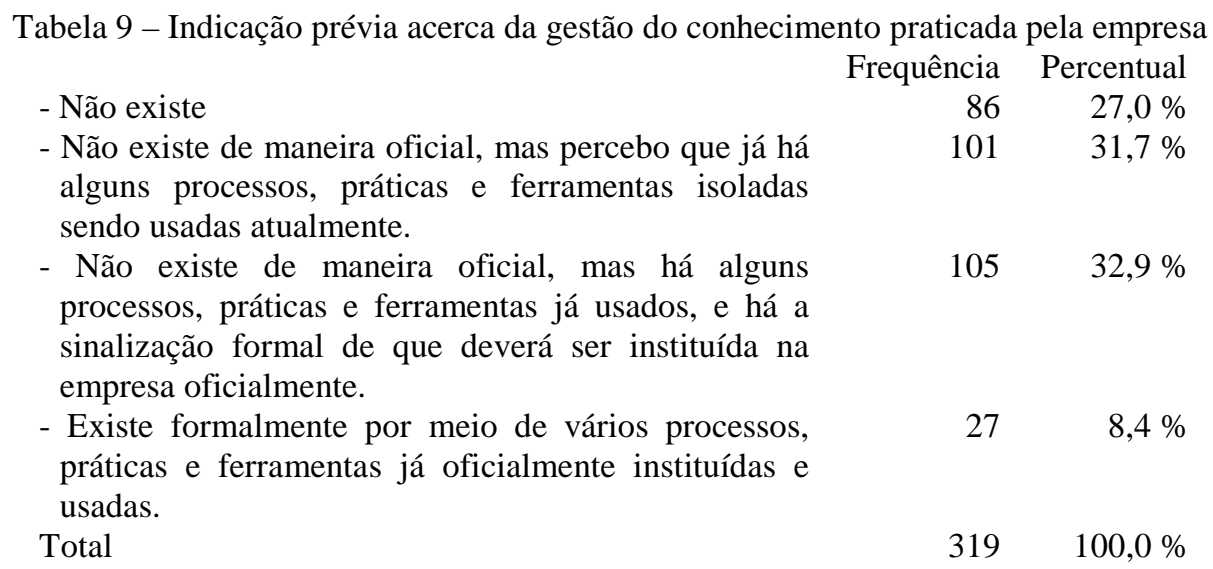

Para pouco mais de $1 / 4$ dos respondentes $(27,0 \%)$ a gestão do conhecimento simplesmente não existe em sua empresa. Outros $31,7 \%$ dos pesquisados percebem que há processos, práticas e ferramentas isoladamente em uso, mesmo que a gestão do conhecimento não esteja formalmente instituída na empresa. Já 32,9\% dos sujeitos asseveram que, além de já ser observada como existente na empresa, a gestão do conhecimento deverá ser formalmente instituída na organização. Por fim, $8,4 \%$ dos respondentes atestaram que a gestão do conhecimento já é oficialmente instituída na empresa.

É interessante indicar que o contexto anteriormente relatado trata da percepção do empregado quanto ao grau de formalidade da gestão do conhecimento em sua empresa. Ou seja, a partir 
de uma questão direta acerca do assunto, o respondente indicou seu grau de percepção em relação à existência ou não da gestão do conhecimento em sua organização. Nos próximos itens será possível vislumbrar que a existência de práticas e ferramentas voltadas à gestão do conhecimento na empresa não necessariamente respalda a percepção prévia demonstrada pelos sujeitos pesquisados.

\subsubsection{Práticas de gestão do conhecimento}

As 46 práticas de gestão do conhecimento averiguadas na pesquisa de campo são expostas individualmente nos itens a seguir. Posteriormente é exposto um resumo com todas as práticas prospectadas, no qual é possível observar a nota mais indicada de cada prática, sua frequência e percentual, além da média da nota.

\subsubsection{Práticas de gestão do conhecimento - Estratégia declarada}

A Tabela 10 expõe a distribuição das respostas obtidas na pesquisa de campo quanto à pergunta: 'A empresa possui ESTRATÉGIA DECLARADA (modelo ou plano detalhado) de gestão do conhecimento'.

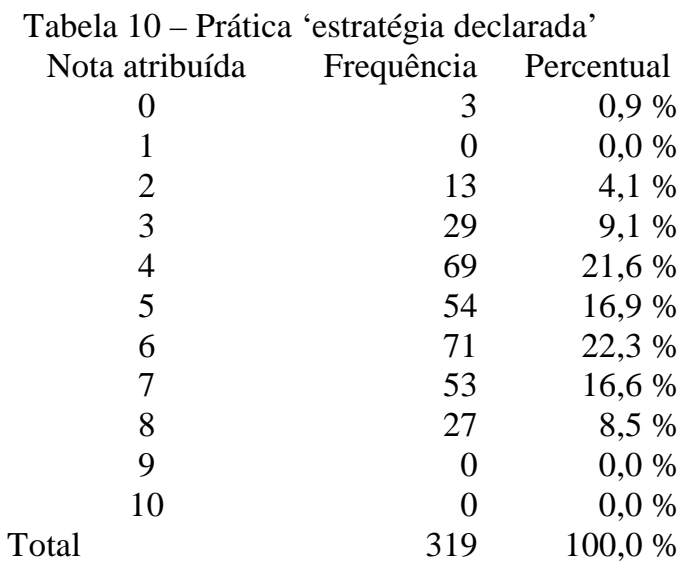

A maior parte dos respondentes $(60,8 \%)$ oscilou entre as notas 4,5 e 6 , com maior predominância para a nota 6. Note-se que não houve atribuição de notas 9 ou 10 para esta prática em especial. 
A nota mais atribuída pelos respondentes para a prática 'estratégia declarada' foi a nota 6 , com 71 indicações (22,3\% do total). A média das notas atribuídas a esta prática foi 5,2.

\subsubsection{Práticas de gestão do conhecimento - Políticas declaradas}

A Tabela 11 expõe a distribuição das respostas obtidas na pesquisa de campo quanto à pergunta 'A empresa possui POLÍTICAS DECLARADAS (regras estabelecidas) de gestão do conhecimento'.

\begin{tabular}{|c|c|c|}
\hline Nota atribuída & Frequência & Percentual \\
\hline 0 & 5 & $1,6 \%$ \\
\hline 1 & 1 & $0,3 \%$ \\
\hline 2 & 16 & $5,0 \%$ \\
\hline 3 & 22 & $6,9^{c}$ \\
\hline 4 & 52 & $16,3 \%$ \\
\hline 5 & 82 & $25,8 \%$ \\
\hline 6 & 60 & $18,8 \%$ \\
\hline 7 & 54 & $16,9 \%$ \\
\hline 8 & 21 & $6,6 \%$ \\
\hline 9 & 2 & $0,6 \%$ \\
\hline 10 & 4 & $1,2 \%$ \\
\hline Total & 319 & $100,0 \%$ \\
\hline
\end{tabular}

A maior parte dos respondentes $(60,9 \%)$ oscilou entre as notas 4, 5, 6 e 7, com maior predominância para a nota 5 .

A nota mais atribuída pelos respondentes para a prática 'políticas declaradas' foi a nota 5, com 82 indicações (25,8\% do total). A média das notas atribuídas a esta prática foi 5,3.

\subsubsection{Práticas de gestão do conhecimento - Gestão da inovação}

A Tabela 12 expõe a distribuição das respostas obtidas na pesquisa de campo quanto à pergunta 'A empresa possui GESTÃO DA INOVAÇÃO estruturada'. 
Tabela 12 - Prática 'gestão da inovação'

\begin{tabular}{|c|c|c|}
\hline Nota atribuída & Frequência & Percentual \\
\hline 0 & 1 & $0,3 \%$ \\
\hline 1 & 0 & $0,0 \%$ \\
\hline 2 & 4 & $1,2 \%$ \\
\hline 3 & 16 & $5,0 \%$ \\
\hline 4 & 49 & $15,4 \%$ \\
\hline 5 & 52 & $16,3 \%$ \\
\hline 6 & 82 & $25,8 \%$ \\
\hline 7 & 69 & $21,7 \%$ \\
\hline 8 & 40 & $12,5 \%$ \\
\hline 9 & 2 & $0,6 \%$ \\
\hline 10 & 4 & $1,2 \%$ \\
\hline & 319 & $100,0 \%$ \\
\hline
\end{tabular}

Nesta prática houve uma maior distribuição das notas atribuídas pelos respondentes, observando-se uma concentração no intervalo compreendido entre as notas 4 e 8, com destaque para a nota 6.

A nota mais atribuída pelos respondentes para a prática 'gestão da inovação' foi a nota 6 , com 82 indicações (25,9\% do total). A média das notas atribuídas a esta prática foi 5,8.

\subsubsection{Práticas de gestão do conhecimento - Gestão por competências}

A Tabela 13 expõe a distribuição das respostas obtidas na pesquisa de campo quanto à pergunta 'A empresa possui GESTÃO POR COMPETÊNCIAS'.

\begin{tabular}{|c|c|c|}
\hline Nota atribuída & Frequência & Percentual \\
\hline 0 & 2 & $0,6 \%$ \\
\hline 1 & 0 & $0,0 \%$ \\
\hline 2 & 22 & $6,9 \%$ \\
\hline 3 & 23 & $7,2 \%$ \\
\hline 4 & 59 & $18,5 \%$ \\
\hline 5 & 71 & $22,3 \%$ \\
\hline 6 & 66 & $20,7 \%$ \\
\hline 7 & 53 & $16,7 \%$ \\
\hline 8 & 16 & $5,0 \%$ \\
\hline 9 & 3 & $0,9 \%$ \\
\hline 10 & 4 & $1,2 \%$ \\
\hline Total & 319 & $100,0 \%$ \\
\hline
\end{tabular}

A prática gestão por competências obteve concentração de notas 4, 5, 6 e 7 com 78,2\% das respostas, evidenciado-se aí a nota 5. 
A nota mais atribuída pelos respondentes para a prática 'gestão por competências' foi a nota 5, com 71 indicações (22,3\% do total). A média das notas atribuídas a esta prática foi 5,2.

\subsubsection{Práticas de gestão do conhecimento - Comunicação corporativa}

A Tabela 14 expõe a distribuição das respostas obtidas na pesquisa de campo quanto à pergunta 'A empresa disponibiliza COMUNICAÇÃO CORPORATIVA para a gestão do conhecimento'.

$\begin{array}{crr}\text { Tabela } 14 \text { - Prática 'comunicação corporativa' } \\ \text { Nota atribuída } & \text { Frequência } & \text { Percentual } \\ 0 & 0 & 0,0 \% \\ 1 & 0 & 0,0 \% \\ 2 & 16 & 5,0 \% \\ 3 & 25 & 7,8 \% \\ 4 & 28 & 8,8 \% \\ 5 & 79 & 24,8 \% \\ 6 & 58 & 18,2 \% \\ 7 & 56 & 17,6 \% \\ 8 & 44 & 13,8 \% \\ 9 & 2 & 0,6 \% \\ 10 & 11 & 3,4 \% \\ \text { Total } & 319 & 100,0 \%\end{array}$

A maioria dos pesquisados concentrou suas respostas entre as notas 5 e 8 (74,3\%). A maior evidência, no entanto, foi da nota 5 com $24,8 \%$ das respostas.

A nota mais atribuída pelos respondentes para a prática 'comunicação corporativa' foi a nota 5, com 79 indicações (24,8\% do total). A média das notas atribuídas a esta prática foi 5,7.

\subsubsection{Práticas de gestão do conhecimento - Benchmarking}

A Tabela 15 expõe a distribuição das respostas obtidas na pesquisa de campo quanto à pergunta 'A empresa efetua BENCHMARKING de conhecimentos'. 


\begin{tabular}{|c|c|c|}
\hline \multicolumn{3}{|c|}{ Tabela 15 - Prática 'benchmarking' } \\
\hline Nota atribuída & Frequência & Percentual \\
\hline 0 & 1 & $0,3 \%$ \\
\hline 1 & 1 & $0,3 \%$ \\
\hline 2 & 3 & $0,9 \%$ \\
\hline 3 & 21 & $6,6 \%$ \\
\hline 4 & 54 & $16,9 \%$ \\
\hline 5 & 80 & $25,1 \%$ \\
\hline 6 & 73 & $22,9 \%$ \\
\hline 7 & 34 & $10,8 \%$ \\
\hline 8 & 37 & $11,6 \%$ \\
\hline 9 & 4 & $1,2 \%$ \\
\hline 10 & 11 & $3,4 \%$ \\
\hline otal & 319 & $100,0 \%$ \\
\hline
\end{tabular}

A concentração nesta prática deu-se nas notas 5 e $6 \mathrm{com} 48,0 \%$ das respostas obtidas. Outro aspecto a ser evidenciado é a incidência da nota 5.

A nota mais atribuída pelos respondentes para a prática 'benchmarking' foi a nota 5 , com 80 indicações $(25,1 \%$ do total). A média das notas atribuídas a esta prática foi 5,7.

\subsubsection{Práticas de gestão do conhecimento - Centros de inovação}

A Tabela 16 expõe a distribuição das respostas obtidas na pesquisa de campo quanto à pergunta 'A empresa conta com CENTROS DE INOVAÇÃO'.

\begin{tabular}{|c|c|c|}
\hline \multicolumn{3}{|c|}{ Tabela 16 - Prática 'centros de inovação' } \\
\hline Nota atribuída & Frequência & Percentual \\
\hline 0 & 0 & $0,0 \%$ \\
\hline 1 & 0 & $0,0 \%$ \\
\hline 2 & 2 & $0,6 \%$ \\
\hline 3 & 9 & $2,8 \%$ \\
\hline 4 & 40 & $12,5 \%$ \\
\hline 5 & 57 & $17,9 \%$ \\
\hline 6 & 106 & $33,2 \%$ \\
\hline 7 & 56 & $17,6 \%$ \\
\hline 8 & 45 & $14,2 \%$ \\
\hline 9 & 0 & $0,0 \%$ \\
\hline 10 & 4 & $1,2 \%$ \\
\hline Total & 319 & $100,0 \%$ \\
\hline
\end{tabular}

Há uma predominância entre as notas 5 e 7 com 68,7\% das respostas, evidenciando-se aí a nota 6 em específico, com praticamente $1 / 3$ de todas as respostas. 
A nota mais atribuída pelos respondentes para a prática 'centros de inovação' foi a nota 6 , com 106 indicações (33,2\% do total). A média das notas atribuídas a esta prática foi 6,0.

\subsubsection{Práticas de gestão do conhecimento - Call center/help desk/suporte online}

A Tabela 17 expõe a distribuição das respostas obtidas na pesquisa de campo quanto à pergunta 'A empresa dispõe de CALL CENTER / HELP DESK / SUPORTE ONLINE'.

\begin{tabular}{|c|c|c|}
\hline Nota atribuída & Frequência & Percentual \\
\hline 0 & 1 & $0,3 \%$ \\
\hline 1 & 0 & $0,0 \%$ \\
\hline 2 & 0 & $0,0 \%$ \\
\hline 3 & 2 & $0,6 \%$ \\
\hline 4 & 28 & $8,8 \%$ \\
\hline 5 & 65 & $20,4 \%$ \\
\hline 6 & 59 & $18,5 \%$ \\
\hline 7 & 68 & $21,3 \%$ \\
\hline 8 & 68 & $21,3 \%$ \\
\hline 9 & 1 & $0,3 \%$ \\
\hline 10 & 27 & $8,5 \%$ \\
\hline Total & 319 & $100,0 \%$ \\
\hline
\end{tabular}

Houve uma distribuição relativamente homogênea entre as notas 5, 67 e 8, com maior incidência para as notas 7 e 8 que apresentaram $21,3 \%$ das repostas cada.

As notas mais atribuídas pelos respondentes para a prática 'call center, help desk, suporte' foram as notas 7 e 8 , ambas com 68 indicações (21,3\% cada uma do total). A média das notas atribuídas a esta prática foi 6,6 .

\subsubsection{Práticas de gestão do conhecimento - CKO/CKM}

A Tabela 18 expõe a distribuição das respostas obtidas na pesquisa de campo quanto à pergunta 'Os cargos de CKO ou CKM (Chief of Knowledge Officer ou Certified Knowledge Manager, ou seja, GESTOR DE GESTÃO DO CONHECIMENTO) existem na empresa'. 


\begin{tabular}{|c|c|c|}
\hline \multicolumn{3}{|c|}{ Tabela 18 - Prática 'CKO/CKM' } \\
\hline Nota atribuída & Frequência & Percentual \\
\hline 0 & 27 & $8,5 \%$ \\
\hline 1 & 1 & $0,3 \%$ \\
\hline 2 & 27 & $8,5 \%$ \\
\hline 3 & 25 & $7,8 \%$ \\
\hline 4 & 73 & $22,9 \%$ \\
\hline 5 & 29 & $9,1 \%$ \\
\hline 6 & 63 & $19,7 \%$ \\
\hline 7 & 32 & $10,0 \%$ \\
\hline 8 & 36 & $11,3 \%$ \\
\hline 9 & 1 & $0,3 \%$ \\
\hline 10 & 5 & $1,6 \%$ \\
\hline Total & 319 & $100,0 \%$ \\
\hline
\end{tabular}

A maior parte dos respondentes indicou a nota 4 (22.9\%), mas também verifica-se relevância para a nota $6(19,7 \%)$. Não obstante a nota zero também indica aspecto significativo com $8,5 \%$ das respostas.

A nota mais atribuída pelos respondentes para a prática 'CKO/CKM' foi a nota 4, com 73 indicações (22,9\% do total). A média das notas atribuídas a esta prática foi 4,7.

\subsubsection{Práticas de gestão do conhecimento - Centro de competências}

A Tabela 19 expõe a distribuição das respostas obtidas na pesquisa de campo quanto à pergunta 'A empresa possui CENTRO DE COMPETÊNCIAS'.

\begin{tabular}{|c|c|c|}
\hline Nota atribuída & Frequência & Percentual \\
\hline 0 & 2 & $0,6 \%$ \\
\hline 1 & 1 & $0,3 \%$ \\
\hline 2 & 20 & $6,3 \%$ \\
\hline 3 & 22 & $6,9 \%$ \\
\hline 4 & 88 & $27,6 \%$ \\
\hline 5 & 76 & $23,8 \%$ \\
\hline 6 & 50 & $15,7 \%$ \\
\hline 7 & 44 & $13,8 \%$ \\
\hline 8 & 13 & $4,1 \%$ \\
\hline 9 & 2 & $0,6 \%$ \\
\hline 10 & 1 & $0,3 \%$ \\
\hline Total & 319 & $100,0 \%$ \\
\hline
\end{tabular}

A concentração verificada nas respostas desta prática está centrada nas notas 4 e 5 com mais da metade das respostas coletadas $(51,4 \%)$. 
A nota mais atribuída pelos respondentes para a prática 'centro de competências' foi a nota 4, com 88 indicações $(27,6 \%$ do total). A média das notas atribuídas a esta prática foi 4,9.

\subsubsection{Práticas de gestão do conhecimento - Área interna/departamento específico}

A Tabela 20 expõe a distribuição das respostas obtidas na pesquisa de campo quanto à pergunta 'A empresa tem uma ÁREA INTERNA OU DEPARTAMENTO ESPECÍFICO para a gestão do conhecimento'.

$\begin{array}{crc}\text { Tabela } 20 \text { - Prática 'Área interna/departamento específico' } \\ \text { Nota atribuída } & \text { Frequência } & \text { Percentual } \\ 0 & 22 & 6,9 \% \\ 1 & 1 & 0,3 \% \\ 2 & 25 & 7,8 \% \\ 3 & 23 & 7,2 \% \\ 4 & 80 & 25,1 \% \\ 5 & 55 & 17,2 \% \\ 6 & 45 & 14,2 \% \\ 7 & 43 & 13,5 \% \\ 8 & 24 & 7,5 \% \\ 9 & 0 & 0,0 \% \\ 10 & 1 & 0,3 \% \\ \text { Total } & 319 & 100,0 \%\end{array}$

Praticamente $1 / 4$ dos respondentes da pesquisa indicaram a nota 4 como indicativo da existência de uma área interna ou departamento específico voltado à gestão do conhecimento. Esta prática apresentou uma maior diluição entre as notas intermediárias, mostrando-se também relevante a atribuição dada para as notas mais baixas, tais como zero, 2 e 3 .

A nota mais atribuída pelos respondentes para a prática 'área interna, departamento específico' foi a nota 4 , com 80 indicações $(25,1 \%$ do total). A média das notas atribuídas a esta prática foi 4,7 .

\subsubsection{Práticas de gestão do conhecimento - Redes de especialistas}

A Tabela 21 expõe a distribuição das respostas obtidas na pesquisa de campo quanto à pergunta 'A empresa conta com REDES DE ESPECIALISTAS para troca de conhecimentos'. 


\begin{tabular}{|c|c|c|}
\hline \multicolumn{3}{|c|}{ Tabela 21 - Prática 'redes de especialistas' } \\
\hline Nota atribuída & Frequência & Percentual \\
\hline 0 & 11 & $3,4 \%$ \\
\hline 1 & 2 & $0,6 \%$ \\
\hline 2 & 15 & $4,7 \%$ \\
\hline 3 & 21 & $6,6 \%$ \\
\hline 4 & 75 & $23,5 \%$ \\
\hline 5 & 44 & $13,8 \%$ \\
\hline 6 & 72 & $22,6 \%$ \\
\hline 7 & 48 & $15,1 \%$ \\
\hline 8 & 26 & $8,2 \%$ \\
\hline 9 & 2 & $0,6 \%$ \\
\hline 10 & 3 & $0,9 \%$ \\
\hline Total & 319 & $100,0 \%$ \\
\hline
\end{tabular}

As notas 4 e 6 obtiveram a maior ocorrência de respostas, apresentando juntas 46,1\% das respostas auferidas na pesquisa. Não obstante, observa-se uma maior diluição das respostas dentre as alternativas disponíveis.

A nota mais atribuída pelos respondentes para a prática 'redes de especialistas' foi a nota 4, com 75 indicações (23,5\% do total). A média das notas atribuídas a esta prática foi 5,2.

\subsubsection{Práticas de gestão do conhecimento - Espaços e situações para socialização}

A Tabela 22 expõe a distribuição das respostas obtidas na pesquisa de campo quanto à pergunta 'A empresa dispõe de ESPAÇOS E SITUAÇÕES dedicadas à SOCIALIZAÇÃO dos conhecimentos'.

\begin{tabular}{|c|c|c|}
\hline \multicolumn{3}{|c|}{ Tabela 22 - Prática 'espaços e situações para socialização } \\
\hline Nota atribuída & Frequência & Percentual \\
\hline 0 & 0 & $0,0 \%$ \\
\hline 1 & 0 & $0,0 \%$ \\
\hline 2 & 7 & $2,2 \%$ \\
\hline 3 & 4 & $1,2 \%$ \\
\hline 4 & 50 & $15,7 \%$ \\
\hline 5 & 69 & $21,6 \%$ \\
\hline 6 & 95 & $29,8 \%$ \\
\hline 7 & 55 & $17,3 \%$ \\
\hline 8 & 32 & $10,0 \%$ \\
\hline 9 & 1 & $0,3 \%$ \\
\hline 10 & 6 & $1,9 \%$ \\
\hline Total & 319 & $100,0 \%$ \\
\hline
\end{tabular}

Quase $1 / 3$ das respostas indicou a nota 6 , com $29,8 \%$ de indicações. Outro ponto a ressaltar foi a baixa frequência das notas dos intervalos 0 a 3, bem como 9 a 10 . 
A nota mais atribuída pelos respondentes para a prática 'espaços e situações' foi a nota 6 , com 95 indicações (29,8\% do total). A média das notas atribuídas a esta prática foi 5,8.

\subsubsection{Práticas de gestão do conhecimento - Mapeamento de competências}

A Tabela 23 expõe a distribuição das respostas obtidas na pesquisa de campo quanto à pergunta 'A empresa faz o MAPEAMENTO DE COMPETÊNCIAS'.

$\begin{array}{crr}\text { Tabela } 23 \text { - Prática 'mapeamento de competências' } \\ \text { Nota atribuída } & \text { Frequência } & \text { Percentual } \\ 0 & 3 & 0,9 \% \\ 1 & 0 & 0,0 \% \\ 2 & 3 & 0,9 \% \\ 3 & 2 & 0,6 \% \\ 4 & 49 & 15,4 \% \\ 5 & 87 & 27,3 \% \\ 6 & 90 & 28,2 \% \\ 7 & 43 & 13,5 \% \\ 8 & 39 & 12,3 \% \\ 9 & 1 & 0,3 \% \\ 10 & 2 & 0,6 \% \\ \text { Total } & 319 & 100,0 \%\end{array}$

Os respondentes, em sua maioria, optaram pelas notas 5 e 6 , praticamente em idêntica proporção. Tais escolhas juntas somam 55,5\% das respostas coletadas.

A nota mais atribuída pelos respondentes para a prática 'mapeamento de competências' foi a nota 6 , com 90 indicações $(28,2 \%$ do total). A média das notas atribuídas a esta prática foi 5,7 .

\subsubsection{Práticas de gestão do conhecimento - Mapeamento de conhecimentos}

A Tabela 24 expõe a distribuição das respostas obtidas na pesquisa de campo quanto à pergunta 'A empresa faz o MAPEAMENTO DE CONHECIMENTOS'. 
Tabela 24 - Prática 'mapeamento de conhecimentos' Nota atribuída Frequência Percentual

$\begin{array}{crr}0 & 2 & 0,6 \% \\ 1 & 1 & 0,3 \% \\ 2 & 2 & 0,6 \% \\ 3 & 3 & 0,9 \% \\ 4 & 48 & 15,1 \% \\ 5 & 90 & 28,2 \% \\ 6 & 88 & 27,6 \% \\ 7 & 29 & 9,2 \% \\ 8 & 51 & 16,0 \% \\ 9 & 3 & 0,9 \% \\ 10 & 2 & 0,6 \% \\ & 319 & 100,0 \%\end{array}$

As respostas coletadas apresentaram uma forte concentração nas notas 5 e 6 , com incidências muito próximas entre si e somando $55,8 \%$ da preferência dos respondentes.

A nota mais atribuída pelos respondentes para a prática 'mapeamento de conhecimentos' foi a nota 5 , com 90 indicações $(28,2 \%$ do total). A média das notas atribuídas a esta prática foi 5,8 .

\subsubsection{Práticas de gestão do conhecimento - Planos de Carreira}

A Tabela 25 expõe a distribuição das respostas obtidas na pesquisa de campo quanto à pergunta 'A empresa tem PLANOS DE CARREIRA voltados ao desenvolvimento da gestão do conhecimento'.

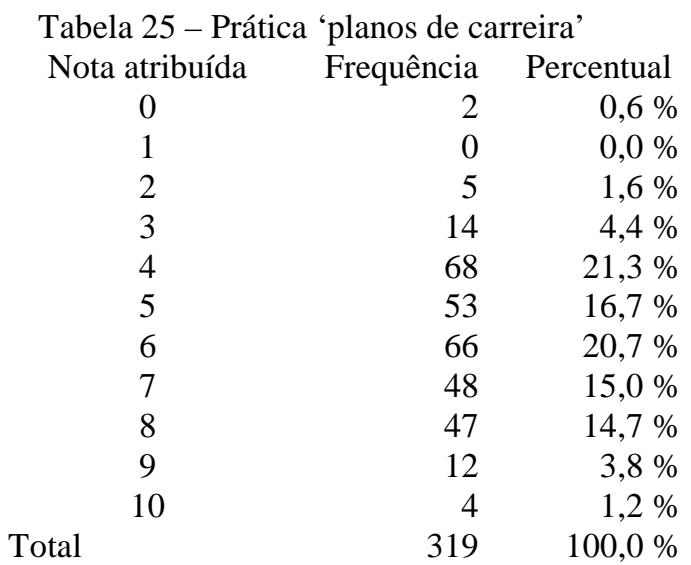

As notas 4, 5 e 6 foram as mais indicadas pelos respondentes, computando ao todo $58,7 \%$ das respostas verificadas na pesquisa. 
A nota mais atribuída pelos respondentes para a prática 'planos de carreira' foi a nota 4 , com 68 indicações (21,3\% do total). A média das notas atribuídas a esta prática foi 5,8.

\subsubsection{Práticas de gestão do conhecimento - Sistema de reconhecimento e recompensa}

A Tabela 26 expõe a distribuição das respostas obtidas na pesquisa de campo quanto à pergunta 'A empresa tem um SISTEMA DE RECONHECIMENTO E RECOMPENSA por gestão do conhecimento'.

$\begin{array}{crc}\text { Tabela } 26 \text { - Prática 'sistema de reconhecimento e recompensa' } \\ \text { Nota atribuída } & \text { Frequência } & \text { Percentual } \\ 0 & 8 & 2,4 \% \\ 1 & 0 & 0,0 \% \\ 2 & 11 & 3,4 \% \\ 3 & 10 & 3,1 \% \\ 4 & 60 & 18,8 \% \\ 5 & 88 & 27,6 \% \\ 6 & 66 & 20,7 \% \\ 7 & 23 & 7,3 \% \\ 8 & 31 & 9,8 \% \\ 9 & 3 & 0,9 \% \\ 10 & 19 & 6,0 \% \\ \text { Total } & 319 & 100,0 \%\end{array}$

27,6\% dos pesquisados apontaram a nota 5 para esta prática de gestão do conhecimento, que ainda apresentou índices também elevados para a nota $6(20,7 \%)$ e para a nota $4(18,8 \%)$.

A nota mais atribuída pelos respondentes para a prática 'sistema de reconhecimento e recompensa' foi a nota 5 , com 88 indicações (27,6\% do total). A média das notas atribuídas a esta prática foi 5,5 .

\subsubsection{Práticas de gestão do conhecimento - Coaching}

A Tabela 27 expõe a distribuição das respostas obtidas na pesquisa de campo quanto à pergunta 'A empresa desenvolve ações de COACHING (tutoria no desenvolvimento de competências) para formação de líderes voltados à gestão do conhecimento'. 


\begin{tabular}{|c|c|c|}
\hline \multicolumn{3}{|c|}{ Tabela 27 - Prática 'Coaching' } \\
\hline Nota atribuída & Frequência & Percentual \\
\hline 0 & 27 & $8,5 \%$ \\
\hline 1 & 3 & $0,9 \%$ \\
\hline 2 & 25 & $7,9 \%$ \\
\hline 3 & 44 & $13,8 \%$ \\
\hline 4 & 72 & $22,6 \%$ \\
\hline 5 & 90 & $28,2 \%$ \\
\hline 6 & 40 & $12,5 \%$ \\
\hline 7 & 10 & $3,1 \%$ \\
\hline 8 & 7 & $2,2 \%$ \\
\hline 9 & 1 & $0,3 \%$ \\
\hline 10 & 0 & $0,0 \%$ \\
\hline tal & 319 & $100,0 \%$ \\
\hline
\end{tabular}

Observa-se nesta prática que as notas do intervalo entre zero e 5 concentram $80,9 \%$ das respostas dadas, evidenciando a baixa ocorrência do coaching para a gestão do conhecimento dentre os empregados das empresas pesquisadas.

A nota mais atribuída pelos respondentes para a prática 'coaching' foi a nota 5, com 90 indicações (28,2\% do total). A média das notas atribuídas a esta prática foi 4,1.

\subsubsection{Práticas de gestão do conhecimento - Mentoring}

A Tabela 28 expõe a distribuição das respostas obtidas na pesquisa de campo quanto à pergunta 'A empresa desenvolve ações de MENTORING (tutoria no desenvolvimento da carreira) para a formação de líderes voltados à gestão do conhecimento’'

\begin{tabular}{|c|c|c|}
\hline \multicolumn{3}{|c|}{ Tabela 28 - Prática 'mentoring' } \\
\hline Nota atribuída & Frequência & Percentual \\
\hline 0 & 41 & $12,9 \%$ \\
\hline 1 & 2 & $0,6 \%$ \\
\hline 2 & 43 & $13,5 \%$ \\
\hline 3 & 25 & $7,8 \%$ \\
\hline 4 & 81 & $25,4 \%$ \\
\hline 5 & 68 & $21,3 \%$ \\
\hline 6 & 39 & $12,3 \%$ \\
\hline 7 & 9 & $2,8 \%$ \\
\hline 8 & 11 & $3,4 \%$ \\
\hline 9 & 0 & $0,0 \%$ \\
\hline 10 & 0 & $0,0 \%$ \\
\hline tal & 319 & $100,0 \%$ \\
\hline
\end{tabular}


Novamente observa-se também nesta prática que as notas do intervalo entre zero e 5 concentram $81,6 \%$ das respostas dadas, evidenciando a baixa ocorrência do mentoring para a gestão do conhecimento dentre os empregados das empresas pesquisadas.

A nota mais atribuída pelos respondentes para a prática 'mentoring' foi a nota 4, com 81 indicações (25,4\% do total). A média das notas atribuídas a esta prática foi 3,8.

\subsubsection{Práticas de gestão do conhecimento - Repositório de lições aprendidas}

A Tabela 29 expõe a distribuição das respostas obtidas na pesquisa de campo quanto à pergunta 'A empresa tem um REPOSITÓRIO DE LIÇÕES APRENDIDAS'.

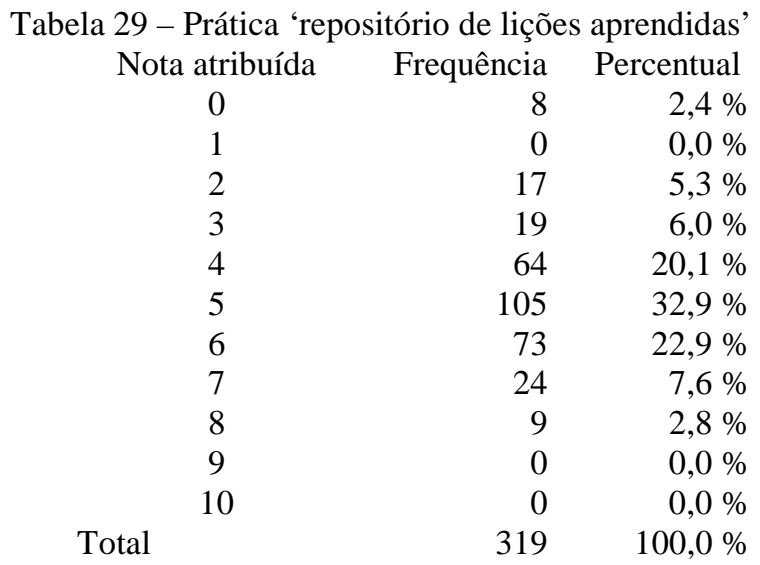

As notas 4, 5 e 6 foram as mais selecionadas pelos respondentes, com 75,9\% de ocorrência, destacando-se de forma mais incisiva a nota 5 , que representa praticamente $1 / 3$ do total de respostas.

A nota mais atribuída pelos respondentes para a prática 'repositório de lições aprendidas' foi a nota 5, com 105 indicações (32,9\% do total). A média das notas atribuídas a esta prática foi 4,6 . 


\subsubsection{Práticas de gestão do conhecimento - Repositório de melhores práticas}

A Tabela 30 expõe a distribuição das respostas obtidas na pesquisa de campo quanto à pergunta 'A empresa tem um REPOSITÓRIO DE MELHORES PRÁTICAS'.

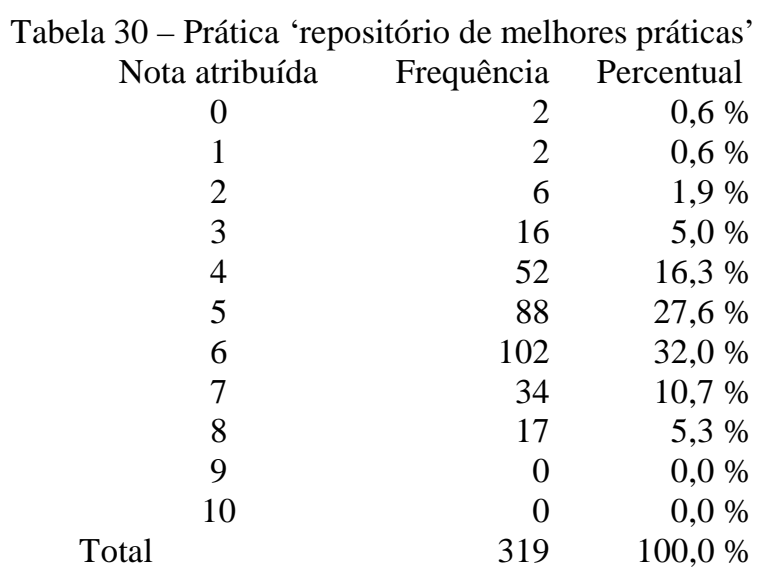

Com $59,6 \%$ das respostas, as notas $5(27,6 \%)$ e $6(32,0 \%)$ foram as mais representativas dentre os respondentes da pesquisa.

A nota mais atribuída pelos respondentes para a prática 'repositório de melhores práticas' foi a nota 6 , com 102 indicações (32,0\% do total). A média das notas atribuídas a esta prática foi 5,3 .

\subsubsection{Práticas de gestão do conhecimento - Comunidades de prática}

A Tabela 31 expõe a distribuição das respostas obtidas na pesquisa de campo quanto à pergunta 'A empresa dispõe de COMUNIDADES DE PRÁTICA (grupos para trocas de experiências práticas)'. 


\begin{tabular}{|c|c|c|}
\hline Nota atribuída & Frequência & Percentual \\
\hline 0 & 2 & $0,6 \%$ \\
\hline 1 & 1 & $0,3 \%$ \\
\hline 2 & 7 & $2,2 \%$ \\
\hline 3 & 10 & $3,1 \%$ \\
\hline 4 & 63 & $19,7 \%$ \\
\hline 5 & 104 & $32,6 \%$ \\
\hline 6 & 73 & $22,9 \%$ \\
\hline 7 & 34 & $10,8 \%$ \\
\hline 8 & 25 & $7,8 \%$ \\
\hline 9 & 0 & $0,0 \%$ \\
\hline 10 & 0 & $0,0 \%$ \\
\hline Total & 319 & $100,0 \%$ \\
\hline
\end{tabular}

Com 32,6\% das indicações, a nota 5 expõe a maior preferência dos respondentes pesquisados. Também foram bem indicadas as notas $6(22,9 \%)$ e $4(19,7 \%)$.

A nota mais atribuída pelos respondentes para a prática 'comunidades de prática' foi a nota 5, com 104 indicações (32,6\% do total). A média das notas atribuídas a esta prática foi 5,3.

\subsubsection{Práticas de gestão do conhecimento - Educação corporativa}

A Tabela 32 expõe a distribuição das respostas obtidas na pesquisa de campo quanto à pergunta 'A empresa conta com ações de EDUCAÇÃO CORPORATIVA'.

\begin{tabular}{|c|c|c|}
\hline Nota atribuída & Frequência & Percentual \\
\hline 0 & 6 & $1,9 \%$ \\
\hline 1 & 1 & $0,3 \%$ \\
\hline 2 & 19 & $6,0 \%$ \\
\hline 3 & 21 & $6,6 \%$ \\
\hline 4 & 79 & $24,8 \%$ \\
\hline 5 & 75 & $23,5 \%$ \\
\hline 6 & 69 & $21,6 \%$ \\
\hline 7 & 25 & $7,8 \%$ \\
\hline 8 & 20 & $6,2 \%$ \\
\hline 9 & 1 & $0,3 \%$ \\
\hline 10 & 3 & $0,9 \%$ \\
\hline $\mathrm{al}$ & 319 & $100,0^{\circ}$ \\
\hline
\end{tabular}

Nesta prática há uma concentração evidenciada nas notas 4, 5 e 6 que juntas respondem por mais de $2 / 3$ das respostas $(69,9 \%)$. 
A nota mais atribuída pelos respondentes para a prática 'educação corporativa' foi a nota 4, com 79 indicações $(24,8 \%$ do total). A média das notas atribuídas a esta prática foi 4,9.

\subsubsection{Práticas de gestão do conhecimento - Treinamentos presenciais}

A Tabela 33 expõe a distribuição das respostas obtidas na pesquisa de campo quanto à pergunta 'A empresa disponibiliza TREINAMENTOS PRESENCIAIS com instrutores'.

\begin{tabular}{|c|c|c|}
\hline Nota atribuída & Frequência & Percentual \\
\hline 0 & 0 & $0,0 \%$ \\
\hline 1 & 0 & $0,0 \%$ \\
\hline 2 & 1 & $0,3 \%$ \\
\hline 3 & 3 & $0,9 \%$ \\
\hline 4 & 28 & $8,8 \%$ \\
\hline 5 & 49 & $15,4 \%$ \\
\hline 6 & 63 & $19,7 \%$ \\
\hline 7 & 54 & $16,9 \%$ \\
\hline 8 & 87 & $27,3 \%$ \\
\hline 9 & 9 & $2,8 \%$ \\
\hline 10 & 25 & $7,9 \%$ \\
\hline Total & 319 & $100,0 \%$ \\
\hline
\end{tabular}

A prática de treinamento presencial obteve dos respondentes da pesquisa uma concentração entre as notas 6,7 e 8 , num total de $63,9 \%$ neste intervalo. A maior incidência ficou para a nota $8 \operatorname{com} 27,3 \%$.

A nota mais atribuída pelos respondentes para a prática 'treinamentos presenciais' foi a nota 8, com 87 indicações (27,3\% do total). A média das notas atribuídas a esta prática foi 6,7 .

\subsubsection{Práticas de gestão do conhecimento - Multiplicadores}

A Tabela 34 expõe a distribuição das respostas obtidas na pesquisa de campo quanto à pergunta 'A empresa conta com MULTIPLICADORES de conhecimentos'. 
Tabela 34 - Prática 'multiplicadores'

\begin{tabular}{|c|c|c|}
\hline Nota atribuída & Frequência & Percentual \\
\hline 0 & 0 & $0,0 \%$ \\
\hline 1 & 1 & $0,3 \%$ \\
\hline 2 & 5 & $1,6 \%$ \\
\hline 3 & 18 & $5,6 \%$ \\
\hline 4 & 42 & $13,2 \%$ \\
\hline 5 & 77 & $24,1 \%$ \\
\hline 6 & 88 & $27,6 \%$ \\
\hline 7 & 34 & $10,7 \%$ \\
\hline 8 & 46 & $14,4 \%$ \\
\hline 9 & 2 & $0,6 \%$ \\
\hline 10 & 6 & $1,9 \%$ \\
\hline t & 319 & $100,0 \%$ \\
\hline
\end{tabular}

A prática de multiplicadores de conhecimentos foi indicada com notas 5 ou 6 por $41,7 \%$ dos sujeitos pesquisados.

A nota mais atribuída pelos respondentes para a prática 'multiplicadores' foi a nota 6 , com 88 indicações (27,6\% do total). A média das notas atribuídas a esta prática foi 5,7.

\subsubsection{Práticas de gestão do conhecimento - Story telling}

A Tabela 35 expõe a distribuição das respostas obtidas na pesquisa de campo quanto à pergunta 'A empresa dispõe de STORY TELLING (reprodução de histórias)'.

\begin{tabular}{crr}
\multicolumn{3}{c}{ Tabela 35 - Prática 'story telling' } \\
Nota atribuída & Frequência & Percentual \\
0 & 18 & $5,6 \%$ \\
1 & 1 & $0,3 \%$ \\
2 & 23 & $7,2 \%$ \\
3 & 24 & $7,5 \%$ \\
4 & 72 & $22,6 \%$ \\
5 & 70 & $21,9 \%$ \\
6 & 51 & $16,0 \%$ \\
7 & 27 & $8,5 \%$ \\
8 & 21 & $6,6 \%$ \\
9 & 4 & $1,3 \%$ \\
10 & 8 & $2,5 \%$ \\
Total & 319 & $100,0 \%$
\end{tabular}

As notas 4 e 5 foram as mais indicadas pelos respondentes em relação à prática story telling, totalizando $44,5 \%$ das repostas. 
A nota mais atribuída pelos respondentes para a prática 'story telling' foi a nota 4, com 72 indicações (22,6\% do total). A média das notas atribuídas a esta prática foi 4,8.

\subsubsection{Práticas de gestão do conhecimento - Mapeamento de processos}

A Tabela 36 expõe a distribuição das respostas obtidas na pesquisa de campo quanto à pergunta 'A empresa efetua o MAPEAMENTO DE PROCESSOS ligados à gestão do conhecimento'.

$\begin{array}{crr}\text { Tabela } 36 \text { - Prática 'mapeamento de processos' } \\ \text { Nota atribuída } & \text { Frequência } & \text { Percentual } \\ 0 & 1 & 0,3 \% \\ 1 & 0 & 0,0 \% \\ 2 & 5 & 1,6 \% \\ 3 & 10 & 3,1 \% \\ 4 & 37 & 11,6 \% \\ 5 & 72 & 22,6 \% \\ 6 & 84 & 26,3 \% \\ 7 & 57 & 17,9 \% \\ 8 & 47 & 14,8 \% \\ 9 & 3 & 0,9 \% \\ 10 & 3 & 0,9 \% \\ \text { Total } & 319 & 100,0 \%\end{array}$

O intervalo entre as notas 5 e 8 obteve $81,6 \%$ das respostas, com predominância da nota 6 com $26,3 \%$.

A nota mais atribuída pelos respondentes para a prática 'mapeamento de processos' foi a nota 6, com 84 indicações (26,3\% do total). A média das notas atribuídas a esta prática foi 5,9.

\subsubsection{Práticas de gestão do conhecimento - Sistema de avaliação}

A Tabela 37 expõe a distribuição das respostas obtidas na pesquisa de campo quanto à pergunta 'A empresa tem um SISTEMA DE AVALIAÇÃO de processos ligados à gestão de conhecimento'. 


\begin{tabular}{|c|c|c|}
\hline \multicolumn{3}{|c|}{ Tabela 37 - Prática 'sistema de avaliação' } \\
\hline Nota atribuída & Frequência & Percentual \\
\hline 0 & 1 & $0,3 \%$ \\
\hline 1 & 2 & $0,6 \%$ \\
\hline 2 & 4 & $1,2 \%$ \\
\hline 3 & 7 & $2,2 \%$ \\
\hline 4 & 36 & $11,3 \%$ \\
\hline 5 & 30 & $9,4 \%$ \\
\hline 6 & 86 & $27,0 \%$ \\
\hline 7 & 65 & $20,4 \%$ \\
\hline 8 & 63 & $19,8 \%$ \\
\hline 9 & 2 & $0,6 \%$ \\
\hline 10 & 23 & $7,2 \%$ \\
\hline Total & 319 & $100,0 \%$ \\
\hline
\end{tabular}

2/3 dos respondentes da pesquisa indicaram notas 6,7 ou 8 para a prática sistema de avaliação.

A nota mais atribuída pelos respondentes para a prática 'sistema de avaliação' foi a nota 6, com 86 indicações $(27,0 \%$ do total). A média das notas atribuídas a esta prática foi 6,5 .

\subsubsection{Práticas de gestão do conhecimento - Patentes}

A Tabela 38 expõe a distribuição das respostas obtidas na pesquisa de campo quanto à pergunta 'A empresa tem PATENTES oriundas da gestão do conhecimento'.

\begin{tabular}{|c|c|c|}
\hline \multicolumn{3}{|c|}{ Tabela 38 - Prática 'patentes' } \\
\hline Nota atribuída & Frequência & Percentual \\
\hline 0 & 0 & $0,0 \%$ \\
\hline 1 & 0 & $0,0 \%$ \\
\hline 2 & 6 & $1,9 \%$ \\
\hline 3 & 14 & $4,4 \%$ \\
\hline 4 & 75 & $23,5 \%$ \\
\hline 5 & 68 & $21,3 \%$ \\
\hline 6 & 73 & $22,9 \%$ \\
\hline 7 & 40 & $12,5 \%$ \\
\hline 8 & 37 & $11,6 \%$ \\
\hline 9 & 1 & $0,3 \%$ \\
\hline 10 & 5 & $1,6 \%$ \\
\hline tal & 319 & $100,0 \%$ \\
\hline
\end{tabular}

Há uma equivalência de respostas entre as notas 4, 5 e 6, indicando nesse intervalo um montante de $67,7 \%$ das respostas obtidas na pesquisa 
A nota mais atribuída pelos respondentes para a prática 'patentes' foi a nota 6 , com 73 indicações (22,9\% do total). A média das notas atribuídas a esta prática foi 5,5.

\subsubsection{Práticas de gestão do conhecimento - Propriedade intelectual}

A Tabela 39 expõe a distribuição das respostas obtidas na pesquisa de campo quanto à pergunta 'A empresa tem PROPRIEDADE INTELECTUAL oriunda da gestão do conhecimento'.

\begin{tabular}{|c|c|c|}
\hline \multicolumn{3}{|c|}{39 - Prática 'propriedade intelectual' } \\
\hline Nota atribuída & Frequência & Percentual \\
\hline 0 & 0 & $0,0 \%$ \\
\hline 1 & 0 & $0,0 \%$ \\
\hline 2 & 12 & $3,8 \%$ \\
\hline 3 & 1 & $0,3 \%$ \\
\hline 4 & 52 & $16,3 \%$ \\
\hline 5 & 81 & $25,4 \%$ \\
\hline 6 & 95 & $29,8 \%$ \\
\hline 7 & 39 & $12,1 \%$ \\
\hline 8 & 32 & $10,0 \%$ \\
\hline 9 & 1 & $0,3 \%$ \\
\hline 10 & 6 & $1,9 \%$ \\
\hline Total & 319 & $100,0 \%$ \\
\hline
\end{tabular}

Mais da metade dos sujeitos pesquisados $(55,2 \%)$ indicaram as notas 5 ou 6 para a prática propriedade intelectual.

A nota mais atribuída pelos respondentes para a prática 'propriedade intelectual' foi a nota 6 , com 95 indicações (29,8\% do total). A média das notas atribuídas a esta prática foi 5,7.

\subsubsection{Práticas de gestão do conhecimento - Banco de conhecimentos}

A Tabela 40 expõe a distribuição das respostas obtidas na pesquisa de campo quanto à pergunta 'A empresa tem um BANCO DE CONHECIMENTOS'. 


$\begin{array}{crr}\text { Tabela } 40 \text { - Prática 'banco de conhecimentos' } \\ \text { Nota atribuída } & \text { Frequência } & \text { Percentual } \\ 0 & 0 & 0,0 \% \\ 1 & 0 & 0,0 \% \\ 2 & 3 & 0,9 \% \\ 3 & 14 & 4,4 \% \\ 4 & 58 & 18,2 \% \\ 5 & 57 & 17,9 \% \\ 6 & 88 & 27,6 \% \\ 7 & 49 & 15,4 \% \\ 8 & 46 & 14,4 \% \\ 9 & 2 & 0,6 \% \\ 10 & 2 & 0,6 \% \\ \text { Total } & 319 & 100,0 \%\end{array}$

Para a prática banco de conhecimentos, os sujeitos da pesquisa concentraram suas respostas nas notas do intervalo entre 4 e 6 , com $63,6 \%$ das respostas.

A nota mais atribuída pelos respondentes para a prática 'banco de conhecimentos' foi a nota 6, com 88 indicações (27,6\% do total). A média das notas atribuídas a esta prática foi 5,8.

\subsubsection{Práticas de gestão do conhecimento - Gestão de conteúdos}

A Tabela 41 expõe a distribuição das respostas obtidas na pesquisa de campo quanto à pergunta 'A empresa faz a GESTÃO DE CONTEÚDOS'.

\begin{tabular}{|c|c|c|}
\hline Nota atribuída & Frequência & Percentual \\
\hline 0 & 0 & $0,0 \%$ \\
\hline 1 & 0 & $0,0 \%$ \\
\hline 2 & 12 & $3,8 \%$ \\
\hline 3 & 8 & $2,5 \%$ \\
\hline 4 & 56 & $17,6 \%$ \\
\hline 5 & 60 & $18,8 \%$ \\
\hline 6 & 69 & $21,6 \%$ \\
\hline 7 & 68 & $21,3 \%$ \\
\hline 8 & 42 & $13,2 \%$ \\
\hline 9 & 1 & $0,3 \%$ \\
\hline 10 & 3 & $0,9 \%$ \\
\hline Total & 319 & $100,0 \%$ \\
\hline
\end{tabular}

As notas 4, 56 e 7 obtiveram uma distribuição próxima, totalizando 79,3\% das respostas coletadas na pesquisa de campo 
A nota mais atribuída pelos respondentes para a prática 'gestão de conteúdos' foi a nota 6 , com 69 indicações (21,7\% do total). A média das notas atribuídas a esta prática foi 5,7.

\subsubsection{Práticas de gestão do conhecimento - Busca de conhecimentos}

A Tabela 42 expõe a distribuição das respostas obtidas na pesquisa de campo quanto à pergunta 'A empresa tem aplicações específicas para BUSCA DE CONHECIMENTOS'.

\begin{tabular}{|c|c|c|}
\hline Tabela 42 - Prática & usca de conhe & imentos' \\
\hline Nota atribuída & Frequência & Percentual \\
\hline 0 & 2 & $0,6 \%$ \\
\hline 1 & 0 & $0,0 \%$ \\
\hline 2 & 1 & $0,3 \%$ \\
\hline 3 & 15 & $4,7 \%$ \\
\hline 4 & 56 & $17,6 \%$ \\
\hline 5 & 80 & $25,1 \%$ \\
\hline 6 & 59 & $18,5 \%$ \\
\hline 7 & 47 & $14,7 \%$ \\
\hline 8 & 56 & $17,6 \%$ \\
\hline 9 & 3 & $0,9 \%$ \\
\hline 10 & 0 & $0,0 \%$ \\
\hline Total & 319 & $100,0 \%$ \\
\hline
\end{tabular}

Verifica-se uma distribuição entre as notas do intervalo de 4 a 8, com predominância da nota $5(25,1 \%)$.

A nota mais atribuída pelos respondentes para a prática 'busca de conhecimentos' foi a nota 5, com 80 indicações $(25,1 \%$ do total). A média das notas atribuídas a esta prática foi $5,7$.

\subsubsection{Práticas de gestão do conhecimento - Inteligência competitiva}

A Tabela 43 expõe a distribuição das respostas obtidas na pesquisa de campo quanto à pergunta 'A empresa desenvolve ações de INTELIGÊNCIA COMPETITIVA'. 
Tabela 43 - Prática 'inteligência competitiva'

\begin{tabular}{|c|c|c|}
\hline Nota atribuída & Frequência & Percentual \\
\hline 0 & 1 & $0,3 \%$ \\
\hline 1 & 1 & $0,3 \%$ \\
\hline 2 & 2 & $0,6 \%$ \\
\hline 3 & 7 & $2,2 \%$ \\
\hline 4 & 61 & $19,2 \%$ \\
\hline 5 & 89 & $27,9 \%$ \\
\hline 6 & 75 & 23,5 \\
\hline 7 & 49 & $15,4 \%$ \\
\hline 8 & 30 & $9,4 \%$ \\
\hline 9 & 2 & 0,6 \\
\hline 10 & 2 & $0,6 \%$ \\
\hline tal & 319 & 100,0 \\
\hline
\end{tabular}

As notas 5 e 6 foram as mais indicadas pelos respondentes para a prática inteligência competitiva, totalizando $51,4 \%$ das respostas.

A nota mais atribuída pelos respondentes para a prática 'inteligência competitiva' foi a nota 5, com 89 indicações (27,9\% do total). A média das notas atribuídas a esta prática foi 5,6.

\subsubsection{Práticas de gestão do conhecimento - Business inteligence}

A Tabela 44 expõe a distribuição das respostas obtidas na pesquisa de campo quanto à pergunta 'A empresa desenvolve ações de BI - BUSINESS INTELIGENCE (inteligência de negócios)'.

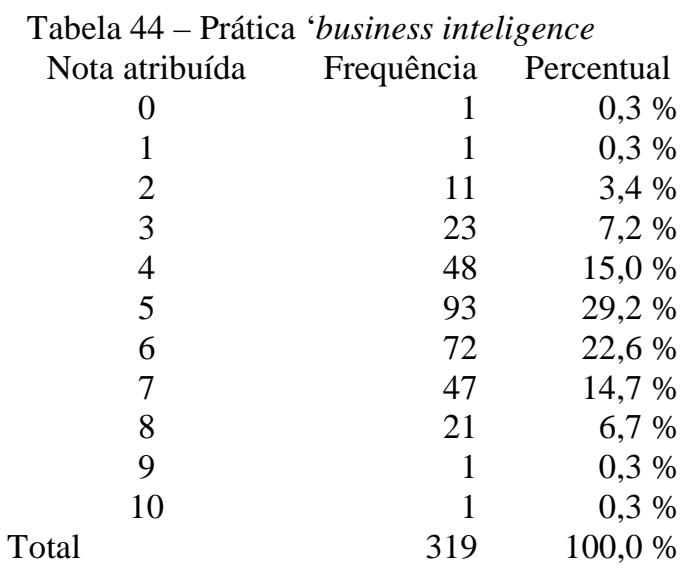

Pouco mais da metade dos pesquisados $(51,7 \%)$ apontaram nota 5 ou 6 para a prática business inteligence. 
A nota mais atribuída pelos respondentes para a prática 'business inteligence' foi a nota 5, com 93 indicações (29,2\% do total). A média das notas atribuídas a esta prática foi 5,3.

\subsubsection{Práticas de gestão do conhecimento - Wikis, blogs, twitters}

A Tabela 45 expõe a distribuição das respostas obtidas na pesquisa de campo quanto à pergunta 'A empresa dispõe de WIKIS internas (enciclopédias virtuais), BLOGS internos (diários virtuais) ou TWITTERS internos (página de publicação de notícias)'.

$\begin{array}{crr}\text { Tabela } 45 \text { - Prática 'wikis, blogs, twitters' } \\ \text { Nota atribuída } & \text { Frequência } & \text { Percentual } \\ 0 & 15 & 4,7 \% \\ 1 & 0 & 0,0 \% \\ 2 & 14 & 4,4 \% \\ 3 & 23 & 7,2 \% \\ 4 & 62 & 19,4 \% \\ 5 & 77 & 24,1 \% \\ 6 & 69 & 21,7 \% \\ 7 & 38 & 11,9 \% \\ 8 & 20 & 6,3 \% \\ 9 & 0 & 0,0 \% \\ 10 & 1 & 0,3 \% \\ \text { Total } & 319 & 100,0 \%\end{array}$

Pouco menos de $2 / 3(65,2 \%)$ das respostas concentraram-se entre as notas 4 e 6 , com predominância da nota 5 .

A nota mais atribuída pelos respondentes para a prática 'wikis, blogs, twitters' foi a nota 5, com 77 indicações $(24,1 \%$ do total). A média das notas atribuídas a esta prática foi 4,9.

\subsubsection{Práticas de gestão do conhecimento - Páginas amarelas internas}

A Tabela 46 expõe a distribuição das respostas obtidas na pesquisa de campo quanto à pergunta 'A empresa dispõe de PÁGINAS AMARELAS INTERNAS'. 
Tabela 46 - Prática 'páginas amarelas internas'

Nota atribuída Frequência Percentual

$\begin{array}{ccrr}0 & 25 & 7,8 \% \\ 1 & 14 & 4,4 \% \\ 2 & 33 & 10,3 \% \\ 3 & 28 & 8,8 \% \\ 4 & 44 & 13,8 \% \\ 5 & 42 & 13,2 \% \\ 6 & 74 & 23,2 \% \\ 7 & 37 & 11,6 \% \\ & 8 & 20 & 6,3 \% \\ & 0 & 0,0 \% \\ \text { Total } & 10 & 2 & 0,6 \% \\ & & 319 & 100,0 \%\end{array}$

A prática páginas amarelas internas apresentou significativa dispersão em suas respostas. Mesmo assim, pode-se verificar uma pequena concentração entre as notas 4, 5 e 6 que juntas acumulam metade das respostas verificadas na pesquisa.

A nota mais atribuída pelos respondentes para a prática 'páginas amarelas internas' foi a nota 6, com 74 indicações (23,2\% do total). A média das notas atribuídas a esta prática foi 4,5.

\subsubsection{Práticas de gestão do conhecimento - Portal corporativo}

A Tabela 47 expõe a distribuição das respostas obtidas na pesquisa de campo quanto à pergunta 'A empresa dispõe de PORTAL CORPORATIVO de gestão do conhecimento'.

\begin{tabular}{|c|c|c|}
\hline \multicolumn{3}{|c|}{ Tabela 47 - Prática 'portal corporativo' } \\
\hline Nota atribuída & Frequência & Percentual \\
\hline 0 & 1 & $0,3 \%$ \\
\hline 1 & 0 & $0,0 \%$ \\
\hline 2 & 9 & $2,8 \%$ \\
\hline 3 & 6 & $1,9 \%$ \\
\hline 4 & 16 & $5,0 \%$ \\
\hline 5 & 42 & $13,2 \%$ \\
\hline 6 & 80 & $25,2 \%$ \\
\hline 7 & 48 & $15,0 \%$ \\
\hline 8 & 99 & $31,0 \%$ \\
\hline 9 & 3 & $0,9 \%$ \\
\hline 10 & 15 & $4,7 \%$ \\
\hline otal & 319 & $100,0 \%$ \\
\hline
\end{tabular}

As notas 6 e 8 foram as mais indicadas pelos sujeitos da pesquisa, com $25,2 \%$ e $31,0 \%$ das respostas, totalizando assim $56,1 \%$ das respostas verificadas. 
A nota mais atribuída pelos respondentes para a prática 'portal corporativo' foi a nota 8 , com 99 indicações (31,0\% do total). A média das notas atribuídas a esta prática foi 6,6.

\subsubsection{Práticas de gestão do conhecimento - Biblioteca corporativa/diretório de documentos}

A Tabela 48 expõe a distribuição das respostas obtidas na pesquisa de campo quanto à pergunta 'A empresa dispõe de BIBLIOTECA CORPORATIVA / REPOSITÓRIO DE DOCUMENTOS (físico ou eletrônico)'.

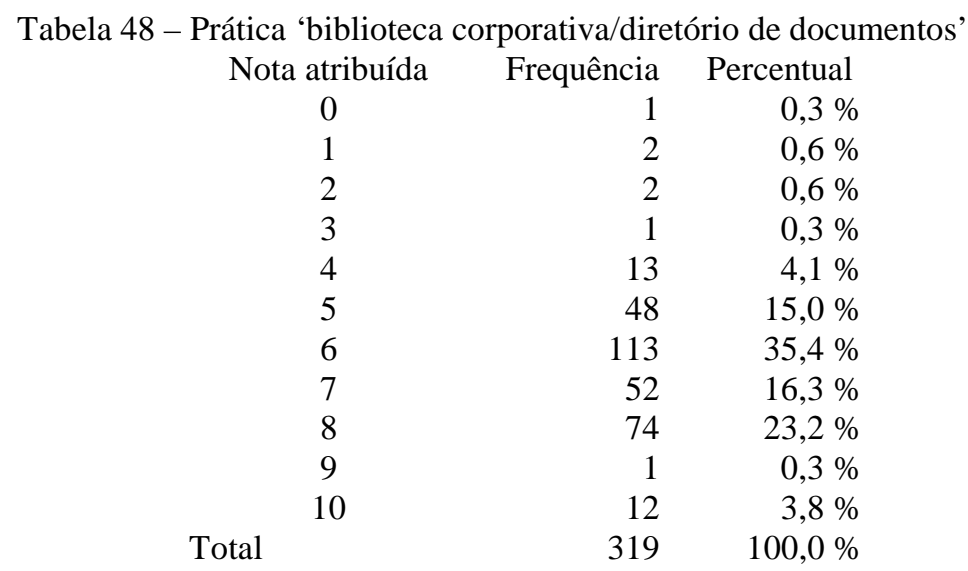

As notas $6(35,4 \%)$ e $8(23,2 \%)$ são as mais representativas a partir das respostas obtidas na pesquisa de campo.

A nota mais atribuída pelos respondentes para a prática 'biblioteca corporativa' foi a nota 6 , com 113 indicações (35,4\% do total). A média das notas atribuídas a esta prática foi 6,5.

\subsubsection{Práticas de gestão do conhecimento - Reuniões e conferências virtuais}

A Tabela 49 expõe a distribuição das respostas obtidas na pesquisa de campo quanto à pergunta 'A empresa efetua REUNIÕES e CONFERÊNCIAS VIRTUAIS'. 
Tabela 49 - Prática 'reuniões e conferências virtuais' Nota atribuída Frequência Percentual

$\begin{array}{rrrr} & 0 & 0 & 0,0 \% \\ & 1 & 0 & 0,0 \% \\ & 2 & 1 & 0,3 \% \\ 3 & 0 & 0,0 \% \\ & 4 & 6 & 1,9 \% \\ & 5 & 11 & 3,4 \% \\ & 6 & 49 & 15,4 \% \\ & 7 & 85 & 26,6 \% \\ & 8 & 107 & 33,6 \% \\ \text { Total } & 9 & 6 & 1,9 \% \\ & 10 & 54 & 16,9 \% \\ & & 319 & 100,0 \%\end{array}$

Verifica-se uma concentração nas notas 7 e 8 que juntas totalizam 60,2\% das respostas. Também é significativa a ocorrência da nota 10 com 16,9\% das respostas.

A nota mais atribuída pelos respondentes para a prática 'reuniões e conferências virtuais' foi a nota 8 , com 107 indicações (33,6\% do total). A média das notas atribuídas a esta prática foi 7,6 .

\subsubsection{Práticas de gestão do conhecimento - Treinamentos virtuais}

A Tabela 50 expõe a distribuição das respostas obtidas na pesquisa de campo quanto à pergunta 'A empresa efetua TREINAMENTOS VIRTUAIS com a presença de instrutores online'.

\begin{tabular}{|c|c|c|}
\hline \multicolumn{3}{|c|}{ Tabela 50 - Prática 'treinamentos virtuais' } \\
\hline Nota atribuída & Frequência & Percentual \\
\hline 0 & 0 & $0,0 \%$ \\
\hline 1 & 0 & $0,0 \%$ \\
\hline 2 & 2 & $0,6 \%$ \\
\hline 3 & 2 & $0,6 \%$ \\
\hline 4 & 14 & $4,4 \%$ \\
\hline 5 & 14 & $4,4 \%$ \\
\hline 6 & 57 & $17,9 \%$ \\
\hline 7 & 75 & $23,6 \%$ \\
\hline 8 & 99 & $31,0 \%$ \\
\hline 9 & 4 & $1,2 \%$ \\
\hline 10 & 52 & $16,3 \%$ \\
\hline Total & 319 & $100,0 \%$ \\
\hline
\end{tabular}

A nota 8 representa quase $1 / 3$ das respostas com $31,0 \%$. Merece destaque também a incidência de respostas que indicaram a nota 7 , com $23,6 \%$ de representatividade. 
A nota mais atribuída pelos respondentes para a prática 'treinamentos virtuais' foi a nota 8 , com 99 indicações (31,0\% do total). A média das notas atribuídas a esta prática foi 7,4.

\subsubsection{Práticas de gestão do conhecimento - E-learning}

A Tabela 51 expõe a distribuição das respostas obtidas na pesquisa de campo quanto à pergunta 'A empresa efetua ações de E-LEARNING (auto-treinamento sem a presença de instrutores)'.

\begin{tabular}{|c|c|c|}
\hline Nota atribuída & Frequência & Percentual \\
\hline 0 & 0 & $0,0 \%$ \\
\hline 1 & 0 & $0,0 \%$ \\
\hline 2 & 2 & $0,6 \%$ \\
\hline 3 & 8 & $2,5 \%$ \\
\hline 4 & 24 & $7,5 \%$ \\
\hline 5 & 35 & $11,0 \%$ \\
\hline 6 & 87 & $27,3 \%$ \\
\hline 7 & 75 & $23,5 \%$ \\
\hline 8 & 64 & $20,1 \%$ \\
\hline 9 & 0 & $0,0 \%$ \\
\hline 10 & 24 & $7,5 \%$ \\
\hline tal & 319 & $100,0 \%$ \\
\hline
\end{tabular}

A prática $e$-learning apresentou uma concentração entre as notas 6 a 8 que juntas representam $70,8 \%$ das respostas obtidas.

A nota mais atribuída pelos respondentes para a prática 'e-learning' foi a nota 6 com 87 indicações (27,3\% do total). A média das notas atribuídas a esta prática foi 6,6.

\subsubsection{Práticas de gestão do conhecimento - Universidade corporativa}

A Tabela 52 expõe a distribuição das respostas obtidas na pesquisa de campo quanto à pergunta 'A empresa tem UNIVERSIDADE CORPORATIVA'. 


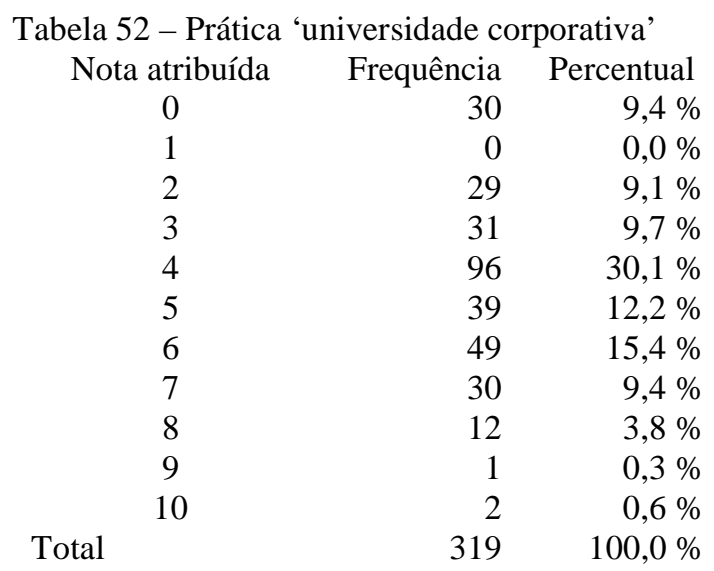

Percebe-se uma significativa concentração no intervalo de notas entre 4 e $6(57,7 \%)$, com ênfase maior para a nota 4 com $30,1 \%$ das respostas.

A nota mais atribuída pelos respondentes para a prática 'universidade corporativa' foi a nota 4 com 96 indicações (30,1\% do total). A média das notas atribuídas a esta prática foi 4,3.

\subsubsection{Práticas de gestão do conhecimento - Sumarização}

A Tabela 53 expõe a distribuição das respostas obtidas na pesquisa de campo quanto à pergunta 'A empresa efetua SUMARIZAÇÃO de conhecimentos'.

\begin{tabular}{|c|c|c|}
\hline \multicolumn{3}{|c|}{ Tabela 53 - Prática 'sumarização' } \\
\hline Nota atribuída & Frequência & Percentual \\
\hline 0 & 18 & $5,6 \%$ \\
\hline 1 & 2 & $0,6 \%$ \\
\hline 2 & 36 & $11,3 \%$ \\
\hline 3 & 47 & $14,8 \%$ \\
\hline 4 & 86 & $27,0 \%$ \\
\hline 5 & 52 & $16,3 \%$ \\
\hline 6 & 52 & $16,3 \%$ \\
\hline 7 & 16 & $5,0 \%$ \\
\hline 8 & 7 & $2,2 \%$ \\
\hline 9 & 3 & $0,9 \%$ \\
\hline 10 & 0 & $0,0 \%$ \\
\hline otal & 319 & $100,0 \%$ \\
\hline
\end{tabular}

A prática sumarização tem como nota mais incidente a nota 4 , com $27,0 \%$ das respostas. Em seguida aparecem também das notas 5 e 6, ambas com 16,3\% de respondentes. 
A nota mais atribuída pelos respondentes para a prática 'sumarização' foi a nota 4 com 86 indicações (27,0\% do total). A média das notas atribuídas a esta prática foi 4,2.

\subsubsection{Práticas de gestão do conhecimento - Inventários}

A Tabela 54 expõe a distribuição das respostas obtidas na pesquisa de campo quanto à pergunta 'A empresa efetua INVENTÁRIOS de conhecimentos'.

\begin{tabular}{|c|c|c|}
\hline \multicolumn{3}{|c|}{ Tabela 54 - Prática 'inventários' } \\
\hline Nota atribuída & Frequência & Percentual \\
\hline 0 & 13 & $4,1 \%$ \\
\hline 1 & 4 & $1,2 \%$ \\
\hline 2 & 42 & $13,2 \%$ \\
\hline 3 & 51 & $16,0 \%$ \\
\hline 4 & 81 & $25,4 \%$ \\
\hline 5 & 58 & $18,2 \%$ \\
\hline 6 & 43 & $13,5 \%$ \\
\hline 7 & 18 & $5,6 \%$ \\
\hline 8 & 8 & $2,5 \%$ \\
\hline 9 & 1 & $0,3 \%$ \\
\hline 10 & 0 & $0,0 \%$ \\
\hline Total & 319 & $100,0 \%$ \\
\hline
\end{tabular}

As notas 3, 4 e 5 respondem por mais da metade das opções registradas pelos sujeitos da pesquisa, com $60,2 \%$ do total.

A nota mais atribuída pelos respondentes para a prática 'inventários' foi a nota 4 com 81 indicações (25,4\% do total). A média das notas atribuídas a esta prática foi 4,2.

\subsubsection{Práticas de gestão do conhecimento - Ontologia/taxonomia}

A Tabela 55 expõe a distribuição das respostas obtidas na pesquisa de campo quanto à pergunta 'A empresa efetua a gestão de conteúdo dos conhecimentos - ONTOLOGIA (essência e natureza de cada conhecimento) ou TAXONOMIA (sistemática de classificação dos conhecimentos)'. 


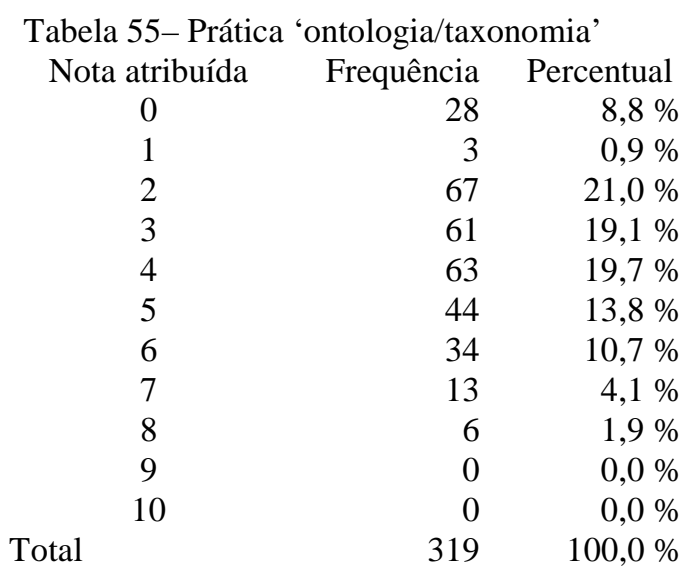

As notas 2, 3 e 4 expõem relativa equivalência, com leve preferência para a nota 2. Juntas, essas três notas perfazem $59,9 \%$ das respostas verificadas na pesquisa.

A nota mais atribuída pelos respondentes para a prática 'ontologia/taxonomia' foi a nota 2 com 67 indicações (21,0\% do total). A média das notas atribuídas a esta prática foi 3,6.

\subsubsection{Principais resultados verificados nas práticas de gestão de conhecimento}

Os principais resultados da pesquisa de campo quanto às práticas de gestão de conhecimento verificadas nas empresas analisadas estão consolidados na Tabela 56. Nela é possível observar, para cada prática de gestão do conhecimento pesquisada, a nota mais indicada pelos respondentes, sua frequência e respectivo percentual, bem como a nota média da prática em questão. 
Tabela 56 - Resumo dos principais resultados verificados acerca das práticas de gestão do conhecimento Práticas de gestão do conhecimento Nota mais Frequência Percentual da Nota

\begin{tabular}{|c|c|c|c|c|}
\hline & indicada & $\begin{array}{l}\text { da nota mais } \\
\text { indicada }\end{array}$ & $\begin{array}{c}\text { nota mais } \\
\text { indicada }\end{array}$ & média \\
\hline PA01. Estratégia declarada & 6 & 71 & $22,3 \%$ & 5,24 \\
\hline PA02. Políticas declaradas & 5 & 82 & $25,8 \%$ & 5,27 \\
\hline PA03. Gestão da inovação & 6 & 82 & $25,8 \%$ & 5,85 \\
\hline PA04. Gestão por competências & 5 & 71 & $22,3 \%$ & 5,22 \\
\hline PA05. Comunicação corporativa & 5 & 79 & $24,8 \%$ & 5,75 \\
\hline PA06. Benchmarking & 5 & 80 & $25,1 \%$ & 5,66 \\
\hline PB07. Centros de inovação & 6 & 106 & $33,2 \%$ & 5,97 \\
\hline PB08. Call center/help desk/suporte & 7 e 8 & 68 cada & $21,3 \%$ cada & 6,57 \\
\hline PB09. CKO/CKM & 4 & 73 & $22,9 \%$ & 4,75 \\
\hline PB10. Centro de competências & 4 & 88 & $27,6 \%$ & 4,95 \\
\hline PB11. Área interna/depto. específico & 4 & 80 & $25,1 \%$ & 4,66 \\
\hline PB12. Redes de especialistas & 4 & 75 & $23,5 \%$ & 5,16 \\
\hline PB13. Espaços e situações & 6 & 95 & $29,8 \%$ & 5,80 \\
\hline PC14. Mapeamento de competências & 6 & 90 & $28,2 \%$ & 5,72 \\
\hline PC15. Mapeamento de conhecimentos & 5 & 90 & $28,2 \%$ & 5,77 \\
\hline PC16. Planos de carreira & 4 & 68 & $21,3 \%$ & 5,78 \\
\hline PC17. Sistema de reconhecimento & 5 & 88 & $27,6 \%$ & 5,50 \\
\hline PC18. Coaching & 5 & 90 & $28,2 \%$ & 4,12 \\
\hline PC19. Mentoring & 4 & 81 & $25,4 \%$ & 3,80 \\
\hline PC20. Repositório de lições aprendidas & 5 & 105 & $32,9 \%$ & 4,86 \\
\hline PC21. Repositório de melhores práticas & 6 & 102 & $32,0 \%$ & 5,35 \\
\hline PC22. Comunidades de prática & 5 & 104 & $32,6 \%$ & 5,32 \\
\hline PC23. Educação corporativa & 4 & 79 & $24,8 \%$ & 4,96 \\
\hline PC24. Treinamentos presenciais & 8 & 87 & $27,3 \%$ & 6,74 \\
\hline PC25. Multiplicadores & 6 & 88 & $27,6 \%$ & 5,74 \\
\hline PC26. Story telling & 4 & 72 & $22,6 \%$ & 4,82 \\
\hline PD27. Mapeamento de processos & 6 & 84 & $26,3 \%$ & 5,91 \\
\hline PD28. Sistema de avaliação & 6 & 86 & $27,0 \%$ & 6,46 \\
\hline PD29. Patentes & 6 & 73 & $22,9 \%$ & 5,54 \\
\hline PD30. Propriedade intelectual & 6 & 95 & $29,8 \%$ & 5,67 \\
\hline PE31. Banco de conhecimentos & 6 & 88 & $27,6 \%$ & 5,77 \\
\hline PE32. Gestão de conteúdos & 6 & 69 & $21,7 \%$ & 5,76 \\
\hline PE33. Busca de conhecimentos & 5 & 80 & $25,1 \%$ & 5,73 \\
\hline PE34. Inteligência competitiva & 5 & 89 & $27,9 \%$ & 5,60 \\
\hline PE35. Business inteligence & 5 & 93 & $29,2 \%$ & 5,32 \\
\hline PE36. Wikis, blogs, twitters & 5 & 77 & $24,1 \%$ & 4,95 \\
\hline PE37. Páginas amarelas internas & 6 & 74 & $23,2 \%$ & 4,49 \\
\hline PE38. Portal corporativo & 8 & 99 & $31,0 \%$ & 6,57 \\
\hline PE39. Biblioteca corporativa & 6 & 113 & $35,4 \%$ & 6,49 \\
\hline PE40. Reuniões e conferências virtuais & 8 & 107 & $33,6 \%$ & 7,59 \\
\hline PE41. Treinamentos virtuais & 8 & 99 & $31,0 \%$ & 7,37 \\
\hline PE42. E-learning & 6 & 87 & $27,3 \%$ & 6,58 \\
\hline PE43. Universidade corporativa & 4 & 96 & $30,1 \%$ & 4,26 \\
\hline PE44. Sumarização & 4 & 86 & $27,0 \%$ & 4,17 \\
\hline PE45. Inventários & 4 & 81 & $25,4 \%$ & 4,16 \\
\hline PE46. Ontologia/taxonomia & 2 & 67 & $21,0 \%$ & 3,56 \\
\hline
\end{tabular}

As notas médias das 46 práticas de gestão do conhecimento variaram dentre o intervalo compreendido entre 3,56 e 7,59, para uma escala de 0 (zero) a dez (10) pontos. 


\subsubsection{Ferramentas de tecnologia da informação e comunicação adotadas para a gestão do conhecimento}

As 38 ferramentas de tecnologia da informação e comunicação (TIC) adotadas para a gestão do conhecimento averiguadas na pesquisa de campo são expostas individualmente nos itens a seguir. Posteriormente é exposto um resumo com todas as ferramentas prospectadas, no qual é possível observar a nota mais indicada em cada ferramenta, suas respectivas frequência e percentual, além da média da nota.

\subsubsection{Ferramentas de TIC para a gestão do conhecimento - Autoria}

A Tabela 57 expõe a distribuição das respostas obtidas na pesquisa de campo quanto à pergunta 'A empresa conta com ferramentas de AUTORIA para gestão do conhecimento'.

\begin{tabular}{crr}
\multicolumn{3}{c}{ Tabela 57 - Ferramenta 'autoria' } \\
Nota atribuída & Frequência & Percentual \\
0 & 0 & $0,0 \%$ \\
1 & 1 & $0,3 \%$ \\
2 & 4 & $1,2 \%$ \\
3 & 19 & $6,0 \%$ \\
4 & 46 & $14,4 \%$ \\
5 & 71 & $22,3 \%$ \\
6 & 98 & $30,7 \%$ \\
7 & 34 & $10,7 \%$ \\
8 & 38 & $11,9 \%$ \\
9 & 1 & $0,3 \%$ \\
10 & 7 & $2,2 \%$ \\
Total & 319 & $100,0 \%$
\end{tabular}

Mais da metade dos respondentes indicaram as notas 5 e 6 , representando juntas $53,0 \%$ das respostas coletadas na pesquisa.

A nota mais atribuída pelos respondentes para a ferramenta de tecnologia da informação e comunicação 'autoria' foi a nota 6 com 98 indicações (30,7\% do total). A média das notas atribuídas a esta prática foi 5,7 . 


\subsubsection{Ferramentas de TIC para a gestão do conhecimento - Modelos}

A Tabela 58 expõe a distribuição das respostas obtidas na pesquisa de campo quanto à pergunta 'A empresa conta com MODELOS para a gestão do conhecimento'.

\begin{tabular}{|c|c|c|}
\hline \multicolumn{3}{|c|}{ Tabela 58 - Ferramenta 'modelos' } \\
\hline Nota atribuída & Frequência & Percentual \\
\hline 0 & 0 & $0,0 \%$ \\
\hline 1 & 0 & $0,0 \%$ \\
\hline 2 & 5 & $1,6 \%$ \\
\hline 3 & 19 & $6,0 \%$ \\
\hline 4 & 49 & $15,4 \%$ \\
\hline 5 & 85 & $26,6 \%$ \\
\hline 6 & 64 & $20,1 \%$ \\
\hline 7 & 46 & $14,4 \%$ \\
\hline 8 & 41 & $12,8 \%$ \\
\hline 9 & 1 & $0,3 \%$ \\
\hline 10 & 9 & $2,8 \%$ \\
\hline tal & 319 & $100,0 \%$ \\
\hline
\end{tabular}

A ferramenta modelos foi posicionada nas notas 5 ou 6 por quase metade dos respondentes $(46,7 \%)$.

A nota mais atribuída pelos respondentes para a ferramenta de tecnologia da informação e comunicação 'modelos' foi a nota 5 com 85 indicações $(26,6 \%$ do total). A média das notas atribuídas a esta prática foi 5,7 .

\subsubsection{Ferramentas de TIC para a gestão do conhecimento - Anotações}

A Tabela 59 expõe a distribuição das respostas obtidas na pesquisa de campo quanto à pergunta 'A empresa faz uso de ferramentas de ANOTAÇÕES para a gestão do conhecimento'. 


\begin{tabular}{|c|c|c|}
\hline \multicolumn{3}{|c|}{ Tabela 59 - Ferramenta 'anotações' } \\
\hline Nota atribuída & Frequência & Percentual \\
\hline 0 & 3 & $0,9 \%$ \\
\hline 1 & 2 & $0,6 \%$ \\
\hline 2 & 15 & $4,7 \%$ \\
\hline 3 & 20 & $6,3 \%$ \\
\hline 4 & 87 & $27,3 \%$ \\
\hline 5 & 73 & $22,9 \%$ \\
\hline 6 & 65 & $20,4 \%$ \\
\hline 7 & 36 & $11,3 \%$ \\
\hline 8 & 14 & $4,4 \%$ \\
\hline 9 & 1 & $0,3 \%$ \\
\hline 10 & 3 & $0,9 \%$ \\
\hline & 319 & $100,0 \%$ \\
\hline
\end{tabular}

Com 70,5\% das respostas, as notas 4, 5 e 6 representam a maior incidência de escolha dos sujeitos da pesquisa.

A nota mais atribuída pelos respondentes para a ferramenta de tecnologia da informação e comunicação 'anotações' foi a nota 4 com 87 indicações (27,3\% do total). A média das notas atribuídas a esta prática foi 5,0.

\subsubsection{Ferramentas de TIC para a gestão do conhecimento - Data mining}

A Tabela 60 expõe a distribuição das respostas obtidas na pesquisa de campo quanto à pergunta 'A empresa conta com ferramenta de DATA MINING (mineração de dados) para a gestão do conhecimento'.

\begin{tabular}{|c|c|c|}
\hline \multicolumn{3}{|c|}{ Tabela 60 - Ferramenta 'data mining' } \\
\hline Nota atribuída & Frequência & Percentual \\
\hline 0 & 8 & $2,5 \%$ \\
\hline 1 & 0 & $0,0 \%$ \\
\hline 2 & 33 & $10,3 \%$ \\
\hline 3 & 41 & $12,9 \%$ \\
\hline 4 & 93 & $29,2 \%$ \\
\hline 5 & 66 & $20,7 \%$ \\
\hline 6 & 51 & $16,0 \%$ \\
\hline 7 & 18 & $5,6 \%$ \\
\hline 8 & 9 & $2,8 \%$ \\
\hline 9 & 0 & $0,0 \%$ \\
\hline 10 & 0 & $0,0 \%$ \\
\hline & 319 & $100,0 \%$ \\
\hline
\end{tabular}

Embora com menos concentração, a ferramenta data mining obteve nas notas 4 e 5 suas maiores incidências de respostas, com $29,2 \%$ e $20,7 \%$, respectivamente. 
A nota mais atribuída pelos respondentes para a ferramenta de tecnologia da informação e comunicação 'data mining' foi a nota 4 com 93 indicações (29,2\% do total). A média das notas atribuídas a esta prática foi 4,4.

\subsubsection{Ferramentas de TIC para a gestão do conhecimento - Perfil de experts}

A Tabela 61 expõe a distribuição das respostas obtidas na pesquisa de campo quanto à pergunta 'A empresa dispõe de ferramentas de PERFIL DE EXPERTS (especialistas) para a gestão do conhecimento'.

\begin{tabular}{|c|c|c|}
\hline \multicolumn{3}{|c|}{ Tabela 61 - Ferramenta 'perfil de experts' } \\
\hline Nota atribuída & Frequência & Percentual \\
\hline 0 & 6 & $1,9 \%$ \\
\hline 1 & 2 & $0,6 \%$ \\
\hline 2 & 27 & $8,5 \%$ \\
\hline 3 & 50 & $15,7 \%$ \\
\hline 4 & 76 & $23,8 \%$ \\
\hline 5 & 68 & $21,3 \%$ \\
\hline 6 & 52 & $16,3 \%$ \\
\hline 7 & 23 & $7,2 \%$ \\
\hline 8 & 13 & $4,1 \%$ \\
\hline 9 & 1 & $0,3 \%$ \\
\hline 10 & 1 & $0,3 \%$ \\
\hline Total & 319 & $100,0 \%$ \\
\hline
\end{tabular}

$45,1 \%$ dos respondentes optaram pelas notas 4 ou 5. Também foram significativas as opções feitas pelas notas $3(15,7 \%)$ e $6(16,3 \%)$.

A nota mais atribuída pelos respondentes para a ferramenta de tecnologia da informação e comunicação 'perfil de experts' foi a nota 4 com 76 indicações (23,8\% do total). A média das notas atribuídas a esta prática foi 4,6.

\subsubsection{Ferramentas de TIC para a gestão do conhecimento - Blogs}

A Tabela 62 expõe a distribuição das respostas obtidas na pesquisa de campo quanto à pergunta 'A empresa possui ferramentas para elaboração de BLOGS (diário eletrônico baseado em tecnologia web) para a gestão do conhecimento'. 


\begin{tabular}{|c|c|c|}
\hline \multicolumn{3}{|c|}{ Tabela 62 - Ferramenta 'blogs' } \\
\hline Nota atribuída & Frequência & Percentual \\
\hline 0 & 17 & $5,3 \%$ \\
\hline 1 & 0 & $0,0 \%$ \\
\hline 2 & 44 & $13,8 \%$ \\
\hline 3 & 36 & $11,3 \%$ \\
\hline 4 & 73 & $22,9 \%$ \\
\hline 5 & 84 & $26,3 \%$ \\
\hline 6 & 43 & $13,5 \%$ \\
\hline 7 & 17 & $5,3 \%$ \\
\hline 8 & 5 & $1,6 \%$ \\
\hline 9 & 0 & $0,0 \%$ \\
\hline 10 & 0 & $0,0 \%$ \\
\hline otal & 319 & $100,0 \%$ \\
\hline
\end{tabular}

A nota 4 com $22,9 \%$ e a nota 5 com $26,3 \%$ das respostas foram as notas com maior incidência de respostas na pesquisa.

A nota mais atribuída pelos respondentes para a ferramenta de tecnologia da informação e comunicação 'blogs' foi a nota 5 com 84 indicações (26,3\% do total). A média das notas atribuídas a esta prática foi 4,1 .

\subsubsection{Ferramentas de TIC para a gestão do conhecimento - Metadados}

A Tabela 63 expõe a distribuição das respostas obtidas na pesquisa de campo quanto à pergunta 'A empresa usa ferramentas de definição de METADADOS para a gestão do conhecimento'.

\begin{tabular}{|c|c|c|}
\hline \multicolumn{3}{|c|}{ Tabela 63 - Ferramenta 'metadados' } \\
\hline Nota atribuída & Frequência & Percentual \\
\hline 0 & 6 & $1,9 \%$ \\
\hline 1 & 0 & $0,0 \%$ \\
\hline 2 & 20 & $6,3 \%$ \\
\hline 3 & 29 & $9,1 \%$ \\
\hline 4 & 53 & $16,6 \%$ \\
\hline 5 & 69 & $21,6 \%$ \\
\hline 6 & 66 & $20,7 \%$ \\
\hline 7 & 48 & $15,0 \%$ \\
\hline 8 & 19 & $6,0 \%$ \\
\hline 9 & 1 & $0,3 \%$ \\
\hline 10 & 8 & $2,5 \%$ \\
\hline tal & 319 & $100,0 \%$ \\
\hline
\end{tabular}


Quase metade dos respondentes atribuíram nota 5 ou 6 à ferramenta metadados, totalizando $42,3 \%$ das respostas.

A nota mais atribuída pelos respondentes para a ferramenta de tecnologia da informação e comunicação 'metadados' foi a nota 5 com 69 indicações (21,6\% do total). A média das notas atribuídas a esta prática foi 5,2 .

\subsubsection{Ferramentas de TIC para a gestão do conhecimento - Classificação de conteúdos}

A Tabela 64 expõe a distribuição das respostas obtidas na pesquisa de campo quanto à pergunta 'A empresa tem ferramentas de CLASSIFICAÇÃO DE CONTEÚDOS para a gestão do conhecimento'.

$\begin{array}{crr}\text { Tabela } 64 \text { - Ferramenta 'classificação de conteúdos' } \\ \text { Nota atribuída } & \text { Frequência } & \text { Percentual } \\ 0 & 0 & 0,0 \% \\ 1 & 1 & 0,3 \% \\ 2 & 22 & 6,9 \% \\ 3 & 27 & 8,5 \% \\ 4 & 74 & 23,1 \% \\ 5 & 92 & 28,8 \% \\ 6 & 41 & 12,9 \% \\ 7 & 35 & 11,0 \% \\ 8 & 20 & 6,3 \% \\ 9 & 1 & 0,3 \% \\ 10 & 6 & 1,9 \% \\ \text { Total } & 319 & 100,0 \%\end{array}$

Pouco mais da metade dos respondentes $(51,9 \%)$ indicaram notas 4 ou 5 para a ferramenta classificação de conteúdos.

A nota mais atribuída pelos respondentes para a ferramenta de tecnologia da informação e comunicação 'classificação de conteúdos' foi a nota 5 com 92 indicações (28,8\% do total). A média das notas atribuídas a esta prática foi 5,0. 


\subsubsection{Ferramentas de TIC para a gestão do conhecimento - Arquivamento de conteúdos}

A Tabela 65 expõe a distribuição das respostas obtidas na pesquisa de campo quanto à pergunta 'A empresa tem ferramentas de ARQUIVAMENTO DE CONTEÚDOS para a gestão do conhecimento'.

\begin{tabular}{|c|c|c|}
\hline \multicolumn{3}{|l|}{ Tabela 65 - Ferramenta ' } \\
\hline Nota atribuída & Frequência & Percentual \\
\hline 0 & 0 & $0,0 \%$ \\
\hline 1 & 0 & $0,0 \%$ \\
\hline 2 & 24 & $7,5 \%$ \\
\hline 3 & 30 & $9,4 \%$ \\
\hline 4 & 62 & $19,4 \%$ \\
\hline 5 & 69 & $21,6 \%$ \\
\hline 6 & 53 & $16,7 \%$ \\
\hline 7 & 34 & $10,7 \%$ \\
\hline 8 & 30 & $9,4 \%$ \\
\hline 9 & 2 & $0,6 \%$ \\
\hline 10 & 15 & $4,7 \%$ \\
\hline Total & 319 & $100,0 \%$ \\
\hline
\end{tabular}

Houve uma concentração entre as notas 4,5 e 6 que juntas responderam por 57,7\% das indicações dos sujeitos pesquisados. Destas, a nota 5 demonstrou a maior incidência de respostas com $21,6 \%$.

A nota mais atribuída pelos respondentes para a ferramenta de tecnologia da informação e comunicação 'arquivamento de conteúdos' foi a nota 5 com 69 indicações (21,6\% do total). A média das notas atribuídas a esta prática foi 5,3.

\subsubsection{Ferramentas de TIC para a gestão do conhecimento - Gestão de conhecimento pessoal}

A Tabela 66 expõe a distribuição das respostas obtidas na pesquisa de campo quanto à pergunta 'A empresa tem ferramentas de GESTÃO DE CONHECIMENTO PESSOAL (individual) para fins de gestão do conhecimento’. 


$\begin{array}{crr}\text { Tabela } 66 \text { - Ferramenta 'gestão de conhecimento pessoal' } \\ \text { Nota atribuída } & \text { Frequência } & \text { Percentual } \\ 0 & 20 & 6,3 \% \\ 1 & 0 & 0,0 \% \\ 2 & 25 & 7,8 \% \\ 3 & 33 & 10,3 \% \\ 4 & 67 & 21,0 \% \\ 5 & 72 & 22,6 \% \\ 6 & 30 & 9,4 \% \\ 7 & 34 & 10,7 \% \\ 8 & 28 & 8,8 \% \\ 9 & 7 & 2,2 \% \\ 10 & 3 & 0,9 \% \\ & 319 & 100,0 \%\end{array}$

Com $43,6 \%$ das respostas, as notas 4 e 5 foram as mais indicadas pelos sujeitos pesquisados, representando quase metade das indicações.

A nota mais atribuída pelos respondentes para a ferramenta de tecnologia da informação e comunicação 'gestão de conhecimento pessoal' foi a nota 5 com 72 indicações $(22,6 \%$ do total). A média das notas atribuídas a esta prática foi 4,7.

\subsubsection{Ferramentas de TIC para a gestão do conhecimento - Telefone fixo}

A Tabela 67 expõe a distribuição das respostas obtidas na pesquisa de campo quanto à pergunta 'O TELEFONE FIXO é usado na gestão do conhecimento na empresa'.

\begin{tabular}{|c|c|c|}
\hline \multicolumn{3}{|c|}{ Tabela 67 - Ferramenta 'telefone fixo' } \\
\hline Nota atribuída & Frequência & Percentual \\
\hline 0 & 3 & $0,9 \%$ \\
\hline 1 & 0 & $0,0 \%$ \\
\hline 2 & 4 & $1,2 \%$ \\
\hline 3 & 12 & $3,8 \%$ \\
\hline 4 & 13 & $4,1 \%$ \\
\hline 5 & 23 & $7,2 \%$ \\
\hline 6 & 23 & $7,2 \%$ \\
\hline 7 & 51 & $16,0 \%$ \\
\hline 8 & 96 & $30,1 \%$ \\
\hline 9 & 28 & $8,8 \%$ \\
\hline 10 & 66 & $20,7 \%$ \\
\hline & 319 & $100,0 \%$ \\
\hline
\end{tabular}

As maiores incidências para a ferramenta telefone fixo foram verificadas nas notas $8(30,1 \%)$, $10(20,7 \%)$ e $7(16,0 \%)$. 
A nota mais atribuída pelos respondentes para a ferramenta de tecnologia da informação e comunicação 'telefone fixo' foi a nota 8 com 96 indicações (30,1\% do total). A média das notas atribuídas a esta prática foi 7,5.

\subsubsection{Ferramentas de TIC para a gestão do conhecimento - Telefone celular/rádio}

A Tabela 68 expõe a distribuição das respostas obtidas na pesquisa de campo quanto à pergunta 'O TELEFONE CELULAR ou RÁDIO é usado na gestão do conhecimento na empresa'.

\begin{tabular}{|c|c|c|}
\hline \multicolumn{3}{|l|}{ Tabela 68} \\
\hline Nota atribuída & Frequência & Percentual \\
\hline 0 & 1 & $0,3 \%$ \\
\hline 1 & 1 & $0,3 \%$ \\
\hline 2 & 1 & $0,3 \%$ \\
\hline 3 & 1 & $0,3 \%$ \\
\hline 4 & 10 & $3,1 \%$ \\
\hline 5 & 15 & $4,7 \%$ \\
\hline 6 & 30 & $9,7 \%$ \\
\hline 7 & 70 & $21,9 \%$ \\
\hline 8 & 97 & $30,4 \%$ \\
\hline 9 & 41 & $12,8 \%$ \\
\hline 10 & 52 & $16,3 \%$ \\
\hline Total & 319 & $100,0 \%$ \\
\hline
\end{tabular}

Pouco mais da metade das respostas (52,3\%) indicam as notas 7 e 8 como as mais representativas da importância do telefone celular ou rádio na gestão do desenvolvimento.

A nota mais atribuída pelos respondentes para a ferramenta de tecnologia da informação e comunicação 'telefone celular/rádio' foi a nota 8 com 97 indicações (30,4\% do total). A média das notas atribuídas a esta prática foi 7,7 .

\subsubsection{Ferramentas de TIC para a gestão do conhecimento - Telefone via internet}

A Tabela 69 expõe a distribuição das respostas obtidas na pesquisa de campo quanto à pergunta 'O TELEFONE VIA INTERNET (Skype ou outros) é usado na gestão do conhecimento na empresa'. 


\begin{tabular}{|c|c|c|}
\hline \multicolumn{3}{|c|}{ Tabela 69 - Ferramenta 'telefone via internet' } \\
\hline Nota atribuída & Frequência & Percentual \\
\hline 0 & 0 & $0,0 \%$ \\
\hline 1 & 0 & $0,0 \%$ \\
\hline 2 & 0 & $0,0 \%$ \\
\hline 3 & 2 & $0,6 \%$ \\
\hline 4 & 13 & $4,1 \%$ \\
\hline 5 & 18 & $5,6 \%$ \\
\hline 6 & 27 & $8,5 \%$ \\
\hline 7 & 62 & $19,5 \%$ \\
\hline 8 & 105 & $32,9 \%$ \\
\hline 9 & 32 & $10,0 \%$ \\
\hline 10 & 60 & $18,8 \%$ \\
\hline Total & 319 & $100,0 \%$ \\
\hline
\end{tabular}

As notas $8(32,9 \%), 7(19,4 \%)$ e $10(18,8 \%)$ juntas perfazem um total de $71,2 \%$ das respostas verificadas para a ferramenta telefone via internet.

A nota mais atribuída pelos respondentes para a ferramenta de tecnologia da informação e comunicação 'telefone via internet' foi a nota 8 com 105 indicações (32,9\% do total). A média das notas atribuídas a esta prática foi 7,8 .

\subsubsection{Ferramentas de TIC para a gestão do conhecimento - Videoconferência}

A Tabela 70 expõe a distribuição das respostas obtidas na pesquisa de campo quanto à pergunta 'A empresa tem ferramentas de VIDEOCONFERÊNCIA para a gestão do conhecimento'.

\begin{tabular}{|c|c|c|}
\hline \multicolumn{3}{|c|}{ Tabela 70 - Ferramenta 'videoconferência' } \\
\hline Nota atribuída & Frequência & Percentual \\
\hline 0 & 0 & $0,0 \%$ \\
\hline 1 & 0 & $0,0 \%$ \\
\hline 2 & 1 & $0,3 \%$ \\
\hline 3 & 2 & $0,6 \%$ \\
\hline 4 & 20 & $6,4 \%$ \\
\hline 5 & 46 & $14,4 \%$ \\
\hline 6 & 55 & $17,2 \%$ \\
\hline 7 & 62 & $19,4 \%$ \\
\hline 8 & 95 & $29,8 \%$ \\
\hline 9 & 11 & $3,4 \%$ \\
\hline 10 & 27 & $8,5 \%$ \\
\hline otal & 319 & 100,0 \\
\hline
\end{tabular}

Com $49,2 \%$ das respostas, as notas $8(29,8 \%)$ e $7(189,4 \%)$ respondem por quase metade das indicações feitas pelos sujeitos da pesquisa. 
A nota mais atribuída pelos respondentes para a ferramenta de tecnologia da informação e comunicação 'videoconferência' foi a nota 8 com 95 indicações (29,8\% do total). A média das notas atribuídas a esta prática foi 6,9 .

\subsubsection{Ferramentas de TIC para a gestão do conhecimento - Salas de bate-papo}

A Tabela 71 expõe a distribuição das respostas obtidas na pesquisa de campo quanto à pergunta 'A empresa tem ferramentas de SALAS DE BATE-PAPO (chats) para a gestão do conhecimento'.

\begin{tabular}{|c|c|c|}
\hline \multicolumn{3}{|c|}{ Tabela 71 - Ferramenta 'salas de bate-papo' } \\
\hline Nota atribuída & Frequência & Percentual \\
\hline 0 & $\begin{array}{ll}1 & 4\end{array}$ & $1,2 \%$ \\
\hline 1 & 0 & $0,0 \%$ \\
\hline 2 & 0 & $0,0 \%$ \\
\hline 3 & 2 & $0,6 \%$ \\
\hline 4 & 48 & $15,0 \%$ \\
\hline 5 & 48 & $15,0 \%$ \\
\hline 6 & 56 & $17,6 \%$ \\
\hline 7 & 39 & $12,3 \%$ \\
\hline 8 & 88 & $27,7 \%$ \\
\hline 9 & 10 & $3,1 \%$ \\
\hline 10 & 24 & $7,5 \%$ \\
\hline Total & 319 & $100,0 \%$ \\
\hline
\end{tabular}

A ferramenta salas de bate-papo mostrou uma desconcentração em suas respostas. Todavia, a nota 8 mostrou-se como a mais reincidente nas respostas dos sujeitos pesquisados.

A nota mais atribuída pelos respondentes para a ferramenta de tecnologia da informação e comunicação 'salas de bate-papo' foi a nota 8 com 88 indicações (27,6\% do total). A média das notas atribuídas a esta prática foi 6,5.

\subsubsection{Ferramentas de TIC para a gestão do conhecimento - Mensagens instantâneas}

A Tabela 72 expõe a distribuição das respostas obtidas na pesquisa de campo quanto à pergunta 'As MENSAGENS INSTANTÂNEAS são usadas na gestão do conhecimento na empresa'. 
Tabela 72 - Ferramenta 'mensagens instantâneas'

Nota atribuída Frequência Percentual

\begin{tabular}{|c|c|c|}
\hline & & \\
\hline 0 & 0 & $0,0 \%$ \\
\hline 1 & 0 & $0,0 \%$ \\
\hline 2 & 2 & $0,6 \%$ \\
\hline 3 & 0 & $0,0 \%$ \\
\hline 4 & 24 & $7,5 \%$ \\
\hline 5 & 22 & $6,9 \%$ \\
\hline 6 & 37 & $11,6 \%$ \\
\hline 7 & 48 & $15,1 \%$ \\
\hline 8 & 111 & $34,8 \%$ \\
\hline 9 & 31 & $9,7 \%$ \\
\hline 10 & 44 & $13,8 \%$ \\
\hline Total & 319 & $100,0 \%$ \\
\hline
\end{tabular}

A nota mais atribuída pelos respondentes para a ferramenta de tecnologia da informação e comunicação 'mensagens instantâneas' foi a nota 8 com 111 indicações (34,8\% do total). A média das notas atribuídas a esta prática foi 7,4 .

\subsubsection{Ferramentas de TIC para a gestão do conhecimento - E-mail}

A Tabela 73 expõe a distribuição das respostas obtidas na pesquisa de campo quanto à pergunta 'O E-MAIL é usado na gestão do conhecimento na empresa'.

\begin{tabular}{|c|c|c|}
\hline \multicolumn{3}{|c|}{ Tabela 73 - Ferramenta 'e-mail' } \\
\hline Nota atribuída & Frequência & Percentual \\
\hline 0 & 0 & $0,0 \%$ \\
\hline 1 & 0 & $0,0 \%$ \\
\hline 2 & 4 & $1,2 \%$ \\
\hline 3 & 2 & $0,6 \%$ \\
\hline 4 & 6 & $1,9 \%$ \\
\hline 5 & 14 & $4,4 \%$ \\
\hline 6 & 20 & $6,3 \%$ \\
\hline 7 & 31 & $9,7 \%$ \\
\hline 8 & 112 & $35,1 \%$ \\
\hline 9 & 42 & $13,2 \%$ \\
\hline 10 & 88 & $27,6 \%$ \\
\hline tal & 319 & $100,0 \%$ \\
\hline
\end{tabular}

As notas $8(35,1 \%)$ e $10(27,6 \%)$ juntas representam 62,7\% das respostas quanto à ferramenta e-mail. 
A nota mais atribuída pelos respondentes para a ferramenta de tecnologia da informação e comunicação 'e-mail' foi a nota 8 com 112 indicações (35,1\% do total). A média das notas atribuídas a esta prática foi 8,1 .

\subsubsection{Ferramentas de TIC para a gestão do conhecimento - Fóruns de discussão}

A Tabela 74 expõe a distribuição das respostas obtidas na pesquisa de campo quanto à pergunta 'A empresa dispõe de FÓRUNS DE DISCUSSÃO para a gestão do conhecimento'.

\begin{tabular}{|c|c|c|}
\hline Nota atribuída & Frequência & Percentual \\
\hline 0 & 1 & $0,3 \%$ \\
\hline 1 & 0 & $0,0 \%$ \\
\hline 2 & 11 & $3,4 \%$ \\
\hline 3 & 10 & $3,1 \%$ \\
\hline 4 & 60 & $18,8 \%$ \\
\hline 5 & 57 & $17,9 \%$ \\
\hline 6 & 71 & $22,3 \%$ \\
\hline 7 & 30 & $9,4 \%$ \\
\hline 8 & 50 & $15,7 \%$ \\
\hline 9 & 9 & $2,8 \%$ \\
\hline 10 & 20 & $6,3 \%$ \\
\hline Total & 319 & $100,0 \%$ \\
\hline
\end{tabular}

Com $59,0 \%$ das respostas, as notas $6(22,3 \%), 4(18,8 \%)$ e $5(17,9 \%)$ foram as mais assinaladas pelos respondentes.

A nota mais atribuída pelos respondentes para a ferramenta de tecnologia da informação e comunicação 'fóruns de discussão' foi a nota 6 com 71 indicações (22,3\% do total). A média das notas atribuídas a esta prática foi 5,9.

\subsubsection{Ferramentas de TIC para a gestão do conhecimento - Groupware}

A Tabela 75 expõe a distribuição das respostas obtidas na pesquisa de campo quanto à pergunta 'A empresa dispõe de ferramentas de GROUPWARE (software colaborativo) para a gestão do conhecimento'. 
Tabela 75 - Ferramenta 'groupware'

\begin{tabular}{|c|c|c|}
\hline Nota atribuída & Frequência & Percentual \\
\hline 0 & 0 & $0,0 \%$ \\
\hline 1 & 0 & $0,0 \%$ \\
\hline 2 & 6 & $1,9 \%$ \\
\hline 3 & 6 & $1,9 \%$ \\
\hline 4 & 53 & $16,6 \%$ \\
\hline 5 & 70 & $21,9 \%$ \\
\hline 6 & 101 & $31,7 \%$ \\
\hline 7 & 34 & $10,7 \%$ \\
\hline 8 & 39 & $12,2 \%$ \\
\hline 9 & 1 & $0,3 \%$ \\
\hline 10 & 9 & $2,8 \%$ \\
\hline al & 319 & $100,0 \%$ \\
\hline
\end{tabular}

$53,6 \%$ das respostas situaram-se entre as notas 5 e 6 relativamente à ferramenta groupware.

A nota mais atribuída pelos respondentes para a ferramenta de tecnologia da informação e comunicação 'groupware' foi a nota 5 com 84 indicações (26,3\% do total). A média das notas atribuídas a esta prática foi 5,8 .

\subsubsection{Ferramentas de TIC para a gestão do conhecimento - Wikis}

A Tabela 76 expõe a distribuição das respostas obtidas na pesquisa de campo quanto à pergunta 'A empresa utiliza ferramentas de WIKIS (enciclopédia aberta baseada na tecnologia web) para a gestão do conhecimento’.

\begin{tabular}{crr}
\multicolumn{3}{c}{ Tabela 76 - Ferramenta 'wikis' } \\
Nota atribuída & Frequência & Percentual \\
0 & 8 & $2,5 \%$ \\
1 & 1 & $0,3 \%$ \\
2 & 18 & $5,6 \%$ \\
3 & 39 & $12,2 \%$ \\
4 & 59 & $18,5 \%$ \\
5 & 66 & $20,7 \%$ \\
6 & 67 & $21,0 \%$ \\
7 & 33 & $10,3 \%$ \\
8 & 23 & $7,3 \%$ \\
9 & 0 & $0,0 \%$ \\
10 & 5 & $1,6 \%$ \\
Total & 319 & $100,0 \%$
\end{tabular}

Mais da metade dos respondentes situaram suas escolhas nas notas $6(21,0 \%), 5(20,7 \%)$ ou 4 $(18,5 \%)$ para a ferramenta wikis. 
A nota mais atribuída pelos respondentes para a ferramenta de tecnologia da informação e comunicação 'wikis' foi a nota 6 com 67 indicações (21,0\% do total). A média das notas atribuídas a esta prática foi 5,0.

\subsubsection{Ferramentas de TIC para a gestão do conhecimento - Workflow}

A Tabela 77 expõe a distribuição das respostas obtidas na pesquisa de campo quanto à pergunta 'A empresa utiliza ferramentas de WORKFLOW (gerenciamento de fluxo de trabalho) para a gestão do conhecimento'.

\begin{tabular}{|c|c|c|}
\hline \multicolumn{3}{|c|}{ Tabela 77 - Ferramenta 'workflow' } \\
\hline Nota atribuída & Frequência & Percentual \\
\hline 0 & 1 & $0,3 \%$ \\
\hline 1 & 0 & $0,0 \%$ \\
\hline 2 & 5 & $1,6 \%$ \\
\hline 3 & 20 & $6,3 \%$ \\
\hline 4 & 35 & $11,0 \%$ \\
\hline 5 & 82 & $25,7 \%$ \\
\hline 6 & 85 & $26,6 \%$ \\
\hline 7 & 40 & $12,5 \%$ \\
\hline 8 & 43 & $13,5 \%$ \\
\hline 9 & 1 & $0,3 \%$ \\
\hline 10 & 7 & $2,2 \%$ \\
\hline & 319 & $100,0 \%$ \\
\hline
\end{tabular}

Pouco mais da metade das respostas situaram-se entre as notas $5(25,7 \%)$ e $6(26,6 \%)$ para a ferramenta workflow.

A nota mais atribuída pelos respondentes para a ferramenta de tecnologia da informação e comunicação 'workflow' foi a nota 6 com 86 indicações (26,6\% do total). A média das notas atribuídas a esta prática foi 5,7 .

\subsubsection{Ferramentas de TIC para a gestão do conhecimento - Intranet}

A Tabela 78 expõe a distribuição das respostas obtidas na pesquisa de campo quanto à pergunta 'A INTRANET é usada na gestão do conhecimento'. 
Tabela 78 - Ferramenta 'intranet'

\begin{tabular}{|c|c|c|}
\hline Nota atribuída & Frequência & Percentual \\
\hline 0 & 0 & $0,0 \%$ \\
\hline 1 & 0 & $0,0 \%$ \\
\hline 2 & 0 & $0,0 \%$ \\
\hline 3 & 0 & $0,0 \%$ \\
\hline 4 & 5 & $1,6 \%$ \\
\hline 5 & 32 & $10,0 \%$ \\
\hline 6 & 42 & $13,2 \%$ \\
\hline 7 & 51 & $16,0 \%$ \\
\hline 8 & 107 & $33,5 \%$ \\
\hline 9 & 17 & $5,3 \%$ \\
\hline 10 & 65 & $20,4 \%$ \\
\hline tal & 319 & $100,0 \%$ \\
\hline
\end{tabular}

As maiores incidências de respostas quanto à ferramenta intranet foram atribuídas pelos respondentes às notas $8(33,5 \%)$ e $10(20,4 \%)$ que juntas perfazem mais da metade das respostas dos sujeitos da pesquisa.

A nota mais atribuída pelos respondentes para a ferramenta de tecnologia da informação e comunicação 'intranet' foi a nota 8 com 107 indicações (33,5\% do total). A média das notas atribuídas a esta prática foi 7,7.

\subsubsection{Ferramentas de TIC para a gestão do conhecimento - Extranet}

A Tabela 79 expõe a distribuição das respostas obtidas na pesquisa de campo quanto à pergunta 'A EXTRANET (rede privativa estabelecida com parceiros externos via tecnologia internet) é usada na gestão do conhecimento' .

\begin{tabular}{|c|c|c|}
\hline \multicolumn{3}{|c|}{ Tabela 79 - Ferramenta 'extranet' } \\
\hline Nota atribuída & Frequência & Percentual \\
\hline 0 & 4 & $1,2 \%$ \\
\hline 1 & 0 & $0,0 \%$ \\
\hline 2 & 3 & $0,9 \%$ \\
\hline 3 & 3 & $0,9 \%$ \\
\hline 4 & 14 & $4,4 \%$ \\
\hline 5 & 43 & $13,5 \%$ \\
\hline 6 & 80 & $25,1 \%$ \\
\hline 7 & 59 & $18,6 \%$ \\
\hline 8 & 72 & $22,6 \%$ \\
\hline 9 & 10 & $3,1 \%$ \\
\hline 10 & 31 & $9,7 \%$ \\
\hline otal & 319 & $100,0 \%$ \\
\hline
\end{tabular}


As notas $6(25,1 \%)$ e $8(22,6 \%)$ são as mais representativas da ferramenta extranet na opinião dos respondentes da pesquisa.

A nota mais atribuída pelos respondentes para a ferramenta de tecnologia da informação e comunicação 'extranet' foi a nota 6 com 80 indicações $(25,1 \%$ do total). A média das notas atribuídas a esta prática foi 6,7 .

\subsubsection{Ferramentas de TIC para a gestão do conhecimento - Servidores web e navegadores}

A Tabela 80 expõe a distribuição das respostas obtidas na pesquisa de campo quanto à pergunta 'Os SERVIDORES WEB e NAVEGADORES são usados na gestão do conhecimento'.

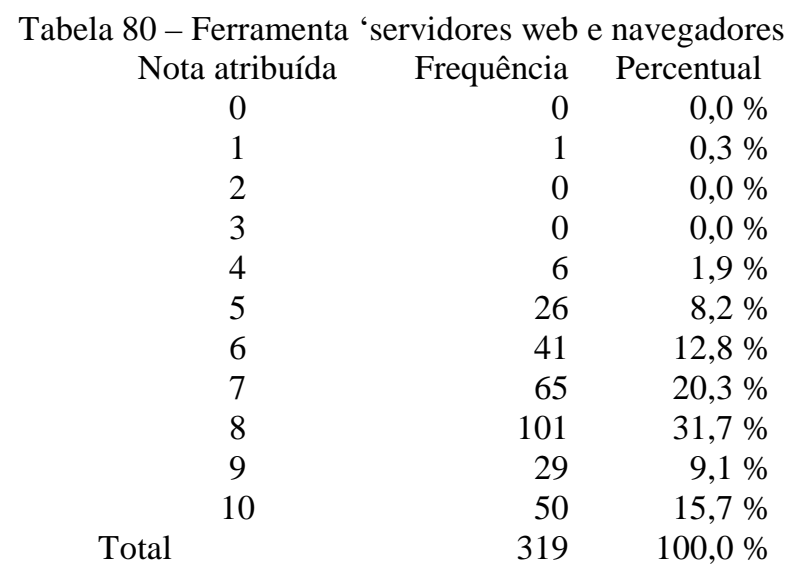

$52,0 \%$ das respostas auferidas na pesquisa indicaram as notas $8(31,7 \%)$ ou $7(20,3 \%)$ como as mais representativas da ferramenta servidores web e navegadores.

A nota mais atribuída pelos respondentes para a ferramenta de tecnologia da informação e comunicação 'servidores web e navegadores' foi a nota 8 com 101 indicações $(31,7 \%$ do total). A média das notas atribuídas a esta prática foi 7,6. 


\subsubsection{Ferramentas de TIC para a gestão do conhecimento - Repositório de conhecimentos}

A Tabela 81 expõe a distribuição das respostas obtidas na pesquisa de campo quanto à pergunta 'A empresa tem REPOSITÓRIO DE CONHECIMENTOS (lições aprendidas e melhores práticas) para a gestão do conhecimento'.

\begin{tabular}{|c|c|c|}
\hline Nota atribuída & Frequência & Percentual \\
\hline 0 & 0 & $0,0 \%$ \\
\hline 1 & 0 & $0,0 \%$ \\
\hline 2 & 3 & $0,9 \%$ \\
\hline 3 & 3 & $0,9 \%$ \\
\hline 4 & 29 & $9,1 \%$ \\
\hline 5 & 41 & $12,9 \%$ \\
\hline 6 & 85 & $26,6 \%$ \\
\hline 7 & 75 & $23,5 \%$ \\
\hline 8 & 61 & $19,1 \%$ \\
\hline 9 & 14 & $4,5 \%$ \\
\hline 10 & 8 & $2,5 \%$ \\
\hline Total & 319 & $100,0 \%$ \\
\hline
\end{tabular}

Metade dos sujeitos da pesquisa indicaram nota $6(26,6 \%)$ ou $7(23,5 \%)$ como suas preferências para a ferramenta repositório de conhecimentos.

A nota mais atribuída pelos respondentes para a ferramenta de tecnologia da informação e comunicação 'repositórios de conhecimentos' foi a nota 6 com 85 indicações $(26,6 \%$ do total). A média das notas atribuídas a esta prática foi 6,5 .

\subsubsection{Ferramentas de TIC para a gestão do conhecimento - Portal corporativo}

A Tabela 82 expõe a distribuição das respostas obtidas na pesquisa de campo quanto à pergunta 'A empresa tem um PORTAL CORPORATIVO ou uma área específica no servidor destinada à gestão do conhecimento'. 
Tabela 82 - Ferramenta 'portal corporativo'

\begin{tabular}{|c|c|c|}
\hline Nota atribuída & Frequência & Percentual \\
\hline 0 & 1 & $0,3 \%$ \\
\hline 1 & 0 & $0,0 \%$ \\
\hline 2 & 2 & $0,6 \%$ \\
\hline 3 & 6 & $1,9 \%$ \\
\hline 4 & 6 & $1,9 \%$ \\
\hline 5 & 23 & $7,2 \%$ \\
\hline 6 & 60 & 18,8 \\
\hline 7 & 94 & $29,5 \%$ \\
\hline 8 & 88 & $27,6 \%$ \\
\hline 9 & 5 & 1,6 \\
\hline 10 & 34 & $10,6 \%$ \\
\hline tal & 319 & 100,0 \\
\hline
\end{tabular}

A ferramenta portal corporativo teve como principais notas atribuídas pelos respondentes as notas $7(29,5 \%)$ e $8(27,6 \%)$, totalizando mais da metade das respostas.

A nota mais atribuída pelos respondentes para a ferramenta de tecnologia da informação e comunicação 'portal corporativo' foi a nota 7 com 94 indicações (29,5\% do total). A média das notas atribuídas a esta prática foi 7,1.

\subsubsection{Ferramentas de TIC para a gestão do conhecimento - CBT}

A Tabela 83 expõe a distribuição das respostas obtidas na pesquisa de campo quanto à pergunta 'A empresa dispõe de ferramentas de CBT (Treinamento baseado em computadores) para a gestão do conhecimento'.

\begin{tabular}{|c|c|c|}
\hline \multicolumn{3}{|c|}{ Tabela 83 - Ferramenta 'CBT' } \\
\hline Nota atribuída & Frequência & Percentual \\
\hline 0 & 0 & $0,0 \%$ \\
\hline 1 & 1 & $0,3 \%$ \\
\hline 2 & 1 & $0,3 \%$ \\
\hline 3 & 0 & $0,0 \%$ \\
\hline 4 & 15 & $4,7 \%$ \\
\hline 5 & 32 & $10,0 \%$ \\
\hline 6 & 55 & $17,2 \%$ \\
\hline 7 & 90 & $28,2 \%$ \\
\hline 8 & 93 & $29,2 \%$ \\
\hline 9 & 13 & $4,1 \%$ \\
\hline 10 & 19 & $6,0 \%$ \\
\hline otal & 319 & $100,0 \%$ \\
\hline
\end{tabular}

$57,4 \%$ das respostas auferidas indicaram as notas $8(29,3 \%)$ e $7(28,2 \%)$ como as mais significativas para a ferramenta CBT (treinamento baseado em computadores). 
A nota mais atribuída pelos respondentes para a ferramenta de tecnologia da informação e comunicação 'CBT' foi a nota 8 com 93 indicações $(29,2 \%$ do total). A média das notas atribuídas a esta prática foi 7,0.

\subsubsection{Ferramentas de TIC para a gestão do conhecimento - WBT}

A Tabela 84 expõe a distribuição das respostas obtidas na pesquisa de campo quanto à pergunta 'A empresa dispõe de ferramentas de WBT (Treinamento baseado em tecnologia web) para a gestão do conhecimento'.

\begin{tabular}{|c|c|c|}
\hline \multicolumn{3}{|c|}{ Tabela 84 - Ferramenta 'WBT' } \\
\hline Nota atribuída & Frequência & Percentual \\
\hline 0 & 0 & $0,0 \%$ \\
\hline 1 & 0 & $0,0 \%$ \\
\hline 2 & 0 & $0,0 \%$ \\
\hline 3 & 5 & $1,6 \%$ \\
\hline 4 & 17 & $5,3 \%$ \\
\hline 5 & 30 & $9,4 \%$ \\
\hline 6 & 71 & $22,3 \%$ \\
\hline 7 & 93 & $29,2 \%$ \\
\hline 8 & 77 & $24,1 \%$ \\
\hline 9 & 9 & $2,8 \%$ \\
\hline 10 & 17 & $5,3 \%$ \\
\hline otal & 319 & $100,0 \%$ \\
\hline
\end{tabular}

Praticamente $3 / 4$ dos respondentes indicaram as notas $7(29,2 \%), 8(24,1 \%)$ ou $6(22,3 \%)$ para a ferramenta WBT (treinamento baseado em web).

A nota mais atribuída pelos respondentes para a ferramenta de tecnologia da informação e comunicação 'WBT' foi a nota 7 com 93 indicações $(29,2 \%$ do total). A média das notas atribuídas a esta prática foi 6,8 .

\subsubsection{Ferramentas de TIC para a gestão do conhecimento - EPSS}

A Tabela 85 expõe a distribuição das respostas obtidas na pesquisa de campo quanto à pergunta 'A empresa dispõe de ferramentas de EPSS (sistema eletrônico de apoio ao desempenho) para a gestão do conhecimento'. 


\begin{tabular}{|c|c|c|}
\hline \multicolumn{3}{|c|}{ Tabela 85 - Ferramenta 'EPSS' } \\
\hline Nota atribuída & Frequência & Percentual \\
\hline 0 & 1 & $0,3 \%$ \\
\hline 1 & 0 & $0,0 \%$ \\
\hline 2 & 2 & $0,6 \%$ \\
\hline 3 & 8 & $2,5 \%$ \\
\hline 4 & 60 & $18,8 \%$ \\
\hline 5 & 71 & $22,3 \%$ \\
\hline 6 & 98 & $30,7 \%$ \\
\hline 7 & 44 & $13,8 \%$ \\
\hline 8 & 28 & $8,9 \%$ \\
\hline 9 & 2 & $0,6 \%$ \\
\hline 10 & 5 & $1,6 \%$ \\
\hline Total & 319 & $100,0 \%$ \\
\hline
\end{tabular}

Pouco mais da metade dos respondentes optaram pelas notas $6(30,7 \%)$ ou $5(22,3 \%)$ para a ferramenta EPSS (sistema eletrônico de apoio ao desempenho).

A nota mais atribuída pelos respondentes para a ferramenta de tecnologia da informação e comunicação 'EPSS' foi a nota 6 com 98 indicações (30,7\% do total). A média das notas atribuídas a esta prática foi 5,7 .

\subsubsection{Ferramentas de TIC para a gestão do conhecimento - Sistemas especializados}

A Tabela 86 expõe a distribuição das respostas obtidas na pesquisa de campo quanto à pergunta 'A empresa dispõe de SISTEMAS ESPECIALIZADOS para a gestão do conhecimento'.

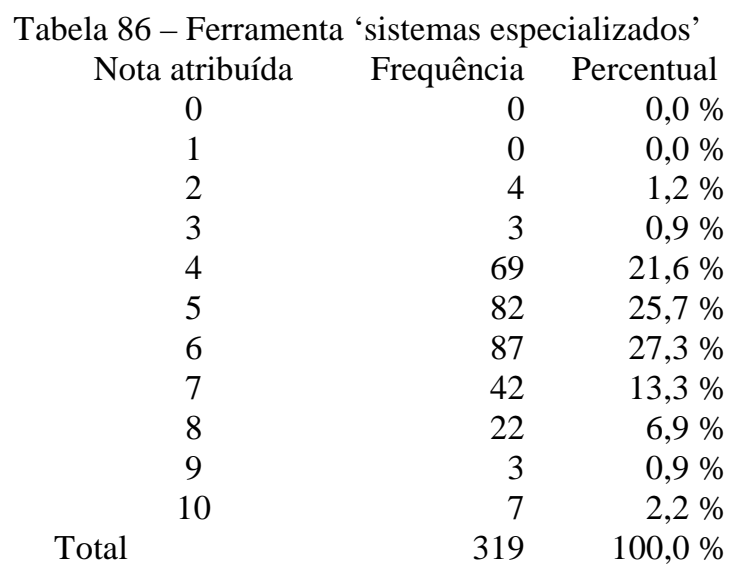


As notas mais significativas atribuídas à ferramenta sistemas especializados foram $6(27,3 \%)$ e $5(25,7 \%)$ com mais da metade das respostas coletadas na pesquisa.

A nota mais atribuída pelos respondentes para a ferramenta de tecnologia da informação e comunicação 'sistemas especializados' foi a nota 6 com 87 indicações (27,3\% do total). A média das notas atribuídas a esta prática foi 5,6.

\subsubsection{Ferramentas de TIC para a gestão do conhecimento - DSS}

A Tabela 87 expõe a distribuição das respostas obtidas na pesquisa de campo quanto à pergunta 'A empresa dispõe de ferramentas de DSS (Sistema de suporte à tomada de decisão) para a gestão do conhecimento'.

\begin{tabular}{|c|c|c|}
\hline \multicolumn{3}{|c|}{ Tabela 87 - Ferramenta 'DSS' } \\
\hline Nota atribuída & Frequência & Percentual \\
\hline 0 & 1 & $0,3 \%$ \\
\hline 1 & 0 & $0,0 \%$ \\
\hline 2 & 9 & $2,8 \%$ \\
\hline 3 & 9 & $2,8 \%$ \\
\hline 4 & 73 & $22,9 \%$ \\
\hline 5 & 66 & $20,7 \%$ \\
\hline 6 & 94 & $29,5 \%$ \\
\hline 7 & 30 & $9,4 \%$ \\
\hline 8 & 26 & $8,2 \%$ \\
\hline 9 & 3 & $0,9 \%$ \\
\hline 10 & 8 & $2,5 \%$ \\
\hline tal & 319 & $100,0 \%$ \\
\hline
\end{tabular}

As notas mais reincidentes dadas à ferramenta DSS (sistema de suporte à tomada de decisão) foram $6(29,5 \%), 4(22,9 \%)$ e $5(20,7 \%)$.

A nota mais atribuída pelos respondentes para a ferramenta de tecnologia da informação e comunicação 'DSS' foi a nota 6 com 94 indicações (29,5\% do total). A média das notas atribuídas a esta prática foi 5,5. 


\subsubsection{Ferramentas de TIC para a gestão do conhecimento - Customização/ personalização}

A Tabela 88 expõe a distribuição das respostas obtidas na pesquisa de campo quanto à pergunta 'A empresa efetua CUSTOMIZAÇÃO/PERSONALIZAÇÃO de produtos com uso da gestão do conhecimento'.

\begin{tabular}{|c|c|c|}
\hline Nota atribuída & Frequência & Percentual \\
\hline 0 & 0 & $0,0 \%$ \\
\hline 1 & 0 & $0,0 \%$ \\
\hline 2 & 7 & $2,2 \%$ \\
\hline 3 & 10 & $3,1 \%$ \\
\hline 4 & 46 & $14,4 \%$ \\
\hline 5 & 71 & $22,3 \%$ \\
\hline 6 & 81 & $25,4 \%$ \\
\hline 7 & 44 & $13,8 \%$ \\
\hline 8 & 47 & $14,9 \%$ \\
\hline 9 & 3 & $0,9 \%$ \\
\hline 10 & 10 & $3,1 \%$ \\
\hline Total & 319 & $100,0 \%$ \\
\hline
\end{tabular}

Quase metade das respostas da ferramenta customização/personalização foram dadas às notas $6(25,4 \%)$ e $5(22,3 \%)$.

A nota mais atribuída pelos respondentes para a ferramenta de tecnologia da informação e comunicação ‘customização/personalização' foi a nota 6 com 81 indicações (25,4\% do total). A média das notas atribuídas a esta prática foi 5,9.

\subsubsection{Ferramentas de TIC para a gestão do conhecimento - Sistema recomendador}

A Tabela 89 expõe a distribuição das respostas obtidas na pesquisa de campo quanto à pergunta 'A empresa possui um SISTEMA RECOMENDADOR (compara coleções de dados e sugere uma lista de recomendações) para a gestão do conhecimento'. 


\begin{tabular}{|c|c|c|}
\hline \multicolumn{3}{|c|}{ Tabela 89 - Ferramenta 'sistema recomendador' } \\
\hline Nota atribuída & Frequência & Percentual \\
\hline 0 & 25 & $7,8 \%$ \\
\hline 1 & 4 & $1,2 \%$ \\
\hline 2 & 35 & $11,0 \%$ \\
\hline 3 & 42 & $13,2 \%$ \\
\hline 4 & 78 & $24,5 \%$ \\
\hline 5 & 56 & $17,6 \%$ \\
\hline 6 & 30 & $9,4 \%$ \\
\hline 7 & 29 & $9,1 \%$ \\
\hline 8 & 17 & $5,3 \%$ \\
\hline 9 & 1 & $0,3 \%$ \\
\hline 10 & 2 & $0,6 \%$ \\
\hline Total & 319 & $100,0 \%$ \\
\hline
\end{tabular}

Quase 2/3 dos respondentes da pesquisa atribuíram notas 4 (24,5\%), $5(17,6 \%), 3(13,2 \%)$ ou $2(11,0 \%)$ para a ferramenta sistema recomendador.

A nota mais atribuída pelos respondentes para a ferramenta de tecnologia da informação e comunicação 'sistema recomendador' foi a nota 4 com 78 indicações ( $24,5 \%$ do total). A média das notas atribuídas a esta prática foi 4,2 .

\subsubsection{Ferramentas de TIC para a gestão do conhecimento - Visualização}

A Tabela 90 expõe a distribuição das respostas obtidas na pesquisa de campo quanto à pergunta 'A empresa possui ferramentas de VISUALIZAÇÃO para a gestão do conhecimento'.

\begin{tabular}{|c|c|c|}
\hline Nota atribuída & Frequência & Percentual \\
\hline 0 & 6 & $1,9 \%$ \\
\hline 1 & 2 & $0,6 \%$ \\
\hline 2 & 14 & $4,4 \%$ \\
\hline 3 & 21 & $6,6 \%$ \\
\hline 4 & 91 & $28,5 \%$ \\
\hline 5 & 59 & $18,5 \%$ \\
\hline 6 & 78 & $24,5 \%$ \\
\hline 7 & 25 & $7,8 \%$ \\
\hline 8 & 19 & $6,0 \%$ \\
\hline 9 & 1 & $0,3 \%$ \\
\hline 10 & 3 & $0,9 \%$ \\
\hline tal & 319 & 100,0 c \\
\hline
\end{tabular}

A maior parte dos respondentes optaram pela nota $4(28,5 \%)$ ou pela nota $6(24,5 \%)$ para a ferramenta visualização. 
A nota mais atribuída pelos respondentes para a ferramenta de tecnologia da informação e comunicação 'visualização' foi a nota 4 com 91 indicações (28,5\% do total). A média das notas atribuídas a esta prática foi 5,0.

\subsubsection{Ferramentas de TIC para a gestão do conhecimento - Mapas de conhecimento}

A Tabela 91 expõe a distribuição das respostas obtidas na pesquisa de campo quanto à pergunta 'A empresa utiliza ferramentas de MAPAS DE CONHECIMENTO para a gestão do conhecimento'.

$\begin{array}{crr}\text { Tabela } 91 \text { - Ferramenta 'mapas de conhecimento' } \\ \text { Nota atribuída } & \text { Frequência } & \text { Percentual } \\ 0 & 6 & 1,9 \% \\ 1 & 2 & 0,6 \% \\ 2 & 7 & 2,2 \% \\ 3 & 10 & 3,1 \% \\ 4 & 69 & 21,6 \% \\ 5 & 63 & 19,8 \% \\ 6 & 87 & 27,3 \% \\ 7 & 46 & 14,5 \% \\ 8 & 23 & 7,2 \% \\ 9 & 4 & 1,2 \% \\ 10 & 2 & 0,6 \% \\ \text { Total } & 319 & 100,0 \%\end{array}$

As notas $6(27,3 \%)$ e $4(21,6 \%)$ foram as mais assinaladas pelos respondentes ao classificarem a ferramenta mapas de conhecimento.

A nota mais atribuída pelos respondentes para a ferramenta de tecnologia da informação e comunicação 'mapas de conhecimento' foi a nota 6 com 87 indicações (27,3\% do total). A média das notas atribuídas a esta prática foi 5,4. 


\subsubsection{Ferramentas de TIC para a gestão do conhecimento - Agentes de inteligência}

A Tabela 92 expõe a distribuição das respostas obtidas na pesquisa de campo quanto à pergunta 'A empresa possui ferramentas de AGENTES DE INTELIGÊNCIA para a gestão do conhecimento'.

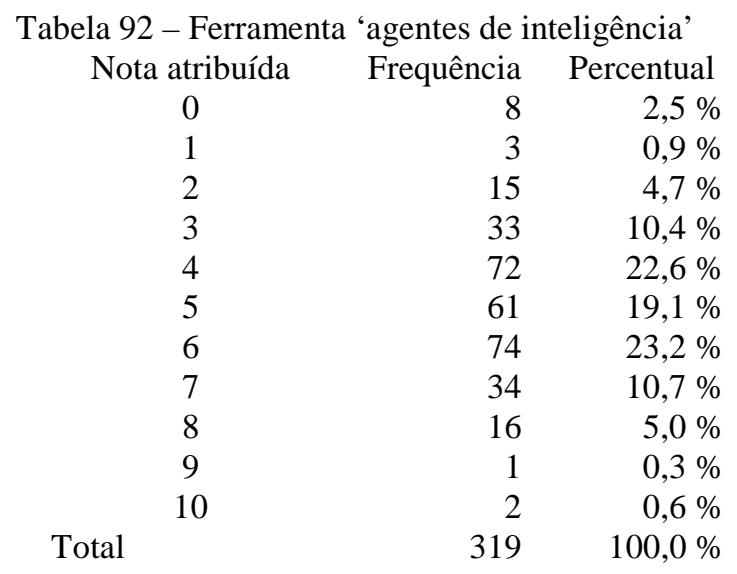

Com quase metade das respostas, as notas $6(23,2 \%)$ e $4(22,6 \%)$ foram as mais selecionadas pelos respondentes da pesquisa, totalizando quase metade das respostas.

A nota mais atribuída pelos respondentes para a ferramenta de tecnologia da informação e comunicação 'agentes de inteligência' foi a nota 4 com 72 indicações (22,6\% do total). A média das notas atribuídas a esta prática foi 4,9 .

\subsubsection{Ferramentas de TIC para a gestão do conhecimento - Sistema de taxonomia automatizado}

A Tabela 93 expõe a distribuição das respostas obtidas na pesquisa de campo quanto à pergunta 'A empresa possui um SISTEMA DE TAXONOMIA AUTOMATIZADO para a gestão do conhecimento’. 


$\begin{array}{crc}\text { Tabela } 93 \text { - Ferramenta 'sistema de taxonomia automatizado } \\ \text { Nota atribuída } & \text { Frequência } & \text { Percentual } \\ 0 & 46 & 14,4 \% \\ 1 & 8 & 2,5 \% \\ 2 & 42 & 13,2 \% \\ 3 & 56 & 17,6 \% \\ 4 & 67 & 21,0 \% \\ 5 & 46 & 14,4 \% \\ 6 & 35 & 11,0 \% \\ 7 & 10 & 3,1 \% \\ 8 & 9 & 2,8 \% \\ 9 & 0 & 0,0 \% \\ 10 & 0 & 0,0 \% \\ \text { Total } & 319 & 100,0 \%\end{array}$

Não há uma clara concentração nas respostas à ferramenta sistema de taxonomia automatizado. A nota mais indicada pelos respondentes foi a nota 4, com 21,0\% das respostas.

A nota mais atribuída pelos respondentes para a ferramenta de tecnologia da informação e comunicação 'sistema de taxonomia automatizado' foi a nota 4 com 67 indicações $(21,0 \%$ do total). A média das notas atribuídas a esta prática foi 3,5.

\subsubsection{Ferramentas de TIC para a gestão do conhecimento - Análise de conteúdos}

A Tabela 94 expõe a distribuição das respostas obtidas na pesquisa de campo quanto à pergunta 'A empresa possui ferramentas de ANÁLISE DE CONTEÚDOS de textos (sumarização) para a gestão do conhecimento'.

\begin{tabular}{|c|c|c|}
\hline \multicolumn{3}{|c|}{ Tabela 94 - Ferramenta 'análise de conteúdos' } \\
\hline Nota atribuída & Frequência & Percentual \\
\hline 0 & 19 & $6,0 \%$ \\
\hline 1 & 4 & $1,2 \%$ \\
\hline 2 & 39 & $12,2 \%$ \\
\hline 3 & 40 & $12,5 \%$ \\
\hline 4 & 95 & $29,8 \%$ \\
\hline 5 & 61 & $19,1 \%$ \\
\hline 6 & 31 & $9,7 \%$ \\
\hline 7 & 13 & $4,1 \%$ \\
\hline 8 & 15 & $4,8 \%$ \\
\hline 9 & 1 & $0,3 \%$ \\
\hline 10 & 1 & $0,3 \%$ \\
\hline Total & 319 & $100,0 \%$ \\
\hline
\end{tabular}

A nota mais indicada para a ferramenta análise de conteúdos pelos sujeitos pesquisados foi a nota 4 , com $28,8 \%$ das respostas. 
A nota mais atribuída pelos respondentes para a ferramenta de tecnologia da informação e comunicação ‘análise de conteúdos' foi a nota 4 com 95 indicações (29,8\% do total). A média das notas atribuídas a esta prática foi 4,1 .

\subsubsection{Principais resultados verificados nas ferramentas de tecnologia da informação e comunicação}

Os principais resultados da pesquisa de campo quanto às ferramentas de tecnologia da informação aplicadas na gestão de conhecimento verificadas nas empresas analisadas estão consolidados na Tabela 95. Nela é possível observar, para cada ferramenta pesquisada, a nota mais indicada pelos respondentes, sua frequência e respectivo percentual, bem como a nota média da ferramenta em questão. 
Tabela 95 - Resumo dos principais resultados acerca das ferramentas de TIC aplicadas na gestão do conhecimento

$$
\begin{gathered}
\text { Ferramentas de tecnologia da informação } \\
\text { e comunicação } \\
\text { na gestão do conhecimento }
\end{gathered}
$$

FA01. Autoria

FA02. Modelos

FA03. Anotações

FA04. Data mining

FA05. Perfil de experts

FA06. Blogs

FB07. Metadados

FB08. Classificação de conteúdos

FB09. Arquivamento de conteúdos

FB10. Gestão de conhecim. pessoal

FC11. Telefone fixo

FC12. Telefone celular/rádio

FC13. Telefone via internet

FC14. Videoconferência

FC15. Salas de bate-papo

FC16. Mensagens instantâneas

FC17. E-mail

FC18. Fóruns de discussão

FC19. Groupware

FC20. Wikis

FC21. Workflow

FD22. Intranet

FD23. Extranet

FD24. Servidores web e navegadores

FD25. Repositório de conhecimentos

FD26. Portal corporativo

FE27. CBT

FE28. WBT

FE29. EPSS

FF30. Sistemas especializados

FF31. DSS

FF32. Customização/personalização

FF33. Sistema recomendador

FF34. Visualização

FF35. Mapas de conhecimento

FF36. Agentes de Inteligência

FF37. Sistema de taxonomia automatizado

\begin{tabular}{|c|c|c|c|}
\hline $\begin{array}{l}\text { Nota } \\
\text { mais } \\
\text { indicada }\end{array}$ & $\begin{array}{c}\text { Frequência } \\
\text { da nota mais } \\
\text { indicada }\end{array}$ & $\begin{array}{c}\text { Percentual da } \\
\text { nota mais } \\
\text { indicada }\end{array}$ & $\begin{array}{l}\text { Nota } \\
\text { média }\end{array}$ \\
\hline 6 & 98 & $30,7 \%$ & 5,69 \\
\hline 5 & 85 & $26,6 \%$ & 5,71 \\
\hline 4 & 87 & $27,3 \%$ & 5,01 \\
\hline 4 & 93 & $29,2 \%$ & 4,37 \\
\hline 4 & 76 & $23,8 \%$ & 4,56 \\
\hline 5 & 84 & $26,3 \%$ & 4,15 \\
\hline 5 & 69 & $21,6 \%$ & 5,19 \\
\hline 5 & 92 & $28,8 \%$ & 5,02 \\
\hline 5 & 69 & $21,6 \%$ & 5,31 \\
\hline 5 & 72 & $22,6 \%$ & 4,74 \\
\hline 8 & 96 & $30,1 \%$ & 7,48 \\
\hline 8 & 97 & $30,4 \%$ & 7,70 \\
\hline 8 & 105 & $32,9 \%$ & 7,75 \\
\hline 8 & 95 & $29,8 \%$ & 6,93 \\
\hline 8 & 88 & $27,6 \%$ & 6,52 \\
\hline 8 & 111 & $34,8 \%$ & 7,45 \\
\hline 8 & 112 & $35,1 \%$ & 8,15 \\
\hline 6 & 71 & $22,3 \%$ & 5,94 \\
\hline 5 & 84 & $26,3 \%$ & 5,79 \\
\hline 6 & 67 & $21,0 \%$ & 4,97 \\
\hline 6 & 86 & $26,6 \%$ & 5,75 \\
\hline 8 & 107 & $33,5 \%$ & 7,67 \\
\hline 6 & 80 & $25,1 \%$ & 6,76 \\
\hline 8 & 101 & $31,7 \%$ & 7,60 \\
\hline 6 & 85 & $26,6 \%$ & 6,47 \\
\hline 7 & 94 & $29,5 \%$ & 7,11 \\
\hline 8 & 93 & $29,2 \%$ & 7,00 \\
\hline 7 & 93 & $29,2 \%$ & 6,82 \\
\hline 6 & 98 & $30,7 \%$ & 5,68 \\
\hline 6 & 87 & $27,3 \%$ & 5,62 \\
\hline 6 & 94 & $29,5 \%$ & 5,50 \\
\hline 6 & 81 & $25,4 \%$ & 5,89 \\
\hline 4 & 78 & $24,5 \%$ & 4,23 \\
\hline 4 & 91 & $28,5 \%$ & 5,00 \\
\hline 6 & 87 & $27,3 \%$ & 5,39 \\
\hline 4 & 72 & $22,6 \%$ & 4,90 \\
\hline 4 & 67 & $21,0 \%$ & 3,48 \\
\hline 4 & 95 & $29,8 \%$ & 4,08 \\
\hline
\end{tabular}

FF38. Análise de conteúdos

As notas médias das 38 ferramentas de tecnologia da informação e comunicação variaram dentre o intervalo compreendido entre 3,48 e 8,15 , para uma escala de 0 (zero) a dez (10) pontos. 


\subsubsection{Indicadores de eficácia empresarial}

Os 15 fatores de eficácia empresarial indicados na pesquisa de campo são expostos individualmente nos itens a seguir. Posteriormente é exposto um resumo com todas os fatores prospectados, no qual é possível observar a nota mais indicada em cada fator, suas respectivas frequência e percentual, além da média da nota.

\subsubsection{Fator de eficácia empresarial - Objetivos corporativos}

A Tabela 96 expõe a distribuição das respostas obtidas na pesquisa de campo quanto à pergunta 'A gestão do conhecimento ajuda a alcançar os OBJETIVOS CORPORATIVOS'.

\begin{tabular}{|c|c|c|}
\hline Nota atribuída & Frequência & Percentual \\
\hline 1 & 0 & $0,0 \%$ \\
\hline 2 & 60 & $18,8 \%$ \\
\hline 3 & 130 & $40,8 \%$ \\
\hline 4 & 97 & $30,4 \%$ \\
\hline 5 & 32 & $10,0 \%$ \\
\hline Total & 319 & $100,0 \%$ \\
\hline
\end{tabular}

A nota mais atribuída pelos respondentes para o fator de eficácia empresarial 'objetivos corporativos' foi a nota 3 com 130 indicações (40,8\% do total). A média das notas atribuídas a esta prática foi 3,3 .

\subsubsection{Fator de eficácia empresarial - Produtividade}

A Tabela 97 expõe a distribuição das respostas obtidas na pesquisa de campo quanto à pergunta 'A gestão do conhecimento traz aumento da PRODUTIVIDADE'.

\begin{tabular}{|c|c|c|}
\hline $\begin{array}{r}\text { Tabela } 97 \text { - Fator de efic } \\
\text { Nota atribuída }\end{array}$ & $\begin{array}{l}\text { empresarial } \\
\text { Frequência }\end{array}$ & $\begin{array}{l}\text { produtividade } \\
\text { Percentual }\end{array}$ \\
\hline 1 & 3 & $0,9 \%$ \\
\hline 2 & 45 & $14,1 \%$ \\
\hline 3 & 88 & $27,6 \%$ \\
\hline 4 & 115 & $36,1 \%$ \\
\hline 5 & 68 & $21,3 \%$ \\
\hline Total & 319 & $100,0 \%$ \\
\hline
\end{tabular}


A nota mais atribuída pelos respondentes para o fator de eficácia empresarial 'produtividade' foi a nota 4 com 115 indicações $(36,1 \%$ do total). A média das notas atribuídas a esta prática foi 3,6 .

\subsubsection{Fator de eficácia empresarial - Lucro e rentabilidade}

A Tabela 98 expõe a distribuição das respostas obtidas na pesquisa de campo quanto à pergunta 'A gestão do conhecimento contribui para o aumento do LUCRO e da RENTABILIDADE'.

$\begin{array}{crc}\text { Tabela } 98 \text { - Fator de eficácia empresarial 'lucro e rentabilidade’ } \\ \text { Nota atribuída } & \text { Frequência } & \text { Percentual } \\ 1 & 12 & 3,8 \% \\ 2 & 40 & 12,4 \% \\ 3 & 115 & 36,1 \% \\ 4 & 94 & 29,5 \% \\ 5 & 58 & 18,2 \% \\ \text { Total } & 319 & 100,0 \%\end{array}$

A nota mais atribuída pelos respondentes para o fator de eficácia empresarial 'lucro e rentabilidade' foi a nota 3 com 115 indicações (36,1\% do total). A média das notas atribuídas a esta prática foi 3,5 .

\subsubsection{Fator de eficácia empresarial - Eficiência}

A Tabela 99 expõe a distribuição das respostas obtidas na pesquisa de campo quanto à pergunta 'A gestão do conhecimento contribui para o aumento da EFICIÊNCIA das operações de negócio'.

Tabela 99 - Fator de eficácia empresarial 'eficiência' Nota atribuída Frequência Percentual

$1 \quad 4 \quad 1,2 \%$

$2 \quad 38 \quad 11,9 \%$

$3 \quad 114 \quad 35,7 \%$

$4 \quad 101 \quad 31,8 \%$

$5-62-19,4 \%$

$\begin{array}{lll}\text { Total } & 319 & 100,0 \%\end{array}$


A nota mais atribuída pelos respondentes para o fator de eficácia empresarial 'eficiência' foi a nota 3 com 114 indicações (35,7\% do total). A média das notas atribuídas a esta prática foi 3,6 .

\subsubsection{Fator de eficácia empresarial - Desenvolvimento e crescimento}

A Tabela 100 expõe a distribuição das respostas obtidas na pesquisa de campo quanto à pergunta 'A gestão do conhecimento contribui para o DESENVOLVIMENTO e CRESCIMENTO do negócio'.

Tabela 100 - Fator de eficácia empresarial 'desenvolvimento e crescimento'

\begin{tabular}{|c|c|c|}
\hline Nota atribuída & Frequência & Percentual \\
\hline 1 & 1 & $0,3 \%$ \\
\hline 2 & 64 & $20,1 \%$ \\
\hline 3 & 113 & $35,4 \%$ \\
\hline 4 & 95 & $29,8 \%$ \\
\hline 5 & 46 & $14,4 \%$ \\
\hline al & 319 & $100,0 \%$ \\
\hline
\end{tabular}

A nota mais atribuída pelos respondentes para $\mathrm{o}$ fator de eficácia empresarial 'desenvolvimento e crescimento' foi a nota 3 com 113 indicações (35,4\% do total). A média das notas atribuídas a esta prática foi 3,4.

\subsubsection{Fator de eficácia empresarial - Coesão e harmonia}

A Tabela 101 expõe a distribuição das respostas obtidas na pesquisa de campo quanto à pergunta 'A gestão do conhecimento proporciona maior COESÃO e HARMONIA entre os indivíduos e áreas envolvidas'.

$\begin{array}{crc}\text { Tabela } 101 \text { - Fator de eficácia empresarial 'coesão e harmonia' } \\ \text { Nota atribuída } & \text { Frequência } & \text { Percentual } \\ 1 & 74 & 23,2 \% \\ 2 & 95 & 29,8 \% \\ 3 & 81 & 25,4 \% \\ 4 & 67 & 21,0 \% \\ 5 & 2 & 0,6 \% \\ \text { Total } & 319 & 100,0 \%\end{array}$


A nota mais atribuída pelos respondentes para o fator de eficácia empresarial 'coesão e harmonia' foi a nota 2 com 95 indicações $(29,8 \%$ do total). A média das notas atribuídas a esta prática foi 2,5.

\subsubsection{Fator de eficácia empresarial - Ambiente organizacional}

A Tabela 102 expõe a distribuição das respostas obtidas na pesquisa de campo quanto à pergunta 'A gestão do conhecimento contribui para a melhoria do AMBIENTE ORGANIZACIONAL'.

\begin{tabular}{|c|c|c|}
\hline Nota atribuída & Frequência & Percentual \\
\hline 1 & 12 & $3,8 \%$ \\
\hline 2 & 94 & $29,5 \%$ \\
\hline 3 & 112 & $35,1 \%$ \\
\hline 4 & 89 & $27,8 \%$ \\
\hline 5 & 12 & $3,8 \%$ \\
\hline Total & 319 & 100,0 \\
\hline
\end{tabular}

A nota mais atribuída pelos respondentes para o fator de eficácia empresarial 'ambiente organizacional' foi a nota 3 com 112 indicações (35,1\% do total). A média das notas atribuídas a esta prática foi 3,0.

\subsubsection{Fator de eficácia empresarial - Moral}

A Tabela 103 expõe a distribuição das respostas obtidas na pesquisa de campo quanto à pergunta 'A gestão do conhecimento aumenta o MORAL de nossos empregados'.

\begin{tabular}{|c|c|c|}
\hline $\mathrm{F}$ & cacia empres & 1al moral \\
\hline Nota atribuída & Frequência & Percentual \\
\hline 1 & 70 & $21,9 \%$ \\
\hline 2 & 125 & $39,2 \%$ \\
\hline 3 & 91 & $28,5 \%$ \\
\hline 4 & 26 & $8.2 \%$ \\
\hline 5 & 7 & $2,2 \%$ \\
\hline Total & 319 & $100,0 \%$ \\
\hline
\end{tabular}


A nota mais atribuída pelos respondentes para o fator de eficácia empresarial 'moral' foi a nota 2 com 125 indicações (39,2\% do total). A média das notas atribuídas a esta prática foi 2,3 .

\subsubsection{Fator de eficácia empresarial - Absenteísmo}

A Tabela 104 expõe a distribuição das respostas obtidas na pesquisa de campo quanto à pergunta 'A gestão do conhecimento ajuda a diminuir o ABSENTEÍSMO (ausências e faltas ao trabalho)'.

$\begin{array}{crc}\text { Tabela } 104 \text { - Fator de eficácia empresarial 'absenteísmo' } \\ \text { Nota atribuída } & \text { Frequência } & \text { Percentual } \\ 1 & 96 & 30,1 \% \\ 2 & 119 & 37,3 \% \\ 3 & 68 & 21,4 \% \\ 4 & 33 & 10,3 \% \\ 5 & 3 & 0,9 \% \\ \text { Total } & 319 & 100,0 \%\end{array}$

A nota mais atribuída pelos respondentes para o fator de eficácia empresarial 'absentismo' foi a nota 2 com 119 indicações (37,3\% do total). A média das notas atribuídas a esta prática foi 2,1 .

\subsubsection{Fator de eficácia empresarial - Rotatividade}

A Tabela 105 expõe a distribuição das respostas obtidas na pesquisa de campo quanto à pergunta 'A gestão do conhecimento ajuda a diminuir a ROTATIVIDADE (turn over relação entre admissões e demissões) de empregados'.

\begin{tabular}{|c|c|c|}
\hline Nota atribuída & Frequência & Percentual \\
\hline 1 & 87 & $27,3 \%$ \\
\hline 2 & 126 & $39,5 \%$ \\
\hline 3 & 83 & $26,0 \%$ \\
\hline 4 & 20 & $6,3 \%$ \\
\hline 5 & 3 & $0,9 \%$ \\
\hline Total & 319 & $100,0 \%$ \\
\hline
\end{tabular}


A nota mais atribuída pelos respondentes para o fator de eficácia empresarial 'rotatividade' foi a nota 2 com 126 indicações (39,5\% do total). A média das notas atribuídas a esta prática foi 2,1 .

\subsubsection{Fator de eficácia empresarial - Motivação e satisfação}

A Tabela 106 expõe a distribuição das respostas obtidas na pesquisa de campo quanto à pergunta 'A gestão do conhecimento ajuda a elevar a MOTIVAÇÃO e SATISFAÇÃO dos empregados no trabalho'.

\begin{tabular}{|c|c|c|}
\hline Nota atribuída & Frequência & Percentual \\
\hline 1 & 54 & $16,9 \%$ \\
\hline 2 & 105 & $32,9 \%$ \\
\hline 3 & 90 & $28,2 \%$ \\
\hline 4 & 63 & $19,8 \%$ \\
\hline 5 & 7 & $2,2 \%$ \\
\hline Total & 319 & $100,0 \%$ \\
\hline
\end{tabular}

A nota mais atribuída pelos respondentes para o fator de eficácia empresarial 'motivação e satisfação' foi a nota 2 com 105 indicações (32,9\% do total). A média das notas atribuídas a esta prática foi 2,6 .

\subsubsection{Fator de eficácia empresarial - Desenvolvimento das pessoas}

A Tabela 107 expõe a distribuição das respostas obtidas na pesquisa de campo quanto à pergunta 'A gestão do conhecimento ajuda no DESENVOLVIMENTO DAS PESSOAS'.

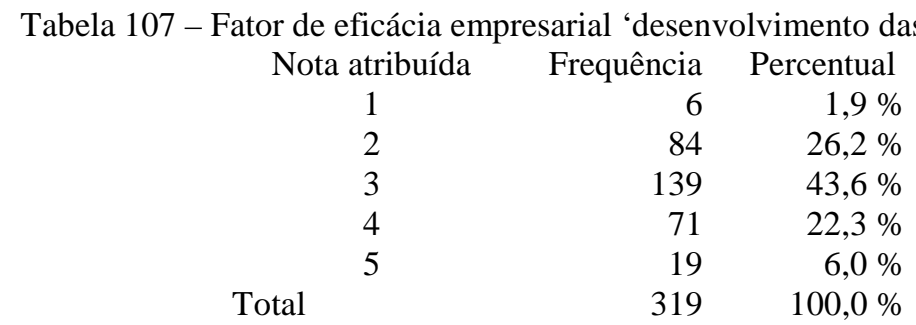

A nota mais atribuída pelos respondentes para $\mathrm{o}$ fator de eficácia empresarial 'desenvolvimento das pessoas' foi a nota 3 com 139 indicações (43,6\% do total). A média das notas atribuídas a esta prática foi 3,0. 


\subsubsection{Fator de eficácia empresarial - Adaptabilidade}

A Tabela 108 expõe a distribuição das respostas obtidas na pesquisa de campo quanto à pergunta 'A gestão do conhecimento aumenta a ADAPTABILIDADE a novas situações de mercado'.

\begin{tabular}{|c|c|c|}
\hline Nota atribuída & Frequência & Percentual \\
\hline 1 & 38 & $11,9 \%$ \\
\hline 2 & 93 & $29,2 \%$ \\
\hline 3 & 105 & $32,9 \%$ \\
\hline 4 & 76 & $23,8 \%$ \\
\hline 5 & 7 & $2,2 \%$ \\
\hline Total & 319 & $100,0 \%$ \\
\hline
\end{tabular}

A nota mais atribuída pelos respondentes para o fator de eficácia empresarial 'adaptabilidade' foi a nota 3 com 105 indicações (32,9\% do total). A média das notas atribuídas a esta prática foi 2,7 .

\subsubsection{Fator de eficácia empresarial - Estabilidade}

A Tabela 109 expõe a distribuição das respostas obtidas na pesquisa de campo quanto à pergunta 'A gestão do conhecimento traz maior ESTABILIDADE às pessoas e à empresa como um todo'.

\begin{tabular}{|c|c|c|}
\hline $\begin{array}{r}\text { Tabela } 109 \text { - Fator de ef } \\
\text { Nota atribuída }\end{array}$ & $\begin{array}{l}\text { ia empresari } \\
\text { Frequência }\end{array}$ & $\begin{array}{l}\text { 'estabilidade } \\
\text { Percentual }\end{array}$ \\
\hline 1 & 56 & $17,6 \%$ \\
\hline 2 & 113 & $35,4 \%$ \\
\hline 3 & 104 & $32,6 \%$ \\
\hline 4 & 36 & $11,3 \%$ \\
\hline 5 & 10 & $3,1 \%$ \\
\hline Total & 319 & $100,0 \%$ \\
\hline
\end{tabular}

A nota mais atribuída pelos respondentes para o fator de eficácia empresarial 'estabilidade' foi a nota 2 com 113 indicações $(35,4 \%$ do total). A média das notas atribuídas a esta prática foi 2,5 . 


\subsubsection{Fator de eficácia empresarial - Controle}

A Tabela 110 expõe a distribuição das respostas obtidas na pesquisa de campo quanto à pergunta 'A gestão do conhecimento ajuda a melhorar o CONTROLE sobre as atividades e os resultados'.

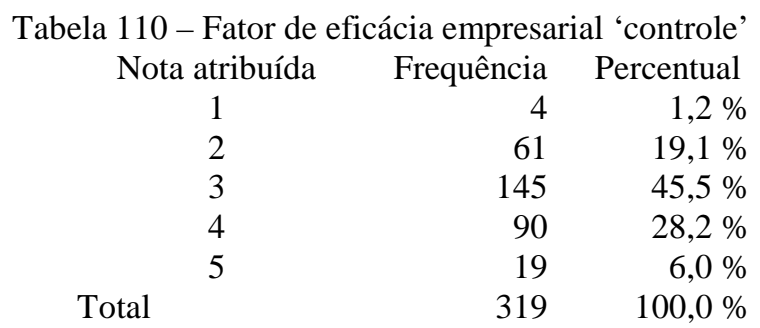

A nota mais atribuída pelos respondentes para o fator de eficácia empresarial 'controle' foi a nota 3 com 145 indicações $(45,5 \%$ do total). A média das notas atribuídas a esta prática foi 3,2 .

\subsubsection{Principais resultados verificados nos fatores de eficácia empresarial}

Os principais resultados da pesquisa de campo quanto aos fatores de eficácia empresarial oriundos das práticas de gestão de conhecimento e das ferramentas de tecnologia da informação e comunicação verificadas nas empresas analisadas estão consolidados na Tabela 111. Nela é possível observar, para cada fator de eficácia empresarial pesquisado, a nota mais indicada pelos respondentes, sua frequência e respectivo percentual, bem como a nota média do fator de eficácia empresarial em questão. 


\begin{tabular}{lcccc}
\multicolumn{3}{c}{ Tabela 111 - Resumo dos principais resultados acerca dos fatores de eficácia empresarial } \\
Fotores de eficácia empresarial & $\begin{array}{c}\text { Notas } \\
\text { indicada }\end{array}$ & $\begin{array}{c}\text { Frequência } \\
\text { da nota mais } \\
\text { indicada }\end{array}$ & $\begin{array}{c}\text { Percentual da } \\
\text { nota mais } \\
\text { indicada }\end{array}$ & $\begin{array}{c}\text { Nota } \\
\text { média }\end{array}$ \\
\cline { 2 - 4 } EA01. Objetivos corporativos & 3 & 130 & $40,8 \%$ & 3,32 \\
EA02. Produtividade & 4 & 115 & $36,1 \%$ & 3,63 \\
EA03. Lucro e rentabilidade & 3 & 115 & $36,1 \%$ & 3,46 \\
EA04. Eficiência & 3 & 114 & $35,7 \%$ & 3,56 \\
EA05. Desenvolvimento e crescimento & 3 & 113 & $35,4 \%$ & 3,38 \\
EB06. Coesão e harmonia & 2 & 95 & $29,8 \%$ & 2,48 \\
EB07. Ambiente organizacional & 3 & 112 & $35,1 \%$ & 2,98 \\
EB08. Moral & 2 & 125 & $39,2 \%$ & 2,29 \\
EB09. Absenteísmo & 2 & 119 & $37,3 \%$ & 2,15 \\
EB10. Rotatividade & 2 & 126 & $39,5 \%$ & 2,14 \\
EB11. Motivação e satisfação & 2 & 105 & $32,9 \%$ & 2,57 \\
EB12. Desenvolvimento das pessoas & 3 & 139 & $43,6 \%$ & 3,04 \\
EC13. Adaptabilidade & 3 & 105 & $32,9 \%$ & 2,75 \\
EC14. Estabilidade & 2 & 113 & $35,4 \%$ & 2,47 \\
ED15. Controle & 3 & 145 & $45,5 \%$ & 3,18
\end{tabular}

As notas médias dos 15 fatores de eficácia empresarial variaram dentre o intervalo compreendido entre 2,14 e 3,63; para uma escala de 0 (zero) a cinco (5) pontos.

\subsection{Análise e discussão dos resultados da pesquisa}

Nos tópicos a seguir os resultados da pesquisa de campo são analisados e discutidos, notadamente a respeito dos seguintes itens:

- Principais práticas de gestão do conhecimento;

- Principais ferramentas de tecnologia da informação e comunicação adotadas na gestão do conhecimento;

- Principais indicadores de eficácia empresarial;

- Influência do ambiente de teletrabalho;

- Influência do nível hierárquico;

- Estatísticas para validação das variáveis latentes do modelo empírico de tratamento e análise dos dados;

- Validação do modelo; 


\subsubsection{Principais práticas de gestão de conhecimento}

A Tabela 112 exibe as práticas de gestão de conhecimento dispostas em ordem decrescente a partir da nota média averiguada na pesquisa de campo.

Tabela 112 - Ranking das práticas de gestão do conhecimento

Práticas de gestão do conhecimento

Primeiro Quartil

PE40. Reuniões e conferências virtuais

PE41. Treinamentos virtuais

PC24. Treinamentos presenciais

PE42. E-learning

PB08. Call center/help desk/suporte

PE38. Portal corporativo

PE39. Biblioteca corporativa

PD28. Sistema de avaliação

PB07. Centros de inovação

PC27. Mapeamento de processos

PA03. Gestão da inovação

Segundo Quartil

PB13. Espaços e situações

PC16. Planos de carreira

PC15. Mapeamento de conhecimentos

PE31. Banco de conhecimentos

PE32. Gestão de conteúdos

PA05. Comunicação corporativa

PC25. Multiplicadores

PD33. Busca de conhecimentos

PC14. Mapeamento de competências

PD30. Propriedade intelectual

PA06. Benchmarking

PE34. Inteligência competitiva

Terceiro Quartil

PD29. Patentes

PC17. Sistema de reconhecimento

PC21. Repositório de melhores práticas

PC22. Comunidades de prática

PE35. Business inteligence

PA02. Políticas declaradas

PA01. Estratégia declarada

PA04. Gestão por competências

PB12. Redes de especialistas

PC23. Educação corporativa

PB10. Centro de competências

PE36. Wikis, blogs, twitters

Quarto Quartil

PC20. Repositório de lições aprendidas

PC26. Story telling

PB09. CKO/CKM

PB11. Área interna/depto. específico

PE37. Páginas amarelas internas

PE43. Universidade corporativa

PE44. Sumarização

PE45. Inventários

PC18. Coaching

PC19. Mentoring

PE46. Ontologia/taxonomia

$\begin{array}{cc}\text { Nota } & \text { Frequência } \\ \text { mais } & \text { da nota mais } \\ \text { indicada } & \text { indicada }\end{array}$

8

8

8

6

7 e 8

8

6

6

6

6

6

6

4

5

6

6

5

6

5

6

6

5

5

6

5

6

5

5

5

6

5

4

4

4

5

5

4

4

4

6

4

4

4

5

4

2

107

68 (cada)

99

Percentual da
nota mais
indicada


Após o ordenamento decrescente dos resultados, as práticas de gestão de conhecimento foram segregadas em quartis, de modo a evidenciar quais foram as mais utilizadas pelas empresas analisadas pela pesquisa de campo. Dessa forma, destacam-se no primeiro quartil as seguintes práticas individuais mais presentes na gestão do conhecimento:

- PE40. Reuniões e conferências virtuais

- PE41. Treinamentos virtuais

- PC24. Treinamentos presenciais

- PE42. E-learning

- PB08. Call center/help desk/suporte

- PF38. Portal corporativo

- PF39. Biblioteca corporativa

- PF28. Sistema de avaliação

- PB07. Centros de inovação

- PD27. Mapeamento de processos

- PA03. Gestão da inovação

Já as práticas de gestão do conhecimento constantes no último quartil, ou seja, as práticas menos indicadas foram:

- PC20. Repositório de lições aprendidas

- PC26. Story telling

- PB09. CKO/CKM

- PB11. Área interna/depto. específico

- PE37. Páginas amarelas internas

- PE43. Universidade corporativa

- PE44. Sumarização

- PE45. Inventários

- PC18. Coaching

- PC19. Mentoring

- PE46. Ontologia/taxonomia 
Outra forma de explicitar a realidade verificada na pesquisa de campo efetuada é a indicação da contribuição de cada dimensão. Ou seja, a dimensão de práticas de gestão do conhecimento conjuntamente apresenta, a partir da soma de suas práticas componetes, um determinado grau de influência na eficácia empresarial. A figura a seguir exibe os resultados de cada uma das dimensões das práticas apuradas.

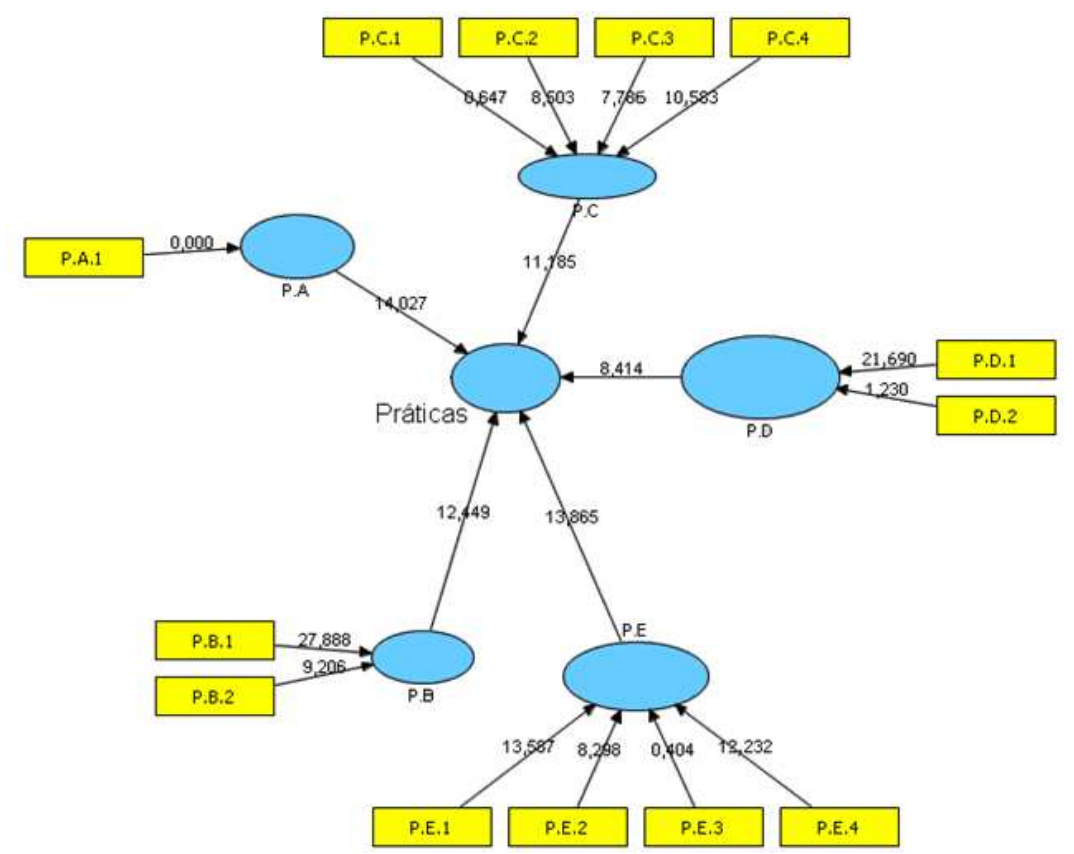

Figura 9 - Resultados das dimensões das práticas de gestão do conhecimento.

A partir das informações acima expostas, obtém-se que as dimensões de práticas de gestão do conhecimento apresentaram-se na seguinte ordem:

- Dimensão estratégia (PA), com peso fatorial 14,027

- Dimensão tecnologia (PE), com peso fatorial 13,865

- Dimensão estrutura (PB), com peso fatorial 12,449

- Dimensão pessoas/cultura organizacional (PC), com peso fatorial 11,185

- $\quad$ Dimensão processos (PD), com peso fatorial 8,414

Assim, observa-se que a dimensão de práticas de gestão do conhecimento que mais contribui para a eficácia empresarial é a dimensão estratégia (PA). Já a que menos contribuiu foi a dimensão processos (PD). 


\subsubsection{Principais ferramentas de tecnologia da informação e comunicação adotadas na gestão do conhecimento}

A Tabela 113 exibe as ferramentas de tecnologia da informação e comunicação voltadas à gestão de conhecimento dispostas em ordem decrescente a partir da nota média averiguada na pesquisa de campo.

Tabela 113 - Ranking das ferramentas de TIC aplicadas na gestão do conhecimento

\begin{tabular}{|c|c|c|c|c|}
\hline $\begin{array}{c}\text { Ferramentas de tecnologia da informação e } \\
\text { comunicação } \\
\text { na gestão do conhecimento }\end{array}$ & $\begin{array}{l}\text { Nota } \\
\text { mais } \\
\text { indicada }\end{array}$ & $\begin{array}{l}\text { Frequência } \\
\text { da nota mais } \\
\text { indicada }\end{array}$ & $\begin{array}{l}\text { Percentual da } \\
\text { nota mais } \\
\text { indicada }\end{array}$ & $\begin{array}{l}\text { Nota } \\
\text { média }\end{array}$ \\
\hline \multicolumn{5}{|l|}{ Primeiro Quartil } \\
\hline FC17. E-mail & 8 & 112 & $35,10 \%$ & 8,15 \\
\hline FC13. Telefone via internet & 8 & 105 & $32,90 \%$ & 7,75 \\
\hline FC12. Telefone celular/rádio & 8 & 97 & $30,40 \%$ & 7,70 \\
\hline FD22. Intranet & 8 & 107 & $33,50 \%$ & 7,67 \\
\hline FD24. Servidores web e navegadores & 8 & 101 & $31,70 \%$ & 7,60 \\
\hline FC11. Telefone fixo & 8 & 96 & $30,10 \%$ & 7,48 \\
\hline FC16. Mensagens instantâneas & 8 & 111 & $34,80 \%$ & 7,45 \\
\hline FD26. Portal corporativo & 7 & 94 & $29,50 \%$ & 7,11 \\
\hline FE27. CBT & 8 & 93 & $29,20 \%$ & 7,00 \\
\hline \multicolumn{5}{|l|}{$\underline{\text { Segundo Quartil }}$} \\
\hline FC14. Videoconferência & 8 & 95 & $29,80 \%$ & 6,93 \\
\hline FE28. WBT & 7 & 93 & $29,20 \%$ & 6,82 \\
\hline FD23. Extranet & 6 & 80 & $25,10 \%$ & 6,76 \\
\hline FC15. Salas de bate-papo & 8 & 88 & $27,60 \%$ & 6,52 \\
\hline FD25. Repositório de conhecimentos & 6 & 85 & $26,60 \%$ & 6,47 \\
\hline FC18. Fóruns de discussão & 6 & 71 & $22,30 \%$ & 5,94 \\
\hline FF32. Customização/personalização & 6 & 81 & $25,40 \%$ & 5,89 \\
\hline FC19. Groupware & 5 & 84 & $26,30 \%$ & 5,79 \\
\hline FC21. Workflow & 6 & 86 & $26,60 \%$ & 5,75 \\
\hline FA02. Modelos & 5 & 85 & $26,60 \%$ & 5,71 \\
\hline \multicolumn{5}{|l|}{ Terceiro Quartil } \\
\hline FA01. Autoria & 6 & 98 & $30,70 \%$ & 5,69 \\
\hline FE29. EPSS & 6 & 98 & $30,70 \%$ & 5,68 \\
\hline FF30. Sistemas especializados & 6 & 87 & $27,30 \%$ & 5,62 \\
\hline FF31. DSS & 6 & 94 & $29,50 \%$ & 5,50 \\
\hline FF35. Mapas de conhecimento & 6 & 87 & $27,30 \%$ & 5,39 \\
\hline FB09. Arquivamento de conteúdos & 5 & 69 & $21,60 \%$ & 5,31 \\
\hline FB07. Metadados & 5 & 69 & $21,60 \%$ & 5,19 \\
\hline FB08. Classificação de conteúdos & 5 & 92 & $28,80 \%$ & 5,02 \\
\hline FA03. Anotações & 4 & 87 & $27,30 \%$ & 5,01 \\
\hline FF34. Visualização & 4 & 91 & $28,50 \%$ & 5,00 \\
\hline \multicolumn{5}{|l|}{ Quarto Quartil } \\
\hline FC20. Wikis & 6 & 67 & $21,00 \%$ & 4,97 \\
\hline FF36. Agentes de Inteligência & 4 & 72 & $22,60 \%$ & 4,90 \\
\hline FB10. Gestão de conhecim. pessoal & 5 & 72 & $22,60 \%$ & 4,74 \\
\hline FA05. Perfil de experts & 4 & 76 & $23,80 \%$ & 4,56 \\
\hline FA04. Data mining & 4 & 93 & $29,20 \%$ & 4,37 \\
\hline FF33. Sistema recomendador & 4 & 78 & $24,50 \%$ & 4,23 \\
\hline FA06. Blogs & 5 & 84 & $26,30 \%$ & 4,15 \\
\hline FF38. Análise de conteúdos & 4 & 95 & $29,80 \%$ & 4,08 \\
\hline FF37. Sistema de taxonomia automatizado & 4 & 67 & $21,00 \%$ & 3,48 \\
\hline
\end{tabular}


Após o ordenamento decrescente dos resultados, as ferramentas de tecnologia da informação e comunicação voltadas à gestão do conhecimento foram segregadas em quartis, de modo a evidenciar quais foram as mais utilizadas pelas empresas analisadas pela pesquisa de campo. Dessa forma, destacam-se no primeiro quartil as seguintes ferramentas mais utilizadas na gestão do conhecimento:

- FC17. E-mail

- FC13. Telefone via internet

- FC12. Telefone celular/rádio

- FD22. Intranet

- FD24. Servidores web e navegadores

- FC11. Telefone fixo

- FC16. Mensagens instantâneas

- FD26. Portal corporativo

- FE27. CBT

Já as ferramentas de tecnologia da informação e comunicação constantes no último quartil, ou seja, as ferramentas menos indicadas foram:

- FC20. Wikis

- FF36. Agentes de Inteligência

- FB10. Gestão de conhecimento pessoal

- FA05. Perfil de experts

- FA04. Data mining

- FF33. Sistema recomendador

- FA06. Blogs

- FF38. Análise de conteúdos

- FF37. Sistema de taxonomia automatizado

Além da análise de cada ferramenta em si, outra possibilidade de analisar a realidade das empresas dos respondentes é a indicação da contribuição de cada dimensão, ou seja, a contribuição do somatório das ferramentas pertencentes à determinada dimensão. Cada dimensão então indica um certo peso de influência na eficácia empresarial. A figura a seguir 
exibe os resultados de cada uma das dimensões das ferramentas de tecnologia da informação e comunicação apuradas.

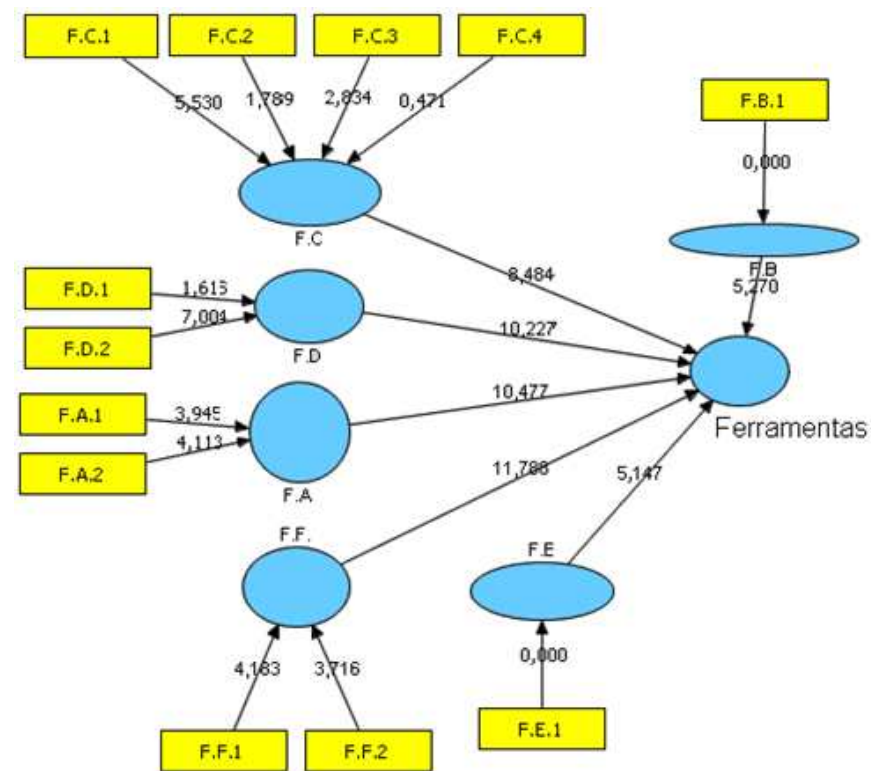

Figura 10 - Resultados das dimensões das ferramentas de tecnologia da informação e comunicação.

A partir das informações acima expostas, obtém-se que as dimensões de ferramentas de tecnologia da informação e comunicação empregadas na gestão do conhecimento apresentaram-se na seguinte ordem:

- Dimensão inteligência artificial (FF), com peso fatorial 11,786

- Dimensão criação de conteúdo (FA), com peso fatorial 10,477

- Dimensão tecnologias de rede (FD), com peso fatorial 10,227

- Dimensão comunicação e tecnologias colaborativas (FC), com peso fatorial 8,484

- Dimensão gestão de conteúdo (FB), com peso fatorial 5,270

- Dimensão e-learning (FE), com peso fatorial 5,147

Assim, observa-se que a dimensão de ferramentas de tecnologia da informação e comunicação que mais contribui para a eficácia empresarial é a dimensão inteligência artificial (FF). Já a que menos contribuiu foi a e-learning (FE). 


\subsubsection{Principais indicadores de eficácia empresarial}

A Tabela 114 exibe os indicadores de eficácia empresarial dispostos em ordem decrescente a partir da nota média averiguada na pesquisa de campo.

Tabela 114 - Ranking dos indicadores de eficácia empresarial

\begin{tabular}{lcrrr} 
Indicadores de eficácia empresarial & $\begin{array}{c}\text { Nota mais } \\
\text { indicada }\end{array}$ & $\begin{array}{c}\text { Frequência } \\
\text { da nota mais } \\
\text { indicada }\end{array}$ & $\begin{array}{c}\text { Percentual da } \\
\text { nota mais } \\
\text { indicada }\end{array}$ & $\begin{array}{c}\text { Nota } \\
\text { média }\end{array}$ \\
\cline { 2 - 4 } Primeiro Quartil & 4 & 115 & $36,10 \%$ & 3,63 \\
EA02. Produtividade & 3 & 114 & $35,70 \%$ & 3,56 \\
EA04. Eficiência & 3 & 115 & $36,10 \%$ & 3,46 \\
EA03. Lucro e rentabilidade & 3 & 113 & $35,40 \%$ & 3,38 \\
EA05. Desenvolvimento e crescimento & 3 & & & \\
Segundo Quartil & 3 & 130 & $40,80 \%$ & 3,32 \\
EA01. Objetivos corporativos & 3 & 145 & $45,50 \%$ & 3,18 \\
ED15. Controle & 3 & 139 & $43,60 \%$ & 3,04 \\
EB12. Desenvolvimento das pessoas & & 112 & $35,10 \%$ & 2,98 \\
EB07. Ambiente organizacional & 3 & & & \\
Terceiro Quartil & 2 & 105 & $32,90 \%$ & 2,75 \\
EC13. Adaptabilidade & 2 & 105 & $32,90 \%$ & 2,57 \\
EC11. Motivação e satisfação & 2 & 95 & $29,80 \%$ & 2,48 \\
EB06. Coesão e harmonia & & 113 & $35,40 \%$ & 2,47 \\
EC14. Estabilidade & 2 & & & \\
Quarto Quartil & 2 & 125 & $39,20 \%$ & 2,29 \\
EC08. Moral & 2 & 119 & $37,30 \%$ & 2,15 \\
EC09. Absenteísmo & & 126 & $39,50 \%$ & 2,14 \\
EC10. Rotatividade & & &
\end{tabular}

Após o ordenamento decrescente dos resultados, os fatores de eficácia empresarial foram segregados em quartis, de modo a evidenciar quais foram os mais utilizados pelas empresas analisadas pela pesquisa de campo. Dessa forma, destacam-se no primeiro quartil os fatores mais indicados, quais sejam:

- EA02. Produtividade

- EA04. Eficiência

- EA03. Lucro e rentabilidade

- EA05. Desenvolvimento e crescimento

Já os fatores de eficácia empresarial constantes no último quartil, ou seja, os fatores menos indicados foram:

- EB08. Moral

- EB09. Absenteísmo 
- EB10. Rotatividade

Ressalte-se que todos os quatro fatores mais indicados pertencem à dimensão econômica, enquanto que os três fatores menos indicados pertencem à dimensão social de eficácia empresarial.

\subsubsection{Influência do ambiente de teletrabalho}

Neste tópico é analisada a influência do ambiente de teletrabalho sobre as práticas de gestão do conhecimento e sobre as ferramentas de tecnologia da informação e comunicação empregadas na gestão do conhecimento das empresas pesquisadas.

\subsubsection{Influência do ambiente de teletrabalho - Práticas de gestão do conhecimento}

Os principais resultados da pesquisa de campo quanto às práticas de gestão de conhecimento verificadas nas empresas analisadas em ambiente de teletrabalho ou ambientes de trabalho presencial estão consolidados na Tabela 115. Nela é possível observar, para cada prática de gestão do conhecimento pesquisada, a nota média geral e as notas médias indicadas pelos respondentes teletrabalhadores e pelos respondentes não-teletrabalhadores. Além disso, também são expostos os resultados do teste estatístico aplicado para a validação da significância das diferenças encontradas. 
Tabela 115 - Resumo comparativo dos principais resultados acerca das práticas de gestão do conhecimento entre teletrabalhadores e não-teletrabalhadores

Práticas de gestão do conhecimento

\begin{tabular}{|c|c|c|c|}
\hline $\begin{array}{l}\text { Nota } \\
\text { média } \\
\text { geral }\end{array}$ & $\begin{array}{l}\text { Nota média } \\
\text { dos teletraba- } \\
\text { lhadores }\end{array}$ & $\begin{array}{c}\text { Nota média dos } \\
\text { não-tele- } \\
\text { trabalhadores }\end{array}$ & $\begin{array}{l}\text { Significância } \\
\text { das diferenças }\end{array}$ \\
\hline 5,24 & $5,29^{\text {(a) }}$ & 5,21 & $0,72^{\text {(b) }}$ \\
\hline 5,27 & $5,32^{\text {(a) }}$ & 5,24 & $0,63^{(b)}$ \\
\hline 5,85 & $6,04^{\text {(a) }}$ & 5,69 & 0,04 \\
\hline 5,22 & $5,37^{\text {(a) }}$ & 5,11 & $0,26^{\text {(b) }}$ \\
\hline 5,75 & $6,00^{\text {(a) }}$ & 5,56 & 0,04 \\
\hline 5,66 & $5,76^{\text {(a) }}$ & 5,59 & $0,33^{\text {(b) }}$ \\
\hline 5,97 & $6,14^{\text {(a) }}$ & 5,83 & 0,04 \\
\hline 6,57 & $6,72^{\text {(a) }}$ & 6,46 & $0,11^{\text {(b) }}$ \\
\hline 4,75 & $4,86^{\text {(a) }}$ & 4,67 & $0,73^{(b)}$ \\
\hline 4,95 & $5,14^{\text {(a) }}$ & 4,81 & 0,03 \\
\hline 4,66 & $4,91^{\text {(a) }}$ & 4,48 & $0,09^{(b)}$ \\
\hline 5,16 & $5,35^{\text {(a) }}$ & 5,01 & $0,16^{\text {(b) }}$ \\
\hline 5,80 & $5,85^{\text {(a) }}$ & 5,77 & $0,75^{\text {(b) }}$ \\
\hline 5,72 & 5,61 & $5,81^{\text {(a) }}$ & 0,17 \\
\hline 5,77 & $5,94^{\text {(a) }}$ & 5,88 & $0,07^{\text {(b) }}$ \\
\hline 5,78 & 5,41 & $6,07^{\text {(a) }}$ & 0,00 \\
\hline 5,50 & 4,98 & $5,90^{\text {(a) }}$ & 0,00 \\
\hline 4,12 & $4,13^{\text {(a) }}$ & 4,12 & $0,61^{\text {(b) }}$ \\
\hline 3,80 & $3,86^{\text {(a) }}$ & 3,83 & $0,83^{\text {(b) }}$ \\
\hline 4,86 & $4,91^{\text {(a) }}$ & 4,82 & $0,25^{\text {(b) }}$ \\
\hline 5,35 & $5,41^{\text {(a) }}$ & 5,30 & $0,29^{\text {(b) }}$ \\
\hline 5,32 & $5,33^{\text {(a) }}$ & 5,31 & $0,77^{\text {(b) }}$ \\
\hline 4,96 & $5,17^{\text {(a) }}$ & 4,79 & $0,07^{\text {(b) }}$ \\
\hline 6,74 & 6,55 & $6,89^{\text {(a) }}$ & 0,11 \\
\hline 5,74 & 5,69 & $5,77^{\text {(a) }}$ & 0,80 \\
\hline 4,82 & $4,96^{\text {(a) }}$ & 4,70 & $0,29^{\text {(b) }}$ \\
\hline 5,91 & $5,93^{\text {(a) }}$ & 5,91 & $0,90^{\text {(b) }}$ \\
\hline 6,46 & 6,17 & $6,69^{\text {(a) }}$ & 0,01 \\
\hline 5,54 & $5,62^{\text {(a) }}$ & 5,48 & $0,61^{\text {(b) }}$ \\
\hline 5,67 & $5,71^{\text {(a) }}$ & 5,64 & $0,82^{\text {(b) }}$ \\
\hline 5,77 & $5,88^{\text {(a) }}$ & 5,69 & $0,25^{\text {(b) }}$ \\
\hline 5,76 & $5,90^{\text {(a) }}$ & 5,65 & $0,22^{\text {(b) }}$ \\
\hline 5,73 & $5,83^{\text {(a) }}$ & 5,66 & $0,38^{\text {(b) }}$ \\
\hline 5,60 & $5,67^{\text {(a) }}$ & 5,54 & $0,37^{\text {(b) }}$ \\
\hline 5,32 & $5,45^{\text {(a) }}$ & 5,23 & $0,18^{\text {(b) }}$ \\
\hline 4,95 & $5,25^{\text {(a) }}$ & 4,72 & 0,02 \\
\hline 4,49 & $4,83^{\text {(a) }}$ & 4,23 & 0,02 \\
\hline 6,57 & $6,78^{\text {(a) }}$ & 6,40 & $0,08^{\text {(b) }}$ \\
\hline 6,49 & $6,50^{(a)}$ & 6,48 & $0,98^{(b)}$ \\
\hline 7,59 & 7,55 & $7,62^{\text {(a) }}$ & 0,77 \\
\hline 7,37 & 7,24 & $7,47^{\text {(a) }}$ & 0,19 \\
\hline 6,58 & 6,44 & $6,68^{\text {(a) }}$ & 0,17 \\
\hline 4,26 & $4,41^{\text {(a) }}$ & 4,14 & $0,42^{\text {(b) }}$ \\
\hline 4,17 & $4,22^{\text {(a) }}$ & 4,12 & $0,72^{\text {(b) }}$ \\
\hline 4,16 & $4,26^{\text {(a) }}$ & 4,08 & $0,38^{\text {(b) }}$ \\
\hline 3,56 & $3,63^{\text {(a) }}$ & 3,50 & $0,55^{\text {(b) }}$ \\
\hline
\end{tabular}

PA01. Estratégia declarada

PA02. Políticas declaradas

PA03. Gestão da inovação

PA04. Gestão por competências

PA05. Comunicação corporativa

PA06. Benchmarking

PB07. Centros de inovação

PB08. Call center/help desk/suporte

PB09. CKO/CKM

PB10. Centro de competências

PB11. Área interna/depto. específico

PB12. Redes de especialistas

PB13. Espaços e situações

PC14. Mapeamento de competências

PC15. Mapeamento de conhecimentos

PC16. Planos de carreira

PC17. Sistema de reconhecimento

PC18. Coaching

PC19. Mentoring

PC20. Repositório de lições aprendidas

PC21. Repositório de melhores práticas

PC22. Comunidades de prática

PC23. Educação corporativa

PC24. Treinamentos presenciais

PC25. Multiplicadores

PC26. Story telling

PD27. Mapeamento de processos

PD28. Sistema de avaliação

PD29. Patentes

PD30. Propriedade intelectual

PE31. Banco de conhecimentos

PE32. Gestão de conteúdos

PE33. Busca de conhecimentos

PE34. Inteligência competitiva

PE35. Business inteligence

PE36. Wikis, blogs, twitters

PE37. Páginas amarelas internas

PE38. Portal corporativo

PE39. Biblioteca corporativa

PE40. Reuniões e conferências virtuais

PE41. Treinamentos virtuais

PE42. E-learning

PE43. Universidade corporativa

PE44. Sumarização

PE45. Inventários

PE46. Ontologia/taxonomia

3,56

Legenda: (a) maior média dos dois grupos analisados; (b) diferença significativa em favor do ambiente de teletrabalho.

Para averiguação das diferenças encontradas entre as respostas dadas à cada variável pelos respondentes teletrabalhadores e não-teletrabalhadores quanto às práticas de gestão do 
conhecimento, fez-se uso do teste não-paramétrico Mann-Whitney. Este teste é empregado em distribuições não-normais de modo a verificar a significância das diferenças encontradas nos resultados de cada variável analisada nas respostas de dois conjuntos de dados (no caso, teletrabalho e não-teletrabalho). Assim, valores superiores a 0,05 são considerados significativos indicando, portanto, a existência de diferença relevante entre os resultados comparados, conforme Pestana e Gageiro (2005).

Das 46 práticas analisadas na pesquisa, observou-se a existência de diferença significativa em favor das respostas fornecidas pelos teletrabalhadores em 31 delas. Considerando-se ainda as 15 práticas restantes, apenas seis apresentram diferença significativa em favor das respostas fornecidas pelos trabalhadores presenciais, restando ainda outras nove que não apontaram diferença significativa entre os dois grupos respondentes. Ou seja, a cada três práticas de gestão do conhecimento analisadas, duas são mais intensamente utilizadas em ambientes de teletrabalho.

Dessa forma é possível diagnosticar que os respondentes teletrabalhadores, de forma geral, afirmam utilizar com mais intensidade as práticas de gestão do conhecimento empregadas em suas atividades, se comparados com os respondentes não-teletrabalhadores.

\subsubsection{Influência do ambiente de teletrabalho - Ferramentas de tecnologia da informação e comunicação}

Os principais resultados da pesquisa de campo quanto às ferramentas de tecnologia da informação e comunicação utilizadas na gestão de conhecimento verificadas nas empresas analisadas em ambiente de teletrabalho ou ambientes de trabalho presencial estão consolidados na Tabela 116. Nela é possível observar, para cada ferramenta de tecnologia da informação e comunicação pesquisada, a nota média geral e as notas médias indicadas pelos respondentes teletrabalhadores e pelos respondentes não-teletrabalhadores. De forma complementar, também são expostos os resultados do teste estatístico aplicado para a validação da significância das diferenças encontradas. 
Tabela 116 - Resumo comparativo dos principais resultados acerca das ferramentas de tecnologia da informação e comunicação aplicadas na gestão do conhecimento entre teletrabalhadores e não-teletrabalhadores

Ferramentas de tecnologia da informação

$$
\text { e comunicação }
$$

na gestão do conhecimento

FA01. Autoria

FA02. Modelos

FA03. Anotações

FA04. Data mining

FA05. Perfil de experts

FA06. Blogs

FB07. Metadados

FB08. Classificação de conteúdos

FB09. Arquivamento de conteúdos

FB10. Gestão de conhecim. pessoal

FC11. Telefone fixo

FC12. Telefone celular/rádio

FC13. Telefone via internet

FC14. Videoconferência

FC15. Salas de bate-papo

FC16. Mensagens instantâneas

FC17. E-mail

FC18. Fóruns de discussão

FC19. Groupware

FC20. Wikis

FC21. Workflow

FD22. Intranet

FD23. Extranet

FD24. Servidores web e navegadores

FD25. Repositório de conhecimentos

FD26. Portal corporativo

FE27. CBT

FE28. WBT

FE29. EPSS

FF30. Sistemas especializados

FF31. DSS

FF32. Customização/personalização

FF33. Sistema recomendador

FF34. Visualização

FF35. Mapas de conhecimento

FF36. Agentes de Inteligência

FF37. Sistema de taxonomia automatizado

FF38. Análise de conteúdos

Legenda: (a) maior média dos dois grupos analisados; teletrabalho.

\begin{tabular}{|c|c|c|c|}
\hline $\begin{array}{l}\text { Nota } \\
\text { média } \\
\text { geral }\end{array}$ & $\begin{array}{l}\text { Nota média } \\
\text { dos teletraba- } \\
\text { lhadores }\end{array}$ & $\begin{array}{l}\text { Nota média } \\
\text { dos não-tele- } \\
\text { trabalhadores }\end{array}$ & $\begin{array}{l}\text { Significância } \\
\text { das diferenças }\end{array}$ \\
\hline 5,69 & 5,59 & $5,76^{\text {(a) }}$ & 0,35 \\
\hline 5,71 & 5,50 & $5,87^{\text {(a) }}$ & 0,06 \\
\hline 5,01 & 4,96 & $5,05^{\text {(a) }}$ & 0,46 \\
\hline 4,37 & 4,24 & $4,47^{\text {(a) }}$ & 0,24 \\
\hline 4,56 & $4,70^{\text {(a) }}$ & 4,60 & $0,72^{(b)}$ \\
\hline 4,15 & $4,24^{\text {(a) }}$ & 4,08 & $0,58^{\text {(b) }}$ \\
\hline 5,19 & $5,27^{\text {(a) }}$ & 5,13 & $0,40^{\text {(b) }}$ \\
\hline 5,02 & $5,19^{\text {(a) }}$ & 5,07 & $0,68^{\text {(b) }}$ \\
\hline 5,31 & $5,45^{\text {(a) }}$ & 5,21 & $0,37^{\text {(b) }}$ \\
\hline 4,74 & $4,93^{\text {(a) }}$ & 4,59 & $0,39^{\text {(b) }}$ \\
\hline 7,48 & $7,58^{\text {(a) }}$ & 7,40 & $0,67^{\text {(b) }}$ \\
\hline 7,70 & $7,73^{\text {(a) }}$ & 7,68 & $0,74^{\text {(b) }}$ \\
\hline 7,75 & 7,60 & $7,86^{\text {(a) }}$ & 0,19 \\
\hline 6,93 & $6,97^{\text {(a) }}$ & 6,90 & $0,56^{(\mathrm{b})}$ \\
\hline 6,52 & $6,74^{\text {(a) }}$ & 6,36 & $0,06^{(b)}$ \\
\hline 7,45 & $7,52^{(a)}$ & 7,48 & $0,87^{\text {(b) }}$ \\
\hline 8,15 & 8,08 & $8,28^{\text {(a) }}$ & 0,20 \\
\hline 5,94 & 5,79 & $6,05^{\text {(a) }}$ & 0,10 \\
\hline 5,79 & $5,86^{(a)}$ & 5,82 & $0,63^{(b)}$ \\
\hline 4,97 & $5,21^{\text {(a) }}$ & 4,79 & $0,09^{\text {(b) }}$ \\
\hline 5,75 & $5,80^{(a)}$ & 5,71 & $0,48^{\text {(b) }}$ \\
\hline 7,67 & $7,91^{\text {(a) }}$ & 7,72 & $0,48^{\text {(b) }}$ \\
\hline 6,76 & 6,61 & $6,87^{\text {(a) }}$ & 0,11 \\
\hline 7,60 & $7,76^{(a)}$ & 7,56 & $0,74^{\text {(b) }}$ \\
\hline 6,47 & $6,64^{\text {(a) }}$ & 6,14 & $0,14^{\text {(b) }}$ \\
\hline 7,11 & $7,12^{\text {(a) }}$ & 7,11 & $0,91^{\text {(b) }}$ \\
\hline 7,00 & 6,93 & $7,06^{\text {(a) }}$ & 0,16 \\
\hline 6,82 & 6,61 & $6,99^{\text {(a) }}$ & 0,02 \\
\hline 5,68 & $5,76^{(a)}$ & 5,73 & $0,20^{\text {(b) }}$ \\
\hline 5,62 & $5,84^{(a)}$ & 5,60 & $0,99^{\text {(b) }}$ \\
\hline 5,50 & $5,67^{(1)}$ & 5,61 & $0,06^{\text {(b) }}$ \\
\hline 5,89 & $6,01^{\text {(a) }}$ & 5,96 & $0,39^{\text {(b) }}$ \\
\hline 4,23 & $4,34^{\text {(a) }}$ & 4,14 & $0,47^{\text {(b) }}$ \\
\hline 5,00 & $5,13^{\text {(a) }}$ & 4,89 & $0,13^{\text {(b) }}$ \\
\hline 5,39 & $5,42^{\text {(a) }}$ & 5,38 & $0,58^{\text {(b) }}$ \\
\hline 4,90 & 4,73 & $5,04^{\text {(a) }}$ & 0,11 \\
\hline 3,48 & $3,60^{(a)}$ & 3,47 & $0,89^{\text {(b) }}$ \\
\hline 4,08 & $4,28^{\text {(a) }}$ & 3,93 & $0,17^{\text {(b) }}$ \\
\hline
\end{tabular}

; (b) diferença significativa em favor do ambiente de
0,06

0,24

$0,58^{(\text {b) }}$

$0,40^{(\mathrm{b})}$

$0,68^{(\mathrm{b})}$

$0,39^{\text {(b) }}$

$0,67^{\text {(b) }}$

$74^{\text {(b) }}$

$0,56^{\text {(b) }}$

$0,06^{(\mathrm{b})}$

0,20

0,10

$0,63^{\text {(b) }}$

$0,48^{\text {(b) }}$

$48^{\text {(b) }}$

0,11

14 (b)

$91^{\text {(b) }}$

0,16

0,02
(b)

$0,99^{\text {(b) }}$

$0,06^{\text {(b) }}$

$0,39^{\text {(b) }}$

$0,13^{\text {(b) }}$

, $58^{\text {(b) }}$

0,11

$0,17^{\text {(b) }}$ 
Das 38 ferramentas analisadas no estudo, observou-se a existência de diferença significativa em favor das respostas fornecidas pelos teletrabalhadores em 27 delas. Das 11 ferramentas restantes, em apenas uma delas (WBT - treinamento baseado na web) não houve diferença significativa apontada, ou seja, nas demais dez ferramentas apurou-se diferença significativa em favor das respostas dos trabalhadores presenciais. Assim, pode-se considerar que praticamente a cada quatro ferramentas de tecnologia da informação e comunicação apuradas analisadas, três são mais intensamente utilizadas em ambientes de teletrabalho.

Dessa forma é possível diagnosticar que os respondentes teletrabalhadores, de forma geral, afirmam utilizar com mais intensidade as ferramentas de tecnologia da informação e comunicação empregadas em atividades voltadas à gestão do conhecimento, se comparados com os respondentes não-teletrabalhadores.

\subsubsection{Influência do nível hierárquico}

Neste tópico a influência do nível hierárquico dos respondentes sobre as práticas de gestão do conhecimento e sobre as ferramentas de tecnologia da informação e comunicação é analisada.

\subsubsection{Influência do nível hierárquico - Práticas de gestão do conhecimento}

Os principais resultados da pesquisa de campo quanto às práticas de gestão de conhecimento verificadas nas empresas analisadas em relação ao nível hierárquico dos respondentes (gestores ou técnicos) estão consolidados na Tabela 117. Nela é possível observar, para cada prática de gestão do conhecimento pesquisada, a nota média geral e as notas médias indicadas pelos respondentes gestores e pelos respondentes técnicos. Além disso, também são expostos os resultados do teste estatístico aplicado para a validação da significância das diferenças encontradas. 
Tabela 117 - Resumo comparativo dos principais resultados acerca das práticas de gestão do conhecimento entre gestores e técnicos

Práticas de gestão do conhecimento

PA01. Estratégia declarada

PA02. Políticas declaradas

PA03. Gestão da inovação

PA04. Gestão por competências

PA05. Comunicação corporativa

PA06. Benchmarking Nota
média
geral
5,24

5,24

5,85

5,22

5,75

5,66

PB07. Centros de inovação

5,97

6,57

4,75

PB09. CKO/CKM

PB10. Centro de competências

PB11. Área interna/depto. específico

PB12. Redes de especialistas

PB13. Espaços e situações

PC14. Mapeamento de competências

PC15. Mapeamento de conhecimentos

PC16. Planos de carreira

PC17. Sistema de reconhecimento

PC18. Coaching

PC19. Mentoring

PC20. Repositório de lições aprendidas

PC21. Repositório de melhores práticas

PC22. Comunidades de prática

PC23. Educação corporativa

PC24. Treinamentos presenciais

PC25. Multiplicadores

PC26. Story telling

PD27. Mapeamento de processos

PD28. Sistema de avaliação

PD29. Patentes

PD30. Propriedade intelectual

PE31. Banco de conhecimentos

PE32. Gestão de conteúdos

PE33. Busca de conhecimentos

PE34. Inteligência competitiva

PE35. Business inteligence

PE36. Wikis, blogs, twitters

PE37. Páginas amarelas internas

PE38. Portal corporativo

PE39. Biblioteca corporativa

PE40. Reuniões e conferências virtuais

PE41. Treinamentos virtuais

PE42. E-learning

PE43. Universidade corporativa

PE44. Sumarização

PE45. Inventários

PE46. Ontologia/taxonomia

Legenda: (a) maior média dos dois grupos analisados; teletrabalho.
Nota média

dos técnicos

$5,78^{(a)}$

$5,79^{\text {(a) }}$

$6,24^{\text {(a) }}$

$5,60^{\text {(a) }}$

$6,03^{\text {(a) }}$

$5,88^{\text {(a) }}$

5,87

$6,58^{\text {(a) }}$

$5,04^{\text {(a) }}$

$5,30^{(a)}$

$5,04^{\text {(a) }}$

$5,37^{\text {(a) }}$

$6,24^{\text {(a) }}$

$6,31^{\text {(a) }}$

$6,36^{\text {(a) }}$

$6,25^{(a)}$

$5,79^{\text {(a) }}$

$4,48^{\text {(a) }}$

$3,94^{\text {(a) }}$

$5,19^{\text {(a) }}$

$5,57^{(\text {a) }}$

$5,66^{\text {(a) }}$

$5,31^{\text {(a) }}$

$7,10^{(\mathrm{a})}$

$6,18^{\text {(a) }}$

$5,27^{\text {(a) }}$

$6,34^{\text {(a) }}$

$6,81^{\text {(a) }}$

$5,64^{\text {(a) }}$

5,61

$6,19^{\text {(a) }}$

$5,87^{\text {(a) }}$

$5,97^{\text {(a) }}$

$5,93^{\text {(a) }}$

$5,60^{\text {(a) }}$

$5,00^{\text {(a) }}$

$4,57^{\text {(a) }}$

$7,01^{\text {(a) }}$

$7,06^{\text {(a) }}$

$7,91^{\text {(a) }}$

$7,73^{\text {(a) }}$

$7,03^{\text {(a) }}$

$4,54^{\text {(a) }}$

$4,58^{\text {(a) }}$

$4,51^{\text {(a) }}$

3,60 (a)
5,10

5,13

5,74

5,12

5,67

5,61

$6,00^{\text {(a) }}$

6,57

4,67

4,86

4,56

5,10

5,69

5,56

5,62

5,66

5,42

4,02

3,76

4,77

5,29

5,23

4,86

6,65

5,62

4,69

5,79

6,37

5,51

$5,68^{\text {(a) }}$

5,66

5,73

5,67

5,51

5,25

4,94

4,47

6,45

6,34

7,50

7,27

6,46

4,19

4,06

4,07

3,55
Significância

das diferenças

$$
\begin{array}{r}
0,00 \\
0,01 \\
0,02 \\
0,06^{\text {(b) }} \\
0,10^{\text {(b) }} \\
0,26^{\text {(b) }} \\
0,57 \\
0,73^{\text {(b) }} \\
0,30^{\text {(b) }} \\
0,09^{\text {(b) }} \\
0,14^{\text {(b) }} \\
0,23^{\text {(b) }} \\
0,02 \\
0,00 \\
0,00 \\
0,01 \\
0,13^{\text {(b) }} \\
0,13^{\text {(b) }} \\
0,68^{\text {(b) }} \\
0,06^{\text {(b) }} \\
0,19^{\text {(b) }} \\
0,03 \\
0,07^{\text {(b) }} \\
0,26^{\text {(b) }} \\
0,08^{\text {(b) }} \\
0,09^{\text {(b) }} \\
0,98^{\text {(b) }} \\
0,12^{\text {(b) }} \\
0,02 \\
0,06^{\text {(b) }} \\
0,02 \\
0,07^{\text {(b) }} \\
0,01^{\text {(b) }} \\
0,61 \\
0,01 \\
0,45^{\text {(b) }} \\
0,15^{\text {(b) }} \\
0,02 \\
0,12^{\text {(b) }} \\
0,94^{\text {(b) }} \\
0,79^{\text {(b) }} \\
0,06^{\text {(b) }} \\
0,00 \\
0,000
\end{array}
$$

(b) diferença significativa em favor do ambiente de 
teste não-paramétrico Mann-Whitney. Este teste é empregado em distribuições não-normais de modo a verificar a significância das diferenças encontradas nos resultados de cada variável analisada nas respostas de dois conjuntos de dados (no caso, gestores e técnicos). Assim, valores superiores a 0,05 são considerados significativos indicando, portanto, a existência de diferença relevante entre os resultados comparados, conforme Pestana e Gageiro (2005).

Em 30 das 46 práticas analisadas observou-se a existência de diferença significativa em prol das respostas fornecidas pelos gestores. Ou seja, a cada três práticas avaliadas pelos respondentes, duas exibem diferença significativa de maior intensidade por parte dos gestores. Das 16 práticas restantes, apenas duas apresentam diferença significativa em favor de práticas apontadas pelos respondentes técnicos (centros de inovação e propriedade intelectual). Outras 14 práticas não apresentaram diferença significativa entre os dois grupos pesquisados.

Assim sendo, é possível diagnosticar que os respondentes gestores, de forma geral, afirmam utilizar com mais intensidade as práticas de gestão do conhecimento empregadas em suas atividades, se comparados com os respondentes técnicos.

\subsubsection{Influência do nível hierárquico - Ferramentas de tecnologia da informação e comunicação}

Os principais resultados da pesquisa de campo quanto às ferramentas de tecnologia da informação e comunicação utilizadas na gestão de conhecimento verificadas nas empresas analisadas quanto ao nível hierárquico dos respondentes (gestores ou técnicos) estão consolidados na Tabela 118. Nela é possível observar, para cada ferramenta de tecnologia da informação e comunicação pesquisada, a nota média geral e as notas médias indicadas pelos respondentes gestores e pelos respondentes técnicos. Além disso, também são expostos os resultados do teste estatístico aplicado para a validação da significância das diferenças encontradas nos dois grupos de respondentes. 
Tabela 118 - Resumo comparativo dos principais resultados acerca das ferramentas TIC aplicadas na gestão do conhecimento entre gestores e técnicos

\begin{tabular}{|c|c|c|c|c|}
\hline $\begin{array}{c}\text { Ferramentas de tecnologia da informação } \\
\text { e comunicação } \\
\text { na gestão do conhecimento }\end{array}$ & $\begin{array}{l}\text { Nota } \\
\text { média } \\
\text { geral }\end{array}$ & $\begin{array}{l}\text { Nota média } \\
\text { dos gestores }\end{array}$ & $\begin{array}{l}\text { Nota média } \\
\text { dos técnicos }\end{array}$ & $\begin{array}{l}\text { Significância } \\
\text { das diferenças }\end{array}$ \\
\hline FA01. Autoria & 5,69 & $5,90^{\text {(a) }}$ & 5,63 & $0,53^{(\mathrm{b})}$ \\
\hline FA02. Modelos & 5,71 & $6,15^{\text {(a) }}$ & 5,59 & $0,07^{\text {(b) }}$ \\
\hline FA03. Anotações & 5,01 & $5,51^{\text {(a) }}$ & 4,88 & 0,02 \\
\hline FA04. Data mining & 4,37 & $4,78^{(a)}$ & 4,27 & $0,06^{(\mathrm{b})}$ \\
\hline FA05. Perfil de experts & 4,56 & $4,90^{\text {(a) }}$ & 4,47 & $0,09^{\text {(b) }}$ \\
\hline FA06. Blogs & 4,15 & $4,30^{\text {(a) }}$ & 4,12 & $0,37^{\text {(b) }}$ \\
\hline FB07. Metadados & 5,19 & $5,63^{\text {(a) }}$ & 5,08 & $0,12^{(b)}$ \\
\hline FB08. Classificação de conteúdos & 5,02 & $5,43^{(a)}$ & 4,91 & $0,06^{(\mathrm{b})}$ \\
\hline FB09. Arquivamento de conteúdos & 5,31 & $5,49^{\text {(a) }}$ & 5,27 & $0,47^{\text {(b) }}$ \\
\hline FB10. Gestão de conhecim. pessoal & 4,74 & $4,81^{\text {(a) }}$ & 4,72 & $0,68^{(b)}$ \\
\hline FC11. Telefone fixo & 7,48 & $7,73^{\text {(a) }}$ & 7,41 & $0,12^{\text {(b) }}$ \\
\hline FC12. Telefone celular/rádio & 7,70 & $7,78^{\text {(a) }}$ & 7,68 & $0,35^{(b)}$ \\
\hline FC13. Telefone via internet & 7,75 & $8,24^{\text {(a) }}$ & 7,62 & 0,00 \\
\hline FC14. Videoconferência & 6,93 & $7,16^{(a)}$ & 6,87 & $0,23^{(b)}$ \\
\hline FC15. Salas de bate-papo & 6,52 & $6,85^{\text {(a) }}$ & 6,44 & $0,19^{\text {(b) }}$ \\
\hline FC16. Mensagens instantâneas & 7,45 & $7,58^{\text {(a) }}$ & 7,41 & $0,50^{(\mathrm{b})}$ \\
\hline FC17. E-mail & 8,15 & $8,43^{\text {(a) }}$ & 8,07 & 0,03 \\
\hline FC18. Fóruns de discussão & 5,94 & $6,27^{\text {(a) }}$ & 5,85 & $0,14^{\text {(b) }}$ \\
\hline FC19. Groupware & 5,79 & $6,24^{(a)}$ & 5,67 & $0,06^{(\mathrm{b})}$ \\
\hline FC20. Wikis & 4,97 & $5,30^{\text {(a) }}$ & 4,89 & $0,11^{\text {(b) }}$ \\
\hline FC21. Workflow & 5,75 & $6,36^{\text {(a) }}$ & 5,58 & 0,00 \\
\hline FD22. Intranet & 7,67 & $8,06^{\text {(a) }}$ & 7,57 & 0,02 \\
\hline FD23. Extranet & 6,76 & $7,40^{\text {(a) }}$ & 6,58 & 0,00 \\
\hline FD24. Servidores web e navegadores & 7,60 & $8,03^{\text {(a) }}$ & 7,49 & 0,01 \\
\hline FD25. Repositório de conhecimentos & 6,47 & $6,67^{\text {(a) }}$ & 6,42 & $0,12^{\text {(b) }}$ \\
\hline FD26. Portal corporativo & 7,11 & $7,39^{\text {(a) }}$ & 7,04 & $0,18^{\text {(b) }}$ \\
\hline FE27. CBT & 7,00 & $7,16^{\text {(a) }}$ & 6,96 & $0,27^{\text {(b) }}$ \\
\hline FE28. WBT & 6,82 & $7,06^{\text {(a) }}$ & 6,76 & $0,26^{(\mathrm{b})}$ \\
\hline FE29. EPSS & 5,68 & $5,96^{(\mathrm{a})}$ & 5,60 & $0,07^{\text {(b) }}$ \\
\hline FF30. Sistemas especializados & 5,62 & $6,06^{\text {(a) }}$ & 5,50 & $0,06^{(b)}$ \\
\hline FF31. DSS & 5,50 & $6,04^{\text {(a) }}$ & 5,36 & 0,01 \\
\hline FF32. Customização/personalização & 5,89 & $5,99^{\text {(a) }}$ & 5,87 & $0,91^{\text {(b) }}$ \\
\hline FF33. Sistema recomendador & 4,23 & $4,66^{(a)}$ & 4,11 & $0,08^{(b)}$ \\
\hline FF34. Visualização & 5,00 & $5,66^{(a)}$ & 4,82 & 0,00 \\
\hline FF35. Mapas de conhecimento & 5,39 & $5,67^{\text {(a) }}$ & 5,32 & $0,22^{(b)}$ \\
\hline FF36. Agentes de Inteligência & 4,90 & $5,28^{\text {(a) }}$ & 4,80 & $0,06^{(b)}$ \\
\hline FF37. Sistema de taxonomia automatizado & 3,48 & $3,90^{\text {(a) }}$ & 3,37 & $0,11^{\text {(b) }}$ \\
\hline FF38. Análise de conteúdos & 4,08 & $4,54^{(a)}$ & 3,96 & $0,06^{(\mathrm{b})}$ \\
\hline
\end{tabular}

Legenda: (a) maior média dos dois grupos analisados; (b) diferença significativa em favor do ambiente de teletrabalho.

Para averiguação das diferenças encontradas entre as respostas dadas à cada variável pelos respondentes gestores e técnicos quanto às ferramentas de tecnologia da informação e comunicação voltadas à gestão do conhecimento, fez-se uso do teste nãoparamétrico Mann-Whitney. Este teste é empregado em distribuições não-normais de modo a verificar a significância das diferenças encontradas nos resultados de cada variável analisada nas respostas de dois conjuntos de dados (no caso, gestores e técnicos). Assim, valores 
superiores a 0,05 são considerados significativos indicando, portanto, a existência de diferença relevante entre os resultados comparados, conforme Pestana e Gageiro (2005).

Em 29 das 38 ferramentas de tecnologia da informação e comunicação analisadas observou-se a existência de diferença significativa a favor das respostas fornecidas pelos gestores. Ou seja, a cada quatro ferramentas avaliadas pelos respondentes, três exibem diferença significativa de maior intensidade por parte dos gestores. Nas nove ferramentas restantes não foi constatada diferença significativa entre os grupos analisados.

Assim sendo, é possível diagnosticar que os respondentes gestores, de forma geral, afirmam utilizar com mais intensidade em suas atividades as ferramentas de tecnologia da informação e comunicação voltadas à gestão do conhecimento, se comparados com os respondentes técnicos.

\subsubsection{Estatísticas para validação das variáveis latentes do modelo empírico de tratamento e análise dos dados}

A partir do modelo empírico de tratamento e análise dos dados exposto previamente no capítulo de metodologia da pesquisa, faz-se necessário utilizar algumas estatísticas a fim de validar os resultados obtidos na pesquisa de campo. Não obstante, as estatísticas a seguir também têm como objetivo validar os resultados para a construção do modelo teórico final da pesquisa. Assim, as seguintes estatísticas foram executadas para cada dimensão das variáveis latentes formativas 'Pn' (práticas de gestão do conhecimento) e 'Fn' (ferramentas de tecnologia de informação e comunicação):

- VIF (fator de inflação da variância)

- Análise fatorial (KMO - Kaiser-Meyer-Olkin e Variância Total)

Posteriormente, as seguintes estatísticas foram executadas:

- Para validação das variáveis latentes formativas ('Pn' - práticas de gestão do conhecimento e 'Fn' - ferramentas de informação e comunicação)

- Peso fatorial 
- $t$ de student

- Para validação da variável latente reflexiva ('En' - eficácia empresarial)

- Peso fatorial

- $\mathrm{t}$ de student

- Confiabilidade

- Variância extraída

- Validade discriminante

\subsubsection{Estatísticas para validação das variáveis latentes formativas}

\subsection{VIF (fator de inflação da variância)}

Esta técnica estatística busca verificar a existência de multicolinearidade dos fatores medidos. Pressupõe-se que valores acima de 1,0 indiquem a presença desse problema estatístico que, uma vez constatado, deve receber tratamento estatístico adequado (HENSELER, RINGLE e SINKOVICS, 2009).

a) Práticas de gestão do conhecimento

A Tabela 119 exibe os resultados da técnica estatística VIF para teste da multicolinearidade dos fatores (práticas) constantes no modelo em análise. 
Tabela 119 - Teste VIF das práticas de gestão do conhecimento

\begin{tabular}{|c|c|c|}
\hline \multirow{2}{*}{ Práticas } & \multicolumn{2}{|c|}{ Multicolinearidade } \\
\hline & Tolerância & VIF \\
\hline \multicolumn{3}{|c|}{ Dimensão Estratégia (PAn) } \\
\hline P01 e P02 & 0.735 & 1.361 \\
\hline P03 & 0.548 & 1.824 \\
\hline P04 & 0.668 & 1.498 \\
\hline P05 & 0.765 & 1.307 \\
\hline P06 & 0.908 & 1.101 \\
\hline \multicolumn{3}{|c|}{ Dimensão Estrutura (PBn) } \\
\hline P07 & 0.862 & 1.160 \\
\hline P08 & 0.822 & 1.217 \\
\hline P09 & 0.355 & 2.821 \\
\hline $\mathrm{P} 10$ & 0.598 & 1.671 \\
\hline $\mathrm{P} 11$ & 0.336 & 2.979 \\
\hline $\mathrm{P} 12$ & 0.618 & 1.618 \\
\hline P13 & 0.805 & 1.242 \\
\hline \multicolumn{3}{|c|}{ Dimensão Pessoas/Cultura (PCn) } \\
\hline P14 & 0.512 & 1.952 \\
\hline $\mathrm{P} 15$ & 0.500 & 2.001 \\
\hline P16 & 0.412 & 2.428 \\
\hline $\mathrm{P} 17$ & 0.448 & 2.230 \\
\hline P18 & 0.524 & 1.907 \\
\hline P19 & 0.486 & 2.057 \\
\hline $\mathrm{P} 20$ & 0.655 & 1.527 \\
\hline $\mathrm{P} 21$ & 0.527 & 1.896 \\
\hline $\mathrm{P} 22$ & 0.683 & 1.463 \\
\hline $\mathrm{P} 23$ & 0.608 & 1.645 \\
\hline $\mathrm{P} 24$ & 0.629 & 1.590 \\
\hline $\mathrm{P} 25$ & 0.761 & 1.314 \\
\hline $\mathrm{P} 26$ & 0.510 & 1.961 \\
\hline \multicolumn{3}{|c|}{ Dimensão Processos (PDn) } \\
\hline $\mathrm{P} 27$ & 0.892 & 1.121 \\
\hline $\mathrm{P} 28$ & 0.867 & 1.153 \\
\hline P29 & 0.759 & 1.318 \\
\hline P30 & 0.761 & 1.313 \\
\hline \multicolumn{3}{|c|}{ Dimensão Tecnologia (PEn) } \\
\hline P31 & 0.467 & 2.142 \\
\hline $\mathrm{P} 32$ & 0.449 & 2.227 \\
\hline P33 & 0.463 & 2.160 \\
\hline P34 & 0.409 & 2.443 \\
\hline P35 & 0.337 & 2.967 \\
\hline P36 & 0.302 & 3.312 \\
\hline P37 & 0.308 & 3.252 \\
\hline P38 & 0.608 & 1.644 \\
\hline P39 & 0.671 & 1.491 \\
\hline $\mathrm{P} 40$ & 0.522 & 1.916 \\
\hline P41 & 0.462 & 2.164 \\
\hline P42 & 0.501 & 1.997 \\
\hline P43 & 0.441 & 2.268 \\
\hline P44 & 0.272 & 3.679 \\
\hline P45 & 0.308 & 3.252 \\
\hline $\mathrm{P} 46$ & 0.404 & 2.474 \\
\hline
\end{tabular}

Conforme é possível observar, todos os fatores (práticas de gestão do conhecimento) apresentaram valor VIF superior à 1,0; ou seja, apresentaram multicolinearidade. Portanto, 
faz-se necessário efetuar o tratamento dessas variáveis para posterior inclusão do modelo no aplicativo PLS-PM, já que este problema pode apresentar grande impacto no resultado dos construtos. Assim, baseado em estudos conduzidos por Bido et al (2010), a alternativa escolhida para a eliminação da multicolinearidade verificada foi a substituição das variáveis pelos escores fatoriais advindos da aplicação da técnica de análise fatorial exploratória, conforme tópico apresentado mais adiante.

b) Ferramentas de tecnologia da informação e comunicação empregadas na gestão do conhecimento

A Tabela 120 exibe os resultados da técnica estatística VIF para teste da multicolinearidade dos fatores (ferramentas) constantes no modelo em análise. 
Tabela 120 - Teste VIF das ferramentas TIC

\begin{tabular}{|c|c|c|}
\hline \multirow{2}{*}{ Ferramentas } & \multicolumn{2}{|c|}{ Multicolinearidade } \\
\hline & Tolerância & VIF \\
\hline \multicolumn{3}{|c|}{ Dimensão Criação de Conteúdo (FAn) } \\
\hline F01 e F02 & 0.674 & 1.484 \\
\hline F03 & 0.469 & 2.131 \\
\hline F04 & 0.465 & 2.152 \\
\hline F05 & 0.614 & 1.630 \\
\hline F06 & 0.594 & 1.683 \\
\hline \multicolumn{3}{|c|}{ Dimensão Gestão de Conteúdo (FBn) } \\
\hline F07 & 0.734 & 1.363 \\
\hline F08 & 0.671 & 1.490 \\
\hline F09 & 0.489 & 2.043 \\
\hline F10 & 0.690 & 1.449 \\
\hline \multicolumn{3}{|c|}{ Dimensão Comunicação e Tecnologias } \\
\hline \multicolumn{3}{|c|}{ Colaborativas $(\mathrm{FCn})$} \\
\hline F11 & 0.539 & 1.857 \\
\hline F12 & 0.569 & 1.758 \\
\hline F13 & 0.491 & 2.038 \\
\hline F14 & 0.557 & 1.795 \\
\hline F15 & 0.541 & 1.850 \\
\hline F16 & 0.626 & 1.597 \\
\hline F17 & 0.619 & 1.616 \\
\hline F18 & 0.581 & 1.721 \\
\hline F19 & 0.685 & 1.460 \\
\hline $\mathrm{F} 20$ & 0.517 & 1.934 \\
\hline $\mathrm{F} 21$ & 0.598 & 1.673 \\
\hline \multicolumn{3}{|c|}{ Dimensão Tecnologias de Rede (FDn) } \\
\hline $\mathrm{F} 22$ & 0.635 & 1.575 \\
\hline $\mathrm{F} 23$ & 0.874 & 1.144 \\
\hline $\mathrm{F} 24$ & 0.591 & 1.693 \\
\hline $\mathrm{F} 25$ & 0.888 & 1.126 \\
\hline F26 & 0.885 & 1.130 \\
\hline \multicolumn{3}{|l|}{ Dimensão E-learning (FEn) } \\
\hline $\mathrm{F} 27$ & 0.446 & 2.242 \\
\hline F28 & 0.420 & 2.379 \\
\hline F29 & 0.728 & 1.373 \\
\hline \multicolumn{3}{|c|}{ Dimensão Inteligência Artificial (FFn) } \\
\hline $\mathrm{F} 30$ & 0.462 & 2.163 \\
\hline F31 & 0.544 & 1.838 \\
\hline F32 & 0.779 & 1.284 \\
\hline F33 & 0.715 & 1.398 \\
\hline F34 & 0.510 & 1.963 \\
\hline F35 & 0.579 & 1.726 \\
\hline F36 & 0.549 & 1.822 \\
\hline F37 & 0.480 & 2.085 \\
\hline F38 & 0.585 & 1.709 \\
\hline
\end{tabular}

Todos os fatores (ferramentas de informação e comunicação empregadas na gestão do conhecimento) apresentaram valor VIF superior à 1,0. Portanto, faz-se necessário efetuar o tratamento dessas variáveis para posterior inclusão do modelo no aplicativo PLS-PM, já que este problema pode apresentar grande impacto no resultado dos construtos. Assim, baseado em estudos conduzidos por Bido et al (2010), a alternativa escolhida para a eliminação da 
multicolinearidade verificada foi a substituição das variáveis pelos escores fatoriais advindos da aplicação da técnica de análise fatorial exploratória, conforme tópico apresentado mais adiante.

\subsection{Análise fatorial}

Para a aplicação da técnica de análise fatorial dos componentes (práticas e ferramentas) do modelo em estudo foi introduzida a adequação a duas estatísticas. A primeira foi a KMO (Kaiser-Meyer-Olkin) que indica a proporção da variância dos dados que pode ser considerada comum a todas as variáveis de um modelo, tendo como índice satisfatório resultados acima de 0,50 (PESTANA E GAGEIRO, 2005). A segunda foi variância acumulada pelos fatores do modelo, que busca indicar a proporção de explicação do modelo considerando-se todas variáveis estudadas, tendo como índice satisfatório resultados acima de 0,60 (PESTANA E GAGEIRO, 2005).

Além disso, para cada dimensão existente nas variáveis latentes formativas analisadas (práticas e ferramentas), buscou-se agrupar os respectivos fatores afins em dimensões e subdimensões, visando assim facilitar a análise do modelo em questão por parte do aplicativo PLS-PM. Tal medida visa a eliminação do problema da multicolinearidade entre as variáveis do modelo, possibilitando assim a continuidade da análise e da validação do modelo proposto no estudo.

a) Práticas de gestão do conhecimento

A Tabela 121 exibe os resultados da análise fatorial que empregou as técnicas estatísticas KMO e variância acumulada para teste dos fatores (práticas) constantes no modelo em análise. 
Tabela 121 - Teste de análise fatorial (KMO e variância total) das práticas de gestão do conhecimento

\begin{tabular}{|c|c|c|}
\hline $\begin{array}{c}\text { Práticas } \\
\text { Dimensões / subdimensões }\end{array}$ & KMO & $\begin{array}{l}\text { Variância } \\
\text { acumulada }\end{array}$ \\
\hline $\begin{array}{l}\text { Dimensão Estratégia (PAn) } \\
\text { - Subdimensão P.A.1 } \\
\quad \text { (PA01, PA02, PA03, PA04, PA05, PA6) }\end{array}$ & 0.740 & 0.471 \\
\hline $\begin{array}{l}\text { Dimensão Estrutura (PBn) } \\
\text { - Subdimensão P.B.1 } \\
\text { (PB09, PB10, PB11, PB12, PB13) } \\
\text { - Subdimensão P.B.2 } \\
\quad \text { (PB07, PB08) }\end{array}$ & 0.737 & 0.588 \\
\hline $\begin{array}{l}\text { Dimensão Pessoas/Cultura (PCn) } \\
\text { Subdimensão P.C.1 } \\
\text { (PC14, PC15, PC16, PC17) } \\
\text { Subdimensão P.C.2 } \\
\text { (PC18, PC19, PC22, PC24, PC26) } \\
\text { Subdimensão P.C.3 } \\
\text { (PC20, PC21) } \\
\text { Subdimensão P.C.4 } \\
\text { (PC23, PC25) }\end{array}$ & 0.743 & 0.656 \\
\hline $\begin{array}{l}\text { Dimensão Processos (PDn) } \\
\text { Subdimensão P.D.1 } \\
\text { (PD29, PD30) } \\
\text { Subdimensão P.D.2 } \\
\text { (PD27, PD28) }\end{array}$ & 0.478 & 0.703 \\
\hline $\begin{array}{l}\text { Dimensão Tecnologia (PEn) } \\
\text { Subdimensão P.E.1 } \\
\text { (PE33, PE34, PE35, PE36, PE37) } \\
\text { Subdimensão P.E.2 } \\
\text { (PE43, PE44, PE45, PE46) } \\
\text { Subdimensão P.E.3 } \\
\text { (PE40, PE41, PE42) } \\
\text { Subdimensão P.E.4 } \\
\text { (PE31, PE32, PE38, PE39) }\end{array}$ & 0.721 & 0.644 \\
\hline
\end{tabular}

A tabela anterior expõe dos resultados das técnicas estatísticas aplicadas aos fatores (práticas) do modelo em análise no estudo. Todas as dimensões apresentaram índices acima de 0,50 para a técnica KMO, com exceção da dimensão de práticas ligadas a processos que apresentou valor muito próximo (0.478). Assim, optou-se pela manutenção desta dimensão para a composição do modelo definitivo, dada a importância teórica dessa dimensão de variáveis. Além disso, conforme já explicitado anteriormente, a opção por esta técnica fez-e necessária como passo preparatório para a inserção dos dados no aplicativo PLS-PM, de modo a eliminar o problema da multicolinearidade entre as variáveis do modelo. 
Em relação à variância acumulada, apenas as dimensões estratégia $(0,471)$ e estrutura $(0,588)$ apresentaram-se abaixo de 0,60. Porém, também optou-se pela manutenção destas dimensões para a composição do modelo definitivo em razão das mesma justificativas acima expostas.

A tabela mostra ainda a composição das subdimensões de cada dimensão das práticas de gestão do conhecimento. A composição de cada dimensão das práticas será mais bem apresentada na figura expositiva dos resultados obtidos no aplicativo PLS-PM mais adiante.

b) Ferramentas de tecnologia da informação e comunicação empregadas na gestão do conhecimento

A Tabela 122 exibe os resultados da análise fatorial que empregou as técnicas estatísticas KMO e variância acumulada para teste dos fatores (ferramentas) constantes no modelo em análise. 
Tabela 122 - Teste de análise fatorial (KMO e variância total) das ferramentas TIC empregadas na gestão do

\begin{tabular}{|c|c|c|}
\hline $\begin{array}{c}\text { Ferramentas } \\
\text { Dimensões / subdimensões }\end{array}$ & $\mathrm{KMO}$ & $\begin{array}{c}\text { Variância } \\
\text { acumulada }\end{array}$ \\
\hline $\begin{array}{c}\text { Dimensão criação de conteúdo (FAn) } \\
\text { - Subdimensão F.A.1 } \\
\text { (FA01, FA02, FA03) } \\
\text { - Subdimensão F.A.2 } \\
\text { (FA04, FA05, FA06) }\end{array}$ & 0.689 & 0.756 \\
\hline $\begin{array}{l}\text { Dimensão gestão de conteúdo (FBn) } \\
\text { - Subdimensão F.B.1 } \\
\text { (FB07, FB08, FB09, FB10) }\end{array}$ & 0.687 & 0.568 \\
\hline $\begin{array}{l}\text { Dimensão comunicação e tecnologias } \\
\text { colaborativas (FCn) } \\
\text { Subdimensão F.C.1 } \\
\text { (FC14, FC15, FC18, FC20) } \\
\text { Subdimensão F.C.2 } \\
\text { (FC16, FC17, FC19) } \\
\text { Subdimensão F.C.3 } \\
\text { (FC11, FC21) } \\
\text { Subdimensão F.C.4 } \\
\text { (FC13, FC12) }\end{array}$ & 0.651 & 0.702 \\
\hline $\begin{array}{l}\text { Dimensão tecnologias de rede (FDn) } \\
\text { Subdimensão F.D.1 } \\
\text { (FD22, FD24, FD26) } \\
\text { Subdimensão F.D.2 } \\
\text { (FD23, FD25) }\end{array}$ & 0.544 & 0.626 \\
\hline $\begin{array}{l}\text { Dimensão e-learning (FEn) } \\
\text { Subdimensão F.E.1 } \\
\text { (FE27, FE28, FE29) }\end{array}$ & 0.654 & 0.715 \\
\hline $\begin{array}{l}\text { Dimensão inteligência artificial (FFn) } \\
\text { Subdimensão F.F.1 } \\
\text { (FF31, FF32, FF34, FF35, FF36) } \\
\text { Subdimensão F.F.2 } \\
\text { (FF30, FF33, FF37, FF38) }\end{array}$ & 0.751 & 0.547 \\
\hline
\end{tabular}

A tabela anterior expõe dos resultados das técnicas estatísticas aplicadas aos fatores (ferramentas) do modelo em análise no estudo. Todas as dimensões apresentaram índices acima de 0,50 para a técnica KMO.

Em relação à técnica de variância acumulada, apenas as dimensões gestão de conteúdo $(0,568)$ e inteligência artificial $(0,547)$ apresentaram-se abaixo de 0,60. Porém, também optou-se pela manutenção destas dimensões para a composição do modelo definitivo. Além disso, conforme já explicitado anteriormente, a opção por esta técnica fez-e necessária como 
passo preparatório para a inserção dos dados no aplicativo PLS-PM, de modo a eliminar o problema da multicolinearidade entre as variáveis do modelo.

A tabela mostra ainda a composição das subdimensões de cada dimensão das ferramentas de tecnologia da informação e comunicação empregadas na gestão do conhecimento. A composição de cada dimensão das ferramentas será mais bem apresentada na figura expositiva dos resultados obtidos no aplicativo PLS-PM mais adiante.

\subsubsection{Estatísticas para validação das variáveis latentes formativas e reflexivas}

De acordo com a lógica de funcionamento do aplicativo PLS-PM, o tratamento e validação das variáveis latentes formativas e da variável latente reflexiva foi segregado em dois modelos, a saber:

- Modelo de mensuração, que envolve três aspectos:

- Práticas de gestão do conhecimento,

- Ferramentas de tecnologia da informação e comunicação,

- Indicadores de eficácia empresarial.

- Modelo estrutural, que envolve as relações existentes as variáveis latentes formativas e a variável latente reflexiva:

- Relação das práticas de gestão do conhecimento e os indicadores de eficácia empresarial,

- Relação das ferramentas de tecnologia da informação e comunicação e os indicadores de eficácia empresarial;

A figura a seguir expõe a lógica de funcionamento do aplicativo PLS-PM para o tratamento e validação das variáveis do modelo: 


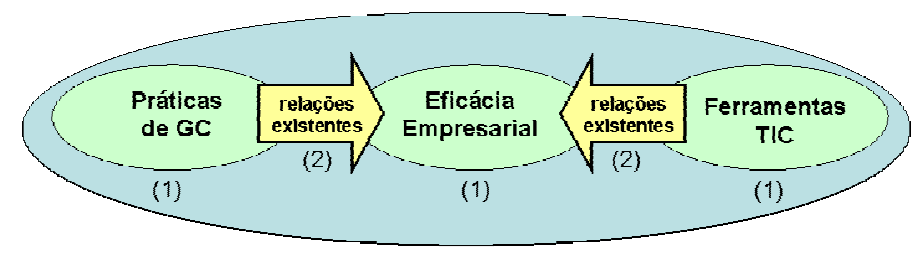

Figura 11- Lógica de funcionamento do aplicativo PLS-PM para tratamento e validação das variáveis do modelo Legenda: (1) Modelo de mensuração; (2) Modelo estrutural.

Os itens a seguir expõem os valores apresentados (peso fatorial e $t$ de student) pelas variáveis do estudo a partir do tratamento executado pelo aplicativo PLS-PM. Também são expostas as estatísticas executadas para validação dos resultados indicados pelo aplicativo PLS-PM.

\subsection{Peso fatorial das variáveis formativas}

A verificação do peso fatorial para a análise da consistência das variáveis formativas (práticas de gestão do conhecimento - Pn e ferramentas de tecnologia da informação e comunicação - Fn) consiste na exposição do peso de cada variável formativa na composição da variável latente. Esta técnica estatística tem o objetivo apenas de priorizar as variáveis, não menosprezando, portanto, as variáveis que apresentem valores abaixo de 0,2 (HAIR JR. et al, 2006). A seguir são expostos os pesos fatoriais encontrados para as variáveis formativas.

a) Práticas de gestão do conhecimento

A Figura 12 exibe os pesos fatoriais encontrados para cada uma das dimensões das práticas de gestão do conhecimento. 


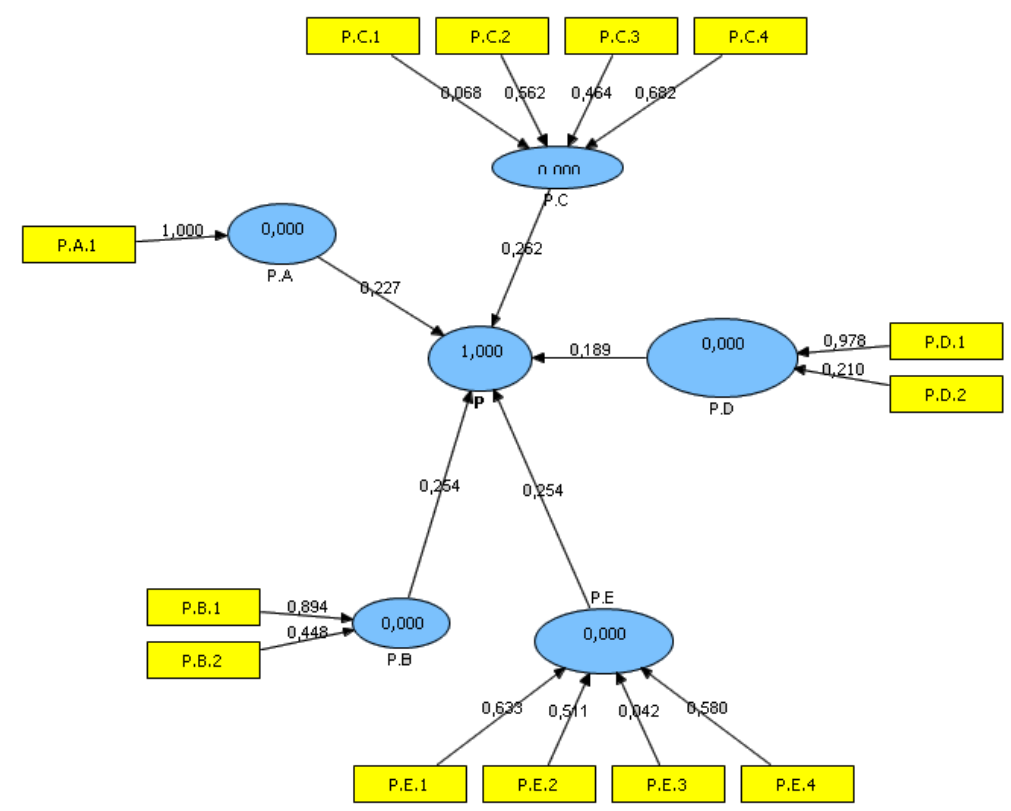

Figura 12 - Resultados dos pesos fatoriais das dimensões das práticas de gestão do conhecimento

É possível observar na figura anterior que todas as subdimensões formativas de práticas de gestão do conhecimento apresentaram valores superiores a 0,2; excetuando-se as seguintes ocorrências específicas: dimensão PD - Processos $(0,189)$, subdimensão PC1 - Pessoas e cultura $(0,068)$ e subdimensão PE3 - Tecnologia $(0,042)$. Conforme explicado anteriormente quanto à natureza de priorização da técnica peso fatorial, optou-se pela manutenção da dimensão e das subdimensões citadas acima, visando com isso preservar o modelo teórico como um todo.

b) Ferramentas de tecnologia da informação e comunicação empregadas na gestão do conhecimento

A Figura 13 exibe os pesos fatoriais encontrados para cada uma das dimensões das ferramentas de tecnologia da informação e comunicação empregadas na gestão do conhecimento. 


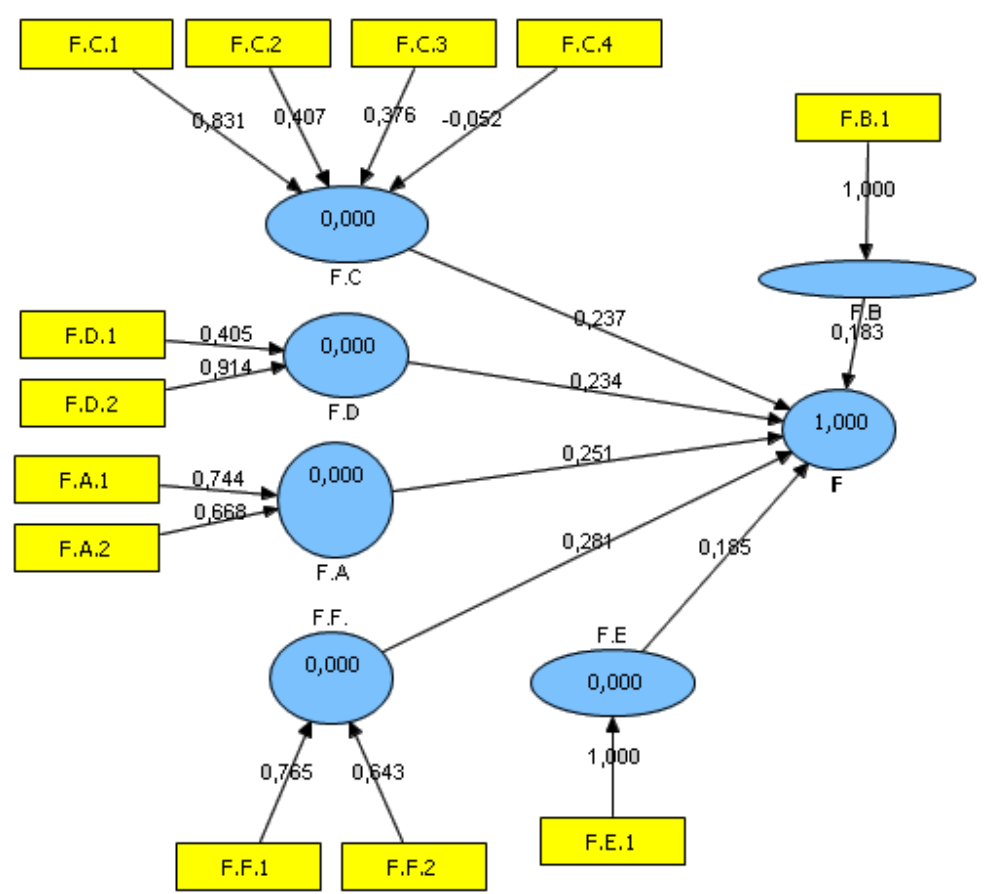

Figura 13 - Resultados dos pesos fatoriais das dimensões das ferramentas de tecnologia da informação e comunicação

É possível observar na figura anterior que todas as variáveis formativas de ferramentas de tecnologia da informação e comunicação empregadas na gestão do conhecimento apresentaram valores superiores a 0,2; excetuando-se as seguintes ocorrências específicas: dimensão FB - Gestão de conteúdos (0,183), dimensão FE - E-learning $(0,185)$ e subdimensão FC4 - Comunicações e tecnologias colaborativas $(-0,052)$. Conforme explicado anteriormente quanto à natureza de priorização da técnica peso fatorial, optou-se por manter as dimensões e a subdimensão citadas anteriormente, visando com isso preservar o modelo teórico como um todo.

\subsubsection{2 $\mathrm{t}$ de student das variáveis formativas}

O teste $\mathrm{t}$ de student serve para validar as relações existentes entre as variáveis formativas (práticas de gestão do conhecimento - Pn e ferramentas de tecnologia da informação e comunicação - Fn) e as respectivas subdimensões às quais pertencem. Além disso, também serve para validar as subdimensões e a respectiva dimensão às quais pertencem. E ainda para a validação definitiva da influência causada pelas práticas e ferramentas empregadas na gestão do conhecimento na eficácia empresarial da organização. Assim, valores superiores a 1,96, para um nível de confiança de 5,0\% são considerados aceitáveis (HAIR JR. et al, 2006). 
a) Práticas de gestão do conhecimento

A Figura 14 exibe os resultados do teste $t$ de student de cada uma das dimensões das práticas de gestão do conhecimento.

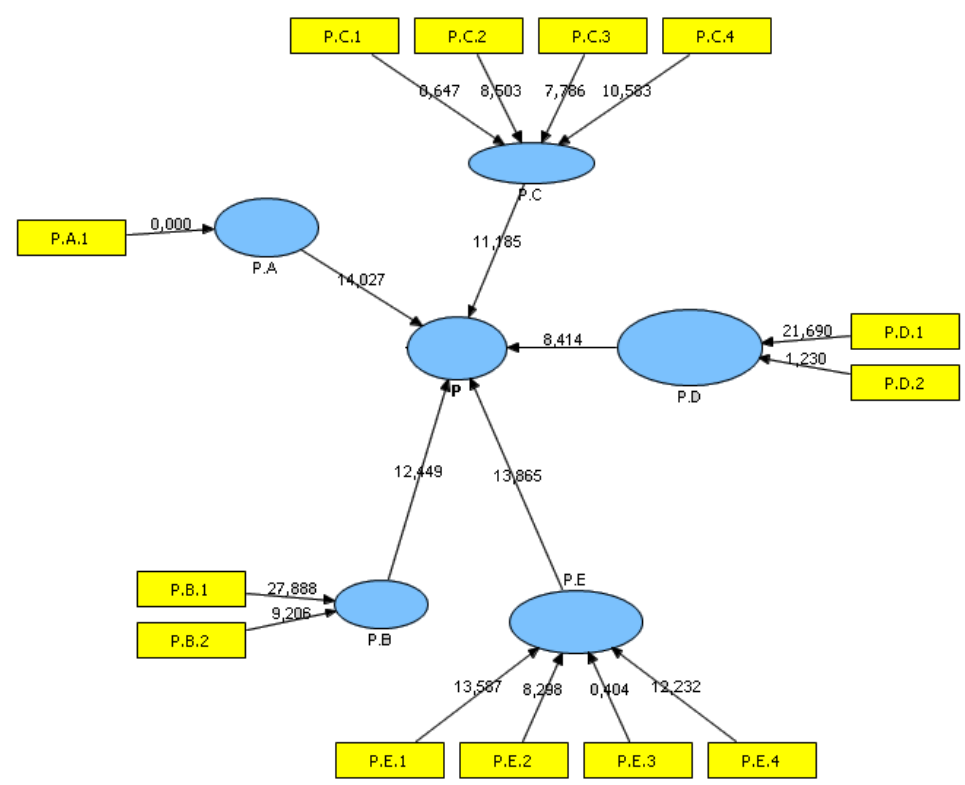

Figura 14 - Resultados do teste t de student das dimensões das práticas de gestão do conhecimento

Todas as dimensões das práticas de gestão do conhecimento componentes do modelo estudado apresentaram valores superiores à 1,96 para um nível de confiança de 5,0\% sendo, portanto, validadas para compor o construto em análise.

b) Ferramentas de tecnologia da informação e comunicação empregadas na gestão do conhecimento

A Figura 15 exibe o teste $\mathrm{t}$ de student de cada uma das dimensões das ferramentas de tecnologia da informação e comunicação empregadas na gestão do conhecimento. 


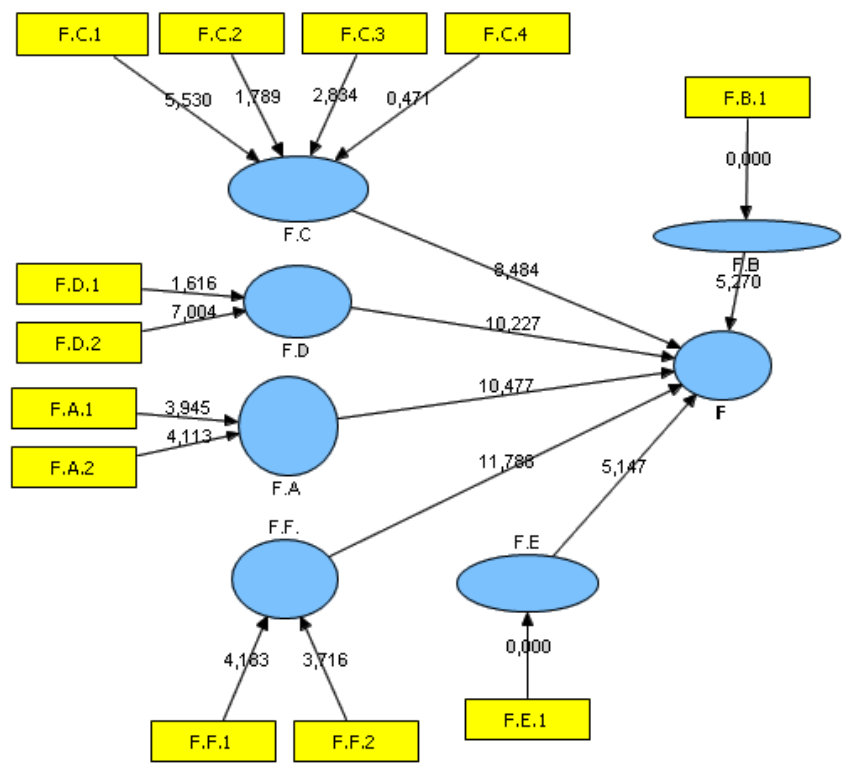

Figura 15 - Resultados do teste $t$ de student das dimensões das ferramentas de tecnologia da informação e comunicação

Todas as dimensões das ferramentas de tecnologia da informação e comunicação componentes do modelo estudado apresentaram valores superiores à 1,96 para um nível de confiança de 5,0\% sendo, portanto, validadas para compor o construto em análise.

\subsection{Peso fatorial da variável reflexiva}

O peso fatorial para a análise da consistência das variáveis reflexivas (indicadores de eficácia empresarial - En) consiste na exposição do peso de cada variável reflexiva na composição da variável latente. Esta estatística tem o objetivo apenas de priorizar as variáveis, não menosprezando, portanto, as variáveis reflexivas que apresentem valores abaixo de 0,2 (HAIR JR. et al, 2006). A Figura 16 exibe os pesos fatoriais encontrados para as variáveis reflexivas. 


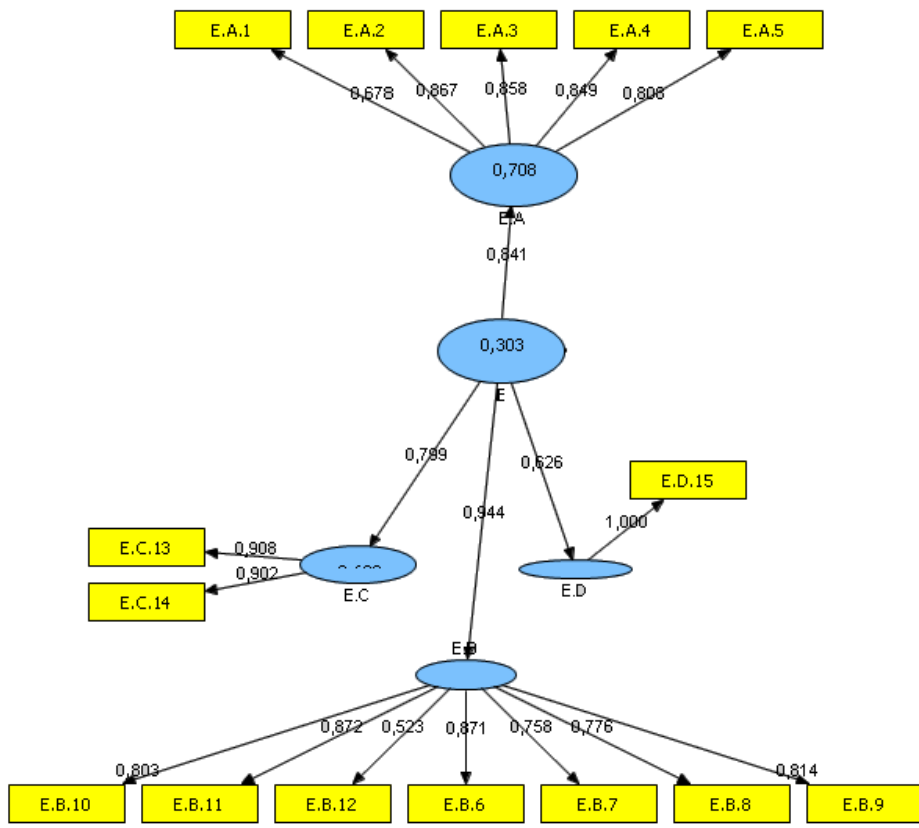

Figura 16 - Resultados dos pesos fatoriais das dimensões de eficácia empresarial

É possível observar na figura anterior que todas as dimensões de eficácia empresarial apresentaram valores superiores a 0,2. Assim, todas as dimensões e subdimensões citadas foram consideradas para efeito do estudo.

\subsubsection{4 t de student da variável reflexiva}

A Figura 17 exibe o teste t de student de cada uma das dimensões dos indicadores de eficácia empresarial. 


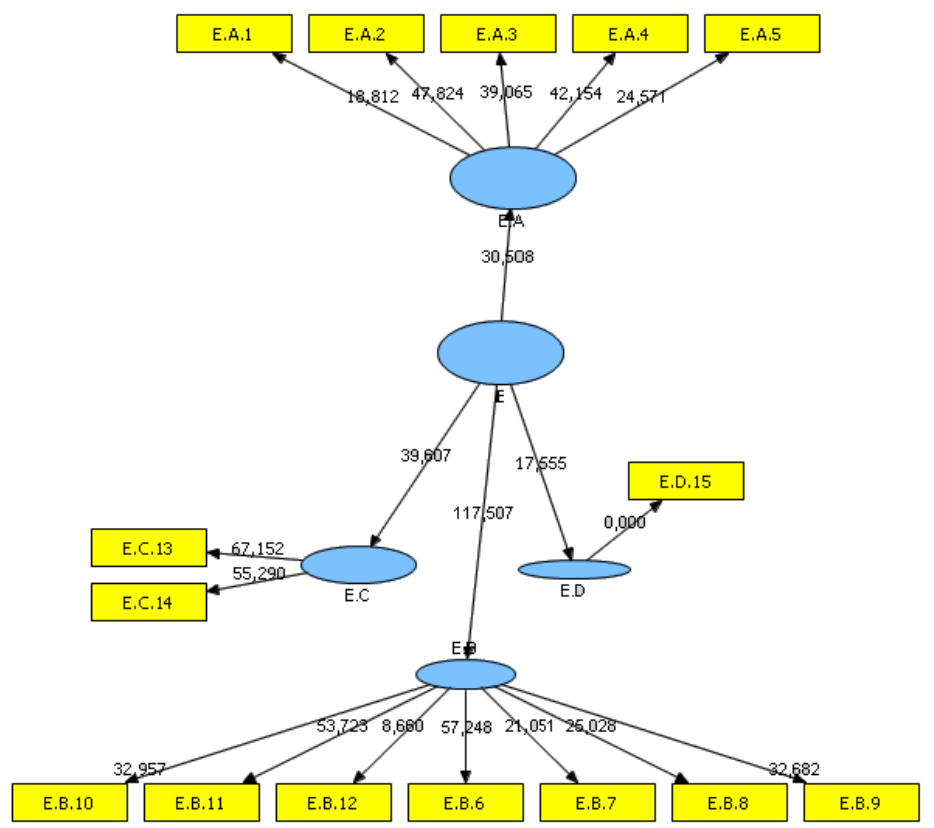

Figura 17 - Resultados do teste $t$ de student das dimensões de eficácia empresarial

Todas as dimensões e subdimensões dos fatores de eficácia empresarial componentes do modelo estudado apresentaram valores superiores à 1,96 sendo, portanto, validados para compor o construto em análise.

\subsection{Confiabilidade composta da variável reflexiva}

A confiabilidade composta visa auferir o grau de confiança de cada variável na construção da dimensão a qual pertence. Para que a dimensão tenha grau de confiança aceitável é desejável valores acima de 0,7 (FORNELL e LARCKER, 1981). A Figura 18 apresenta a fórmula para cálculo da confiabilidade composta:

$$
\begin{aligned}
& \text { Conf }=\frac{\left(\sum \lambda_{i}\right)^{2}}{\left(\sum \lambda_{i}\right)^{2}+\sum \operatorname{var}\left(\varepsilon_{i}\right)} \\
& \operatorname{var}\left(\varepsilon_{i}\right)=1-\lambda_{i}^{2}
\end{aligned}
$$

Figura 18 - Fórmula de cálculo da confiabilidade composta

Legenda: $(\lambda)$ peso fatorial da variável 
a) Dimensão EA - Econômica

Os resultados das variáveis reflexivas de eficácia empresarial relacionadas à dimensão econômica são evidenciados na figura a seguir:

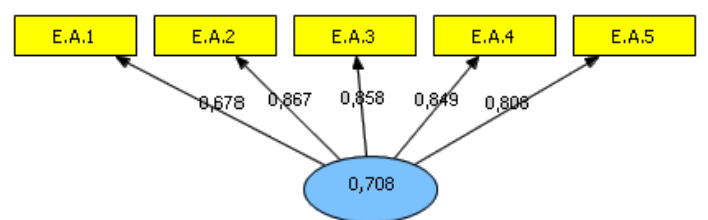

Figura 19 - Pesos fatoriais das variáveis da dimensão econômica de eficácia empresarial

A dimensão EA - Econômica apresentou valor de confiabilidade composta igual a 0,907. Assim, esta dimensão de eficácia empresarial foi validada pelo teste estatístico efetuado.

b) Dimensão EB - Social

Os resultados das variáveis reflexivas de eficácia empresarial relacionadas à dimensão social são evidenciados na figura a seguir:

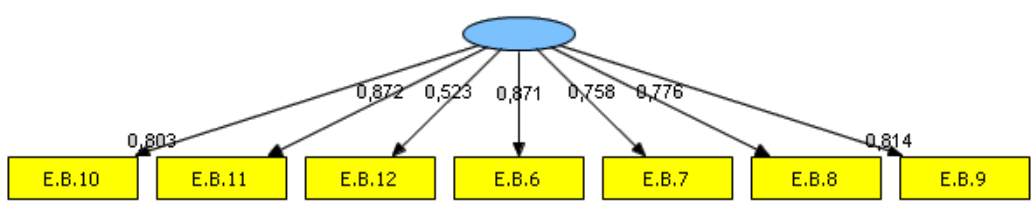

Figura 20 - Pesos fatoriais das variáveis da dimensão social de eficácia empresarial

A dimensão EB - Social apresentou valor de confiabilidade composta igual a 0,915. Assim, esta dimensão de eficácia empresarial foi validada pelo teste estatístico efetuado.

c) Dimensão EC - Sistêmica

Os resultados das variáveis reflexivas de eficácia empresarial relacionadas à dimensão sistêmica são evidenciados na figura a seguir:

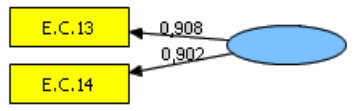

Figura 21 - Pesos fatoriais das variáveis da dimensão sistêmica de eficácia empresarial 
A dimensão EC - Sistêmica apresentou valor de confiabilidade composta igual a 0,901. Assim, esta dimensão de eficácia empresarial foi validada pelo teste estatístico efetuado.

d) Dimensão ED - Política

Os resultados das variáveis reflexivas de eficácia empresarial relacionadas à dimensão política são evidenciados na figura a seguir:

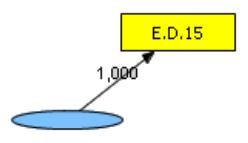

Figura 22 - Pesos fatoriais das variáveis da dimensão política de eficácia empresarial

A dimensão ED - Política apresentou valor de confiabilidade composta igual a 1,000. Assim, esta dimensão de eficácia empresarial foi validada pelo teste estatístico efetuado.

\subsection{Variância extraída da variável reflexiva}

A variância extraída visa aferir a proporção da variância da dimensão explicada a partir das variáveis que a compõem. Para que a dimensão seja válida são aceitos valores acima de 0,5 (FORNELL e LARCKER, 1981). A fórmula do cálculo da variância extraída é exposta a seguir:

$$
A V E=\frac{\sum \lambda_{I}^{2}}{\sum \lambda_{I}^{2}+\sum \operatorname{var}\left(\varepsilon_{i}\right)}
$$

Figura 23 - Fórmula de cálculo da variância extraída Legenda: $(\lambda)$ peso fatorial da variável

a) Dimensão EA - Econômica

Os resultados das variáveis reflexivas de eficácia empresarial relacionadas à dimensão econômica são evidenciados na figura a seguir: 


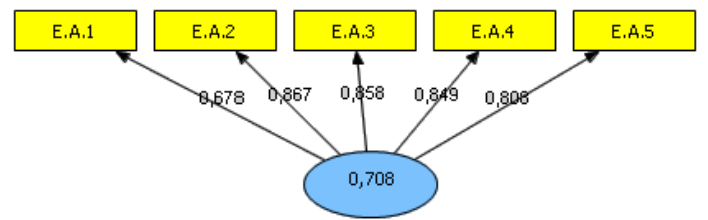

Figura 24 - Pesos fatoriais das variáveis da dimensão econômica de eficácia empresarial

A dimensão EA - Econômica apresentou valor de variância extraída igual a 0,664. Assim, esta dimensão de eficácia empresarial foi validada pelo teste estatístico efetuado.

\section{b) Dimensão EB - Social}

Os resultados das variáveis reflexivas de eficácia empresarial relacionadas à dimensão social são evidenciados na figura a seguir:

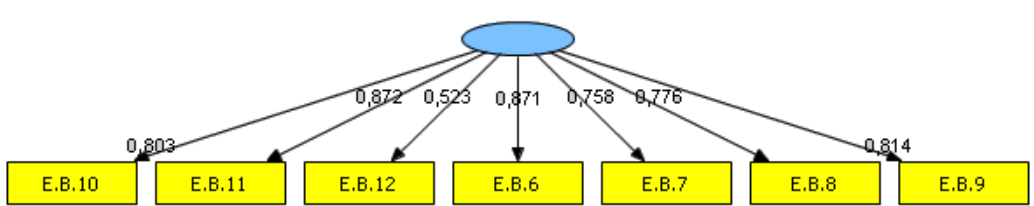

Figura 25 - Pesos fatoriais das variáveis da dimensão social de eficácia empresarial

A dimensão EB - Social apresentou valor de variância extraída igual a 0,611. Assim, esta dimensão de eficácia empresarial foi validada pelo teste estatístico efetuado.

c) Dimensão EC - Sistêmica

Os resultados das variáveis reflexivas de eficácia empresarial relacionadas à dimensão sistêmica são evidenciados na figura a seguir:

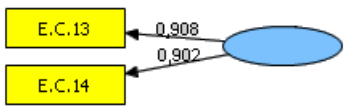

Figura 26 - Pesos fatoriais das variáveis da dimensão sistêmica de eficácia empresarial

A dimensão EC - Sistêmica apresentou valor de variância extraída igual a 0,819. Assim, esta dimensão de eficácia empresarial foi validada pelo teste estatístico efetuado.

d) Dimensão ED - Política 
Os resultados das variáveis reflexivas de eficácia empresarial relacionadas à dimensão política são evidenciados na figura a seguir:

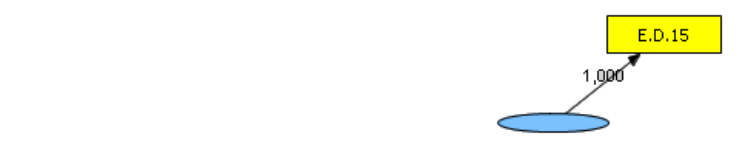

Figura 27 - Pesos fatoriais das variáveis da dimensão política de eficácia empresarial

A dimensão ED - Política apresentou valor de confiabilidade composta igual a 1,000. Assim, esta dimensão de eficácia empresarial foi validada pelo teste estatístico efetuado.

\subsection{Validade discriminante da variável reflexiva}

A validade discriminante busca evidenciar se a variável é a mais representativa dentre todas as correlações entre as demais variáveis envolvidas no modelo. Assim, se a raiz quadrada da variância extraída de cada variável é maior que as correlações entre as demais variáveis, verifica-se a validade discriminante (FORNELL e LARCKER, 1981). A tabela a seguir exibe as correlações existentes entre as dimensões de eficácia empresarial.

\begin{tabular}{cccc}
\multicolumn{4}{c}{ Tabela 123 - Validade discriminante das dimensões de eficácia empresarial } \\
$\begin{array}{c}\text { Subdimensões de } \\
\text { eficácia empresarial }\end{array}$ & $\begin{array}{c}\text { Variância } \\
\text { extraída }\end{array}$ & $\begin{array}{c}\text { Raiz quadrada da } \\
\text { variância extraída }\end{array}$ & $\begin{array}{c}\text { Maior correlação } \\
\text { verificada }\end{array}$ \\
EA & 0,665 & 0,816 & 0,741 \\
EB & 0,611 & 0,782 & 0,664 \\
EC & 0,820 & 0,910 & 0,766 \\
ED & 1,000 & --- & - - -
\end{tabular}

A maior correlação verificada na última coluna ainda é menor do que o resultado da própria subdimensão (coluna 'raiz quadrada da variância extraída), o que para Fornell e Larcker (1981) é um indicativo de validade discriminante. Ou seja, cada dimensão de eficácia empresarial, quando comparada às demais, apresenta-se válida na composição do modelo proposto. 


\subsubsection{Validação do modelo}

Por fim, duas últimas estatísticas foram necessárias de modo a comprovar a influência das práticas de gestão do conhecimento e das ferramentas de tecnologia da informação e comunicação na eficácia empresarial das empresas analisadas na pesquisa de campo. São elas peso fatorial e t de student.

\subsubsection{Peso fatorial}

A verificação do peso fatorial para a análise da consistência das práticas de gestão do conhecimento $(\mathrm{P})$ e das ferramentas de tecnologia da informação e comunicação $(\mathrm{F})$ consiste na exposição do peso de cada variável na composição da variável. Esta técnica estatística tem o objetivo apenas de priorizar as variáveis, não menosprezando, portanto, as variáveis que apresentem valores abaixo de 0,2 (HAIR JR. et al, 2006). A seguir são expostos os pesos fatoriais encontrados para as variáveis do estudo.

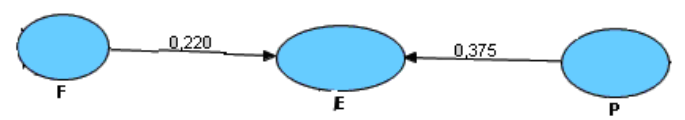

Figura 28 - Resultados dos pesos fatoriais das ferramentas de tecnologia de informação e comunicação e práticas aplicadas na gestão do conhecimento em relação à eficácia empresarial

Tanto as práticas de gestão do conhecimento (0,375), quanto as ferramentas de tecnologia de informação e comunicação $(0,220)$ apresentaram valores superiores a 0,2. Assim, ambas as variáveis influenciam na eficácia empresarial das empresas analisadas. Não obstante, cabe ressaltar que as práticas de gestão do conhecimento têm maior influência na eficácia empresarial do que as ferramentas de tecnologia da informação e comunicação.

\subsubsection{2 t de student}

O teste $\mathrm{t}$ de student serve para validar as relações existentes entre as práticas de gestão do conhecimento (P) e as ferramentas de tecnologia da informação e comunicação (Fn) em 
relação à eficácia empresarial das empresas pesquisadas. Assim, valores superiores a 1,96, para um nível de confiança de 5,0\% são considerados aceitáveis (HAIR JR. et al, 2006). A seguir são expostos os valores t de student encontrados para as variáveis do estudo.

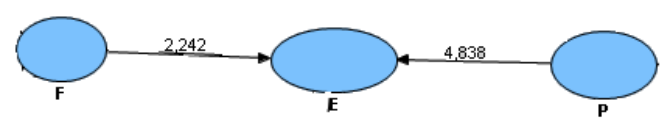

Figura 29 - Resultados do teste $\mathrm{t}$ de student das ferramentas de tecnologia de informação e comunicação e práticas aplicadas na gestão do conhecimento em relação à eficácia empresarial

Tanto as práticas de gestão do conhecimento $(4,838)$, quanto as ferramentas de tecnologia de informação e comunicação $(2,242)$ apresentaram valores superiores a 1,96 para um nível de significância de 5,0\%. Assim, ambas as variáveis influenciam na eficácia empresarial das empresas analisadas. Não obstante, cabe ressaltar que novamente evidencia-se que as práticas de gestão do conhecimento têm maior influência na eficácia empresarial do que as ferramentas de tecnologia da informação e comunicação.

\subsection{Modelo validado}

A Figura 28 a seguir exibe os principais resultados já validados do modelo empírico de tratamento e análise dos dados (figura 7 do capítulo de metodologia da pesquisa) que, por sua vez, face aos testes previamente descritos, valida o modelo teórico da pesquisa (figura 8 do capítulo de metodologia da pesquisa). 


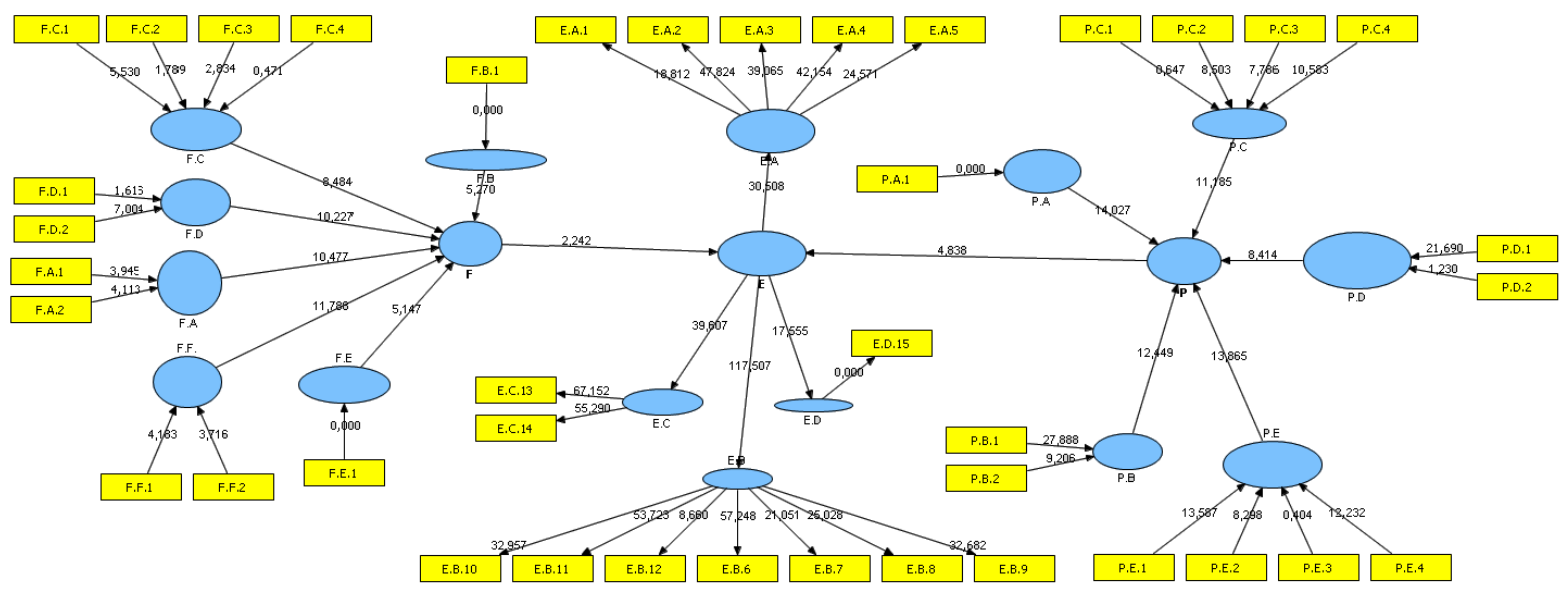

Figura 30 - Modelo empírico validado 
A partir dos resultados acima dispostos, é possível evidenciar de forma sucinta que os principais objetivos do estudo junto às empresas analisadas na pesquisa de campo foram alcançados, quais sejam:

- Caracterização da gestão do conhecimento;

- Práticas de gestão do conhecimento mais comuns;

- Ferramentas de tecnologia da informação e comunicação mais comuns;

- Influências da gestão do conhecimento na eficácia empresarial.

Dessa forma, o modelo conceitual definitivo da pesquisa é exposto a seguir:

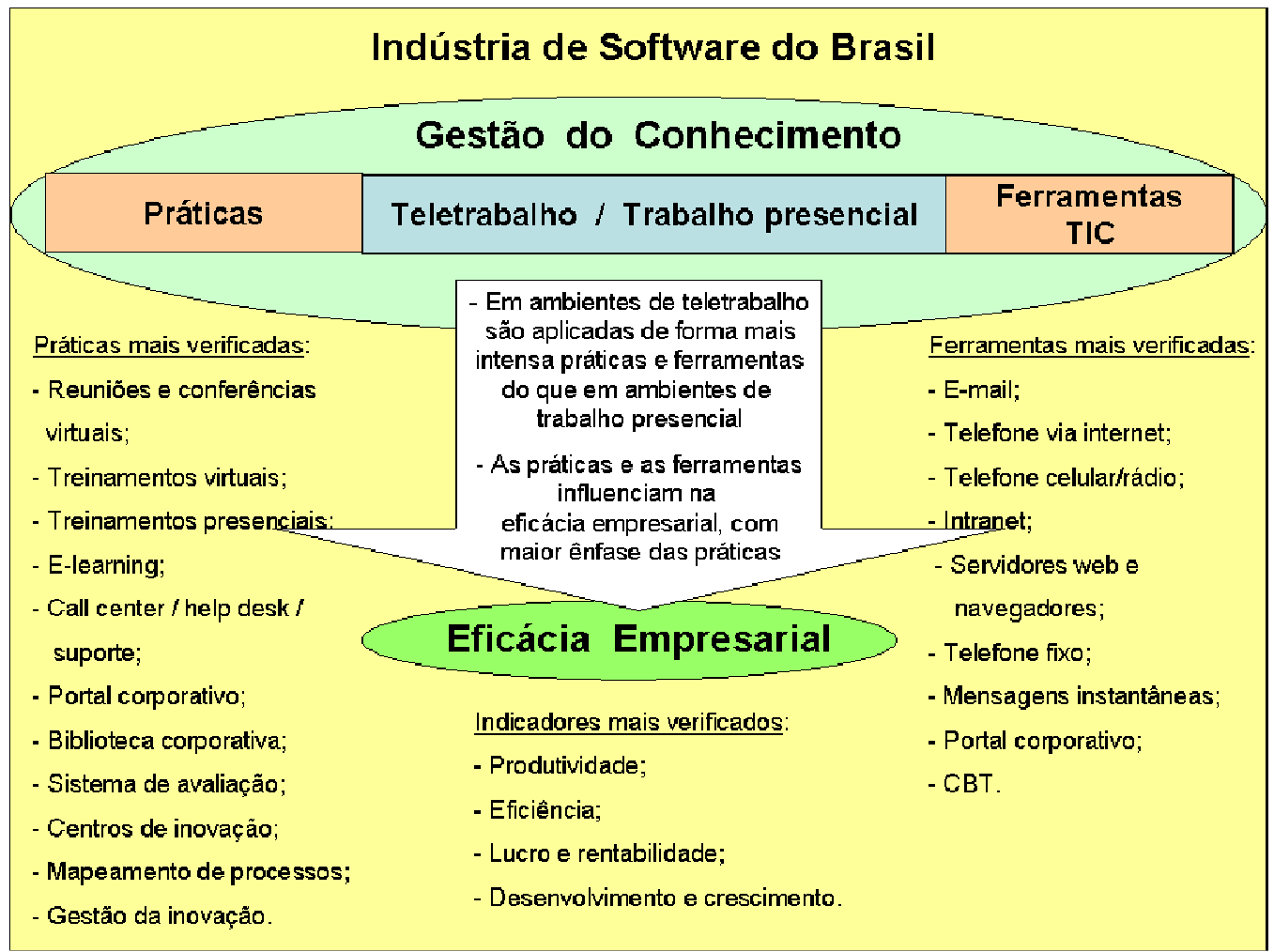

Figura 31 - Modelo conceitual validado

Fonte: elaborado pelo autor.

\subsection{Verificação das hipóteses de pesquisa}

As hipóteses de pesquisa são apresentadas e comentadas nos tópicos a seguir, visando assim sua validação ou refutação a partir dos resultados obtidos na pesquisa de campo. 


\subsubsection{Hipótese H01}

A hipótese H01 previamente formulada apresentava a seguinte afirmação:

H01 - Não é possível afirmar que a utilização de práticas de gestão do conhecimento adotadas pelas empresas atuantes na indústria de software no Brasil influencie a eficácia empresarial.

Conforme os resultados verificados na pesquisa de campo efetuada, pôde-se constatar que a utilização das práticas de gestão do conhecimento adotadas pelas empresas analisadas influenciam em sua eficácia empresarial. Isto porque tanto o valor do peso fatorial $(0,375$; ou seja, superior à 0,2$)$ quanto o valor do teste t de student $(4,838$; ou seja, superior à 1,96 para um nível de significância de 5,0\%) dessa variável indicam correlação positiva entre as práticas de gestão do conhecimento e a eficácia empresarial das empresas analisadas.

Dessa forma, a hipótese H01 fica rejeitada, podendo-se assim afirmar que as práticas de gestão do conhecimento influenciam na eficácia empresarial das empresas analisadas.

\subsubsection{Hipótese H02}

A hipótese $\mathrm{H} 02$ previamente formulada apresentava a seguinte afirmação:

H02 - Não é possível afirmar que a utilização de ferramentas de tecnologia da informação e comunicação empregadas na gestão do conhecimento nas empresas atuantes na indústria de software no Brasil influencie a eficácia empresarial.

Conforme os resultados verificados na pesquisa de campo efetuada, pôde-se constatar que a utilização das ferramentas de tecnologia da informação e comunicação empregadas na gestão do conhecimento das empresas analisadas influenciam em sua eficácia empresarial. Isto porque tanto o valor do peso fatorial $(0,220$; ou seja, superior à 0,2$)$ quanto o valor do teste $t$ de student (2,242; ou seja, superior à 1,96 para um nível de significância de 5,0\%) dessa 
variável indicam correlação positiva entre as ferramentas de tecnologia da informação e comunicação e a eficácia empresarial das empresas analisadas.

Dessa forma, a hipótese H02 fica rejeitada, podendo-se assim afirmar que as ferramentas de tecnologia da informação e comunicação empregadas na gestão do conhecimento influenciam na eficácia empresarial das empresas analisadas.

\subsubsection{Hipótese $\mathrm{H03}$}

A hipótese H03 previamente formulada apresentava a seguinte afirmação:

H03 - Não é possível afirmar que a utilização de práticas de gestão do conhecimento pelas empresas atuantes na indústria de software no Brasil seja mais intensa nas atividades de teletrabalho do que em atividades semelhantes realizadas por colaboradores dentro do ambiente físico interno das empresas.

Conforme os resultados verificados na pesquisa de campo efetuada, pôde-se constatar que a utilização das práticas de gestão de conhecimento é mais intensa por parte dos teletrabalhadores do que por parte dos trabalhadores presenciais. Isto porque em 31 das 46 práticas analisadas na pesquisa de campo verificou-se a existência de diferença significativa de utilização das práticas de gestão do conhecimento em favor dos teletrabalhadores. Assim, das 15 práticas práticas restantes, verificou-se maior indicação por parte dos trabalhadores presenciais em apenas seis delas. E ainda deve-se observar que nove práticas não apresentaram diferenças significativas para nenhum dos grupos estudados. Ou seja, a cada três práticas de gestão do conhecimento verificadas, duas são mais intensamente utilizadas em ambientes de teletrabalho.

Assim, é possível diagnosticar que os teletrabalhadores afirmam utilizar com maior intensidade as práticas de gestão do conhecimento empregadas em suas atividades, se comparados aos trabalhadores presenciais. 
Dessa forma, a hipótese H03 fica rejeitada, podendo-se assim afirmar que em ambientes de teletrabalho as práticas de gestão do conhecimento são mais intensamente utilizadas do que em ambientes de trabalho presencial nas empresas analisadas.

\subsubsection{Hipótese H04}

A hipótese H04 previamente formulada apresentava a seguinte afirmação:

H04 - Não é possível afirmar que a utilização de ferramentas de tecnologia de informação e comunicação empregadas na gestão do conhecimento das empresas atuantes na indústria de software no Brasil seja mais intensa nas atividades de teletrabalho do que em atividades semelhantes realizadas por colaboradores dentro do ambiente físico interno das empresas.

Conforme os resultados verificados na pesquisa de campo efetuada, pôde-se constatar que a utilização das ferramentas de tecnologia da informação e comunicação empregadas na gestão de conhecimento é mais intensa por parte dos teletrabalhadores do que por parte dos trabalhadores presenciais. Em vinte e sete ferramentas observou-se diferença significativa em favor da maior utilização das ferramentas pelos teletrabalhadores.

Portanto, é possível diagnosticar que os teletrabalhadores utilizam com mais intensidade as ferramentas de tecnologia da informação e comunicação empregadas na gestão do conhecimento em suas atividades, se comparados aos trabalhadores presenciais.

Dessa forma, a hipótese H04 fica rejeitada, podendo-se assim afirmar que em ambientes de teletrabalho as ferramentas de tecnologia da informação e comunicação empregadas na gestão do conhecimento são mais intensamente utilizadas do que em ambientes de trabalho presencial nas empresas analisadas. 
A intensidade e velocidade das mudanças verificadas no mundo contemporâneo são fatos inexoráveis ao atual estágio de desenvolvimento das sociedades modernas. A evolução de uma sociedade fundamentada em informações e conhecimentos é um claro sinal desse movimento. Não obstante, deve-se acrescentar a centralidade do papel que as empresas desempenham nesse contexto, tornando-se elementos indissociáveis à formação dessa nova estruturação da sociedade baseada em conhecimento. Considerando-se ainda que as empresas são intrinsecamente formadas por pessoas, por consequência denota-se a importância dos funcionários das empresas na construção e entrega de valor baseado em conhecimento. Portanto, a gestão do conhecimento nas empresas merece especial atenção dos gestores interessados em seu sucesso.

Especialmente em empresas calcadas na criatividade e, por conseguinte, voltadas à inovação, cuja premissa é a oferta de produtos e serviços que busquem satisfazer seus clientes, a gestão do conhecimento se faz ainda mais necessária como potencial provedora de diferenciais competitivos duradouros. É o caso de empresas atuantes na indústria de software que buscam tornar-se cada vez mais eficazes por meio da gestão de um recurso fundamental à evolução do negócio software em si, o conhecimento.

Por sua vez, a gestão do conhecimento baseia-se em práticas e processos estruturados que visam melhor gerir o recurso conhecimento. Associadas às práticas, também verificam-se ferramentas de tecnologia da informação e comunicação que viabilizam os processos de gestão do conhecimento. Assim, depreende-se que a gestão do conhecimento bem estruturada na empresa pode contribuir para uma maior eficácia empresarial desta.

Outro componente a ser inserido no contexto anteriormente explicitado é a disponibilização cada vez maior de ambientes de teletrabalho nas empresas, proporcionando assim o trabalho colaborativo de diferentes funcionários fisicamente dispersos entre si. Não obstante a distância física, verifica-se a proliferação de redes de relacionamentos que fundamentam-se em práticas, processos e ferramentas disponibilizadas pelas empresas aos seus funcionários. 
A partir dos desafios impostos às empresas por esse novo contexto corporativo, o presente estudo buscou verificar a influência de práticas de gestão do conhecimento e de ferramentas de tecnologia da informação e comunicação a ela associadas, na eficácia empresarial, investigando ainda seus comportamentos em ambientes de teletrabalho.

Para tanto, foi efetuada uma pesquisa de campo com 319 respondentes distribuídos em 15 empresas de médio e grande porte atuantes na indústria de software no Brasil. Os respondentes da pesquisa são em sua maioria do sexo masculino, com idade entre 35 e 44 anos, ocupando cargo de gestão como coordenador ou cargo técnico como analista de sistemas e entre 4 e 6 anos de atuação na empresa atual. Notadamente em relação à questão da atuação em regime de teletrabalho, a maioria dos respondentes afirma não atuar em fisicamente distantes das instalações da empresa. Dos respondentes que atuam em ambiente de teletrabalho, a maior parte o faz distante da empresa em um único dia por semana.

Em relação à gestão do conhecimento verificada pelos respondentes em sua empresa, a maior parte observa a gestão do conhecimento como já existente na empresa, embora não tenha sido formalmente instituída. Outra parcela significativa dos respondentes acusa a existência de processos, práticas e ferramentas associadas à gestão do conhecimento, mesmo que também não formalmente instituídos.

As práticas de gestão do conhecimento mais verificadas na pesquisa de campo levada a cabo neste estudo são, nesta ordem de prioridade: reuniões e conferências virtuais, treinamentos virtuais, treinamentos presenciais, e-learning, call center/help desk/suporte online, portal corporativo, biblioteca corporativa, sistema de avaliação, centros de inovação, mapeamento de processos e, por fim, gestão da inovação. Tais práticas foram as mais indicadas pelos respondentes, configurando-se, portanto, nas mais empregadas nas empresas analisadas. Já as práticas de gestão do conhecimento menos indicadas na pesquisa de campo são: repositório de lições aprendidas, story telling, CKO/CKM (gestor de gestão do conhecimento), área ou departamento interno específico, páginas amarelas internas, universidade corporativa, sumarização, inventários, coaching, mentoring e ontologia/taxonomia.

Outro resultado a ser considerado recai sobre uma visão baseada nas diferentes dimensões de práticas de gestão do conhecimento. Nesse contexto, a categoria de práticas de gestão do conhecimento que mais se evidenciou na pesquisa foi a dimensão estratégia. Já a categoria 
que se mostrou menos contributiva foi a dimensão processos. Há de se ressaltar que as práticas tratadas isoladamente obtiveram um comportamento diverso das práticas agrupadas em dimensões. Assim, não necessariamente o desempenho de determinada dimensão (e suas respectivas práticas) coincide com o desempenho das práticas isoladamente.

No tocante às ferramentas de tecnologia da informação e comunicação empregadas na gestão do conhecimento das empresas pesquisadas, as mais indicadas pelos respondentes foram: email, telefone via internet, telefone celular/rádio, intranet; servidores web e navegadores, telefone fixo, mensagens instantâneas; portal corporativo e CBT (treinamento baseado em computador. Já as ferramentas de tecnologia da informação e comunicação voltadas à gestão do conhecimento menos indicadas na pesquisa foram: wikis, agentes de inteligência, gestão de conhecimento pessoal, perfil de experts, data mining, sistema recomendador, blogs, análise de conteúdos e, por fim, sistema de taxonomia automatizado.

Além da observação das ferramentas isoladamente, também foi possível apurar o desempenho das diferentes dimensões de ferramentas de tecnologia da informação e comunicação voltadas à gestão do conhecimento. Assim, a categoria de ferramentas que demonstrou maior influência foi a dimensão inteligência artificial. Por outro lado, a categoria que menos influenciou as ferramentas foi a dimensão e-learning. Também aqui deve-se atentar para o fato de que a observação individual das ferramentas acaba por oferecer um resultado diferente dos indicadores visualizados nas dimensões das ferramentas. Em função disso, há de se sublinhar que o desempenho de determinada ferramenta, de forma independente, pode não coincidir com o desempenho de sua respectiva dimensão.

Não obstante as considerações acima dispostas, sugere-se que as práticas e ferramentas com melhores resultados individuais, bem como as dimensões com melhores performances coletivas, possam ser consideradas como as mais largamente empregadas pelos funcionários das empresas pesquisadas em processos de gestão do conhecimento. Derivado a esse fato, pode-se inclusive apresentá-las como parâmetros a serem seguidos por outras organizações interessadas em melhorar seus processos internos de gestão do conhecimento.

Como último item verificado no questionário disponibilizado aos respondentes, os indicadores de eficácia empresarial associados à gestão do conhecimento mais citados nas empresas pesquisadas foram, na ordem em que se apresentam: a produtividade, a eficiência, o 
lucro/rentabilidade e, por fim, o desenvolvimento/crescimento organizacional. Há de ser ressaltado que todos os quatro indicadores citados pertencem à dimensão econômica de eficácia empresarial. Este é um fato significativo pois sinaliza uma relação importante entre a efetivação da gestão do conhecimento na empresa e o resultado econômico desta ação para a própria empresa. Por outro lado, os fatores de eficácia empresarial menos indicadas na pesquisa de campo foram a moral, o absenteísmo e a rotatividade; todos pertencentes à dimensão social de eficácia empresarial. Ou seja, a dimensão social se perfaz como o conjunto de indicadores de eficácia empresarial menos influenciados pelas práticas e ferramentas voltadas à gestão do conhecimento nas empresas analisadas na pesquisa.

Sobre o impacto do ambiente de teletrabalho na gestão do conhecimento das empresas pesquisadas, constatou-se que os teletrabalhadores indicaram uma maior utilização das práticas e das ferramentas voltadas à gestão do conhecimento em suas rotinas de trabalho do que os trabalhadores presenciais. Tal situação foi evidenciada pela maior quantidade de práticas, bem como pela maior quantidade de ferramentas indicadas como mais intensamente utilizadas pelos teletrabalhadores em detrimento à realidade verificada junto aos trabalhadores presenciais. No caso específico das práticas de gestão do conhecimento, a cada três práticas verificadas, duas foram mais intensamente utilizadas em ambientes de teletrabalho. Já no que se refere às ferramentas de tecnologia da informação e comunicação voltadas à gestão do conhecimento, verifica-se que praticamente sete em cada dez ferramentas analisadas foram indicadas com maior intensidade de uso quando o ambiente é de teletrabalho.

Outro quesito investigado na pesquisa voltou sua atenção à influência do nível hierárquico dos respondentes em relação à utilização de práticas e ferramentas voltadas à gestão do conhecimento. Nesse item especificamente, observou-se que os trabalhadores ocupantes de cargos de gestão indicaram maior uso de práticas e de ferramentas de tecnologia de informação e comunicação em processos voltados à gestão do conhecimento em suas empresas do que os trabalhadores ocupantes de cargos técnicos. Especificamente em relação às práticas de gestão do conhecimento, verificou-se que a cada três práticas, duas foram indicadas com maior grau de utilização por parte dos trabalhadores gestores do que dos técnicos. Já acerca das ferramentas de tecnologia da informação e comunicação voltadas à gestão do conhecimento, verificou-se que três em cada quatro ferramentas foram apontadas com maior intensidade de uso pelos trabalhadores gestores. Tal situação parece indicar que os 
gestores tenham maior consciência, maior acesso ou ainda maior familiaridade com as práticas e ferramentas pesquisadas do que os trabalhadores técnicos.

Quanto à influência das práticas de gestão do conhecimento na eficácia empresarial das organizações analisadas, pôde-se concluir a existência de influência direta do uso das práticas na eficácia empresarial das empresas analisadas. A partir da utilização de aplicativos específicos e de estatísticas empregadas no presente estudo, foi possível comprovar a existência de influência positiva das práticas de gestão do conhecimento na eficácia empresarial. De forma similar, relativamente às ferramentas de tecnologia da informação e comunicação empregadas na gestão do conhecimento, também verificou-se a influência positiva destas na eficácia empresarial das organizações pesquisadas. O estudo aponta, inclusive que as práticas de gestão do conhecimento têm maior influência do que as ferramentas de tecnologia da informação e comunicação na eficácia empresarial das empresas analisadas que atuam na indústria de software no Brasil.

Assim, fica evidenciado que a gestão do conhecimento, baseada em práticas e ferramentas voltadas para essa finalidade, pode exercer influência na eficácia empresarial de organizações voltadas à criatividade e inovação, como é o caso das empresas atuantes na indústria de software. Ou seja, a gestão do conhecimento pode apresentar-se como uma opção viável à construção de diferenciais competitivos de longo prazo em empresas atuantes no desenvolvimento, manutenção e prestação de serviços do produto software. Assim, considerase factível que práticas e ferramentas envolvidas em processos de gestão do conhecimento na empresa efetivamente contribuam para a ocorrência dos fatores de eficácia empresarial mais indicados neste estudo, quais sejam: acréscimo da produtividade, elevação da eficiência operacional, aumento de lucro e rentabilidade, além de subsidiar o desenvolvimento organizacional como um todo.

Os resultados desta pesquisa ora explicitados trazem contribuições tanto em termos teóricos, quanto em termos práticos. Para os membros da Academia, os resultados expostos são uma contribuição para o avanço de estudos sobre a gestão do conhecimento, o teletrabalho e a eficácia empresarial, notadamente em relação à intersecção decorrente dentre estes temas. Para os praticantes da Administração em empresas atuantes em diversos mercados, os resultados expostos podem indicar benchmarks a serem seguidos por empresas que desejem 
melhor gerenciar a gestão do conhecimento em ambientes de teletrabalho, visando assim o aumento da eficácia empresarial da organização.

Algumas limitações da presente pesquisa merecem destaque no sentido de melhor delimitar as possibilidades de aplicação dos resultados expostos. Em virtude de esta pesquisa ter caráter descritivo de natureza quantitativa, empregando como método de pesquisa o levantamento de informações a partir de uma amostra não probabilística intencional por conveniência e acessibilidade; não é possível que os resultados ora apurados possam ser estendidos a todas as empresas atuantes na indústria de software no Brasil. Há de serem consideradas diversas especificidades inerentes às empresas enfocadas neste estudo, tais como o porte da empresa, a quantidade de funcionários e o estágio de evolução da gestão do conhecimento nela existente. Outra limitação importante refere-se ao recorte transversal no tempo efetuado para a coleta de dados nas empresas pesquisadas. Dado o dinamismo da indústria de software, caso fossem efetuadas outras coletas de dados em diferentes momentos, possivelmente outras respostas poderiam ser captadas, o que contribuiria para a alteração dos resultados ora expostos.

Uma vez que as vertentes teóricas do presente estudo apresentam-se cada vez mais expressivas à realidade das empresas, também faz-se relevante a indicação de outros estudos extensivos e/ou complementares, visando-se assim a evolução da teoria, bem como o seu comportamento em diferentes realidades. Para tanto, alguns estudos são propostos, a saber: a) pesquisa em empresas atuantes em outras indústrias que não a de software; b) pesquisas com empresas de diferentes portes visando auferir potenciais diferenças de desempenho; c) pesquisas com empresas de outras regiões ou países, visando compreender se há diferenças em função de aspectos relacionados à cultura e à localização geográfica, dentre outros; e, por fim, d) pesquisas com empresas atuantes em redes de negócios, clusters ou arranjos produtivos locais, visando compreender os aspectos analisados num contexto interorganizacional. 


\section{REFERÊNCIAS}

AARON, B. C. Determining the business impact of knowledge management. Performance Management, v. 48, n. 4, p. 35-45, 2009.

ABES - Associação Brasileira das Empresas de Software. Dados do setor de software. 2009. Disponível em: < http://www.abes.org.br/templ2.aspx?id=306\&sub=306 >. Acesso em: 22 out. 2009.

AGNIHOTRI, R. A.; TROUTT, M. D. The effective use of technology in personal knowledge management: a framework of skills, tools and user context. Online Information Review, v. 33, n. 2, p. 329-42, 2009.

ALAVI, H.; JUN, H. J. L.; KYEHYUN CHO, S. J. K. Utilizing Knowledge context in virtual collaborative work. Decision Support Systems, v. 39, p. 563-82, 2005.

ALLAMESH, S. M.; ABBAS, S. K. The relationship between knowledge management practices and innovation level in organizations: case study of sub-companies of selected corporations in the city of Esfahan. Journal of Business Cases Studies, v. 6, n. 1, p. 89-97, Jan.-Feb. 2010.

ALTSCHULD, J.; ZHENG, H. Assessing the effectiveness of research organizations: an examination of multiple approaches. Evaluation Review, v. 19, n. 2, p. 197-216, 1995.

ANDONE, I. I. Measuring the performance of corporate knowledge management systems. Informatica Economicã, v. 13, n. 4, p. 24-31, 2009.

ARGYRIS, C. A integração indivíduo-organização. São Paulo: Atlas, 1975.

BARROS, Maria do S. M. de. A indústria criativa em Pernambuco: criatividade e tecnologia digital na produção do cinema local. In: CONGRESSO BRASILEIRO DE CIÊNCIAS DA COMUNICAÇÃO, XXX, Santos, 2007. Anais... Santos, 29 ago. a 02 set. 2007.

BATRA, J. Knowledge management: emerging practices in IT industry in NCR. The IUP Journal of Knowledge Management, v. VIII, n. 1/2, p. 58-67, 2010.

BAUMGARTNER, H.; HOMBURG, C. Applications of structural equation modeling in marketing and consumer research: a review. International Journal of Research in Marketing, v. 13, n. 2, p. 139-61, 1996.

BENNIS, W. G. Organizações em mudança. São Paulo: Atlas, 1976.

BIDO, D. S.; SILVA, D.; SOUZA, C. A.; GODOY, A. S. Indicadores formativos na modelagem em equações estruturais com estimação via PLS-PM: Como lidar com a multicolinearidade entre eles? In: EnEPQ - ENCONTRO DE ENSINO E PESQUISA EM 
ADMINISTRAÇÃO E CONTABILIDADE , II. Curitiba, 2009. Anais... Rio de Janeiro: ANPAD, 2009.

BIDO, D. S.; SILVA, D.; SOUZA, C. A.; GODOY, A. S. Mensuração com indicadores formativos nas pesquisas em administração de empresas: como lidar com a multicolinearidade entre eles? Administração: Ensino e Pesquisa, Rio de Janeiro, v. 11, n. 2, p. 245-69, abr.jun. 2010.

BISHOP, J.; BOUCHLAGHEM, D.; GLASS, J.; MATSUMOTO, I. Ensuring the effectiveness of a knowledge management initiative. Journal of Knowledge Management, v. 12, n. 4, p. 16-29, 2008.

BRASIL. Ministério da Ciência e Tecnologia - MCT. Mercado de software cresce 6,1\% em 2004. Disponível em: <http://www.mct.gov.br/Temas/info/Imprensa/Noticias_4/ Software_4.htm>. Acesso em: 03 de out. 2007.

BRAUNER, E.; BECKER, A. Beyond knowledge sharing: the management of transactive knowledge systems. Knowledge and Process Management, v. 13, n. 1, p. 62-71, 2006.

BRUTON, G. D.; DESS, G. G.; JANNEY, J. J. Knowledge management in technologyfocused firms in developing countries: caveats on capabilities, networks, and real options. Aisa Pacific Journal Management. v. 24, p. 115-30, 2007.

BUZOKOWITZ, W.; WILLIAMS, R. Manual de gestão do conhecimento: ferramentas e técnicas que criam valor para a empresa. Porto Alegre: Bookman, 2002.

BYRNE, B. M. Structural equation modeling with Lisrel, Prelis and Simples: basic concepts, applications and programming. New Jersey: Lawrence Erlbaum, 1998.

CAMPOS, Renato R.; NICOLAU, José A.; CARIO, Sílvio F. A indústria de software de Joinville: um estudo de caso de arranjo inovativo local. Instituto de Economia da Universidade Federal do Rio de Janeiro - IE/UFRJ. Rio de Janeiro, out. 2000.

CARDOSO, L. Gestão do conhecimento e competitividade organizacional: um modelo estrutural. Comportamento organizacional e gestão. Coimbra, v. 13, n. 2, p. 191-211, 2007.

CARVALHO, C.; GOMES, D. Eficácia organizacional: determinantes e dimensões. Psychologica. Coimbra, v. 25, p. 179-202, 2000.

CASTELLS, Manuel. A sociedade em rede. A era da informação: economia, sociedade e cultura. São Paulo: Paz e Terra, 1999.

CAVALCANTI, M.; GOMES, E.; PEREIRA, A. Gestão de empresas na sociedade do conhecimento. Rio de Janeiro, Campus, 2001. 
CHADHA, S. K.; KAPOOR, D. A study on knowledge management practices of auto component manufacturing companies in Ludhiana City. The IUP Journal of Knowledge Management, v. VIII, n. 1/2, p. 68-76, 2010.

CHIN, W. W. The partial least squares approach to structural modeling. In: MARCOULIDES, G. A. (Ed.). Modern methods for business research. New Jersey: Erlbaum, 1998, p. 295-336.

CORSOA, M.; MARTINIB, A.; PELLIGRINIB, L.; MASSAC, S.; TESTAC, S. Managing dispersed workers: the new challenge in knowledge management. Technovation, v. 26, n. 5/6, p. 583-94, 2006.

CRAWFORD, Chris. The art of computer games. Whashington: Washington State University. 2002.

DAFT, R. I. Administração. Rio de Janeiro: LTC, 1999

DALKIR, Kimiz. Knowledge management in theory and practice. Burlington: Elsevier, 2005.

DAVENPORT, T.; PEARLSON, K. Two cheers for the virtual office. Sloan Management Review, Cambridge, v. 39, n. 4, p. 51-65, 1998.

DAVENPORT, T.; PRUSAK, L. Ecologia da informação: por que só a tecnologia não basta para o sucesso na era da informação. São Paulo: Futura, 1998.

DAVENPORT, T.; PRUSAK, L. Conhecimento empresarial: como as organizações gerenciam seu capital intelectual. Rio de Janeiro: Campus, 1999.

DE SORDI, J. O. Administração da informação - Fundamentos e práticas para uma nova gestão do conhecimento. São Paulo: Saraiva, 2008.

DEVELLIS, R. F. Scale development: theory and application. 2 ed. Newbury Park: Sage Publications, 2003.

DIXON, N. M. Common knowledge: how companies thrive by sharing what they know. Harvard: Harvard Business Review, 2000.

DRUCKER, P. Sociedade pós-capistalista. São Paulo: Pioneira, 1994.

DRUCKER, P. O advento da nova organização. In: HARVARD BUSINESS REVIEW. Gestão do Conhecimento. 2 ed. Rio de Janeiro: Campus, 2001.

DUGAL, S.; ROY, M. H. Creating value through relationship building in a globalized marketplace. Journal of International Business and Entrepreneurship, v. 9, n. 1, p. 15370, 2002. 
EISENHARDT, K.; SANTOS F. Knowledge-based view: A new theory of strategy? In: PETTIGREW, A.; THOMAS, H.; WHITTINGTON, R. (eds.). Handbook of strategy and management. London: Sage, 2002.

ELORDUY, J. M. Manual de la eficacia. Madri: Evergráficas, 1998.

FERRARESI, Alex.; SANTOS, Silvio Aparecido dos. Reflexões teóricas sobre a gestão do conhecimento. In: SANTOS, Silvio Aparecido dos.; LEITE, Nildes Pitombo.; DUTRA, Ivan de Souza. Fronteiras da administração II: teorias, aplicações e tendências. 2006.

FERREIRA, M. A.; NEVES, J. T. Informação, conhecimento e empreendedorismo: alimentando a dinâmica de inovação tecnológica na província do Quebec, Canadá. In: EnANPAD - Encontro Nacional da Associação Nacional de Pós-Graduação e Pesquisa em Administração, XXIX, 2005, Brasília, Anais... Rio de Janeiro: ANPAD, 2005.

FIRESTONE, J. M.; McELROY, M. W. Key issues in the new knowledge management. Amsterdam: KMCI/Butterworth-Heinemann, 2001.

FLECK, J. Contingent knowledge and technological development. Technology Analisys \& Strategic Management, Londres, v. 9, n. 4, p. 383-397, dec. 1997.

FORNEL, C.; LARCKER, D. Evaluating structural equation models with unobservable variables and measurement error. Journal of Marketing Research, v. 18, n. 1, p. 39-50, 1981.

FREIRE, E.; BRISOLLA, S. de N. A contribuição do caráter transversal do software para a política de inovação. Revista Brasileira de Inovação, v. 4, n. 1, jan./jun. 2005.

GILES, T. R. Dicionário de filosofia. São Paulo: EPU, 1993.

GOLD, A. H.; MALHOTRA, A.; SEGARS, A. H. Knowledge management: an organizational capabilities perspective. Journal of Management Information Systems, v. 18, n. 1, p. 185-214, 2001.

GOMES, A. D. Eficácia organizacional: processos e resultados, indicadores e critérios, discursos e metáforas. Faculdade de Psicologia e de Ciências da Educação da Universidade de Coimbra. Coimbra: UC, 2001.

GRAHAM, A.; PIZZO, V. Uma questão de equilíbrio: estudo de casos na gestão estratégica do conhecimento. In: KLEIN, D. A gestão estratégica do capital intelectual: recursos para a economia baseada em conhecimento. Rio de Janeiro: Qualitymark, 1998. p. 15-39.

GRANT, R. M. Prospering in dynamic-competitive environments: organizational capability as knowledge integration. Organization Science, v. 7, n. 4, p. 375-87, 1996. 
GREEN, A. Knowledge valuation: building blocks to a knowledge valuation system (KVS). Journal of Information and Knowledge Management Systems, v. 36, n. 2, p. 146-54, 2006.

GREINER, M. E.; BOHMANN, T.; KRCMAR, H. A strategy for knowledge management. Journal of Knowledge Management, v. 11, n. 6, p. 3-15, 2007.

GRIFFITH, T. L.; SAWYER, S. E. Supporting technologies for the transfer of knowledge in virtual environments. Group Decision and Negotiation, v. 15, p. 407-23, 2006.

GRIMALDI, M.; RIPPA, P.; RUFFOLO, M. A methology to evaluate the organizational impact of IT on knowledge management: an Italian case study. Journal of Information Technology Case and Application Research, v. 10, n. 2, p. 8-24, 2008.

GROTTO, Daniela. Um olhar sobre a gestão do conhecimento. Revista de Ciências da Administração, Florianópolis, ano 3, n. 6, p. 31-37, set. 2001.

HAIR JR., J. F.; BABIN, B.; MONEY, A. H.; SAMOUEL, P. Fundamentos de métodos de pesquisa em administração. São Paulo: Bookman, 2005.

HAIR JR., J. F.; ANDERSON, R. E.; ROLPH, E.; TATHAM, R. L. Análie multivariada de dados. 5 ed. Porto Alegre: Bookman, 2006.

HENSELER, J.; RINGLE, C. M.; SINKOVICS, R. R. The use of partial least squares path modeling in international marketing. Advances in International Marketing, Bingley, v. 20, p. 277-319, 2009.

HILL, E. J.; MILLER, B. C.; WEINER, S. P.; COLIHAN, J. Influences of the virtual office on aspects of work and work/life balance. Personnel Psychology, Durham, v. 51, n. 3, p. 66783, 1998.

HITT, M. A.; IRELAND, R. D.; HOSKISSON, R. E. Administração estratégica. São Paulo: Pioneira Thomson Learning, 2005.

HO, L. A. What affects organizational performance? The linking of learning and knowledge management. Industrial Management \& Data Systems. V. 108, n. 9, p. 1234-54, 2008.

HOJO, T. L.; MINGOTI, S. H. Modelos de equações estruturais: uma avaliação dos métodos de máxima verossimilhança, mínimos quadrados ordinários e mínimos quadrados parciais usados na estimação de parâmetros do modelo. In: ENCONTRO NACIONAL DE ENGENHARIA DE PRODUÇÃO, XXIV, Anais... Florianópolis, 2004.

HOYLE, R. H. Structural equation modeling: concepts, issues, and applications. Thousand Oaks: Sage Publications, 1995. 
HUWS, U.: JAGGER, N; BATES, P. Where the butterfly alights: the global location of eWork. London: Institute for Employment Studies, 2001.

IGBARIA, M.; GUIMARÃES, T. Exploring differences in employee turnover intentions and its determinants among telecommuters and non-telecommuters. Journal of Management Information Systems, Armonk, v. 16, p. 147-64, 1999.

JAPIASSÚ, H.; MARCONDES, D. Dicionário básico de filosofia. 3 ed. São Paulo: Zahar, 1996.

JARVIS, C. B.; MACKENZIE, S. B.; PODSAKOFF, P. M. A critical review of construct indicators and measurement model misspecification in marketing and consumer research. Journal of Consumer Research, v. 30, n. 2, p. 199-218, Sep. 2003.

JÖRESKOG, K.; SÖRBOM, D. Recent developments in structural equation modeling. Journal of Marketing Research, v.16, p. 1-19, 1999.

KALVAN, V. D. An overall view of knowledge management challenges for global business. Business Process Management Journal, v. 14, n. 3, p. 390-400, 2008.

KARAYAZ, G. Utilizing knowledge management for effective virtual teams. The Business Review, Cambridge, v. 10, n. 1, Summer 2008.

KATZ, D.; KAHN, R. L. Psicologia social das organizações. São Paulo: Atlas, 1987.

KIPLEY, D. H.; LEWIS, A. O.; HELM, R. Achieving strategic advantage and organizational legitimacy for small and medium sized NFPs through the implementation of knowledge management. Business Reinassence Quarterly, v. 3, n. 3, p. 21-42, Fall 2008.

KUBOTA, L. C. Desafios para a indústria de software. Textos para discussão. Brasília: IPEA, jan. 2006. Disponível em: <http://www.ipea.gov.br/pub/td/2006/td_1150.pdf>. Acesso em: 03 out. 2007.

KUNIYOSHI, M. S.; SANTOS, S. A. dos. As melhores práticas de gestão do conhecimento: um estudo de casos em empresas que fazem uso intensivo do conhecimento. In: SANTOS, Silvio Aparecido dos.; LEITE, Nildes Pitombo.; FERRARESI, Alex Antonio. Gestão do conhecimento: instuticionalização e práticas nas empresas e instituições (pesquisas e casos). Maringá: Unicorpore, 2007.

LACOMBE, F.; HEILBORN, G. Administração: princípios e tendências. São Paulo: Saraiva, 2003.

LATIF, S. A. Modelagem de equações estruturais. 180 f. Dissertação (Mestrado em Estatística) - IME-USP. São Paulo, 2000. 
LEE, L. T.; SUKOCO, B. M. The effects of entrepreneurial orientation and knowledge management capability on organizational effectiveness in Taiwan: the moderating role of social capital. International Journal of Management, v. 24, n. 3, Sep. 2007.

LEITCH, J. M.; ROSEN, P. W. Knowledge Management, CKO and CKM: the keys to competitive advantage. The Manchester Review, v. 6, n. 2-3, p. 9-13, 2001.

LEWIN, A.; MINTON, J. Determining organizational effectiveness: another look and an agenda for research, Management Science, v. 32, n. 1, p. 514-38, 1986.

LIEBOWITZ, J. Building organizational intelligence: a knowledge management primer. CRC Press, 2000.

LIKERT, R. Novos padrões em administração. São Paulo: Pioneira, 1971.

LUPTON, P.; HAYNES, B. Teleworking - the perception-reality gap. Facilities, Bradford, v. 18, n. $7 / 8$, p. 323-37, 2000.

LUTHANS, F.; WELSH, D.; TAYLOR III, L. A descriptive model of managerial effectiveness. Group \& Organization Studies, v. 13, n. 2, p. 148-62, 1988.

MARTINS, G. de A.; THEÓFILO, C. R. Metodologia da investigação científica para ciências sociais aplicadas. 2 ed. São Paulo: Atlas, 2009.

MAY, D.; TAYLOR, P. Knowledge management with patterns. Communications of the ACM. v. 46, n. 7, p. 94-9, July 2003.

McDONOUGH, E.; KAHN, K. 'Hard' and 'Soft' technologies for global new product development. R \& D Management, Oxford, v. 26, n. 3, p. 241-53, 1996.

McDONOUG, E.; KAHN, K.; BARCZAK, G. An investigation of the use of global, virtual, and colocated new product development teams. Journal of Product Innovation Management, New York, v. 18, n. 2, p. 110-20, 2001.

MICHEL, M. H. Metodologia e pesquisa científica em ciências sociais. São Paulo: Atlas, 2009.

MOHAMED, M. The continuumization of knowledge management technology. The Journal of Information and Knowledge Management Systems. v. 38, n. 2, p. 167-73, 2008.

MORIN, E.; SAVOIE, A.; BEAUDIN, G. L'éfficacité de l'organization - Théories, représentations et mesures. Montréal: Gaëtan Morin Éditeur, 1994.

MURRAY, P. Como as empresas mais inteligentes obtêm resultados da GC. In: DAVENPORT, T. H.; MARCHAND, D. A.; DICKSON, T. Dominando a gestão da informação. Porto Alegre: Bookman, 2004, p. 213-19. 
NADLER, D. A. Arquitetura organizacional: a chave para a vantagem competitiva. São Paulo: Atlas, 1994.

NILLES, J. Managing telework strategies for managing the virtual workforce. New York: Wiley, 1998.

NONAKA, Ikujiro. A theory or organizational knowledge creation. New York: Prentice Hall, 1990.

A empresa criadora do conhecimento. In: Gestão do conhecimento - Harvard Business Review. Rio de Janeiro: Campus, 2001.

NONAKA, I. TAKEUCHI, H. Criação de conhecimento na empresa: como as empresas japonesas geram a dinâmica da inovação. Rio de Janeiro: Campus, 1997.

NONAKA, I. TAKEUCHI, H. Gestão do conhecimento. Porto Alegre: Artmed, 2008.

OCDE - Organização de Cooperação e Desenvolvimento Econômicos. Perspectivas da tecnologia da informação: as tecnologias da comunicação e da informação e a economia da informação. São Paulo: Senac, 2005.

O’DELL, C.; ELLIOT, S.; HUBERT, C. Achieving knowledge management outcomes. Handbook on knowledge management. Berlin, v. 1, p. 253-287, Springer 2003.

OLSZEWSKI, P.; LAM, S.H. Can teleworking help to reduce traffic congestion in Singapore? In: TransAsia'93 Conference, 1993, Cingapura. Anais... 02-04 set. 1993.

OZER, M. Process implications of the use of the internet in new product development: a conceptual analysis. Industrial Marketing Management, New York, v. 32, p. 517-30, 2003.

PEREIRA, C.; CAMINO, L.; COSTA, J. B. (2004). Análise fatorial confirmatória do questionário de valores psicossociais - QVP24. Estudos de Psicologia, v. 9, n. 3, 505-12, 2004.

PEREZ, M. P.; SANCHEZ, A. M. CARNICER, Pilar de Luis. The organisational implications of human resources managers' perception of teleworking. Personnel Review, Farnborough, v. 32, n. 6, p. 733-55, 2003.

PILLANIA, R. K. Demystifing knowledge management. Business Strategy Series, v. 10, n. 2, p. 97-100, 2009.

POLANYI, M. The tacit dimension. London: Rotledge and Kegan Paul, 1964.

PORTER, M. What is strategy? Harvard Business Review, Boston, v. 74, n. 6, p. 61-78, Nov.-Dec. 1996. 
POUNDER, J. Public accountability in Hong Kong higher education: human resource management implications of assessing organizational effectiveness. The International Journal of Public Sector Management, v. 15, n. 6, p. 458-74, 2002.

PRATT, J. ITAC Telework America 1999: Telework America 1999 summary and key findings. 1999. Disponível em: <www.workingfromanywhere.org>. Acesso em: 15 nov. 2006.

QUIJANO, S. de A. Auditoria do sistema humano: modelos de qualidade e avaliação organizacional. In: GOMES, A. D.; CAETANO, J. K.; CUNHA, M. P. (Eds.). Organizações em transição. Coimbra: Coimbra: UC, 2000.

RAMOS, E. A. Análisis de la eficacia organizacional em el modelo de sistemas. Revista del Ministerio de Trabajo y Assuntos Sociales. Madri, n. 61, jun. 2006.

ROBBINS, S. Organization theory: structured, design, and applications. New Jersey: Prentice Hall, 1990.

ROBBINS, P. S.; COULTER, M. Management. Upper Saddle River: Prentice-Hall, 2002.

ROBINSON, H.; CARRILlO, P.; ANUMBA, C.; AL-GHASSANI, A. Knowledge management practices in large construction companies. Engineering, Construction and Architectural Management, v. 12, n. 5, p. 431-45, 2005.

ROSELINO, J. E. Análise da indústria brasileira de software com base em uma taxonomia das empresas: subsídios para a política industrial. Revista Brasileira de Inovação, v. 5, n. 1, jan./jun. 2006.

SAMPIERI, R. H.; COLLADO, C. F.; LUCIO, P. B. Metodologia de pesquisa. 3 ed. São Paulo: McGraw Hill, 2006.

SANTOS, A. R.; PACHECO, F. F.; PEREIRA, H. J.; BASTOS Jr., P. A. Gestão do conhecimento: uma experiência para o sucesso empresarial. Curitiba: Champagnat, 2001.

SAVOIE, A.; MORIN, E. Representações da eficácia organizacional: desenvolvimentos recentes. Psychologica, v. 27, p.7-29, 2001.

SCARBROUGH, H.; SWAN, J.; PRESTON, J. Knowledge management: a literature review. London: Institute of Personnel and Development, 1999.

SCHUMACHER, R. E.; LOMAX, R. G. A beginner's guide to structural equation modeling. Mahwah: Lawrence Erlbaum Associates, 1996.

SCOTT, W. R. Effectiveness of organizational effectiveness criteria: towards a competing values approach of organizational analysis. Management Science, v. 29, n. 3, 1983. 
SHANKAR, R.; ACHARIA, S.; BAVEJA, A. Soft-system knowledge management framework for new product development. Journal of Knowledge Management, v. 13, n. 1, p. $135-53,2009$.

SHARMA, R. S.; HUI, P. T. Y.; TAN, M. W. Value-added knowledge management for financial performance: the case of an East Asian conglomerate. The Journal of Information and Knowledge Management Systems, v. 37, n. 4, p. 484-501, 2007.

SHIN, B.; SHENG, O.; HIGA K. Telework: existing research and future directions. Journal of Organizational Computing and Electronic Commerce, Mahwah, v. 10. n. 2, p. 85-101, 2000 .

SONG, S. An internet knowledge sharing system. The Journal of Computing Information Systems, v. 42, n. 3, p. 25-30, 2001.

SOO, C. Knowledge management: philosophy, processes and pitfalls. California Management Review, v. 44, n. 4, p. 129-51, 2002.

STANKOSKY, M. A.; BALDANZA, C. Knowledge management: an evolutionary architecture toward enterprise engineering. Reston: INCOSE, 2000.

STEERS, R. M. Problems in measurement of organizational effectiveness. Administrative Science Quarterly, v. 20, p. 546-558, 1975.

STEWART, Thomas A. Capital intelectual. Rio de Janeiro: Campus, 1998.

SVEIBY, K. E. Knowledge management - Lessons from pioneers. 2001. Disponível em: <http://www.sveiby.com/KM-lesssons.doc>. Acesso em: 03 mar. 2010.

TABACHNICK, B. G.; FIDELL, L. S. Using multivariate statistics. 3 ed. New York: Harper Collins, 1996.

TAPSCOTT, D. Economia digital. São Paulo: Makron Books, 1997.

TAPSCOTT, D.; CASTON A. Mudança de paradigma. São Paulo: Makron Books, 1995.

TEECE, D. J. Strategies for managing knowledge assets: the role of firm structure and industrial context. Long Range Planning, v. 3, p. 35-54, 2000.

TOBIN, Tom. The top five reasons you need knowledge management today. Best practices in enterprise knowledge management, IV. Nov.-Dec. 2004. v. 13. Disponível em: <www.kmworld.com>. Acesso em: 12 nov. 2006.

TURBAN, Efraim. Administração de tecnologia da informação. Rio de Janeiro: Campus, 2003. 
US OPM - US Office of Personnel Management. Telework: a management priority. A guide for managers, supervisors, and telework coordinators. Maio, 2003. Disponível em: <www.telework.gov>. Acesso em: 14 jan. 2007.

VANDENBOSCH, B.; HUFF, S. Searching and scanning: How executives obtain information from executive information systems. Management Information Systems Quarterly, v. 21, n. 1, p. 81-107, 1997.

VASCONCELOS, F. C. Da gestão do conhecimento à gestão da ignorância: uma visão corevolucionária. Revista de Administração de Empresas. São Paulo, v. 41, n. 4, out./dez. 2001.

WAJIDI, M. A. Z.; ASIM, M. The realms of knowledge management from an organizational perpective. The International Business \& Economics Research Journal, v. 8, n. 11, p. 12132, Nov. 2009.

WILD, R.; GREGGS, K. A model of information technology opportunities for facilitating the practice of knowledge management. Journal of Information and Knowledge Management Systems, v. 38, n. 4, p. 490-506, 2008.

YIN, Robert K. Estudo de caso: planejamento e métodos. Porto Alegre: Bookman, 2005.

YUCHTMAN, E.; SEASHORE, S. E. A system resource approach to organizational effectiveness. American Sociological Review, v. 32, p. 891-903, 1967.

ZACK, M. H. Developing a knowledge strategy. California Management Review, v. 41, n. 3, p. 125-45, 1999.

ZAIM, H.; TATOGLU, E.; ZAIM, S. Performance of knowledge management practices: a causal analysis. Journal of Knowledge Management, v. 11, n. 6, p. 56-67, 2007.

ZWICKER, R.; SOUZA, C. A. de.; BIDO, D. de S. Uma revisão do modelo do grau de informatização de empresas: novas propostas de estimação e modelagem usando PLS (Partial Least Squares). In: EnANPAD - ENCONTRO DA ANPAD, XXXII. Rio de Janeiro, 2008. Anais... Rio de Janeiro: ANPAD, 2008. 


\section{APÊNDICES}

Apêndice A - Questionário 


\section{Apêndice A}

\section{Questionário eletrônico aplicado aos colaboradores das empresas}

\section{Gestão do Conhecimento}

1.

Prezado(a) Senhor(a)

Esta é uma pesquisa de tese de doutorado do Programa de Pós-graduaçâo em Administraçăo da Faculdade de Economia, Administração e Contabilidade da Universidade de São Paulo (FEA-USP).

Ao responder a pesquisa sobre gestăo do conhecimento (GC), você ajudará na identificaçăo e melhor compreensăo das principais práticas e iniciativas de $\mathrm{GC}$, bem como das principais ferramentas de tecnologia da informação e comunicação relacionadas à $\mathrm{GC}$ praticada nas empresas atuantes na indústria de software do Brasil, além de sua influência na eficácia empresarial destas empresas.

Cabe ressaltar o caráter sigiloso das informaçôes aqui prestadas, ou seja, as informaçôes năo serâo divulgadas de forma individualizada năo sendo possivel identificar as empresas ou os individuos que participaram.

Para maiores informações, entre em contato direto por meio do endereço: marcos.gaspar@usp.br

Antecipadamente agradeço suas contribuiçôes.

Prof. Marcos Antonio Gaspar

Doutorando e pesquisador responsável

Grupo de Pesquisa em Administração Avançada e Empreendedorismo - GPEADE / FEA-USP 
Gestão do Conhecimento

2. Caracterização do respondente

\section{* 1. Sexo:}

Masculino

Feminino

* 2. Idade:

Menor de 18 anos

$\int 18$ a 24 anos

J 25 a 34 anos

35 a 44 anos

$\int 5$ a 54 anos

acima de 55 anos

* 3. Cargo ou funçäo exercida (assinale uma única alternativa mais representativa de sua condição):
Proprietário
$\checkmark$ Líder de equipe/projeto
Analista de testes
Presidente
Analista de sistemas
Analista de documentação
$\checkmark$ Diretor
$\int$ Analista de processos
Consultor de negócios
Gerente
Analista de negócios
Programador
$\checkmark$ Coordenador
Analista de ambiente/plataforma
Supervisor
Analista de banco de dados

Outro (especifique)

* 4. Tempo de empresa:
Até 1 ano
Entre 1 e 3 anos
Entre 4 e 6 anos
Acima de 7 anos

* 5. Indique o período de tempo por semana no qual você costuma atuar em regime de teletrabalho (trabalho à distância), ou seja, exercendo suas atividades fora das instalaçöes físicas disponibilizadas pela empresa:

Nenhum, sempre exerço minhas atividades dentro da própria empresa

Meio período num único dia

1 dia inteiro

$\int 2$ dias inteiros

3 dias inteiros

4 dias inteiros

A semana inteira $e$, quando necessário, compareço às instalaçőes da empresa

\begin{tabular}{|l|l|}
\hline & $29 \%$ \\
\hline Anterior Próximo & \\
\hline
\end{tabular}


Gestão do Conhecimento

3. Caracterização da empresa

* 1. Nome da empresa:

* 2. Segmento de atuação da empresa (assinale quantas alternativas julgar conveniente):

[Software - desenvolvimento

—Software - manutençẫo

[Software - prestaçẫo de serviços

- Outro (especifique)

* 3. Indique o porte da empresa no Brasil:

() Micro

$\int$ Pequeno

Médio

Grande

* 4. Quantidade de empregados da empresa no Brasil:

J Até 9 empregados

Entre 10 e 49 empregados

Entre 50 e 99 empregados

Acima de 100 empregados 
Gestão do Conhecimento

4. A gestão do conhecimento na empresa

Partindo-se da definição de gestäo do conhecimento abaixo:

"Gestâo do conhecimento é a coordenação deliberada e sistemática de pessoas, tecnologias, processos e estrutura da empresa na busca da criação de valor através do recurso do conhecimento. [...] Essa coordenação tanto é realizada através da criação compartilhamento e aplicação do conhecimento como por meio de alimentaçäo de valiosas liçôes aprendidas e das melhores práticas dentro da memória corporativa, fomentando continuamente a aprendizagem organizacional" (DALKIR, 2005, p. 3).

* 1. Assinale a alternativa que melhor representa a situação de sua empresa em relação à gestão do conhecimento atualmente verificada (assinale uma única alternativa mais representativa):

Nã̃o existe

Nã̃o existe de maneira oficial, mas percebo que já há alguns processos, práticas e ferramentas isoladas sendo usadas atualmente

Não existe de maneira oficial, mas há alguns processos, práticas e ferramentas já usados, e há a sinalização formal de que deverá ser instituída na empresa oficialmente.

Existe formalmente por meio de vários processos, práticas e ferramentas já oficialmente instituídas e usadas.

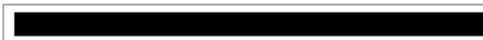


Gestão do Conhecimento

5. Práticas de gestão do conhecimento adotadas pela empresa

Nas questôes abaixo, você deverá atribuir uma nota entre 0 (zero) e 10 (dez) que indique a intensidade da utilização de cada prática associada à gestäo do conhecimento que sua empresa dispőe

Observação: a nota 0 (zero) indica que a empresa não dispổe da respectiva prática para a gestão do conhecimento; já a nota dez (10) indica que a empresa dispốe e utiliza intensamente a respectiva prática na gestäo do conhecimento. As demais notas intermediárias entre os extremos 0 (zero) e 10 (dez) deverão ser utilizadas para indicar a intensidade de utilização da respectiva prática de gestäo do conhecimento na empresa.

* 1. A empresa possui ESTRATÉGIA DECLARADA (modelo ou plano detalhado) de gestão do conhecimento

Atribua uma nota:

$\begin{array}{lllllllllll}0 & 1 & 2 & 3 & 4 & 5 & 6 & 7 & 8 & 9 & 10\end{array}$

* 2. A empresa possui POLÍTICAS DECLARADAS (regras estabelecidas) de gestão do conhecimento

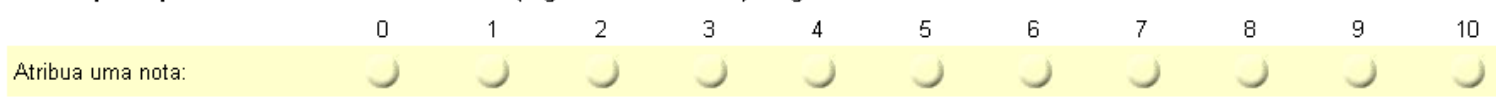

* 3. A empresa possui GESTÃO DA INOVAÇÃO estruturada

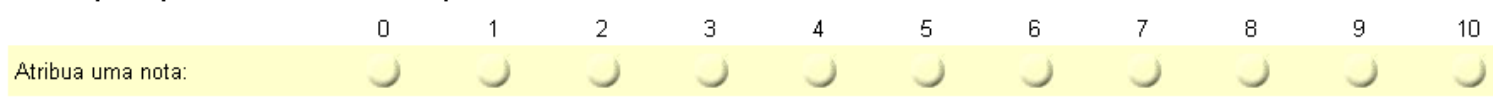

* 4. A empresa possui gESTÃo POR COMPETÊNCIAS

\begin{tabular}{|c|c|c|c|c|c|c|c|c|c|c|}
\hline & 0 & 1 & 2 & 3 & 4 & 5 & 6 & 7 & 8 & 9 \\
\hline Atribua uma nota: & $J$ & & & $J$ & J & 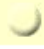 & $J$ & $\mathcal{J}$ & $\mathcal{J}$ & 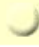 \\
\hline
\end{tabular}

* 5. A empresa disponibiliza COMUNICAÇÃO CORPORATIVA para a gestão do conhecimento

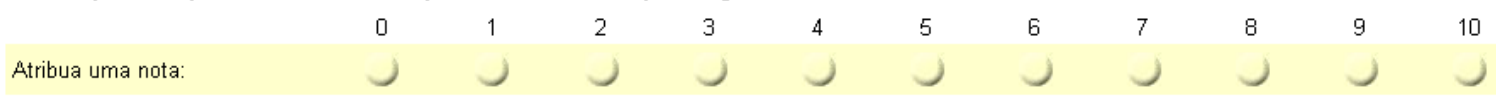

* 6. A empresa efetua BENCHMARKING de conhecimentos

\begin{tabular}{|c|c|c|c|c|c|c|c|c|c|c|}
\hline & 0 & 1 & 2 & 3 & 4 & 5 & 6 & 7 & 8 & 9 \\
\hline la not & & ) & & $J$ & $J$ & $J$ & $J$ & $J$ & $J$ & $J$ \\
\hline
\end{tabular}

* 7. A empresa conta com CENTROS DE INOVAÇÄO

\begin{tabular}{|c|c|c|c|c|c|c|c|c|c|c|}
\hline & 0 & 1 & 2 & 3 & 4 & 5 & 6 & 7 & 8 & 9 \\
\hline Atribua uma nota: & 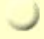 & & 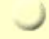 & $J$ & 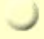 & 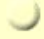 & $\circlearrowleft$ & J & $\circlearrowleft$ & $J$ \\
\hline
\end{tabular}

* 8. A empresa dispõe de CALL CENTER / HELP DESK / SUPORTE ONLINE

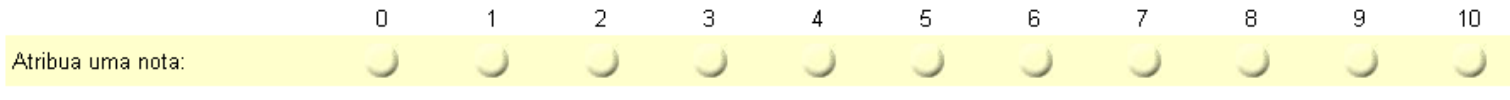

* 9. Os cargos de CKO ou CKM (Chief of Knowledge Officer ou Certified Knowledge Manager, ou seja, GESTOR DE GESTÄO DO CONHECIMENTO) existem na empresa

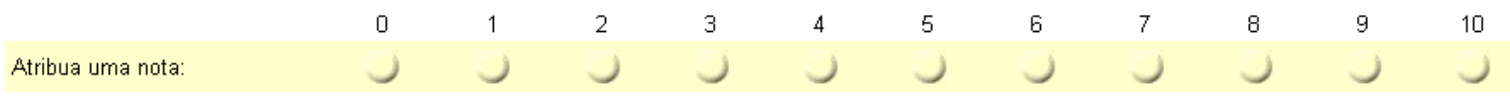

* 10. A empresa possui CENTRO DE COMPETÉNCIAS

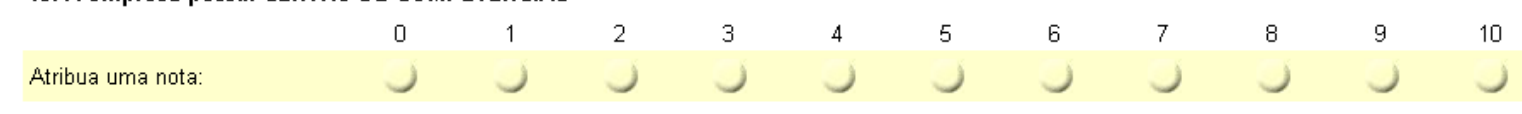


* 11. A empresa tem uma ÁREA INTERNA OU DEPARTAMENTO ESPECÍFICO para a gestão do conhecimento

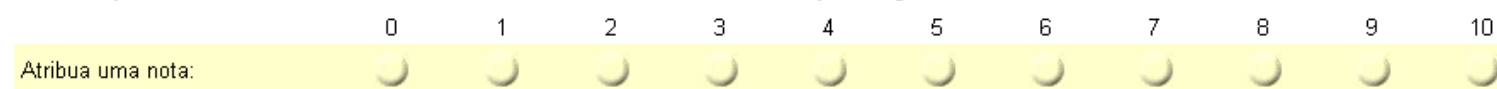

* 12. A empresa conta com REDES DE ESPECIALISTAS para troca de conhecimentos

\begin{tabular}{|c|c|c|c|c|c|c|c|c|c|c|}
\hline & 0 & 1 & 2 & 3 & 4 & 5 & 6 & 7 & 8 & 9 \\
\hline Atribua uma nota: & $J$ & $J$ & $J$ & $J$ & $J$ & $j$ & $J$ & $J$ & $J$ & ) \\
\hline
\end{tabular}

* 13. A empresa dispõe de ESPAÇOS E SITUAÇÕES dedicadas à SOCIALIZAÇÃo dos conhecimentos

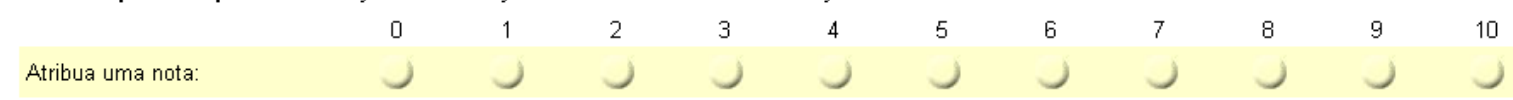

* 14. A empresa faz o MAPEAMENTO DE COMPETÊNCIAS

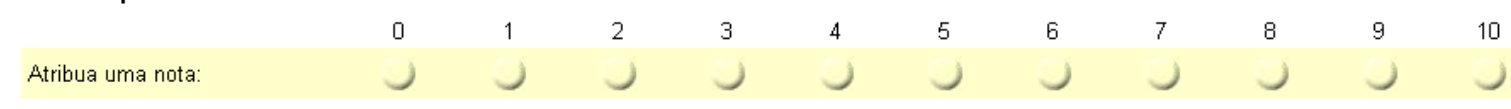

* 15. A empresa faz o MAPEAMENTO dE CONHECIMENTOS

\begin{tabular}{|c|c|c|c|c|c|c|c|c|c|c|}
\hline & 0 & 1 & 2 & 3 & 4 & 5 & 6 & 7 & 8 & 9 \\
\hline Atribua uma nota: & $J$ & & $J$ & & 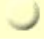 & $J$ & 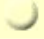 & $\circlearrowleft$ & $\circlearrowleft$ & $J$ \\
\hline
\end{tabular}

* 16. A empresa tem PLANOS DE CARREIRA voltados ao desenvolvimento da gestão do conhecimento

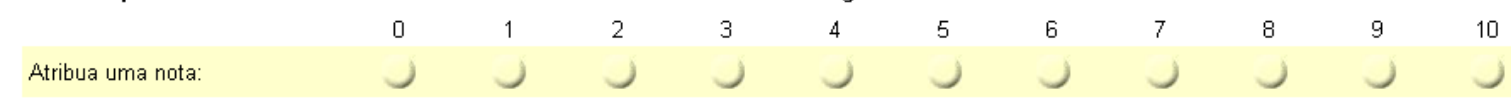

* 17. A empresa tem um SISTEMA DE RECONHECIMENTO E RECOMPENSA por gestão do conhecimento

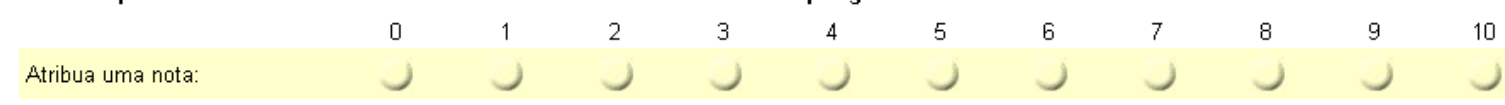

* 18. A empresa desenvolve ações de COACHING (tutoria no desenvolvimento de competências) para formação de líderes voltados à gestão do conhecimento

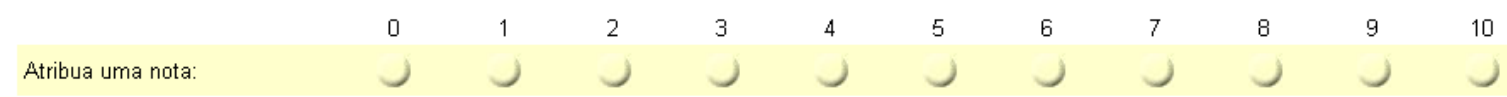

* 19. A empresa desenvolve ações de MENTORING (tutoria no desenvolvimento da carreira) para a formação de líderes voltados à gestão do conhecimento

Atribua uma nota:

* 20. A empresa tem um REPOSITÓRIO DE LIÇÕES APRENDIDAS

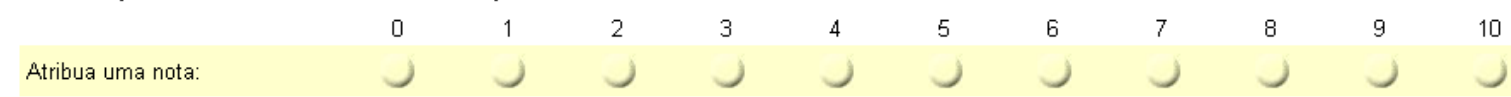

* 21. A empresa tem um REPOSITÓRIO dE MELHORES PRÁTICAS

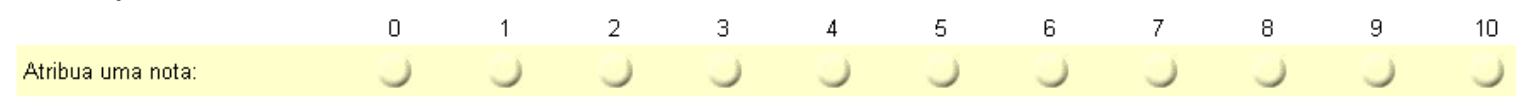

* 22. A empresa dispõe de COMUNIDADES DE PRÁTICA (grupos para trocas de experiências práticas)

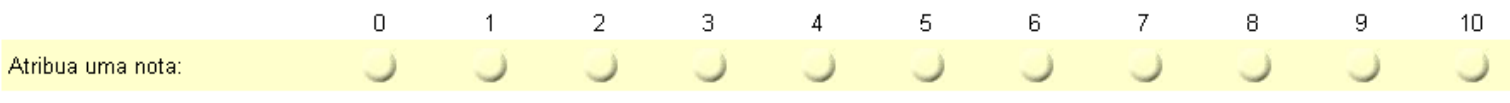


* 23. A empresa conta com ações de EDUCAÇÃO CORPORATIVA

$\begin{array}{llllllllllll} & 0 & 1 & 2 & 3 & 4 & 5 & 6 & 7 & 8 & 9 & 10 \\ \text { Atribua uma nota: } & & & & & & & & & & & \end{array}$

* 24. A empresa disponibiliza TREINAMENTOS PRESENCIAIS com instrutores

\begin{tabular}{|c|c|c|c|c|c|c|c|c|c|c|}
\hline & 0 & 1 & 2 & 3 & 4 & 5 & 6 & 7 & 8 & 9 \\
\hline Atribua uma nota: & $J$ & $J$ & $J$ & $J$ & $J$ & $J$ & $J$ & $J$ & $J$ & $J$ \\
\hline
\end{tabular}

* 25. A empresa conta com MULTIPLICADORES de conhecimentos

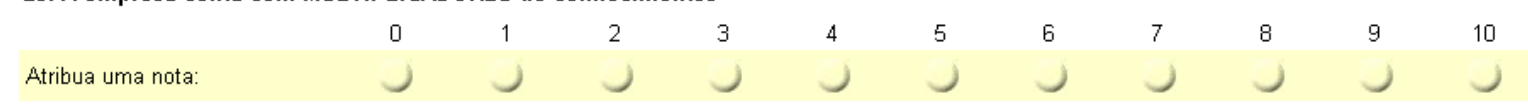

* 26. A empresa dispõe de STORY TELLING (reprodução de histórias)

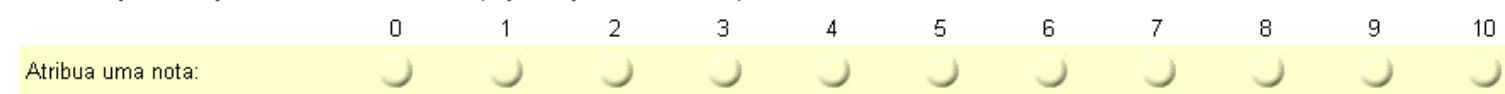

* 27. A empresa efetua o MAPEAMENTO DE PROCESSOS ligados à gestão do conhecimento

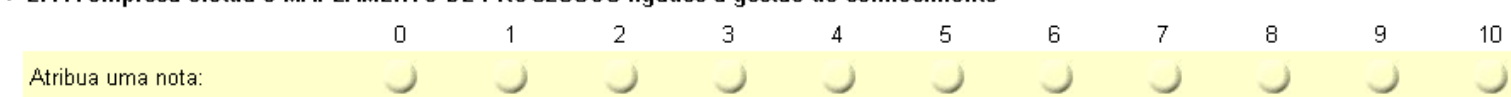

* 28. A empresa tem um SISTEMA DE AVALIAÇÄO de processos ligados à gestão de conhecimento

\begin{tabular}{|c|c|c|c|c|c|c|c|c|}
\hline & 0 & 1 & 2 & 3 & 4 & 5 & 6 & 7 \\
\hline uma nota: & & a & & & 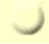 & $J$ & $J$ & \\
\hline
\end{tabular}

* 29. A empresa tem PATENTES oriundas da gestão do conhecimento

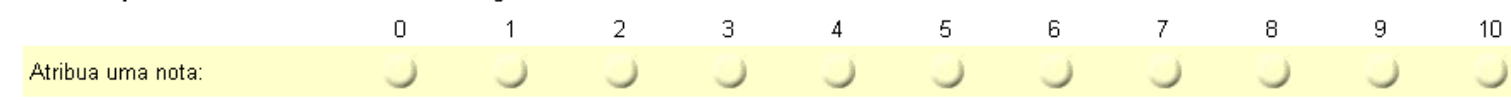

* 30. A empresa tem PROPRIEDADE INTELECTUAL oriunda da gestão do conhecimento

\begin{tabular}{|c|c|c|c|c|c|c|c|c|c|c|c|}
\hline & 0 & 1 & 2 & 3 & 4 & 5 & 6 & 7 & 8 & 9 & 10 \\
\hline Atribua uma nota: & $J$ & $J$ & $\checkmark$ & $J$ & $J$ & $J$ & $J$ & $J$ & $J$ & 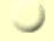 & \\
\hline
\end{tabular}

* 31. A empresa tem um BANCO DE CONHECIMENTOS

\begin{tabular}{|c|c|c|c|c|c|c|c|c|c|c|}
\hline & 0 & 1 & 2 & 3 & 4 & 5 & 6 & 7 & 8 & 9 \\
\hline Atribua uma not & $J$ & & $J$ & & 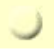 & $\circlearrowleft$ & $J$ & $J$ & $J$ & $J$ \\
\hline
\end{tabular}

* 32. A empresa faz a GESTÄO DE CONTEÚdOS

\begin{tabular}{|c|c|c|c|c|c|c|c|c|c|c|c|}
\hline & 0 & 1 & 2 & 3 & 4 & 5 & 6 & 7 & 8 & 9 & 10 \\
\hline Atribua uma nota: & J & 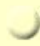 & J & 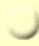 & $J$ & $J$ & $J$ & 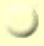 & $J$ & $J$ & \\
\hline
\end{tabular}

* 33. A empresa tem APLICAÇõES ESPECífICAS para BUSCA DE CONHECIMENTOS

\begin{tabular}{|c|c|c|c|c|c|c|c|c|c|c|}
\hline & 0 & 1 & 2 & 3 & 4 & 5 & 6 & 7 & 8 & 9 \\
\hline Atribua uma nota: & 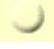 & $\checkmark$ & $\circlearrowleft$ & $J$ & 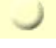 & 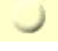 & $J$ & $J$ & $J$ & $J$ \\
\hline
\end{tabular}

* 34. A empresa desenvolve ações de INTELIGÊNCIA COMPETITIVA

\begin{tabular}{|c|c|c|c|c|c|c|c|c|c|c|c|}
\hline & 0 & 1 & 2 & 3 & 4 & 5 & 6 & 7 & 8 & 9 & 10 \\
\hline Atribua uma nota: & 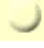 & $J$ & $J$ & $J$ & $\checkmark$ & $J$ & $J$ & $J$ & $J$ & $J$ & 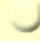 \\
\hline
\end{tabular}

* 35. A empresa desenvolve ações de BI - BUSINESS INTELIGENCE (inteligência de negócios)

\begin{tabular}{|c|c|c|c|c|c|c|c|c|c|c|c|}
\hline & 0 & 1 & 2 & 3 & 4 & 5 & 6 & 7 & 8 & 9 & 10 \\
\hline Atribua uma nota: & 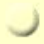 & & J & $\mathcal{~}$ & 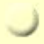 & 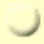 & 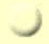 & $\checkmark$ & 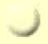 & $\mathcal{~}$ & 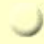 \\
\hline
\end{tabular}


* 36. A empresa dispõe de WIKIS internas (enciclopédias virtuais), BLOGS internos (diários virtuais) ou TWITTERS internos (página de publicação de notícias)

Atribua uma nota:

* 37. A empresa dispõe de PÁGINAS AMARELAS INTERNAS

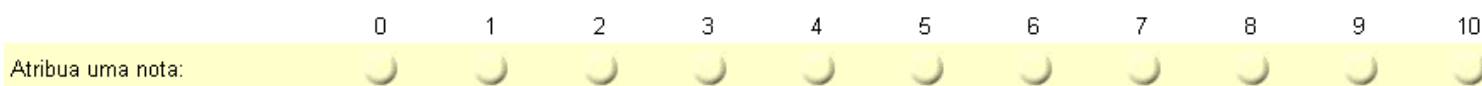

* 38. A empresa dispõe de PORTAL CORPoRATIVo de gestão do conhecimento

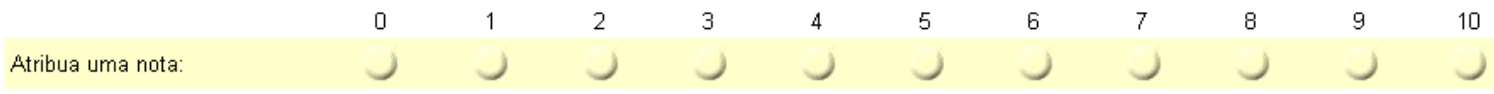

* 39. A empresa dispõe de BIBLIOTECA CORPORATIVA / REPOSITÓRIO DE DOCUMENTOS (físico ou eletrônico)

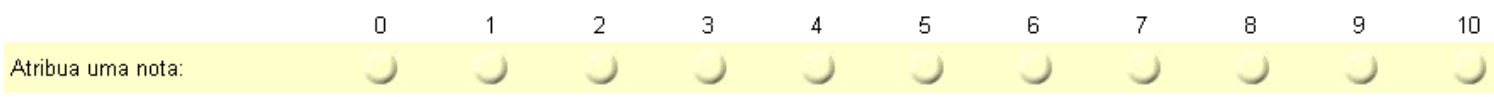

* 40. A empresa efetua REUNIÕES e CONFERÊNCIAS VIRTUAIS

\begin{tabular}{|c|c|c|c|c|c|c|c|c|c|c|}
\hline & 0 & 1 & 2 & 3 & 4 & 5 & 6 & 7 & 8 & 9 \\
\hline Atribua uma nota: & & $J$ & $J$ & $J$ & $J$ & $J$ & $J$ & $J$ & $J$ & $J$ \\
\hline
\end{tabular}

* 41. A empresa efetua TREINAMENTOS VIRTUAIS com a presença de instrutores online

\begin{tabular}{|c|c|c|c|c|c|c|c|c|c|c|}
\hline & 0 & 1 & 2 & 3 & 4 & 5 & 6 & 7 & 8 & 9 \\
\hline Atribua u & & & $J$ & $J$ & $J$ & $J$ & $J$ & $J$ & $J$ & \\
\hline
\end{tabular}

* 42. A empresa efetua ações de E-LEARNING (auto-treinamento sem a presença de instrutores)

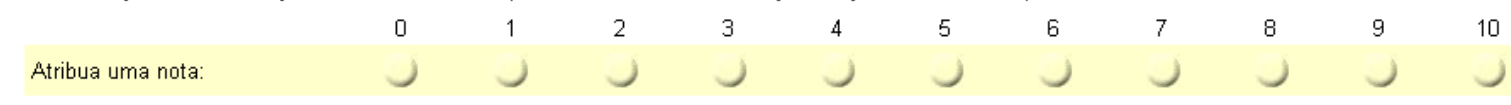

* 43. A empresa tem UNIVERSIDADE CORPORATIVA

\begin{tabular}{|c|c|c|c|c|c|c|c|c|c|c|c|}
\hline & 0 & 1 & 2 & 3 & 4 & 5 & 6 & 7 & 8 & 9 & 10 \\
\hline Atribua uma nota: & $\checkmark$ & & 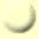 & 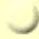 & 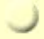 & $J$ & $\circlearrowleft$ & $J$ & $\mathcal{J}$ & J & \\
\hline
\end{tabular}

* 44. A empresa efetua SUMARIZAÇÃo DE CONHECIMENTOS

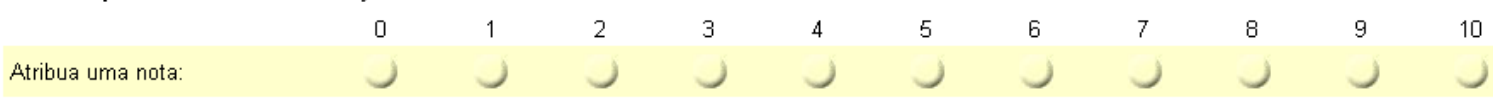

* 45. A empresa efetua INVENTÁRIOS DE CONHECIMENTOS

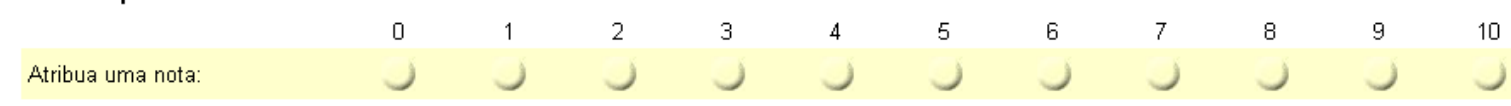

* 46. A empresa efetua a gestão de conteúdo dos conhecimentos - ONTOLOGIA (essência e natureza de cada conhecimento) ou TAXONOMIA (sistemática de classificação dos conhecimentos)

Atribua uma nota: 
Gestão do Conhecimento

6. Ferramentas de tecnologia da informação adotadas para a gestão do conhecimento

Nas questôes abaixo, você deverá atribuir uma nota entre 0 (zero) e 10 (dez) que indique a intensidade da utilização das ferramentas de tecnologia da informaçâo e comunicaçấo associadas à gestấo do conhecimento que sua empresa dispổe.

Obs: a nota 0 (zero) indica que a empresa nấo dispổe da respectiva ferramenta de tecnologia da informaçấo e comunicaçấo para a gestấo do conhecimento; já a nota dez (10) indica que a empresa dispốe e utiliza intensamente a respectiva ferramenta de TIC na gestâo do conhecimento. As demais notas intermediárias entre os extremos 0 (zero) e 10 (dez) deverão ser utilizadas para indicar a intensidade de utilização da respectiva ferramenta de TIC na gestẫo do conhecimento na empresa.

* 1. A empresa conta com ferramentas de AUTORIA para gestão do conhecimento

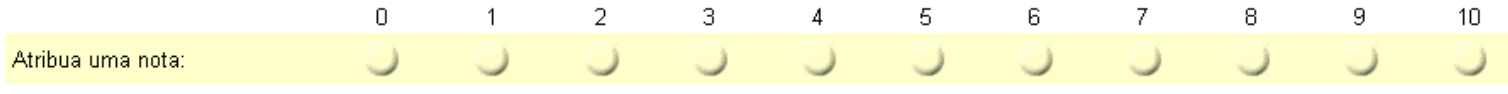

* 2. A empresa conta com MODELOS para a gestão do conhecimento

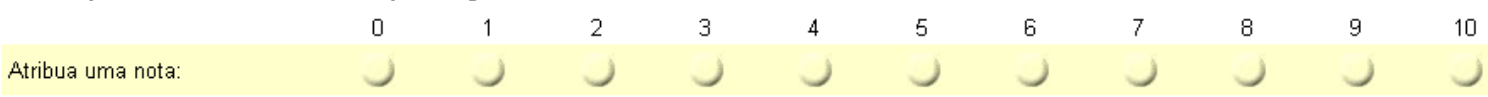

* 3. A empresa faz uso de ferramentas de ANOTAÇÕES para a gestão do conhecimento

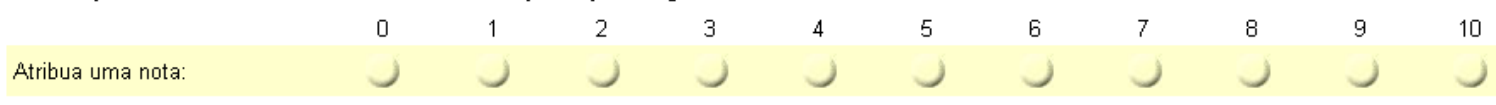

* 4. A empresa conta com ferramenta de DATA MINING (mineração de dados) para a gestão do conhecimento

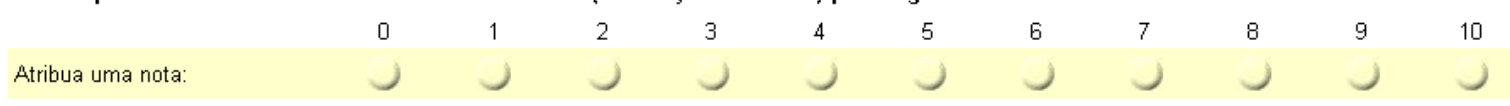

* 5. A empresa dispõe de ferramentas de PERFIL DE EXPERTS (especialistas) para a gestão do conhecimento

Atribua uma nota:

$\begin{array}{lllllllllll}0 & 1 & 2 & 3 & 4 & 5 & 6 & 7 & 8 & 9 & 10\end{array}$

* 6. A empresa possui ferramentas para ELABORAÇÃO DE BLOGS (diário eletrônico baseado em tecnologia web) para a gestão do conhecimento

Atribua uma nota:

* 7. A empresa usa ferramentas de DEFINIÇÃO DE METADADOS para a gestão do conhecimento

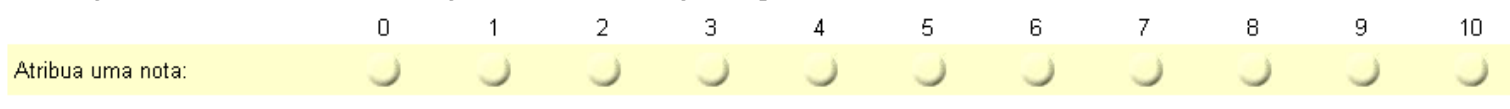

* 8. A empresa tem ferramentas de CLASSIFICAÇÃO DE CONTEÚDOS para a gestão do conhecimento

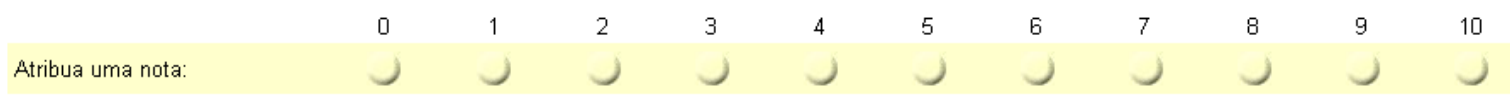

* 9. A empresa tem ferramentas de ARQUIVAMENTO DE CONTEÚDOS para a gestão do conhecimento

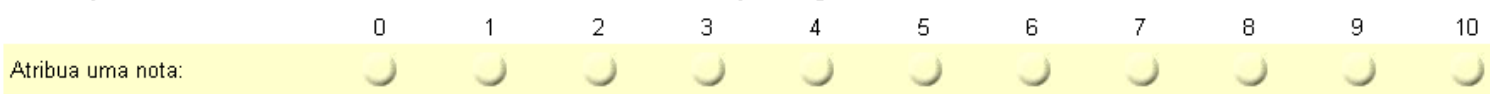

* 10. A empresa tem ferramentas de GESTÃO DE CONHECIMENTO PESSOAL (individual) para fins de gestão do conhecimento

\begin{tabular}{|c|c|c|c|c|c|c|c|c|c|c|}
\hline & 0 & 1 & 2 & 3 & 4 & 5 & 6 & 7 & 8 & 9 \\
\hline Atribua uma nota: & & $J$ & & 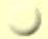 & $J$ & $\circlearrowleft$ & $\circlearrowleft$ & 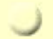 & $\jmath$ & $J$ \\
\hline
\end{tabular}


* 11. 0 TELEFONE FIXO é usado na gestão do conhecimento na empresa

$\begin{array}{llllllllllllll}0 & 1 & 2 & 3 & 4 & 5 & 6 & 7 & 8 & 9 & 10\end{array}$
Atribua uma nota:

* 12. O TELEFONE CELULAR ou RÁDIO é usado na gestão do conhecimento na empresa

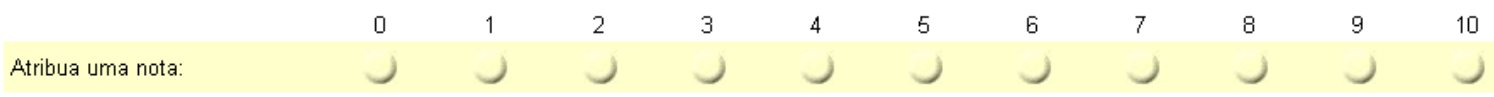

* 13. O TELEFONE VIA INTERNET (Skype ou outros) é usado na gestão do conhecimento na empresa

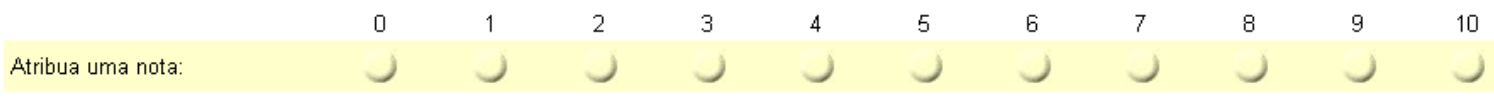

* 14. A empresa tem ferramentas de VIDEOCONFERÊNCIA para a gestão do conhecimento

$\begin{array}{llllllllllllll}0 & 1 & 2 & 3 & 4 & 5 & 6 & 7 & 8 & 9 & 10\end{array}$
Atribua uma nota:

* 15. A empresa tem ferramentas de SALAS DE BATE-PAPO (chats) para a gestão do conhecimento

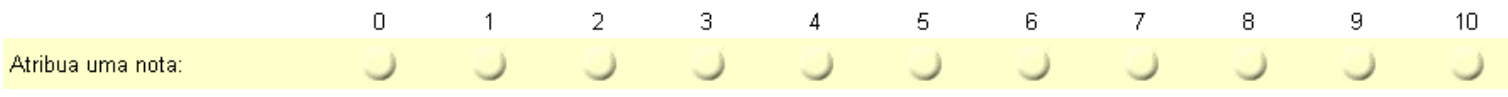

* 16. As MENSAgENS INSTANTÂNEAS são usadas na gestão do conhecimento na empresa

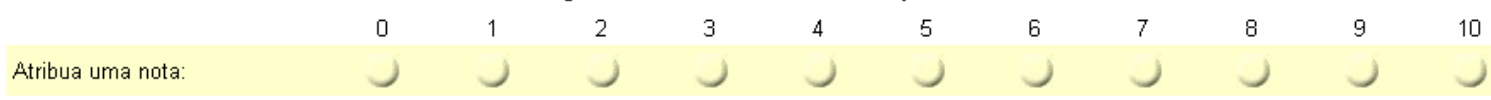

* 17. O E-MAIL é usado na gestão do conhecimento na empresa

\begin{tabular}{|c|c|c|c|c|c|c|c|c|c|c|}
\hline & 0 & 1 & 2 & 3 & 4 & 5 & 6 & 7 & 8 & 9 \\
\hline Atribua uma nota: & $J$ & $\checkmark$ & $J$ & $J$ & $J$ & $J$ & $J$ & $J$ & $\circlearrowleft$ & $J$ \\
\hline
\end{tabular}

* 18. A empresa dispõe de FóRUNS DE DISCUSSÃo para a gestão do conhecimento

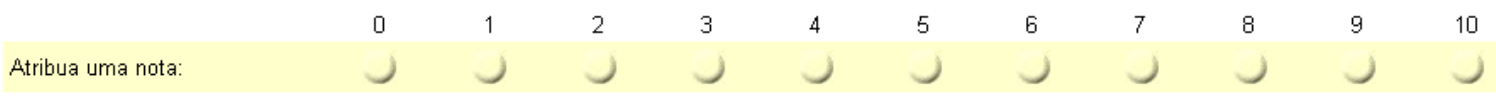

* 19. A empresa dispõe de ferramentas de GROUPWARE (software colaborativo) para a gestão do conhecimento

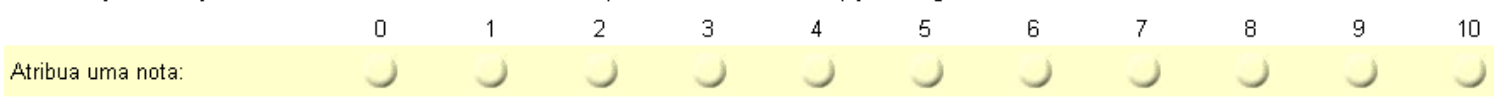

* 20. A empresa utiliza ferramentas de WIKIS (enciclopédia aberta baseada na tecnologia web) para a gestão do conhecimento

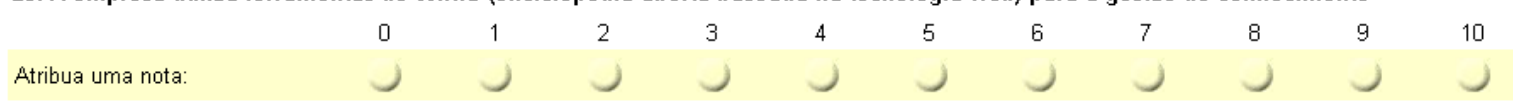

* 21. A empresa utiliza ferramentas de WORKFLOW (gerenciamento de fluxo de trabalho) para a gestão do conhecimento

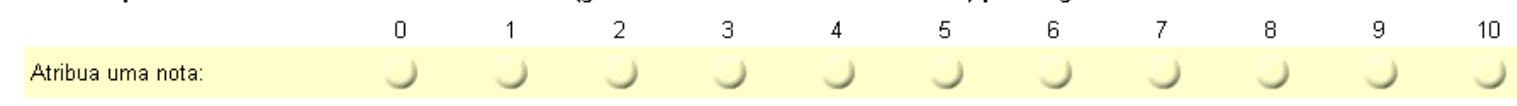

* 22. A INTRANET é usada na gestão do conhecimento

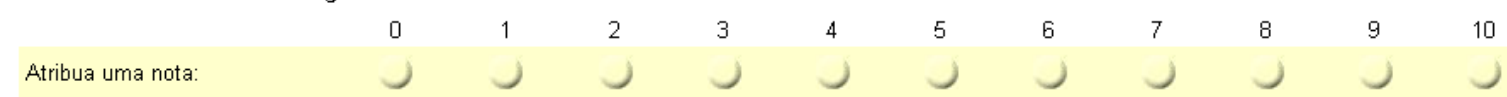

* 23. A EXTRANET (rede privativa estabelecida com parceiros externos via tecnologia internet) é usada na gestão do conhecimento

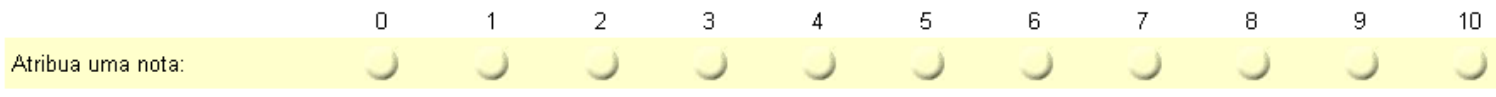


* 24. Os SERVIDORES WEB e NAVEGADORES são usados na gestão do conhecimento

\begin{tabular}{|c|c|c|c|c|c|c|c|c|c|c|}
\hline & 0 & 1 & 2 & 3 & 4 & 5 & 6 & 7 & 8 & 9 \\
\hline Atribua uma nota: & 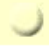 & 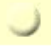 & $\mathcal{J}$ & $\mathcal{J}$ & $\circlearrowleft$ & $\circlearrowleft$ & 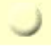 & $J$ & 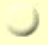 & 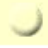 \\
\hline
\end{tabular}

* 25. A empresa tem REPOSITÓRIO DE CONHECIMENTOS (lições aprendidas e melhores práticas) para a gestão do conhecimento

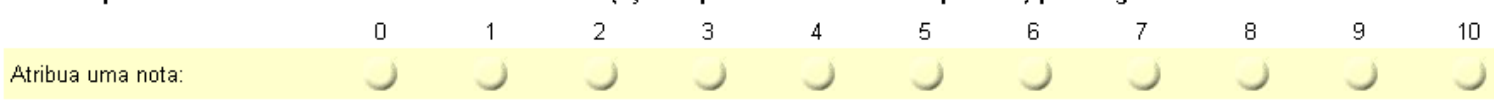

* 26. A empresa tem um PORTAL CORPORATIVo ou uma área específica no servidor destinada à gestão do conhecimento

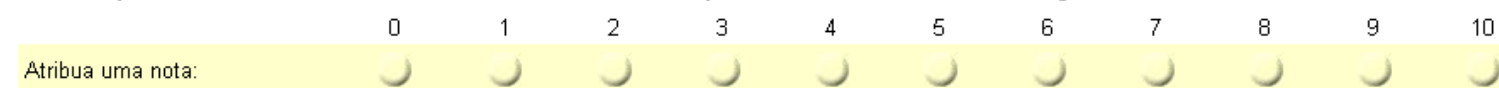

* 27. A empresa dispõe de ferramentas de CBT (Treinamento baseado em computadores) para a gestão do conhecimento

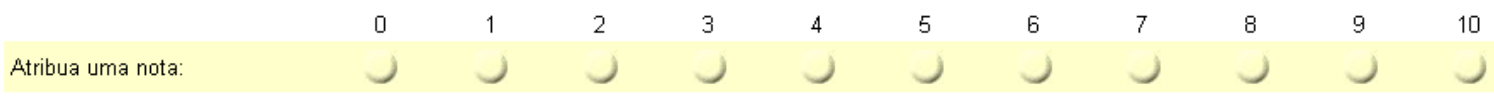

* 28. A empresa dispõe de ferramentas de WBT (Treinamento baseado em tecnologia web) para a gestão do conhecimento

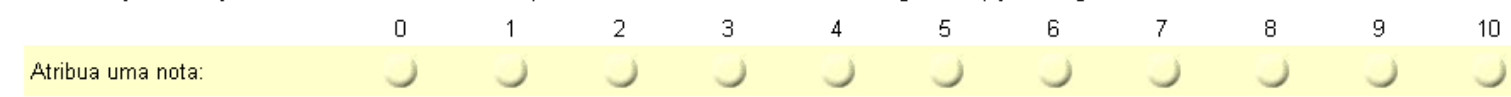

* 29. A empresa dispõe de ferramentas de EPSS (sistema eletrônico de apoio ao desempenho) para a gestão do conhecimento

\begin{tabular}{|c|c|c|c|c|c|c|c|c|c|c|c|}
\hline & 0 & 1 & 2 & 3 & 4 & 5 & 6 & 7 & 8 & 9 & 10 \\
\hline Atribua uma nota: & $J$ & & ) & 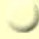 & 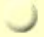 & ) & $J$ & 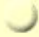 & $J$ & $J$ & \\
\hline
\end{tabular}

* 30. A empresa dispõe de SISTEMAS ESPECIALIZADOS para a gestão do conhecimento

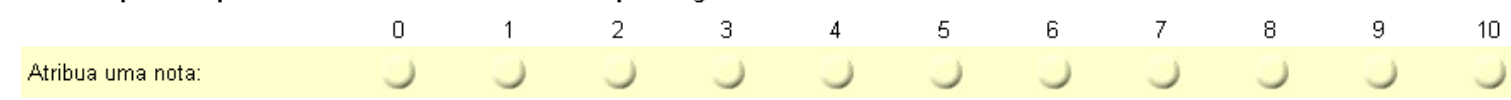

* 31. A empresa dispõe de ferramentas de DSS (Sistema de suporte à tomada de decisão) para a gestão do conhecimento

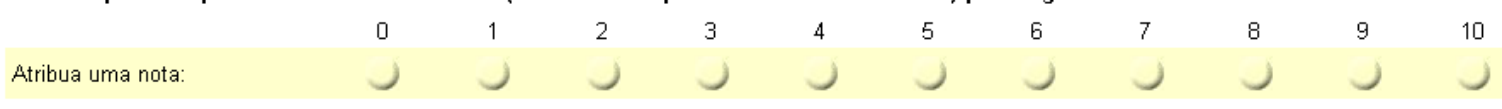

* 32. A empresa efetua CUSTOMIZAÇÃO/PERSONALIZAÇÃO de produtos com uso da gestão do conhecimento

\begin{tabular}{|c|c|c|c|c|c|c|c|c|c|c|}
\hline & 0 & 1 & 2 & 3 & 4 & 5 & 6 & 7 & 8 & 9 \\
\hline ribua uma nota: & & & $\circlearrowleft$ & $\circlearrowleft$ & $\circlearrowleft$ & $\checkmark$ & $J$ & $J$ & $\circlearrowleft$ & \\
\hline
\end{tabular}

* 33. A empresa possui um SISTEMA RECOMENDADOR (compara coleções de dados e sugere uma lista de recomendações) para a gestão do conhecimento

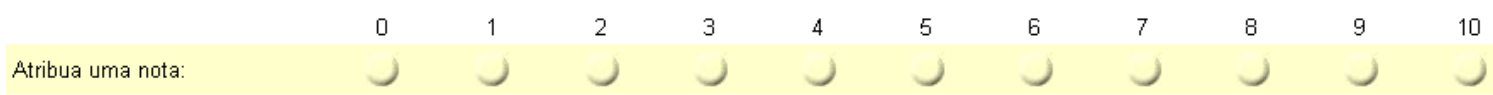

* 34. A empresa possui ferramentas de VISUALIZAÇÃO para a gestão do conhecimento

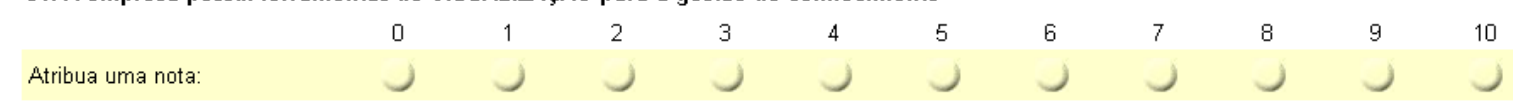

* 35. A empresa utiliza ferramentas de MAPAS DE CONHECIMENTO para a gestão do conhecimento

\begin{tabular}{|c|c|c|c|c|c|c|c|c|c|c|}
\hline & 0 & 1 & 2 & 3 & 4 & 5 & 6 & 7 & 8 & 9 \\
\hline Atribua uma nota: & $J$ & $J$ & $J$ & & $J$ & $\checkmark$ & $J$ & $\mathcal{J}$ & $J$ & $J$ \\
\hline
\end{tabular}

* 36. A empresa possui ferramentas de AGENTES DE INTELIGÊNCIA para a gestão do conhecimento

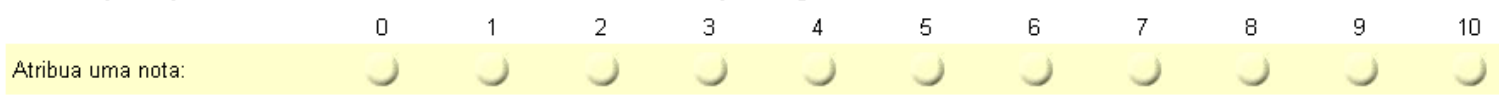


* 37. A empresa possui um SISTEMA DE TAXONOMIA AUTOMATIZADO para a gestão do conhecimento

Atribua uma nota:

0

$1 \quad 2 \quad 3$

Atibua una nota:

* 38. A empresa possui ferramentas de ANÁLISE DE CONTEÚDOS de textos (SUMARIZAÇÃO) para a gestão do conhecimento

\begin{tabular}{l|lllllllll|l|l|l|l}
\hline & 0 & 1 & 2 & 3 & 4 & 5 & 6 & 7 & 8 & 9 & 10 \\
\hline
\end{tabular}


Gestão do Conhecimento

7. Influência da gestão do conhecimento na eficácia empresarial da empresa

Assinale a intensidade de sua concordância ou discordância em relação às afirmaçőes abaixo listadas, sendo que:

1 - Discordo totalmente

2 - Discordo

3 - Năo concordo e nem discordo

4 - Concordo

5 - Concordo totalmente

* 1. A Gestão do Conhecimento (GC) ajuda a alcançar os OBJETIVOS CoRPoRATIVoS

Atribua uma nota: $\quad 1 \quad 2$

* 2. A gC traz aumento da PRODUTIVIDADE

$\begin{array}{llccc} & 1 & 2 & 3 & 4 \\ \text { Atribua uma nota: } & \ddots & 5 & \jmath\end{array}$

* 3. A GC contribui para o aumento do LUCRO e da RENTABILIDADE

$\begin{array}{lccccc} & 1 & 2 & 3 & 4 & 5 \\ \text { Atribua uma nota: } & & \jmath & \jmath & \end{array}$

* 4. A GC contribui para o aumento da EFICIÊNCIA das operações de negócio

$\begin{array}{lccccc} & 1 & 2 & 3 & 4 & 5 \\ \text { Atribua uma nota: } & & 5 & 5 & \end{array}$

* 5. A GC contribui para o DESENVOLVIMENTO e CRESCIMENTO do negócio

$\begin{array}{lllll} & & & 4 & 4 \\ \text { Atribua uma nota: } & 1 & 2 & 3 & \end{array}$

* 6. A GC proporciona maior COESÃO e HARMONIA entre os indivíduos e áreas envolvidas

$\begin{array}{llcc} & 1 & 2 & 3 \\ \text { Atribua uma nota: } & \ddots & j & \end{array}$

* 7. A GC contribui para a melhoria do AMBIENTE ORGANIZACIONAL

$\begin{array}{llllll} & 1 & 2 & 3 & 4 & 5 \\ \text { Atribua uma nota: } & \ddots & \ddots & j & \end{array}$

* 8. A GC aumenta o MORAL de nossos empregados

\begin{tabular}{|c|c|c|c|c|c|}
\hline & 1 & 2 & 3 & 4 & 5 \\
\hline Atribua uma nota: & $\circlearrowleft$ & 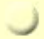 & $J$ & $J$ & $\mathcal{J}$ \\
\hline
\end{tabular}


* 9. A GC ajuda a diminuir o ABSENTÉ́SMO (ausências e faltas ao trabalho)

$\begin{array}{lccc} & 1 & 2 & 3 \\ \text { Atribua uma nota: } & \ddots & \ddots & \jmath\end{array}$

* 10. A GC ajuda a diminuir a ROTATIVIDADE (turn over - relação entre admissões e demissões) de empregados

$\begin{array}{llccc} & 1 & 2 & 3 & 4 \\ \text { Atribua uma nota: } & \jmath & \jmath & \jmath\end{array}$

* 11. A GC ajuda a elevar a MOTIVAÇÃo e SATISFAÇÃo dos empregados no trabalho

$\begin{array}{lccccc} & 1 & 2 & 3 & 4 & 5 \\ \text { Atribua uma nota: } & \ddots & \ddots & \jmath & & \end{array}$

* 12. A GC ajuda no DESENVOLVIMENTO DAS PESSOAS

$\begin{array}{lccccc} & 1 & 2 & 3 & 4 & 5 \\ \text { Atribua uma nota: } & \ddots & J & \jmath & \end{array}$

* 13. A GC aumenta a ADAPTABILIDADE a novas situações de mercado

$\begin{array}{llcccc} & 1 & 2 & 3 & 4 & 5 \\ \text { Atribua uma nota: } & j & \ddots & \jmath & \end{array}$

* 14. A GC traz maior ESTABILIDADE às pessoas e à empresa como um todo

$\begin{array}{lccccc} & 1 & 2 & 3 & 4 & 5 \\ \text { Atribua uma nota: } & \ddots & j & \jmath & \end{array}$

* 15. A GC ajuda a melhorar o CONTROLE sobre as atividades e os resultados

$\begin{array}{lccccc} & 1 & 2 & 3 & 4 & 5 \\ \text { Atribua uma nota: } & & & 5 & & \end{array}$

